\title{
Relationship between angiogenesis and the immune response against solid tumors
}

Citation for published version (APA):

Castermans, K. E. R. (2008). Relationship between angiogenesis and the immune response against solid tumors. [Doctoral Thesis, Maastricht University]. Maastricht University. https://doi.org/10.26481/dis.20080201kc

Document status and date:

Published: 01/01/2008

DOI:

$10.26481 /$ dis.20080201kc

Document Version:

Publisher's PDF, also known as Version of record

\section{Please check the document version of this publication:}

- A submitted manuscript is the version of the article upon submission and before peer-review. There can be important differences between the submitted version and the official published version of record.

People interested in the research are advised to contact the author for the final version of the publication, or visit the DOI to the publisher's website.

- The final author version and the galley proof are versions of the publication after peer review.

- The final published version features the final layout of the paper including the volume, issue and page numbers.

Link to publication

\footnotetext{
General rights rights.

- You may freely distribute the URL identifying the publication in the public portal. please follow below link for the End User Agreement:

www.umlib.nl/taverne-license

Take down policy

If you believe that this document breaches copyright please contact us at:

repository@maastrichtuniversity.nl

providing details and we will investigate your claim.
}

Copyright and moral rights for the publications made accessible in the public portal are retained by the authors and/or other copyright owners and it is a condition of accessing publications that users recognise and abide by the legal requirements associated with these

- Users may download and print one copy of any publication from the public portal for the purpose of private study or research.

- You may not further distribute the material or use it for any profit-making activity or commercial gain

If the publication is distributed under the terms of Article $25 \mathrm{fa}$ of the Dutch Copyright Act, indicated by the "Taverne" license above, 


\title{
Relationship between angiogenesis and the immune response against solid tumors
}

\author{
PROEFSCHRIFT
}

ter verkrijging van de graad van doctor aan de Universiteit Maastricht, op gezag van de Rector Magnificus, Prof. mr. G.P.M.F. Mols

volgens het besluit van het College van Decanen,

in het openbaar te verdedigen

op vrijdag 1 februari 2008 om 12.00 uur

door

Karolien Elly Renée Castermans

Geboren op 30 maart 1979 te Hasselt 


\section{Promotor:}

Prof. dr. A.W. Griffioen

\section{Beoordelingscommissie:}

Prof. dr. W. Buurman (voorzitter)

Dr. G. M. J. Bos

Prof. dr. M.J.A.P. Daemen

Prof. dr. J. de Haan

Prof. dr. A. Noël (Université de Liège)

Financial support by Stichting Nationaal Fonds tegen Kanker, Hycult biotechnology bv, BD Biosciences, Sanquin Reagentia, Greiner Bio-one, for the publication of this thesis was gratefully acknowledged. 


\section{Contents}

$\begin{array}{ll}\text { Abbreviations } & 7\end{array}$

Chapter 1

General introduction

9

Chapter 2

Tumor blood vessels, a difficult hurdle for

infiltrating leukocytes.

Chapter 3

Proliferating endothelial cells and leukocyte infiltration are related prognostic markers in colorectal cancer.

Chapter 4

Anti-angiogenesis therapy can overcome endothelial cell anergy and promote leukocyteendothelium interactions and infiltration in tumors.

Chapter 5

Anti-angiogenesis therapy enhances tumor specific immunity.

Chapter 6

Epigenetic regulation of tumor endothelial cell anergy: silencing of intercellular adhesion molecule- 1 by histone modifications.

Chapter 7

Angiostatic activity of the anti-tumor cytokine interleukin-21

Chapter 8

Vascular adhesion protein-1 mediates leukocyte recruitment in tumors.

Chapter 9

General discussion and conclusions

Summary

Samenvatting

Curriculum vitae

Dankwoord 
Contents 


\section{Abbreviations}

ANG

b.END5

bFGF

BPI

C3d

CA4P

CAM

cDNA

CEACAM

ChIP

CLEVER-1

CRC

CTL

$\mathrm{DAB}$

DAC

DNA

DNMT

EC

ECGF-1

EGF

EMSA

FCS

FDA

FGFR

gal

GM-CSF

$\mathrm{HA}$

HDAC

HUVEC

ICAM

IDO

INF- $\alpha, \gamma$

IL

i.p.

JAK

JAM

LFA-1

Mac-1

MAdCAM

MHC angiopoietin

brain endothelioma cells

basic fibroblast growth factor

bacterial/ permeability-increasing protein

degradation fragment of complement factor-3

combretastatin A4 phosphate

chorioallantoic membrane

copy DNA

carcinoembryonic antigen related cell adhesion

molecule

chromatin immunoprecipitation

common lymphatic endothelial and vascular

endothelial receptor

colorectal carcinoma

cytotoxic T lymphocytes

diaminobenzidine

5-aza-2' - deoxycytidine

deoxyribonucleic acid

DNA methyltransferase

endothelial cell

endothelial cell growth factor-1

epidermal growth factor

electrophoretic mobility shift assay

fetal calf serum

food and drug administration

fibroblast growth factor receptor

galectin

granulocyte-macrophage colony stimulating factor

hyaluronate

histone deacetylase

human umbilical vein endothelial cells

intercellular adhesion molecule

indoleamine 2,3-dioxygenase

interferon $-\alpha, \gamma$

interleukin

inter-peritoneal

janus tyrosine kinase

junctional adhesion molecule

leukocyte function-associated antigen-1

integrin $\alpha \mathrm{M} \beta 2$

mucosal addressin

major histocompatibility complex 


\begin{tabular}{|c|c|}
\hline $\mathrm{MMN}$ & monomorphonuclear cells \\
\hline MMP & matrix metalloproteinases \\
\hline mRNA & messenger ribonucleic acid \\
\hline MRI & magnetic resonance imaging \\
\hline MSC & myeloid derived suppressor cells \\
\hline MVD & microvessel density \\
\hline NCAM & neural cell adhesion molecule \\
\hline NK & natural killer cells \\
\hline PBS & phosphate buffered saline \\
\hline PCR & polymerase chain reaction \\
\hline PECAM-1 & platelet-endothelial cell adhesion molecule-1 \\
\hline PET & positron emission tomography \\
\hline PF4 & platelet factor- 4 \\
\hline PFA & paraformaldehyde \\
\hline PMN & polumorphonuclear leukocyte \\
\hline PlGF & placenta growth factor \\
\hline PNAd & peripheral lymph node addressin \\
\hline Q & flow \\
\hline RGD & tripeptide sequence arginine-glycine-aspartic acid \\
\hline RT-PCR & reverse transcription PCR \\
\hline s.c. & subcutaneous \\
\hline SDF-1 & stromal derived factor-1 \\
\hline sHLA & soluble histocompatibility antigen \\
\hline SPECT & single photon emission computed tomography \\
\hline Stat & signal and activator of transcription \\
\hline SSAO & semicarbazide-sensitive amine oxidation \\
\hline SVEC & simian virus 40 -transfected mouse ECs \\
\hline TAM & tumor associated macrophage \\
\hline TGF $\beta$ & transforming growth factor $\beta$ \\
\hline TIE & $\begin{array}{l}\text { tyrosine kinase with immunoglobuline and EGF-like } \\
\text { domains }\end{array}$ \\
\hline $\mathrm{TNF} \alpha$ & tumor necrosis factor $\alpha$ \\
\hline Tregs & regulatory $\mathrm{T}$ cells \\
\hline TSA & trichostatin A \\
\hline TSP-1 & trombospondin-1 \\
\hline $\mathrm{U}$ & reduced velocity \\
\hline VAP-1 & vascular adhesion protein-1 \\
\hline VCAM & vascular cell adhesion molecule \\
\hline VEGF & vascular endothelial growth factor \\
\hline VEGFR & vascular endothelial growth factor receptor \\
\hline VLA-4 & very late antigen- 4 \\
\hline VPF & vascular permeability factor \\
\hline
\end{tabular}




\section{Chapter 1}

\section{General introduction}

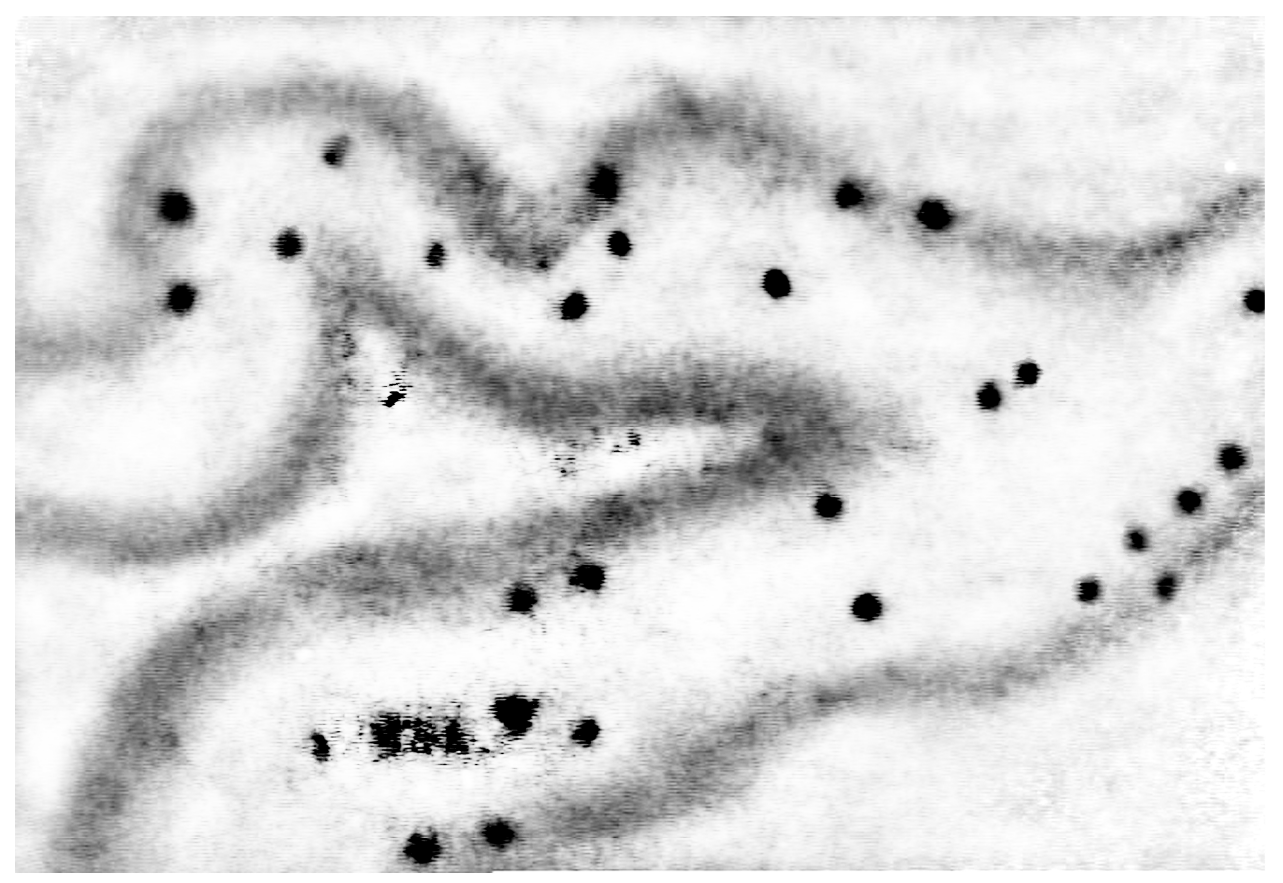




\section{Angiogenesis and tumor angiogenesis}

Angiogenesis, or the formation of new blood vessels from preexisting ones, is a process that is necessary for growth and repair of different organs and tissues. It is essential in physiological processes like the reproductive cycle, embryonic development and wound healing and is under strict regulation. Blood vessel formation is turned-on for a short period of time followed by a complete inhibition. However, without tight regulation, angiogenesis contributes to numerous pathological diseases. Persistent angiogenesis drives diseases like arthritis, diabetic retinopathy, psoriasis, endometriosis and cancer ${ }^{1}$.

In normal healthy tissues, vessels remain in a dormant state, which means that a balance between stimulators and inhibitors of blood vessel formation is preserved. A shift in this balance in favor of the pro-angiogenic factors, the socalled angiogenic switch, initiates the angiogenesis cascade ${ }^{2}$. Various stimuli can induce this process including excessive inflammation, hypoxia, metabolic stress and cellular responses ${ }^{1,3}$.

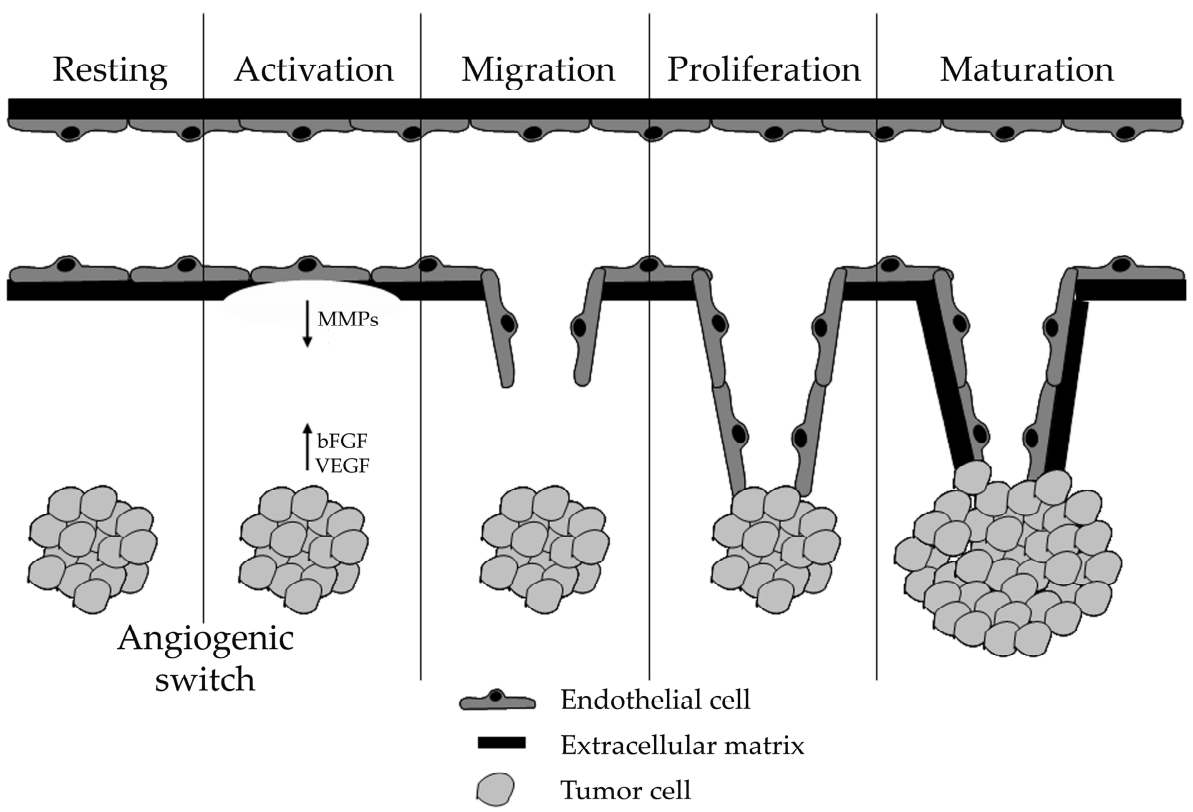

Figure 1.1 The multi-step process of tumor angiogenesis.

After the angiogenic switch has occurred, a tumor starts to produce pro-angiogenic factors like basic fibroblast growth factor (bFGF) and vascular endothelial growth factor (VEGF) which bind to endothelial cells (ECs) of a nearby vessel. EC become activated and produce matrix metalloproteinnases (MMPs) that locally degrade the extracellular matrix (EM), allowing invasion of ECs in the surrounding tissue. Subsequently, EC migrate and proliferate towards the tumor and form a lumen. Eventually, a mature blood vessel is formed after recruitment of pericytes and EM formation. 
Since a tumor is unable to grow beyond the size of approximately $2 \mathrm{~mm}^{3}$ without the supply of oxygen and nutrients, pro-angiogenic factors are produced by the tumor cells that initiate a chain reaction of events. First endothelial cells that line the lumen of nearby vessels are activated by angiogenic factors. After degradation of the basement membrane by matrix metalloproteinases (MMPs), these activated EC migrate and proliferate in the direction of the angiogenic stimulus. Subsequently, tube-like structures are formed which are stabilized by the recruitment of mural cells like pericytes to finally form a mature blood vessel (Figure 1.1) ${ }^{4}$. In tumors the imbalance between pro- and antiangiogenic factors results in abnormal, chaotic organization of vessels that are leaky, tortuous and possess imperfect EC lining and often abnormal basement membrane structures. Furthermore, continuous remodeling of the vascularization leads to great variations in blood flow within the same tumor ${ }^{5}$.

\section{Pro-angiogenic factors}

The induction of the angiogenesis cascade is initiated when pro-angiogenic factors take the upper hand of anti-angiogenic factors. Various molecules have been characterized as inducers of blood vessel formation. One of the most extensively investigated angiogenesis stimulators is vascular endothelial growth factor (VEGF) was first described as vascular permeability factor (VPF) in 1983 by Senger et al. . The VEGF family consists of VEGF-A (also referred to as VEGF), placenta growth factor (PIGF), VEGF-B, VEGF-C and VEGF-D, of which VEGF-A is the most critical and central regulator of angiogenesis. At least eight VEGF-A isoforms exist as a result of alternative patterns of splicing. The four main isoforms are 121, 165, 189 and 206 amino acids long, with the 165-amino acid form representing the predominant species 7. VEGF is a basic, heparin-binding, homodimeric glycoprotein of $45 \mathrm{kDa}$ that can be secreted although a significant fraction remains bound to the cell surface and the extracellular matrix. Its expression is upregulated by a variety of factors like oxygen tension, growth factors and oncogenes, all implicated in cancer. Low oxygen tension in tumor tissues, induces the hypoxiainducible factor (HIF)-1 and consequently VEGF is released from the underlying tumor tissue ${ }^{7}$. The biological functions of the VEGF family are mediated upon binding to cell surface VEGF receptors VEGFR-1 (Flt-1), VEGFR-2 (KDR) and VEGFR-3 (Flt-4). Both ligands of VEGF-A ,VEGFR-1 and VEGFR-2, are predominantly expressed by EC whereas VEGFR-3 is largely restricted to lymphatic vessels 8,9 . VEGF secreted by tumor cells induces tumor angiogenesis by a direct effect on ECs. It increases EC proliferation, migration and survival as well as expression of plasminogen activators and collagenases. In addition, enhanced vascular permeability is observed after VEGF exposure ${ }^{10,11}$. 
Besides VEGF, basic fibroblast growth factor (bFGF, FGF2) is also a major angiogenesis stimulating factor. bFGF is a heparin binding growth factor that belongs to the large FGF family that is comprised of 22 members. It is a multifunctional growth factor which has various effects in a large panel of cells and tissues. In a tumor, bFGF is produced by tumor cells leading to induction of MMP synthesis in EC and consequently degradation of the extracellular matrix. Additionally, bFGF stimulates quiescent endothelial cells for morphogenesis, migration and proliferation 12-14. Signaling occurs via four high affinity tyrosine kinase transmembrane receptors (FGFR1-4) and activates several pathways including the PI3K and the RAS pathway. Furthermore, bFGF and VEGF have been found to exert synergistic effects on tumor blood vessel development ${ }^{13}$.

In addition to VEGF and bFGF, angiopoietins (Ang) possess angiogenesis stimulating properties too. Ang-1 and Ang-2 retain crucial but different roles in angiogenesis. Ang- 1 acts as a maturation factor whereas Ang-2 induces a destabilization signal and is expressed prior to vessel sprouting. However, neither Ang-1 nor Ang-2 is known to promote EC proliferation. Two other members of the angiopoietin family, mouse Ang-3 and human Ang-4, have been described, although their function in regulation of angiogenesis has not yet been unraveled. Angiopoietins (Ang1-4) operate through the endothelial cells restricted receptor tyrosine kinase Tie2. Unlike for Tie2, the ligand for the Tie1 receptor has not been identified yet, and thus the function has remained undefined. Still, in vivo studies indicate that Tie1 is required for vascular development ${ }^{15}$.

Interestingly, several cytokines can operate as pro-angiogenic factors. Interleukin-8 (IL-8) supports angiogenesis by enhancing proliferation and survival and inhibiting apoptosis of ECs. Furthermore, treatment of ECs with IL-8 enhances MMP production and capillary tube organization 16. Along with IL-8, IL-1 promotes EC proliferation as well. Moreover, IL-1 accounts for the ability of tumor cells to initiate and complete the processes of angiogenesis ${ }^{17}$.

\section{Anti-angiogenic factors}

Various endogenous molecules have been reported to inhibit angiogenesis 18,19 . Platelet factor-4 (PF-4), a member of the C-X-C chemokine family, is one of these endogenous compounds. This platelet specific protein inhibits proliferation, migration and tube formation of $\mathrm{EC}$ and has been shown to restrict tumor growth by diminishing vessel formation. PF-4 executes its angiostatic function partially by a direct interaction with bFGF and/or VEGF ${ }^{20-22}$.

Bacterial/permeability-increasing protein (BPI), produced by human neutrophils, is a bactericidal protein that resembles PF-4. Both molecules are cationic and bactericidal. Interestingly, they also share the angiostatic potential. BPI inhibits angiogenic processes in vitro as well as in vivo ${ }^{23}$. 
Multifunctional matricellular glycoprotein trombospondin-1 (TSP-1) has also been identified as natural angiostatic agent ${ }^{24}$. It manifests its function by suppressing EC migration and stimulating EC apoptosis. Expression of TPS-1 in the tumor microenvironment is up-regulated by tumor suppressor gene, p53, and downregulated by oncogenes like Myc and Ras ${ }^{25}$. Furthermore, TSP-1 inhibits mobilization of pro-angiogenic factors like MMPs which only underlines its angiostatic potential ${ }^{26}$.

Several anti-angiogenic factors are fragments of molecules that, without cleavage, have no effect on angiogenesis. For example, angiostatin, a $38-\mathrm{kDa}$ internal fragment of plasminogen, is able to induce apoptosis of EC as well as inhibit EC proliferation 27,28. Likewise, endostatin has been identified as a $20-\mathrm{kDa}$ fragment of type XVIII collagen that can be generated by elastase or cathepsin L released by tumor cells ${ }^{27,29}$. The bioactive domain of type IV collagen alpha3 chain, called tumstatin, imparts anti-angiogenic activity by inducing apoptosis of proliferating ECs. The expression of $\alpha \mathrm{v} \beta 3$, only present on pathological angiogenic vessels, is necessary for the inhibitory functions of this collagen fragment 30,31 .

Similar to pro-angiogenic factors, several cytokines are described to exert anti-angiogenic properties. Interferon alpha (IFN- $\alpha$ ) reduces bFGF expression in vivo and consequently diminishes tumor neovascularization as well as tumor growth ${ }^{32,33}$. Comparable results are demonstrated for interleukin 12 and 6. Both cytokines strongly inhibit angiogenic processes ${ }^{34,35}$.

\section{Angiogenesis inhibition}

In the early seventies it was already postulated by Judah Folkman that tumors rely on blood vessels for their development and growth ${ }^{36}$. Therefore, depriving tumors from their oxygen and nutrients via destruction of tumor blood vessels as well as inhibition of tumor neovascularization is an interesting strategy for cancer therapy. Inhibition of angiogenesis as a cancer treatment is considered to have several advantages compared to other approaches like surgery, radiation therapy, and chemotherapy. Side effects are less expected after angiostatic treatment since angiogenesis in adults is limited. Furthermore, endothelial cells are genetically stable which is in contrast with tumor cells. Acquiring resistance to angiostatic inhibition is therefore unlikely. In addition, EC are accessible to serum soluble drugs due to their direct contact with the blood flow 37,38 .

Over the last 15 years, numerous hypotheses and strategies have been exerted leading to the development of a variety of angiogenesis inhibitors. The first one to be FDA approved in the United States was bevacizumab (Avastin). This monoclonal antibody binds to and neutralizes all human VEGF isoforms resulting in decreased vessel formation and reduced tumor growth. VEGF is a frequently used target for angiogenesis inhibition ${ }^{39}$. In addition to bevacizumab, a 
VEGF-trap has been developed consisting of decoy-soluble receptors for VEGFRs which are able to prevent VEGF from binding to its normal receptor and consequently inhibit angiogenesis ${ }^{40}$. Inhibition of the tyrosine kinase activity of angiogenic growth factor receptors like Flt-1, KDR and FGFR-1 is a nice tool to inhibit angiogenic processes as well. Several compounds like SU6668, PTK787/ZK 222584, and SU11248 have been generated that inhibit the phosphorylation and activity of these receptors ${ }^{41-43}$.

Combretastatin A4 phosphate (CA4P) is a microtubule-disrupting agent. This compound is derived from the Combretum caffrum tree and possesses potent angiostatic activity. CA4P reduces proliferation, migration and sprouting and induces apoptosis of activated EC ${ }^{44}$. It has been successfully used in mouse and rat tumor models where it inhibits tumor growth by diminishing tumor neovascularization ${ }^{45}$.

Fumagillin has been identified as an angiogenesis inhibitor during routine culturing of EC. Proliferation of these cells as well as angiogenesis in the growing chick chorioallantoic membrane was inhibited by this fungus derived compound. However, its effectiveness as an inhibitor in tumor models was limited due to sever weight loss ${ }^{46}$. Therefore analogues of this molecule were developed. The most competent analogue is TNP-470 (AGM-1470). TNP-470 is an outstanding angiogenesis inhibitor that shows a great anti-tumor response ${ }^{47}$

An other exogenous angiogenesis inhibitor is thalidomide. This teratogen was initially developed and used as a sedative. Unfortunately, when used during pregnancy thalidomide had severe side effects in the new born child, which, later on, where attributed to inhibition of blood vessel growth 48,49. Currently, thalidomide is accepted as a potent angiogenesis inhibitor and was FDA approved in Australia in 2003 for treatment of multiple myeloma ${ }^{50}$.

Endogenous angiostatic agents endostatin and angiostatin have been used in different anti-tumor treatment strategies with divergent success ${ }^{51-53}$. Recently, Endostatin (Endostar) has been approved in China for clinical use ${ }^{54}$.

Comparison of the three-dimensional structure of several endogenous angiostatic agents like PF-4, BPI, thrombospondin, angiostatin and endostatin, led to the synthesis of a new peptide, anginex, with excessive angiostatic potential. Anginex specifically inhibits proliferation, migration and sprouting and induces apoptosis of ECs. Its competence has also been demonstrated in different mouse tumor models 55-57. Anginex specifically targets tumor EC which makes it a mighty tool for gene therapy and imaging purposes 58,59 . Recently, partial mimetics as well as topo-mimetics of anginex were designed 60,61. Especially topo-mimetic 0118 shows strong angiostatic power.

Besides inhibition of neovascularization and reduction of tumor vessels, angiogenesis inhibitors can also normalize tumor vasculature. They fix the 
delivery system for drugs and oxygen. Therefore, a combination of angiogenesis inhibitors and cytotoxic therapies has been shown to improve cancer treatment ${ }^{62}$.

A pitfall of blocking angiogenic factors as an angiostatic tumor therapy lies in the fact that some tumors express redundant angiogenic factors. These tumors could become refractory to an angiogenesis inhibitor that blocks a single angiogenic factor. Such a potential refractory state can be prevented by combining different angiogenesis inhibitors ${ }^{54,63}$.

\section{Anti-tumor immunity}

The idea that the immune system is involved in the control of tumors dates back to the 1950s when the hypothesis of immune surveillance was formulated ${ }^{64}$. It was suggested that tumors continuously arise in the body, but that these tumors are recognized by a very efficient immune system that eliminates the tumor cells early before they become clinically apparent. Nevertheless, many tumors can progress without any signs of attack by immune cells ${ }^{65}$. The reason why immune responses are unable to eradicate the tumor is not fully understood. Several processes have been shown to contribute to the escape of a tumor from the immune response. One explanation of ineffective immunity is aberrant leukocyte-vessel wall interactions and trans-vessel migration. A prerequisite for anti-tumor immunity is that immune cells actually enter into the tumor. However, the tumor microenvironment modulates leukocyte recruitment in such a way that leukocyte infiltration into cancer tissues is reduced. In addition, once entered in the tumor tissue, leukocytes have to be able to fulfill their effector function in order to assess tumor cell eradication. A tumor possesses various mechanisms of immune evasion at the effector phase of the anti-tumor immune response. The next section will give a short overview of these immune escape mechanisms of tumors.

\section{Hampered leukocyte effector functions induced by tumor microenvironmental factors.}

Cancer immune surveillance is considered to be the an important host protection process to inhibit carcinogenesis ${ }^{66}$. Once entered into the tumor tissue, immune cells have to exert their effector function in order to destroy the malignant cells. However, the tumor microenvironment induces several mechanisms of immune evasion at the effector phase of the anti-tumor immune response. First of all, tumor cells can be ignored by anti-tumor immune cells which means that reactive $\mathrm{T}$ cells might not have encountered tumor antigens and initial $\mathrm{T}$ cell priming is hampered. During oncogenic processes, tumor cells undergo series of genetic modifications leading to multiple cellular antigens that are qualitatively and quantitatively different from the parental cell. These antigens can be subdivided 
into four major categories: (1) differentiation antigens; (2) overexpressed antigens with higher expression levels in tumor compared to normal tissues; (3) tumorspecific shared antigens, only expressed in different tumors; and (4) tumor-specific unique antigens, resulting from mutations in a single tumor 67,68 . In many cases, tumor antigens, presented by major histocompatibility complex (MHC) class I molecules, are identical to, or closely resemble self. In addition, the amount of tumor antigen that is presented to cytotoxic T cells is insufficient, especially during tumor initiation. This makes recognizing tumor antigen by $\mathrm{T}$ cells likely of low avidity, termed "immunological ignorance" 67.

In several cases, anti-tumor immune responses are observed, indicating tumor awareness, though without accompanying rejection. Therefore, tumor ignorance of effector cells may often not be the major reason for failed anti-tumor immunity. There have to be barriers downstream from the initial priming of $\mathrm{T}$ cells 69,70. T cells that home to the tumor site are found to be dysfunctional. Defective antigen-specific cytolytic activity has been linked to limited maturation of effector cells. T cells are associated with poor adhesion or ineffective granule exocytosis and lack of perforin expression. Furthermore, tumor infiltrated $\mathrm{T}$ cells display defective cytokine production as well as proliferation, suggestive for $\mathrm{T}$ cell anergy 69,70. Interestingly, lytic deficiency can be reversible and has been strongly implied to be tumor-specific ${ }^{67}$.

A number of tumor microenvironmental factors induce $\mathrm{T}$ cell deficiency. Tumor derived soluble factors like interleukin-10 (IL-10), transforming growth factor- $\beta$ (TGF- $\beta$ ) and VEGF have been shown to inhibit $\mathrm{T}$ cells function. The immunosuppressive cytokines, IL-10 and TGF- $\beta$, induce the function of regulatory $\mathrm{T}$ cells (Tregs) ${ }^{71}$. Tregs are $\mathrm{CD} 4{ }^{+} \mathrm{CD} 25^{+} \mathrm{Foxp}^{+}$cells that suppress the effector function of cytotoxic $\mathrm{T}$ cells. Regulatory $\mathrm{T}$ cells control the balance between immune tolerance and effective immunity. In various tumor types, an accumulation of Tregs was shown, leading to suppressed tumor-specific $\mathrm{T}$ cell immunity and thus tumor tolerance. Depletion of these regulatory $\mathrm{T}$ cells contributes to restoration of anti-tumor immunity ${ }^{72-75}$.

Tumor derived VEGF is a strong chemoattractant for myeloid derived suppressor cells (MSC) which can also inhibit cytotoxic T cell responses ${ }^{71}$. MSC inhibit antigen-dependent cytokine secretion, induce apoptosis in activated T cells, secrete a variety of immunomodulatory factors and are able to induce production of enzymes that mediate amino acid metabolism like indoleamine 2,3-dioxygenase (IDO) 67. IDO, mainly produced by stromal cells in tumor tissue, can be immunosuppressive. Inhibition of this metabolic factor improves $\mathrm{T}$ cell mediated tumor control in vivo 76,77. Interestingly, signal transducer and activator of transcription 3 (Stat3) can activate VEGF and obstructs dendritic cells 
differentiation and maturation. Inhibition of Stat3 consequently might improve anti-tumor immunity ${ }^{66}$.

Tumors can actively induce $\mathrm{T}$ cell apoptosis in situ, a phenomenon called "tumor counterattack". Some tumors adopt killing mechanisms from cytotoxic immune cells and have been found to express the apoptosis-inducing cell surface molecule CD95L (Fas ligand), enabling them to kill $\mathrm{T}$ cells that are sensitive for CD95- mediated cell death ${ }^{78}$. In addition, tumors can release soluble histocompatibility antigen-1 (sHLA-1) that not only decreases cell-mediated immune responses but also induces apoptosis of cytolytic effector cells ${ }^{79}$. Galectins expressed and secreted by tumor cells, can also mediate tumor escape from the immune response. Galectin-1 induces apoptosis of tumor infiltrated T cells ${ }^{80,81}$.

Finally, during tumor progression, immune selection produces tumor cell variants that escape from the anti-tumor immune response. These mutated tumor cells can lose their MHC class I and II antigens and/or their sensitivity to interferon gamma (IFN- $\gamma$ ) signaling. An important role for IFN- $\gamma$ signaling in effective tumor rejection has been demonstrated in different mouse models. Part of this mechanism depends on IFN- $\gamma$ signaling at the level of the tumor cells themselves 66,69 .

In conclusion it can be stated that tumor cells and microenvironment edit the immune surveillance to immune escape ${ }^{66,69}$.

\section{Impaired leukocyte recruitment via tumor blood vessels}

Although a tumor frequently behaves as an inflammatory process, it can also evoke a tumor-specific immune response partly by effecting endothelial cell adhesion molecule expression. These molecules mediate the leukocyte-vessel wall interactions that are necessary for leukocytes to escape from the blood vessel into a tissue under shear flow. The recruitment of leukocytes is a multi-step cascade that is comprised of initial tethering and rolling, activation, firm adhesion and finally transmigration of leukocytes through the vessel wall (Figure 1.2) 82,83. Selectins predominantly mediate initial tethering and rolling of leukocytes. Endothelial(E)selectin as well as platelet(P)-selectin expressed by ECs upon cytokine activation, bind leukocyte(L)-selectin on leukocytes ${ }^{84,85}$. These reversible adhesion processes are then replaced by stronger bindings mainly obtained by three members of the immunoglobulin gene superfamily: intercellular adhesion molecule-1 (ICAM-1), ICAM-2 and vascular cell adhesion molecule-1 (VCAM-1) ${ }^{86}$. Subsequently, diapedesis of leukocytes occurs with minimal disruption of the endothelial cell lining ${ }^{87}$. Expression of endothelial cell adhesion molecules and leukocyte recruitment is induced by cytokines such as tumor necrosis factor $\alpha$ (TNF $\alpha)$, interleukin-1 (IL-1), and interferon $\gamma(\operatorname{IFN} \gamma)^{86,88}$. An overview of all endothelial cell adhesion molecules involved in the different steps of the leukocyte adhesion cascade can be found in chapter 2 of this thesis. 


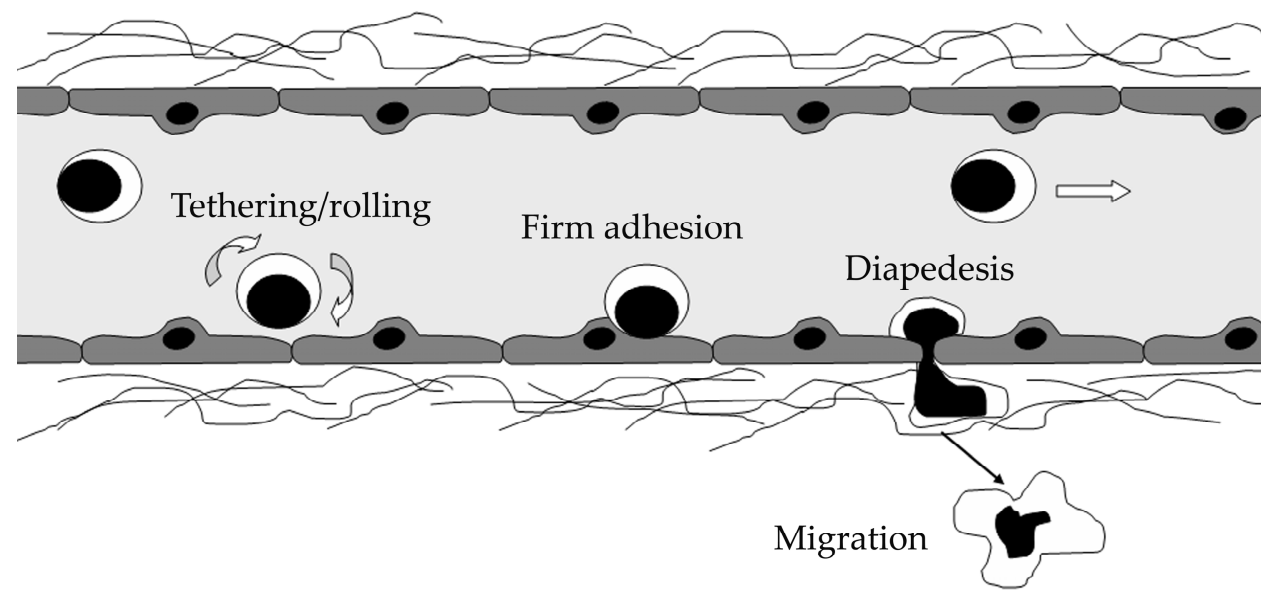

Figure 1.2 The leukocyte adhesion cascade

In order to escape from the blood vessel under shear flow, leukocytes initially tether and roll along the vessel wall. During this process of reversible interactions, leukocytes can become activated, resulting in firm adhesion. Finally, leukocytes migrate through the vessel wall into the surrounding tissue.

As leukocyte recruitment is a multistep process, the tumor can manipulate endothelial cell adhesion molecule expression at different steps during leukocyte recruitment. For example, tumor-related angiogenic factors VEGF and bFGF, diminish expression of E-selectin and CD34 that mediate leukocyte rolling ${ }^{89,90}$. Furthermore, ICAM-1,-2 and VCAM-1 expression on endothelial cells after stimulation with inflammatory cytokines is decreased by bFGF and VEGF in vitro. In vivo studies confirmed this decrease of adhesion molecules on angiogenic tumor vessels (for review see chapter 2). The restricted cytokine-induced upregulation of adhesion molecules is called endothelial cell anergy which results in decreased leukocyte-tumor vessel wall interactions ${ }^{88,91-94}$. Interestingly, in the presence of a large tumor burden, reduction of leukocyte-vessel wall interactions is not restricted to tumor vessels alone, it can be observed as a systemic event. This is probably due to a high level of angiogenic factors released by the tumor into the circulation system ${ }^{95}$.

In conclusion, angiogenesis induces tumor development, growth and expansion by increasing neovascularisation as well as by preventing recruitment of leukocytes into the tumor tissue. Therefore, inhibition of angiogenesis might have dual effects on cancer progression: (i) inhibition of growth and metastasis by diminishing tumor vessels and, (ii) destruction of tumor cells by generating a massive influx of leukocytes within the tumor tissue. These findings could be of great importance in the search of new strategies for cancer therapy and consequently an interesting field to investigate. 


\section{Aim and outline of the thesis}

Tumors have developed numerous mechanisms like angiogenesis and evasion of anti-tumor immunity that contribute to their initiation and progression. Angiogenic factors produced by tumor cells and released in the tumor microenvironment, initiate the angiogenesis cascade leading to the formation of tumor microvessels necessary for delivery of nutrients and oxygen to the tumor as well as removal of waste products. Furthermore, tumor related factors adapt the immune response in such a way that immune surveillance is diminished and escape is established. Both mechanisms have been a target for numerous cancer treatments. However, there are several common tumor factors that mediate both processes. The aim of the present study was to investigate the relationship between angiogenesis and the immune response and to utilize these findings to gain new insights in these processes and work towards new cancer treatment strategies using a combination between angiogenesis inhibition and immune stimulatory therapy.

Chapter 2 gives an overview of the leukocyte recruitment process and how tumor angiogenesis related factors manipulate this cascade by regulation of endothelial cell adhesion molecule expression, resulting in endothelial cell anergy and escape from anti-tumor immunity. The tumor-specific composition of adhesion molecules on tumor endothelial cells can be exploited for different imaging and treatment modalities.

Tumor angiogenesis as well as tumor leukocyte recruitment determine partly the survival of patients with colorectal cancer as has been shown in the patient study described in chapter 3 . These findings suggest that affecting both processes, inhibition of tumor angiogenesis and induction of tumor leukocyte infiltration and activation, could improve patient survival.

The experimental study of chapter 4 presents that inhibition of angiogenesis restores endothelial cell adhesion molecule expression, leukocytevessel wall interactions, and leukocyte tumor infiltration in mouse models. This is confirmed for human models in chapter 5. In addition, it is demonstrated that mimetics of angiostatic synthetic peptide anginex can posses the same properties as parent anginex. Especially one of these mimetics, 0118, possesses great potential for further development in clinical studies. Furthermore, inhibition of angiogenesis increases the amount of leukocytes that present activation markers and consequently are able to eradicate tumor cells. However, no proof has been found that the tested angiogenesis inhibitors affect the cytolytic capacity of immune effector cells. They predominantly induce the overall leukocyte tumor influx by increasing endothelial adhesion molecule expression on tumor vessels. 
In chapter 6 we tried to unravel a part of the mechanism behind the downregulation of endothelial cell adhesion molecule expression on tumor conditioned endothelium. Epigenitic modifications can regulate the angiogenesismediated escape from anti-tumor immunity since repression of ICAM-1 by promoter histone modifications was found.

In search for an immunotherapy that could be combined with angiogenesis inhibition and that would improve the cytolytic capacity of effector cells within the tumor tissue, we found interleukin-21 as a possible suitable compound. However, interleukins effect the angiogenic processes, negatively or positively. Therefore, we tested the angiostatic properties of this cytokine (chapter 7) which is necessary knowledge if we want to use IL-21 in the future as a combination therapy with angiogenesis inhibitors like anginex or 0118.

The focus of the above presented chapters is mainly on illustrious endothelial cell adhesion molecules ICAM-1, VCAM-1 and E-selectin. Still, the role of other, less studied and less well-known adhesion molecules, could be important in the relationship between angiogenesis and the immune response in and against solid tumors. Vascular adhesion protein-1 (VAP-1) is such an adhesion molecule. In chapter 8 the results of research on the role of VAP-1 in leukocyte-tumor vessel wall interactions and tumor angiogenesis is presented.

Finally, in chapter 9 the findings of the previous chapters are discussed in an integral way with ideas and plans for future imaging and treatment modalities.

\section{References}

1. Carmeliet P. Angiogenesis in life, disease and medicine. Nature. 2005;438:932-936.

2. Hanahan D, Folkman J. Patterns and emerging mechanisms of the angiogenic switch during tumorigenesis. Cell. 1996;86:353-364.

3. Pugh CW, Ratcliffe PJ. Regulation of angiogenesis by hypoxia: role of the HIF system. Nat Med. 2003;9:677-684.

4. Griffioen AW, Molema G. Angiogenesis: potentials for pharmacologic intervention in the treatment of cancer, cardiovascular diseases, and chronic inflammation. Pharmacol Rev. 2000;52:237-268.

5. Jain RK. Molecular regulation of vessel maturation. Nat Med. 2003;9:685-693.

6. Senger DR, Galli SJ, Dvorak AM, Perruzzi CA, Harvey VS, Dvorak HF. Tumor cells secrete a vascular permeability factor that promotes accumulation of ascites fluid. Science. 1983;219:983-985.

7. Ferrara N. Role of vascular endothelial growth factor in the regulation of angiogenesis. Kidney Int. 1999;56:794-814.

8. Cebe-Suarez S, Zehnder-Fjallman A, Ballmer-Hofer K. The role of VEGF receptors in angiogenesis; complex partnerships. Cell Mol Life Sci. 2006;63:601-615.

9. Ferrara N, Gerber HP, LeCouter J. The biology of VEGF and its receptors. Nat Med. 2003;9:669676.

10. Carmeliet P. VEGF as a key mediator of angiogenesis in cancer. Oncology. 2005;69 Suppl 3:4-10. 
11. Jain RK. Tumor angiogenesis and accessibility: role of vascular endothelial growth factor. Semin Oncol. 2002;29:3-9.

12. Okada-Ban M, Thiery JP, Jouanneau J. Fibroblast growth factor-2. Int J Biochem Cell Biol. 2000;32:263-267.

13. Presta M, Dell'Era P, Mitola S, Moroni E, Ronca R, Rusnati M. Fibroblast growth factor/fibroblast growth factor receptor system in angiogenesis. Cytokine Growth Factor Rev. 2005;16:159-178.

14. Rak J, Kerbel RS. bFGF and tumor angiogenesis--back in the limelight? Nat Med. 1997;3:1083-1084.

15. Morisada T, Kubota Y, Urano T, Suda T, Oike Y. Angiopoietins and angiopoietin-like proteins in angiogenesis. Endothelium. 2006;13:71-79.

16. Li A, Dubey S, Varney ML, Dave BJ, Singh RK. IL-8 directly enhanced endothelial cell survival, proliferation, and matrix metalloproteinases production and regulated angiogenesis. J Immunol. 2003;170:3369-3376.

17. Voronov E, Shouval DS, Krelin Y, et al. IL-1 is required for tumor invasiveness and angiogenesis. Proc Natl Acad Sci U S A. 2003;100:2645-2650.

18. Nyberg P, Xie L, Kalluri R. Endogenous inhibitors of angiogenesis. Cancer Res. 2005;65:3967-3979.

19. Sato Y. Update on endogenous inhibitors of angiogenesis. Endothelium. 2006;13:147-155.

20. Bikfalvi A. Recent developments in the inhibition of angiogenesis: examples from studies on platelet factor-4 and the VEGF/VEGFR system. Biochem Pharmacol. 2004;68:1017-1021.

21. Gupta SK, Singh JP. Inhibition of endothelial cell proliferation by platelet factor-4 involves a unique action on S phase progression. J Cell Biol. 1994;127:1121-1127.

22. Maurer AM, Zhou B, Han ZC. Roles of platelet factor 4 in hematopoiesis and angiogenesis. Growth Factors. 2006;24:242-252.

23. van der Schaft DW, Toebes EA, Haseman JR, Mayo KH, Griffioen AW. Bactericidal/permeabilityincreasing protein (BPI) inhibits angiogenesis via induction of apoptosis in vascular endothelial cells. Blood. 2000;96:176-181.

24. Rastinejad F, Polverini PJ, Bouck NP. Regulation of the activity of a new inhibitor of angiogenesis by a cancer suppressor gene. Cell. 1989;56:345-355.

25. Ren B, Yee KO, Lawler J, Khosravi-Far R. Regulation of tumor angiogenesis by thrombospondin-1. Biochim Biophys Acta. 2006;1765:178-188.

26. Lawler J. Thrombospondin-1 as an endogenous inhibitor of angiogenesis and tumor growth. J Cell Mol Med. 2002;6:1-12.

27. Hajitou A, Grignet C, Devy L, et al. The antitumoral effect of endostatin and angiostatin is associated with a down-regulation of vascular endothelial growth factor expression in tumor cells. Faseb J. 2002;16:1802-1804.

28. Sim BK, MacDonald NJ, Gubish ER. Angiostatin and endostatin: endogenous inhibitors of tumor growth. Cancer Metastasis Rev. 2000;19:181-190.

29. Dixelius J, Cross M, Matsumoto T, Sasaki T, Timpl R, Claesson-Welsh L. Endostatin regulates endothelial cell adhesion and cytoskeletal organization. Cancer Res. 2002;62:1944-1947.

30. Hamano Y, Kalluri R. Tumstatin, the NC1 domain of alpha3 chain of type IV collagen, is an endogenous inhibitor of pathological angiogenesis and suppresses tumor growth. Biochem Biophys Res Commun. 2005;333:292-298.

31. Hamano Y, Zeisberg M, Sugimoto H, et al. Physiological levels of tumstatin, a fragment of collagen IV alpha3 chain, are generated by MMP-9 proteolysis and suppress angiogenesis via alphaV beta3 integrin. Cancer Cell. 2003;3:589-601.

32. Dinney CP, Bielenberg DR, Perrotte $\mathrm{P}$, et al. Inhibition of basic fibroblast growth factor expression, angiogenesis, and growth of human bladder carcinoma in mice by systemic interferon-alpha administration. Cancer Res. 1998;58:808-814.

33. Rosewicz S, Detjen K, Scholz A, von Marschall Z. Interferon-alpha: regulatory effects on cell cycle and angiogenesis. Neuroendocrinology. 2004;80 Suppl 1:85-93.

34. Voest EE, Kenyon BM, O'Reilly MS, Truitt G, D'Amato RJ, Folkman J. Inhibition of angiogenesis in vivo by interleukin 12. J Natl Cancer Inst. 1995;87:581-586. 
35. Hatzi E, Murphy C, Zoephel A, et al. N-myc oncogene overexpression down-regulates leukemia inhibitory factor in neuroblastoma. Eur J Biochem. 2002;269:3732-3741.

36. Folkman J. Tumor angiogenesis: therapeutic implications. N Engl J Med. 1971;285:1182-1186.

37. Kerbel RS. Inhibition of tumor angiogenesis as a strategy to circumvent acquired resistance to anticancer therapeutic agents. Bioessays. 1991;13:31-36.

38. Bouma-ter Steege JC, Mayo KH, Griffioen AW. Angiostatic proteins and peptides. Crit Rev Eukaryot Gene Expr. 2001;11:319-334.

39. Ferrara N, Hillan KJ, Novotny W. Bevacizumab (Avastin), a humanized anti-VEGF monoclonal antibody for cancer therapy. Biochem Biophys Res Commun. 2005;333:328-335.

40. Holash J, Davis S, Papadopoulos N, et al. VEGF-Trap: a VEGF blocker with potent antitumor effects. Proc Natl Acad Sci U S A. 2002;99:11393-11398.

41. Laird AD, Vajkoczy P, Shawver LK, et al. SU6668 is a potent antiangiogenic and antitumor agent that induces regression of established tumors. Cancer Res. 2000;60:4152-4160.

42. Mendel DB, Laird AD, Xin X, et al. In vivo antitumor activity of SU11248, a novel tyrosine kinase inhibitor targeting vascular endothelial growth factor and platelet-derived growth factor receptors: determination of a pharmacokinetic/pharmacodynamic relationship. Clin Cancer Res. 2003;9:327-337.

43. Wood JM, Bold G, Buchdunger E, et al. PTK787/ZK 222584, a novel and potent inhibitor of vascular endothelial growth factor receptor tyrosine kinases, impairs vascular endothelial growth factor-induced responses and tumor growth after oral administration. Cancer Res. 2000;60:21782189.

44. Ahmed B, Van Eijk LI, Bouma-Ter Steege JC, et al. Vascular targeting effect of combretastatin A-4 phosphate dominates the inherent angiogenesis inhibitory activity. Int J Cancer. 2003;105:20-25.

45. Vincent L, Kermani P, Young LM, et al. Combretastatin A4 phosphate induces rapid regression of tumor neovessels and growth through interference with vascular endothelial-cadherin signaling. J Clin Invest. 2005;115:2992-3006.

46. Ingber D, Fujita $\mathrm{T}$, Kishimoto $\mathrm{S}$, et al. Synthetic analogues of fumagillin that inhibit angiogenesis and suppress tumour growth. Nature. 1990;348:555-557.

47. Yamaoka M, Yamamoto T, Ikeyama S, Sudo K, Fujita T. Angiogenesis inhibitor TNP-470 (AGM1470) potently inhibits the tumor growth of hormone-independent human breast and prostate carcinoma cell lines. Cancer Res. 1993;53:5233-5236.

48. D'Amato RJ, Loughnan MS, Flynn E, Folkman J. Thalidomide is an inhibitor of angiogenesis. Proc Natl Acad Sci U S A. 1994;91:4082-4085.

49. Belo AV, Barcelos LS, Teixeira MM, Ferreira MA, Andrade SP. Differential effects of antiangiogenic compounds in neovascularization, leukocyte recruitment, VEGF production, and tumor growth in mice. Cancer Invest. 2004;22:723-729.

50. Habeck M. Australia approves thalidomide. Lancet Oncol. 2003;4:713.

51. O'Reilly MS, Boehm T, Shing Y, et al. Endostatin: an endogenous inhibitor of angiogenesis and tumor growth. Cell. 1997;88:277-285.

52. O'Reilly MS, Holmgren L, Shing Y, et al. Angiostatin: a novel angiogenesis inhibitor that mediates the suppression of metastases by a Lewis lung carcinoma. Cell. 1994;79:315-328.

53. Tabruyn SP, Griffioen AW. Molecular pathways of angiogenesis inhibition. Biochem Biophys Res Commun. 2007;355:1-5.

54. Folkman J. Antiangiogenesis in cancer therapy--endostatin and its mechanisms of action. Exp Cell Res. 2006;312:594-607.

55. Dings RP, van der Schaft DW, Hargittai B, Haseman J, Griffioen AW, Mayo KH. Anti-tumor activity of the novel angiogenesis inhibitor anginex. Cancer Lett. 2003;194:55-66.

56. Griffioen AW, van der Schaft DW, Barendsz-Janson AF, et al. Anginex, a designed peptide that inhibits angiogenesis. Biochem J. 2001;354:233-242. 
57. van der Schaft DW, Dings RP, de Lussanet QG, et al. The designer anti-angiogenic peptide anginex targets tumor endothelial cells and inhibits tumor growth in animal models. Faseb J. 2002;16:1991-1993.

58. Brandwijk RJ, Griffioen AW, Thijssen VL. Targeted gene-delivery strategies for angiostatic cancer treatment. Trends Mol Med. 2007;13:200-209.

59. Brandwijk RJ, Mulder WJ, Nicolay K, Mayo KH, Thijssen VL, Griffioen AW. Anginex-Conjugated Liposomes for Targeting of Angiogenic Endothelial Cells. Bioconjug Chem. 2007;18:785-790.

60. Mayo KH, van der Schaft DW, Griffioen AW. Designed beta-sheet peptides that inhibit proliferation and induce apoptosis in endothelial cells. Angiogenesis. 2001;4:45-51.

61. Dings RP, Chen X, Hellebrekers DM, et al. Design of nonpeptidic topomimetics of antiangiogenic proteins with antitumor activities. J Natl Cancer Inst. 2006;98:932-936.

62. Jain RK. Normalization of tumor vasculature: an emerging concept in antiangiogenic therapy. Science. 2005;307:58-62.

63. Abdollahi A, Hlatky L, Huber PE. Endostatin: the logic of antiangiogenic therapy. Drug Resist Updat. 2005;8:59-74.

64. Burnet M. Cancer; a biological approach. I. The processes of control. Br Med J. 1957;1:779-786.

65. Nagorsen D, Scheibenbogen C, Marincola FM, Letsch A, Keilholz U. Natural T cell immunity against cancer. Clin Cancer Res. 2003;9:4296-4303.

66. Kim R, Emi M, Tanabe K. Cancer immunoediting from immune surveillance to immune escape. Immunology. 2007;121:1-14.

67. Frey AB, Monu N. Effector-phase tolerance: another mechanism of how cancer escapes antitumor immune response. J Leukoc Biol. 2006;79:652-662.

68. Ochsenbein AF. Immunological ignorance of solid tumors. Springer Semin Immunopathol. 2005;27:19-35.

69. Gajewski TF, Meng Y, Blank $\mathrm{C}$, et al. Immune resistance orchestrated by the tumor microenvironment. Immunol Rev. 2006;213:131-145.

70. Gajewski TF, Meng Y, Harlin H. Immune suppression in the tumor microenvironment. J Immunother (1997). 2006;29:233-240.

71. Kim R, Emi M, Tanabe K. Cancer immunosuppression and autoimmune disease: beyond immunosuppressive networks for tumour immunity. Immunology. 2006;119:254-264.

72. Becker C, Stoll S, Bopp T, Schmitt E, Jonuleit H. Regulatory T cells: present facts and future hopes. Med Microbiol Immunol (Berl). 2006;195:113-124.

73. Beyer M, Schultze JL. Regulatory T cells in cancer. Blood. 2006;108:804-811.

74. Lizee G, Radvanyi LG, Overwijk WW, Hwu P. Improving antitumor immune responses by circumventing immunoregulatory cells and mechanisms. Clin Cancer Res. 2006;12:4794-4803.

75. Zou W. Regulatory T cells, tumour immunity and immunotherapy. Nat Rev Immunol. 2006;6:295307.

76. Uyttenhove C, Pilotte L, Theate I, et al. Evidence for a tumoral immune resistance mechanism based on tryptophan degradation by indoleamine 2,3-dioxygenase. Nat Med. 2003;9:1269-1274.

77. Chiou SH, Sheu BC, Chang WC, Huang SC, Hong-Nerng H. Current concepts of tumorinfiltrating lymphocytes in human malignancies. J Reprod Immunol. 2005;67:35-50.

78. Igney FH, Krammer PH. Tumor counterattack: fact or fiction? Cancer Immunol Immunother. 2005;54:1127-1136.

79. Poggi A, Zocchi MR. Mechanisms of tumor escape: role of tumor microenvironment in inducing apoptosis of cytolytic effector cells. Arch Immunol Ther Exp (Warsz). 2006;54:323-333.

80. Liu FT, Rabinovich GA. Galectins as modulators of tumour progression. Nat Rev Cancer. 2005;5:29-41.

81. Rabinovich GA, Toscano MA, Ilarregui JM, Rubinstein N. Shedding light on the immunomodulatory properties of galectins: novel regulators of innate and adaptive immune responses. Glycoconj J. 2004;19:565-573. 
82. Shimizu Y, Newman W, Tanaka Y, Shaw S. Lymphocyte interactions with endothelial cells. Immunol Today. 1992;13:106-112.

83. Springer TA. Traffic signals for lymphocyte recirculation and leukocyte emigration: the multistep paradigm. Cell. 1994;76:301-314.

84. Bevilacqua MP. Endothelial-leukocyte adhesion molecules. Annu Rev Immunol. 1993;11:767-804.

85. Kunkel EJ, Jung U, Bullard DC, et al. Absence of trauma-induced leukocyte rolling in mice deficient in both P-selectin and intercellular adhesion molecule 1. J Exp Med. 1996;183:57-65.

86. Carlos TM, Harlan JM. Leukocyte-endothelial adhesion molecules. Blood. 1994;84:2068-2101.

87. Luscinskas FW, Ma S, Nusrat A, Parkos CA, Shaw SK. The role of endothelial cell lateral junctions during leukocyte trafficking. Immunol Rev. 2002;186:57-67.

88. Griffioen AW, Damen CA, Blijham GH, Groenewegen G. Tumor angiogenesis is accompanied by a decreased inflammatory response of tumor-associated endothelium. Blood. 1996;88:667-673.

89. Hellwig SM, Damen CA, van Adrichem NP, Blijham GH, Groenewegen G, Griffioen AW. Endothelial CD34 is suppressed in human malignancies: role of angiogenic factors. Cancer Lett. 1997;120:203-211.

90. Melder RJ, Koenig GC, Witwer BP, Safabakhsh N, Munn LL, Jain RK. During angiogenesis, vascular endothelial growth factor and basic fibroblast growth factor regulate natural killer cell adhesion to tumor endothelium. Nat Med. 1996;2:992-997.

91. Griffioen AW, Damen CA, Martinotti S, Blijham GH, Groenewegen G. Endothelial intercellular adhesion molecule-1 expression is suppressed in human malignancies: the role of angiogenic factors. Cancer Res. 1996;56:1111-1117.

92. Griffioen AW, Relou IA, Gallardo Torres HI, et al. The angiogenic factor bFGF impairs leukocyte adhesion and rolling under flow conditions. Angiogenesis. 1998;2:235-243.

93. Kitayama J, Nagawa H, Yasuhara H, et al. Suppressive effect of basic fibroblast growth factor on transendothelial emigration of CD4(+) T-lymphocyte. Cancer Res. 1994;54:4729-4733.

94. Tromp SC, oude Egbrink MG, Dings RP, et al. Tumor angiogenesis factors reduce leukocyte adhesion in vivo. Int Immunol. 2000;12:671-676.

95. Dirkx AE, Oude Egbrink MG, Kuijpers MJ, et al. Tumor angiogenesis modulates leukocyte-vessel wall interactions in vivo by reducing endothelial adhesion molecule expression. Cancer Res. 2003;63:2322-2329. 


\section{Chapter 2}

\section{Tumor blood vessels, a difficult hurdle for infiltrating leukocytes}

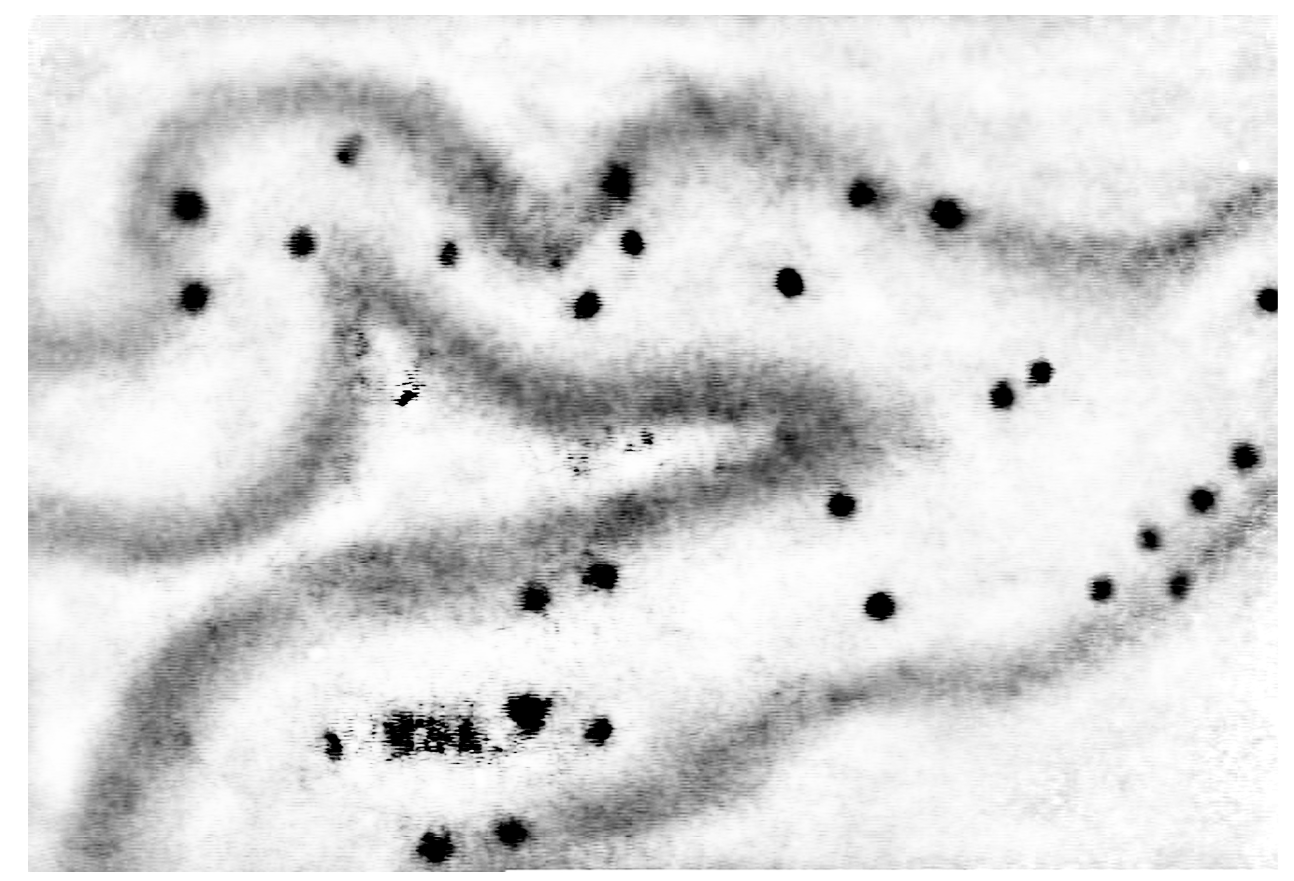

Karolien Castermans, Arjan W. Griffioen

Biochimica et Biophysica Acta 1776 (2007) 160-174 


\section{Abstract}

In spite of a gradual improvement of its therapy, cancer is still a deadly disease for millions of patients. Immunotherapy is one of promising treatment strategies, but several mechanisms counteract the development of a proper anti-tumor immune response and the formation of an effective inflammatory infiltrate. One of the difficult hurdles is the hampered recruitment of leukocytes from the blood into the tumor site. It has been demonstrated that tumor cells evolved mechanisms to escape immunity, based on down regulation of endothelial adhesion molecules. This paper reviews the endothelial cell adhesion molecules that mediate leukocyte recruitment and the regulation of them during tumor development. In addition, an overview will be given of the translational development and clinical application of the specific composition of adhesion molecules on tumor endothelium, in diagnosis and therapy. 


\section{Introduction}

Cancer is a diverse, complex and deadly disease that afflicts millions of people each year. In search of a remedy for this terrible disease, different strategies have been explored. About $50 \%$ of cancer patients are curable with surgery, radiation therapy, and chemotherapy, which leaves $50 \%$ of the patients without a future. Therefore, other strategies for cancer treatment have to be investigated. One promising approach is immunotherapy, especially the design of methods that generate tumor-specific immune effector cells through the use of tumor vaccines or cytokine therapies ${ }^{1-4}$. All such approaches are dependent on the ability of tumor-specific effector cells to cross the vessel wall into the tumor. The recruitment of immune cells into a tissue is under the control of tissue-specific micro-environmental factors that regulate leukocyte and endothelial adhesion molecule expression and leukocyte-vessel wall interactions necessary for extravasation. This transendothelial migration of leukocytes is a multistep adhesion cascade that is mediated by a variety of tissue-specific endothelial adhesion molecules. This review summarizes the adhesion molecules involved in leukocyte recruitment in general, giving special attention to the role of less investigated and more recently discovered adhesion molecules. As will become clear from this review, tumors have evolved mechanisms to escape immune surveil-lance, one of which is the suppression of adhesion molecules on its blood vessels, making extravasation out of their vessels a difficult hurdle for anti-tumor immunity. In addition, imaging and therapy modalities that exploit the specific balance of endothelial cell adhesion molecules in order to improve cancer treatment will be discussed.

\section{The adhesion cascade for leukocyte recruitment}

Recruitment of leukocytes from the blood into tissues under shear flow is a multistep process, comprised of initial tethering and rolling, activation, firm adhesion, and transendothelial migration of leukocytes 5,6 (Figure 2.1A). This adhesion cascade is orchestrated by tissue-specific communication between leukocytes, endothelium, stromal cells and in tumors also by tumor cells, through factors secreted in the microenvironment.

Initial tethering and rolling of leukocytes is predominantly mediated by selectins. Low affinity binding of endothelial (E)-selectin and platelet (P)-selectin on endothelial cells, to leukocyte (L)-selectin, leads to initial rolling of the leukocytes along the endothelium ${ }^{7,8}$. Next to selectins, other adhesion molecules can initiate tethering and rolling of leukocytes on the vessel wall. Vascular 
addressins, such as peripheral lymph node addressin (PNAd), CD34, GlyCAM and mucosal addressin (MAdCAM-1) ${ }^{9}$, all ligands of L-selectin, can also mediate low-affinity binding between endothelial cells and leukocytes. In addition, vascular adhesion protein-1 (VAP-1) 10-14, vascular cell adhesion molecule-1 (VCAM-1) ${ }^{15,16}$ and hyaluronate (HA)/CD44 ${ }^{17}$ expression on endothelial cells can be involved in such primary adhesion processes of leukocytes as well. Tethering and rolling are processes based on reversible adhesion events. In order to achieve firm and tight binding, these must be replaced by stronger adhesion through other adhesion molecules. This is accomplished during activation of endothelial cells and leukocytes by cytokines, chemokines or chemoattractants excreted by surrounding cells and tissues as well as by the adhesion events itself 5,6,8,18,19. Upon activation, expression of endothelial ligands for leukocytes is either increased or induced de novo. The specific patterns of endothelial cell adhesion molecules are complex and depend on the combination of cytokines and the type of endothelial cells ${ }^{6,8}$. Activation of leukocytes by chemokines increases the expression and functional activity of leukocyte integrins ${ }^{20}$, leading to high-affinity binding with endothelial cell adhesion molecules. An overview of the most well-known and well-described endothelial cell adhesion molecules and their leukocyte counterligands is given in Table 2.1. Firm adhesion of leukocytes to the endothelial wall is mainly obtained by three members of the immunoglobulin gene superfamily: intercellular adhesion molecule-1 (ICAM-1), ICAM-2 and VCAM-1 21-24 (Figure 2.1A). MAdCAM-1 5,24 and platelet-endothelial cell adhesion molecule-1 (PECAM1) 25 , have also been associated with firm adhesion, although their involvement in this process is less pronounced. The adhesive properties of some immunoglobulinlike adhesion molecules are not yet fully unraveled. L1 adhesion molecule ${ }^{26-28}$, neural cell adhesion molecule (NCAM) ${ }^{29}$ and carcinoembryonic antigen-related cell adhesion molecule-1 (CEACAM-1) ${ }^{30,31}$ are able to mediate cell-cell adhesion, however leukocyte-endothelial cell adhesion has not yet been convincingly demonstrated. Adhesion molecules not related to the immunoglobulin gene superfamily have been associated with leukocyte arrest as well. One of them is the common lymphatic endothelial and vascular endothelial receptor-1 (CLEVER-1 also known as FEEL-1, stabilin-1) which can mediate leukocyte adhesion both on vascular as well as lymphatic endothelium ${ }^{32}$.

Interestingly, cell matrix adhesion molecule alpha(v)beta(3) integrin $(\alpha \mathrm{v} \beta 3)$, might be implicated in leukocyte-vessel wall interactions when expressed on endothelial cells ${ }^{25}$, since there are reports that show leukocyte adhesion to endothelial cells via $\alpha v \beta 3-\mathrm{CD} 31$ interaction ${ }^{33}$. Galectins are also suggested to mediate leukocyte-vessel wall interactions. Galectins are a family of carbohydrate binding proteins that has been implicated in cell-cell adhesion interactions. Galectin-1, -3 and -9 are described to be expressed by endothelial cells, of which 

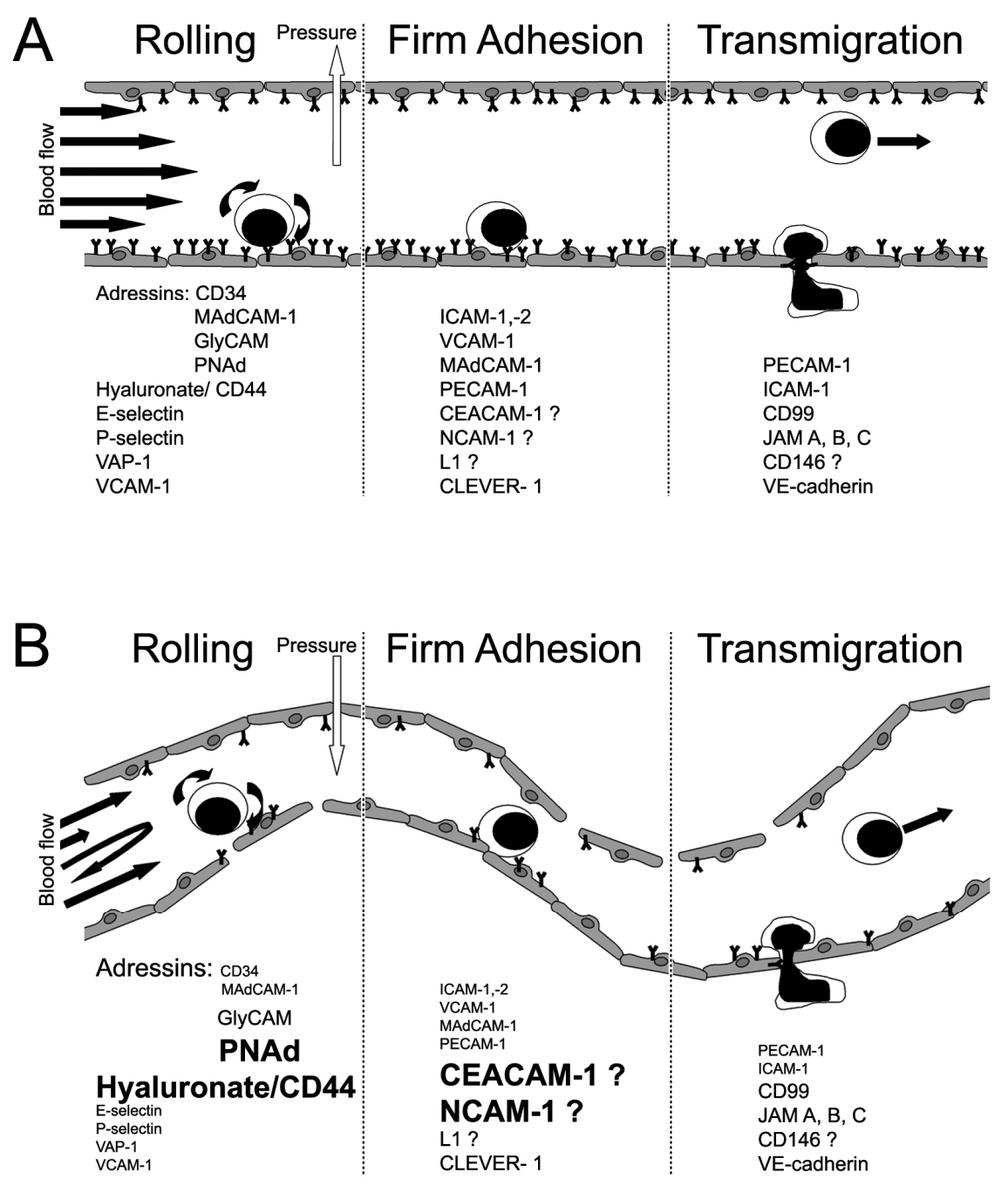

Figure 2.1 The leukocyte adhesion cascade is modulated by tumor cells to escape anti-tumor immunity. A) The recruitment of leukocytes from a normalblood vessels into tissues under shear flow (black arrows) is mediated through a cascade of events that is comprised of the following steps: (i) initial leukocyte tethering and rolling, (ii) firm adhesion and (iii) transmigration through the endothelial cell lining. Every step in this cascade is mediated by specific endothelial cell adhesion molecules $(\Upsilon)$ as indicated. B) In order to evoke the anti-tumor immune response, tumors modulate the expression of these adhesion molecules in a specific manner. The size of the font indicates the induction (bold large) or reduction (small) of expression levels on tumor endothelial cells. The amount of expression of a few adhesion molecules is not affected (unchanged size of font) by the tumor microenvironment. In addition, blood flow (black arrows) and interstitial pressure (white arrow) are very irregular and different compared to normal vessels. 
galectin-3 and -9 might mediate adhesion of neutrophils ${ }^{34,35}$ and eosinophils ${ }^{36,37}$, respectively.

Firm adhesion is followed by diapedesis of leukocytes through the vessel wall with minimal disruption of the vascular lining. Although it has been reported that a small number of leukocytes transmigrate at non-junctional locations ${ }^{38}$, leukocytes mainly cross the endothelium via inter-endothelial junctions. PECAM1, ICAM-2, CD99, junctional adhesion molecule (JAM)-A, -B, -C and vascular endothelial-cadherin (VE-cadherin) have been predominantly described to mediate this paracellular diapedesis 19,39-45. CLEVER-1 46 and VAP-1 14,47,48 also participate in leukocyte migration. Next to PECAM-1, ICAM-2 and JAMs, a fourth member of the immunoglobulin gene superfamily is enriched at cell-cell junctions, namely CD146 (Mel-CAM) ${ }^{42}$. Its possible role in transendothelial migration has not yet been described.

The combination of molecules expressed by the endothelium, receptors on leukocytes and tissue-specific microenvironmental factors act together to determine whether a leukocyte is recruited. This intricately regulated process provides numerous events at which diversity can be introduced to regulate tissuespecific recruitment of a diverse and effective leukocyte infiltrate ${ }^{49-51}$.

\section{Regulation of endothelial adhesion molecule expression by tumor cells}

Cytotoxic T cells are, when activated, able to control tumor growth ${ }^{52}$, whereas $\mathrm{T}$ helper cells also play an important role in regulation of tumor destruction ${ }^{53}$. Nevertheless, many tumors can progress without any signs of attack by immune cells ${ }^{54}$. The reason why immune responses are unable to eradicate the tumor is not fully understood. Several processes have been shown to contribute to the escape of a tumor from the immune system. The expression on tumor cells of MHC/HLA determinants that present tumor antigens, can be suppressed 55-57. Compounds from the tumor microenvironment prohibit effector $\mathrm{T}$ cell maturation and function 58,59. Furthermore, immunosuppressive leukocytes like regulatory $\mathrm{T}$ cells and myeloid derived suppressor cells are preferentially attracted and activated in tumor tissues ${ }^{60,61}$. In addition, it has also been described that tumor derived VEGF can prevent the proper maturation of dendritic cells. Besides these processes, one other very significant explanation of ineffective immunity is aberrant leukocytevessel wall interactions and trans-vessel migration. A prerequisite for anti-tumor immunity is that immune cells actually enter into the tumor. However, the tumor microenvironment modulates leukocyte recruitment in such a way that infiltration of tumor specific effector leukocytes into cancer tissues is inhibited and 
consequently tumor eradication by the immune system is prevented. As leukocyte recruitment is a multistep process, the tumor can interfere at different levels of this cascade in order to decrease total influx of leukocytes. Tumor vessels differ from normal vessels in their irregular structure, tortuous morphology, leakiness and aberrant blood flow (Figure 2.1 A,B). Furthermore, rapid proliferation of tumor cells increases interstitial pressure which can lead to collapsed vessels within the tumor tissue ${ }^{62}$. The following section will give an overview of the manipulation of endothelial adhesion molecule expression by the tumor at different steps during leukocyte recruitment (Figure 2.1B). Special emphasis will be on the importance of less well-known and more recently described adhesion molecules expressed on tumor endothelium.

Table 2.1 Endothelial cell adhesion molecules implicated in the adhesion cascade and their leukocyte counter receptors.

\begin{tabular}{|c|c|c|c|}
\hline $\begin{array}{c}\text { Endothelial-cell } \\
\text { molecule }\end{array}$ & $\begin{array}{c}\text { Leukocyte counter- } \\
\text { receptor } \\
\end{array}$ & $\begin{array}{c}\text { Leukocyte-vessel wall } \\
\text { interaction }\end{array}$ & References \\
\hline CD34 & L-selectin & rolling & 24 \\
\hline MAdCAM & L-selectin, $\alpha_{4} \beta_{7}$ & rolling, firm adhesion & 24 \\
\hline GlyCAM & L-selectin & rolling & 24 \\
\hline PNAd & L-selectin & rolling & 24 \\
\hline E-selectin & PSGL-1, L-selectin & rolling & 24 \\
\hline P-selectin & PSGL-1, L-selectin & rolling & 24 \\
\hline VAP-1 & $?$ & rolling & $47,48,63$ \\
\hline VCAM-1 & VLA- $4, \alpha_{4} \beta_{7}$ & rolling, & 24 \\
\hline $\mathrm{HA}$ & CD44 & rolling & 17 \\
\hline CD44 & HA/CD44 & rolling & 64 \\
\hline ICAM-1 & LFA-1, Mac-1 & $\begin{array}{l}\text { firm adhesion, } \\
\text { transmigration }\end{array}$ & 24 \\
\hline ICAM-2 & LFA-1, Mac-1 & firm adhesion & 24 \\
\hline PECAM-1 & PECAM-1 & $\begin{array}{l}\text { firm adhesion, } \\
\text { transmigration }\end{array}$ & 43 \\
\hline NCAM-1 & ? NCAM-1? & ? firm adhesion? & 29 \\
\hline L1 & VLA5, $\alpha_{\mathrm{v}} \beta_{3,}$ L1 & ? firm adhesion? & $26-28$ \\
\hline CEACAM-1 & ? LFA-1? & ? firm adhesion? & 30 \\
\hline CLEVER-1 & $?$ & firm adhesion & 32 \\
\hline CD99 & CD99 & transmigration & 43 \\
\hline JAM A & LFA-1, JAM A & transmigration & 43 \\
\hline JAM B & VLA-4 & transmigration & 43 \\
\hline JAM C & Mac-1, JAM C & transmigration & 43 \\
\hline CD146 & $?$ & ? transmigration? & 42 \\
\hline VE-cadherin & $\begin{array}{c}\text { No direct interaction with } \\
\text { leukocytes }\end{array}$ & transmigration & 43 \\
\hline
\end{tabular}




\section{Rolling}

In blood vessels activated by inflammatory factors, leukocytes are able to roll along the vessel wall before firm adhesion is established. Although a tumor frequently behaves as an inflammation, these interactions in a tumor are much less frequent 65,66 . It has been described that exposure to angiostatic factors, produced by tumor cells to induce angiogenesis, is causally related to a suppressed endothelial adhesion molecule expression and a diminished number of lowaffinity interactions. Although angiogenic factors like basic fibroblast growth factor (bFGF) and vascular endothelial growth factor (VEGF) initially increase expression of E-selectin on endothelial cells in vitro, chronic stimulation as occurs in the tumor microenvironment, leads to a significant decrease of selectins ${ }^{67-69}$. Animal and patient reports confirmed in different tumor types that the expression of E- and P-selectin is decreased on tumor microvasculature as compared to expression in normal vessels in healthy tissues ${ }^{70-73}$. Studies in melanoma and colorectal cancer even showed progressive loss of P-selectin expression with increasing tumor malignancy ${ }^{74,75}$. Furthermore, decreased expression of P-selectin on tumor vessels was correlated with diminished leukocyte tumor infiltration, indicating that tumor lesions can evade inflammatory regression processes via decreasing leukocyte rolling along the tumor vessel wall. On the other hand, there are studies that found high E- and P-selectin expression levels in tumor vessels compared to control. However, in these studies, the expression levels of endothelial adhesion molecules on tumor vessels was very heterogeneous, suggesting a inefficient leukocyte recruitment throughout the tumor tissue. In addition, high levels of E- and P-selectin contribute to the invasive character of the tumor and tumor metastasis 76,77 .

PNAd and GlyCAM-1 mainly mediate leukocyte rolling in high endothelial venules in secondary lymphoid tissues, whereas MAdCAM-1 is predominantly present on endothelial cells in the gastrointestinal tract ${ }^{78-82}$. However, they have also been implicated to mediate rolling of leukocytes within tumor vessels ${ }^{83}$. Onrust et al. showed that lack of L-selectin ligand expression on vessels in $\beta$ cell tumors is associated with diminished leukocyte tumor infiltration 84. In addition, a recent study with gastric adenocarcinomas by Enarsson and coworkers revealed a shift in the homing mechanisms of $\mathrm{T}$ lymphocytes used for migration to normal and tumor gastric tissue. In normal gastric mucosa, $\mathrm{T}$ lymphocytes are recruited by MAdCAM-1 whereas the expression of MAdCAM-1 in gastric adenocarcinomas is decreased in favor of PNAd expression, leading to recruitment of a-typical $\mathrm{T}$ lymphocytes to the tumor tissue ${ }^{85}$. CD34, also a member of the addressin family, is actively regulated on endothelial cells by angiogenic factors. Furthermore, endothelial CD34 is suppressed in renal cell carcinoma compared to normal renal tissue ${ }^{86}$. These findings suggest that tumors can evade 
immune-mediated destruction by failure and/or modifications of addressin expression on tumor vessels (Figure 2.1B).

Since L-selectin ligands play an important role in leukocyte recruitment to secondary lymphoid tissues, the first stage of tumor metastasis, one can imagine that leukocyte recruitment to these nodes may determine the development of metastatic disease. Indeed, trafficking of effective natural killers cells to tumor draining lymph nodes via L-selectin, suppresses tumor formation in these tissues ${ }^{87}$.

It is important to mention that the specific composition of integrins, growth factors and chemokines within the tumor microenvironment, also contributes to the recruitment of a-typical $\mathrm{T}$ lymphocytes and especially stimulates the attraction of leukocytes that participate in tumor progression. Over-expression of VEGF in tumors is associated with elevated numbers of regulatory $\mathrm{T}$ cells within the tumor tissue. The balance between regulatory $\mathrm{T} /$ effector $\mathrm{T}$ cells is thereby altered and tumor-associated antigen specific immunity is suppressed ${ }^{60}$. The trafficking of regulatory $\mathrm{T}$ cells to the tumor site is also partly mediated by the chemokine CCL22 in ovarian carcinoma and reduces patient survival ${ }^{88}$. In addition, stromal-derived factor-1 (SDF-1), expressed at high levels by human ovarian epithelial tumor cells, recruits plasmacytoid dendritic cell precursors. These cells produce high amounts of interleukin 10 into the tumor microenvironment consequently leading to impaired effector T cell function ${ }^{89}$.

The most recent endothelial cell adhesion molecule found to be involved in leukocyte recruitment is VAP-1. Besides mediating leukocyte tethering and transmigration, VAP-1 also possesses an enzymatic function 63,90-93. However, neither the mechanism nor the ligand by which VAP-1 binds leukocytes is fully elucidated. A few studies have shown that VAP-1 mediates rolling of tumorinfiltrating lymphocytes and proved expression of VAP-1 on tumor vessels although significantly decreased compared to expression in normal vessels $83,94,95$. The degree of VAP-1 expression is correlated with the amount of lymphocytes that infiltrates a tumor, suggesting that a tumor can dodge immune responses by decreasing VAP-1 expression in its vessels ${ }^{96}$.

Finally, CD44 is involved in leukocyte endothelium interactions. This molecule, described as a leukocyte homing receptor, is expressed by both leukocytes and endothelium. With its natural ligand hyaluronic acid (HA) as a bridging molecule, CD44 provides a primary adhesion pathway for leukocyte rolling ${ }^{64}$. Cytokine stimulation leads to an induction of HA and CD44 expression 97,98 on endothelial cells derived of microvasculature followed by increased CD44dependent primary adhesive interactions 17,98. However, these interactions have not yet been described in tumor vessels. In cancer, $\mathrm{HA}$ is mainly studied as a product of tumor cells where, next to an association with tumor aggressiveness and metastatic potential, it has been reported to affect tumor angiogenesis 99,100 . 
HA has different roles in neovascularization depending on molecular mass ${ }^{101}$. These findings suggest that an increase in HA in tumor vessels would lead to induction of tumor growth rather than an increase of leukocyte influx, nevertheless so far no negative correlation between HA expression and leukocyte infiltration has been shown.
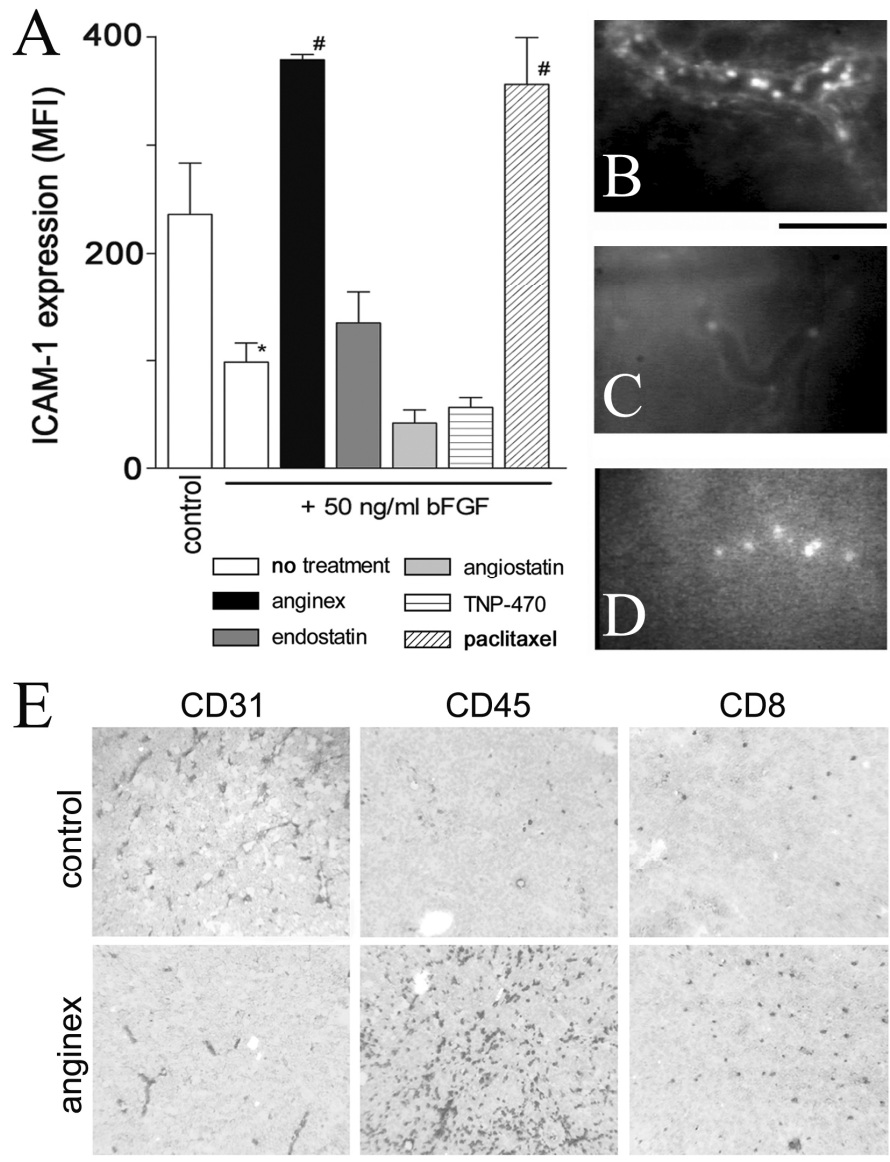

Figure 2.2 Suppressed leukocyte recruitment in tumors can be normalized by angiostatic and chemotherapeutic compounds. A) FACS analysis of ICAM-1 expression in b.END5 mouse endothelial cells in the presence or absence of bFGF, and after treatment with angiostatic and chemotherapeutic agents. Data are expressed as mean fluorescence intensity (MFI), +/- SEM, 4 independent experiments. ${ }^{*} P<0.05$ vs. cells without bFGF, $\# P<0.05$ vs. untreated cells. B-D) Typical intravital fluorescence microscopy images of a normal ear skin vessel (B), an untreated tumor vessel (C), and an anginextreated tumor vessel (D). Leukocytes are fluorescently labeled with Rhodamin 6G. The bar between panels $\mathrm{B}$ and $\mathrm{C}$ represents $45 \mu \mathrm{m}$. Video images can be viewed at www.angiogenesis.nl E) Immunohistochemical images of microvessel density (CD31), and infiltration by CD45 leukocytes and $\mathrm{CD}^{+} \mathrm{T}$ lymphocytes in B16F10 melanoma of control and anginex treated mice. Bar in upper left panel represents $50 \mu \mathrm{m}$. Figure extracted with permission from Dirkx et al. The FASEB J, 20, 621-630 (2006). 


\section{Firm adhesion}

As mentioned before, rolling and tethering are low-affinity interactions and must be replaced by high-affinity ones to make leukocyte recruitment possible. Chronic stimulation of endothelial cells by angiogenic factors, abundantly present in tumor microenvironment, inhibits firm adhesion of leukocytes to endothelial cells in vitro $67,69,102,103$. In addition, intravital microscopy showed that exposure of non-tumor vessels to angiogenic factors, bFGF or VEGF, decreased cytokine-induced leukocyte adhesion ${ }^{104}$. Reduction of leukocyte adhesion was associated with a decrease of ICAM-1 and VCAM-1 expression on endothelial cells (Figure 2.2A). Furthermore, firm interactions in tumor vessels (Figure 2.2C) in vivo are diminished compared to interactions in normal vessels (Figure 2.2B) and once again a positive relationship with ICAM-1 and VCAM-1 expression was observed 66. Investigation of endothelial cells from different tumor tissues established a decrease in the endothelial cell adhesion molecules ICAM-1, ICAM-2 and VCAM-1 compared to endothelial cells of normal tissues ${ }^{72,73}$. This decrease was positively correlated with decreased leukocyte infiltration and associated with tumor progression 105,106 . To the contrary, tumor angiogenic factors can induce adhesion molecule expression on EC. Acute stimulation of endothelial cells with VEGF or bFGF induces ICAM-1 and VCAM-1 expression ${ }^{68,107}$. However, this is in conflict with the tumor microenvironmental conditions where prolonged release of angiogenic factors occurs. Bessa and co-workers stated that impaired leukocyte recruitment in tumor vasculature cannot be attributed to suppressed expression of the main endothelial cell adhesion molecules ${ }^{76}$. A recent publication by Bouzin and co-workers may give an explanation for this finding ${ }^{108}$. They found that besides quantity of adhesion molecule expression, the distribution of ICAM-1 and VCAM-1 on the endothelial cells surface determines leukocyte adhesion. Caveolin1, a caveolar structural protein on EC, is diminished by VEGF stimulation. As caveolin-1 affects ICAM-1 and VCAM-1 clustering, a decrease of this protein leads to ineffective clustering and consequently decreased leukocyte adhesion ${ }^{108}$.

Despite the fact that NCAM and CEACAM-1 are able to mediate cell-cell adhesion, they have not yet been implicated in leukocyte-EC adhesion. However, their expression on tumor endothelial cells has been established, suggesting that they could play a role in leukocyte adhesion in tumor vessels. NCAM has been found on tumor endothelial cells of renal cell carcinoma but not on vessels of normal renal tissue ${ }^{109-111}$. The expression of NCAM is associated with an immature phenotype of endothelial cells and tumor neo-angiogenesis. In addition, NCAM was detected on endothelial cells of smooth muscle and peripheral nerve sheath tumors ${ }^{112}$. Presence of NCAM on tumor endothelial cells is positively correlated with metastatic potential, in contrast with leukocyte infiltration which is not affected by NCAM expression ${ }^{109}$. Decreased expression of NCAM on malignant 
tumor cells increases their invasive capacity ${ }^{113}$ as has also been shown for adhesion molecule L1. This neural cell adhesion molecule on tumor cells serves as a potential ligand for $\alpha v \beta 3$ integrin during melanoma transendothelial migration suggesting a contribution of L1 to tumor progression by promoting cell adhesion and migration 144,115. Like NCAM, CEACAM-1 is associated with newly formed immature tumor blood vessels and is positively correlated with aggressiveness of bladder cancer, melanoma and prostate cancer $30,116,117$. Furthermore, VEGF induces CEACAM-1 expression on endothelial cells and constitutive expression of CEACAM-1 in microvascular endothelial cells switches them to an angiogenic phenotype ${ }^{118-120}$. Interestingly, leukocyte adhesion is increased by CEACAM-1 expression on neutrophils, although via modulation of CD18/CD11 on leukocytes 121. In contrast, CEACAM-1 appears to function as a coinhibitory receptor during T cell activation ${ }^{122}$. These reports show that while ICAM-1, ICAM-2 and VCAM-1 expression are diminished on tumor vasculature, NCAM and CEACAM-1 are upregulated on these vessels (Figure 2.1) consequently leading to induction of angiogenesis, decreased leukocyte influx and ultimately tumor progression.

Similarly to NCAM and CEACAM, CLEVER-1 can mediate tumor metastasis. CLEVER-1 expression has been reported on vasculature of melanoma, squamous cell cancer of the head and neck and breast cancer where it might be involved in the adhesive interaction between tumor cells and endothelial cells 123,124. The role of CLEVER-1 in leukocyte adhesion and migration has been under debate ${ }^{125,126}$. However, treatment with inhibitory antibodies against this molecule showed a decrease in leukocyte adhesion and diapedesis on/through vascular and lymphatic endothelium ${ }^{32,127}$. Since CLEVER-1 expression on tumor vasculature has been determined, CLEVER-1 might mediate leukocyte-tumor vessel wall interactions, although further investigation needs to be performed.

Cell adhesion molecule $\alpha v \beta 3$ integrin is involved in many tumor-related processes and is highly expressed on activated endothelial cells, especially tumor EC, whereas it is hardly expressed on resting and quiescent endothelial cells in non-diseased tissues ${ }^{128}$. However, a role for $\alpha v \beta 3$ integrin in leukocyte-tumor vessel wall interactions is unlikely considering the low number of interactions in contrast to the high abundance of $\alpha v \beta 3$ integrin expression on tumor endothelial cells.

\section{Transmigration}

After leukocytes are firmly bound to the vessel wall, they can cross the endothelial cell barrier. As mentioned before, tumors prevent rolling and firm adhesion of leukocytes partly by decreasing endothelial adhesion molecule expression that mediates these processes. Consequently, only a small number of leukocytes has the opportunity to pass the endothelial lining. The best described endothelial 
adhesion molecule that mediates leukocyte migration is PECAM-1 which is expressed by tumor EC. PECAM-1 expression is not affected by tumor growth factors bFGF or VEGF 72,102,129. Nevertheless, a study by Berger et al. showed a redistribution of PECAM-1 expression from a constitutive circumferential membrane pattern on healthy and inflamed vessels to a pattern restricted to cellcell junctions in tumor vessels ${ }^{70}$. This suggests a negligible role for PECAM-1 in firm adhesion of leukocytes on tumor EC. Anastassiou et al. showed that high PECAM-1 expression is correlated with extended survival in patients with renal cell carcinoma ${ }^{130}$. In addition, high PECAM-1 expression on vessels of these tumors is associated with stronger leukocyte infiltration within the tumor, proposing that, by reducing PECAM-1 expression on its vessels, the tumor can circumvent leukocyte influx.

CD99 is a type I transmembrane protein that is expressed on most hematopoietic cells and many other cell types ${ }^{131}$. For instance, its expression is characteristic for Ewing sarcomas and is used for differential diagnosis among sarcomas ${ }^{132,133}$. Schenkel et al. demonstrated CD99 expression on endothelial cells and function in the migration of monocytes through endothelial junctions ${ }^{134}$. Furthermore, it has been shown that CD99 is a key player in lymphocyte and neutrophil diapedesis 135,136. Although CD99 expression has been extensively described on tumor cells, till now, no reports have shown the expression of this adhesion molecule on endothelial cells of tumor blood vessels. However, this does not exclude a role for CD99 in leukocyte transmigration through tumor endothelial cell lining. CD99 mediated transmigration is independent and subsequential to PECAM-1 mediated diapedesis and may therefore be involved in the final steps of leukocyte migration through tumor vessels ${ }^{137}$.

The JAM family members were initially described as adhesion molecules localized in cell-cell contacts and specifically enriched at tight junctions ${ }^{138}$. They are expressed by leukocytes and platelets as well as by endothelial and epithelial cells $137,139,140$. JAMs are suggested to posses dual functions ${ }^{138}$. They appear to regulate on one hand, leukocyte/platelet/endothelial cell interactions in the immune system ${ }^{141,142}$, and on the other hand tight junction formation in epithelial and endothelial cells during acquisition of polarity 143,144. JAMs can undergo homophilic as well as heterophilic interactions with other JAM family members as well as intergrins. JAM-A, JAM-B and JAM-C interact with respectively leukocyte function-associated antigen-1(LFA-1) 142,145, very late antigen-4 (VLA-4) and integrin alphaMbeta2 (Mac-1) ${ }^{146-148}$ expressed by leukocytes. These interactions can all lead to transmigration of leukocytes through the vessel wall. JAM-A and JAM$C$ have also been demonstrated to be involved in the process of angiogenesis ${ }^{149-152}$. Inhibitory antibodies of JAM-A decreased neovascularization in different models 153. Furthermore, Lamagna and co-workers showed that besides tumor growth 
reduction by angiogenesis inhibition, JAM-C inhibitory antibody treatment in mice also reduces macrophages tumor infiltration, suggesting a role for JAMs in leukocyte recruitment in tumors ${ }^{149}$. Interestingly, angiogenic factors that induce angiogenesis do not decrease protein expression levels of JAM-A, JAM-B nor JAMC. However, the distribution of JAMs is shifted to a broad zipper-like pattern and appeared to relocalize diffusely along the entire cell membrane, liberated from the tight junctions 154,155 . This finding might explain the decrease of trans-endothelial migration of leukocytes in tumor vessels.

Similar to a $\alpha v \beta 3$ integrin and CD44, galectin- 1 has been shown to increase upon angiogenic stimulation of tumor microvessels. Galectin-1 expression on endothelium has been described to hamper transmigration of leukocytes. An increase of this protein might therefore decrease the leukocyte influx in tumor tissues ${ }^{156,157}$.

Finally, also VE-cadherin mediates leukocyte migration. In contrast to CD99, PECAM-1 and the JAM family, VE-cadherin does not mediate leukocyte transmigration via direct binding of the immune cells. During leukocyte transmigration, transient and reversible changes in VE-cadherin localization on the endothelium are observed, leading to an increased vascular permeability and a higher influx of leukocytes into inflamed tissues 137,158,159. Angiogenic factors produced by tumor cells do not affect the expression level of VE-caderin on EC. Interestingly, VE-cadherin blocking antibodies are able to inhibit tumor growth and angiogenesis in a mouse model 152,155,160. These reports indicate that, despite the fact that tumors are not able to affect VE-cadherin expression, it plays an important role in tumor angiogenesis and tumor progression and most of all operates as a barrier for immune cells. The above mentioned studies indicate that tumor cells can display regulatory functions in all sequential steps in the adhesion cascade of leukocytes, in order to diminish exposure to cytotoxic effector cells.

\section{Imaging and therapeutic exploitations of endothelial adhesion molecules expression on tumor vessels}

Over the last decades, scientists have searched for different strategies in treatment and diagnosis of cancer. One of these strategies is to target the tumor vasculature. By eradicating their vasculature, tumors become deprived of oxygen and nutritional supplies. Consequently, tumor growth decreases, however, in many cases without complete remission. As described previously, the tumor vasculature is modulated in such a way that immune cells can hardly cross the endothelial cell lining. Therapies that increase the distribution and extent of endothelial cell adhesion molecules on tumor EC, thereby augmenting leukocyte recruitment, 
might improve cancer therapy especially when combined with other strategies like anti-angiogenesis treatment. In addition, the specific composition of adhesion molecules present on tumor vessels (Figure 2.1) can be used for different imaging modalities and targeted tumor therapy as will be discussed in the present section.

\section{Imaging modalities}

The in vivo regulation of receptors on vascular endothelial cells at diseased sites represents an attractive marker for visualization, early detection and monitoring of treatment responses, based on a range of important disease processes ${ }^{128}$. In angiogenic tissues such as tumors, blood vessels express a specific composition of adhesion molecules which can be applied in different tumor imaging strategies.

Cell adhesion molecule $\alpha v \beta 3$ integrin is a frequently used tool for noninvasive imaging of tumor vessels. As mentioned before, this integrin is involved in many tumor-related processes and is highly expressed on activated endothelial cells, especially tumor EC, whereas it is hardly expressed on resting and quiescent endothelial cells ${ }^{128}$. This finding makes it a suitable marker for angiogenic vessels in malignant tissues. The $\alpha v \beta 3$ integrin binds to a wide variety of extracellular matrix proteins, which expose the tripeptide sequence arginine-glycine-aspartic acid (RGD) as a common receptor motif ${ }^{161}$. Therefore, RGD-peptides and mimetics have become a popular tool for targeting $\alpha v \beta 3$ integrin-expressing tumor vasculature and they have been used in different non-invasive tumor imaging modalities like SPECT (single photon emission computed tomography), PET (positron emission tomography), scintigraphic imaging and MRI (magnetic resonance imaging) ${ }^{162-167}$. Recently, Mulder et al. proved that by using RGDlabeled, $\alpha v \beta 3$ integrin targeted liposomes for noninvasive MRI utilities, imaging of tumor angiogenesis as well as early in vivo response to angiostatic tumor treatment can be assessed 168,169 .

As mentioned before, NCAM is stably expressed by renal tumor-derived endothelial cells but not by normal quiescent ECs. This finding makes NCAM, like $\alpha v \beta 3$ integrin, a suitable marker for tumor vascular imaging modalities. GeninattiCrich et al. showed in a recent paper that a specific NCAM-binding peptide, the chemoattractant degradation fragment of complement factor 3 (C3d), coupled to a gadolinium-loaded apoferritin is a highly efficient and selective contrast agent for MRI imaging of tumor vessels ${ }^{170}$. Aside from NCAM, CEACAM (CD146) expression has been demonstrated on activated EC. Anti-CD146 antibody showed restricted binding to CD146 expressed in blood vessels of tumors, suggesting potential for CEACAM in different tumor vasculature imaging strategies ${ }^{171}$.

Although not yet demonstrated in tumor models, ICAM-1, VCAM-1, VAP1 and E-selectin expression on endothelial cells can be used for visualization of vasculature as well. E-selectin expression was applied as an endothelial 
inflammatory marker in MRI studies using in vitro and in vivo models of inflammation and was found to posses an interesting capacity as a diagnostic tool 172-174. In addition, non-invasive imaging of activated endothelium was obtained by using antibody fragments against VCAM-1 175. Even atherosclerosis, with lowgrade endothelial activation, can be visualized by VCAM-1 targeted imaging, using MRI techniques 176,177. In addition, MRI and scintigraphic imaging with respectively ICAM-1 and VAP-1 probes have been performed in different inflammation models in animals ${ }^{178,179}$. These reports indicate that increases of adhesion molecule expression can be visualized in different vessel types, suggesting that induction of adhesion molecule expression on tumor vessels by specific treatment could be assessed.

\section{Treatment strategies}

In addition to imaging modalities, the characteristic composition of adhesion molecules on tumor vessels are also an excellent tool for specific tumor targeted therapy. For instance, $\alpha v \beta 3$ integrin is used in different strategies for selective delivery of therapeutics to tumor vasculature. Antibodies, peptides and small molecule peptidomimetics targeted to $\alpha v \beta 3$ integrin on tumor endothelial cells via RGD motifs are successfully used in tumor therapies. Furthermore, efficiency of RGD-mediated viral gene delivery was demonstrated. These topics are elegantly reviewed by Temming ${ }^{180}$ and Lim ${ }^{166}$.

The specific tumor-associated arrangement of endothelial cell adhesion molecules may also be an interesting target for vaccine strategies. Tumor-vessel associated adhesion molecules could be used as tumor-associated antigens to create a selective immune response against tumor endothelial cells. This vaccination approach has already been successfully used for several tumor endothelium related molecules like VEGF, VEGF receptor 2 and angiogenic endothelial-cell growth factor-1 (ECGF-1) ${ }^{181-183}$.

As mentioned before, besides $\alpha \mathrm{v} \beta 3$ integrin, CEACAM- 1 is prominently expressed on tumor vessels. Several studies suggest that the constitutive expression of CEACAM-1 on tumor microvascular ECs switches them to an angiogenic phenotype 117,119,120. Consequently, treatment with an inhibitory antibody for CEACAM-1 reduces tumor angiogenesis, growth and metastatic potential, providing a promising strategy for cancer therapy $171,184,185$. Furthermore, other family members of the immunoglobulin family, JAM-A and JAM-C, participate in angiogenesis and are subsequently interesting targets for antiangiogenesis tumor treatment $150,155,186$. Nevertheless, junctional adhesion molecules are implicated in leukocyte transmigration processes, indicating that treatment of cancer with functional inhibitory antibodies of these molecules does not only inhibit tumor angiogenesis but also decreases leukocyte recruitment to tumor 
tissues 149,153. Clearly, therapy that inhibits angiogenesis without diminishing leukocyte tumor recruitment would improve disease outcome. Inhibitory antibody against VE-cadherin might be such an agent. Monoclonal antibody to VE-cadherin is a potent inhibitor of angiogenesis, tumor growth and metastasis ${ }^{160}$ and has been reported to induce vascular permeability thereby enhancing neutrophil extravasation ${ }^{158}$.

Reports from our laboratory and others show that in addition to diminishing tumor vessel formation, a number of angiostatic compounds can also restore the expression of several adhesion molecules on activated endothelial cells (Figure 2.2A). ICAM-1, VCAM-1, E-selectin and CD34 expression that are, as mentioned before, substantially decreased on angiogenically stimulated endothelial cells, can be normalized after treatment with potent angiogenesis inhibitors like for example platelet factor 4, endostatin, angiostatin, SU6668 and anginex 65,129,187,188. A recent paper by Hellebrekers et al. indicated the importance of epigenetic mechanisms in the normalization of adhesion molecules expression on tumor vessels, since DNA methyltransferase and histone deacetylase are able to reexpress these molecules on endothelial cells in tumor conditions 189,190. The restoration of endothelial cell adhesion molecule expression on tumor vessels leads to an amelioration of leukocyte-vessel wall interactions and consequently an induction of leukocyte infiltration in the tumor tissue (Figure 2.2C-E) 65,189. These findings indicate that by using angiogenesis inhibitors, the gate for leukocytes to the tumor can be unlocked and many doors for combinations with modern immunotherapeutic approaches can be opened.

Until now, combination of angiostatic and immunotherapy to treat cancer was performed with the rational that angiostatic therapy reduces tumor growth thereby gaining time for the tumor specific immune response to assess 191-193. Another combination strategy is immunization of animals against angiogenesisassociated antigens in order to induce anti-angiogenic immunity ${ }^{194}$. However these combination therapies have not fully exploit the dual function (Figure 2.2E) of angiogenesis inhibitors namely (i) inhibition of vessel formation and (ii) the induction of adhesion molecule expression and leukocyte-vessel wall interactions in tumors, which might even increase affectivity of cancer treatments.

Interestingly, the endogenous angiogenesis inhibitor endostatin does not only increase expression of endothelial cell adhesion molecules on activated EC, it also requires the expression of E-selectin on endothelial cells in order to perform its angiostatic functions ${ }^{195}$. Furthermore, E-selectin expression might predict the efficacy of endostatin therapy and the modulation of E-selectin expression may improve antiangiogenic therapy mediated by endostatin. In addition to endothelial cells membrane associated E-selectin, the soluble form of E-selectin (sE-selectin) in the blood circulation possesses prognostic properties, dependently 
of the tumor type. In breast carcinoma, it has been demonstrated that high serum concentration of sE-selectin in patients is associated with poor survival ${ }^{196}$. However, in patients with renal cell carcinoma, no correlation with prognosis could be assessed ${ }^{197}$. Soluble ICAM-1 (sICAM-1) and soluble VCAM-1 (sVCAM-1) are both important prognostic markers in several malignant diseases. Especially sICAM-1, that besides its diagnostic potential, has been implicated as a marker for treatment response. High serum levels of sICAM-1 and/or sVCAM-1 indicate a poor survival for the patient, whereas decreased concentrations of sICAM-1 after treatment indicate a positive response to therapy 198-202. The role of soluble adhesion molecules in carcinogenesis is not yet fully unraveled, but it has been suggested that the shedding of sICAM-1 may enhance metastasis by protecting tumor cells from host immune surveillance ${ }^{203}$. Soluble adhesion molecules may bind to and block circulating cytotoxic lymphocytes, thereby helping tumor cells to escape from immune recognition ${ }^{204}$. Because sICAM-1, sVCAM-1 and sEselectin can also promote angiogenesis ${ }^{205-208}$, these soluble adhesion molecules may have a dual role in enhancing tumor growth.

\section{Paradoxal role of leukocyte infiltration in tumor progression}

Infiltration of leukocytes into tumors is not always beneficial to the process of tumor growth inhibition. Various studies report a positive correlation between the amount of tumor infiltrated leukocytes and tumor growth as well as tumor angiogenesis 209-215. Tumor associated macrophages have pleitropic actions. Macrophages can release growth and angiogenic factors that stimulate tumor cell proliferation, promote angiogenesis, and favor invasion and metastasis. To the contrary, when activated, these tumor associated macrophages are able to kill neoplastic cells and/or elicit tumor-destructive reactions centered on the tumor vasculature. The outcome depends on the net result of individual functions, dictated by the activation state of the macrophages and the intrinsic properties of the tumor cell $216-218$.

Tumor infiltration of T-lymphocytes mainly promotes patient survival 219224 although there are studies that show the opposite ${ }^{209,210 .}$. The latter studies suggest that the immune response can not act to attenuate tumor growth. This apparent paradox may be resolved by assessing the activation status and cytolytic capacity of tumor infiltrated lymphocytes. In addition, the T-lymphocyte population that decreases patient outcome generally consists of CD4 positive $\mathrm{T}$ cells 209,210 . The previous mentioned immune suppressive regulatory $\mathrm{T}$ cells are positive for this marker as well as for CD25 and Foxp3. These cells prevent, as stated higher, the induction of tumor-associated antigen specific immunity and inhibit the anti-tumor immune response ${ }^{225-228}$. 
Furthermore, infiltration of tumor tissues with plasmacytoic dendritic ${ }^{214}$ cells as well as myeloid derived suppressor cells ${ }^{61}$ reduce the functions of effector $\mathrm{T}$ cells in tumors and promote tumor outgrowth.

These reports suggest that by increasing leukocyte influx in a tumor, it will expand rather than degrade. However, the effect of the leukocyte infiltrate in tumors on his progression depends on the composition of the leukocyte populations within this tissue and especially their activation status. The tumor microenvironment displays various factors that manipulate the expression of endothelial cell adhesion molecules and cytokines/chemokines in such a way that a-typical and immune suppressive leukocytes are preferentially attracted to the tumor tissue $60,61,85,88,228$. Moreover, different mechanisms provided by the tumor diminish the possibility of the establishment of an effective anti-tumor immune response regardless of the amount of leukocytes that infiltrated in the tumor tissue $55,56,58,59,61$. Therefore, it might be recommended that therapy which increases leukocyte influx in tumors and in several studies shows positive effects $65,74,189$, is combined with strategies that stimulate cytotoxic $\mathrm{T}$ cell function and eliminates the function and presence of suppressive immune cells. It has already been demonstrated that anti-tumor therapy can be improved by removal of regulatory $\mathrm{T}$ cells, which permits a robust and persistent immune response in the tumor 229,230 . Therapy with immune stimulatory cytokines like interleukin 2 (IL-2), IL-15 and IL12 has also shown promising results in various mouse models 139,231-233.

\section{Concluding remarks}

Taken together, it can be concluded that factors of the tumor microenvironment like bFGF and VEGF modulate the expression of endothelial cell adhesion molecules in such a way that tumor progression is stimulated. The development of an effective immune response is prohibited partly by suppression of endothelial cell adhesion molecule expression and consequently leukocyte-vessel wall interactions and leukocyte tumor infiltration. In addition, modifications of endothelial cell adhesion molecules that mediate leukocyte rolling can lead to an influx of a-typical, less competent T-cells in the tumor tissue. Thus, a tumor can escape eradication by the immune system in part by evoking infiltration of tumor specific immune cells. Moreover, the non-regulation of endothelial cell adhesion molecules that have not yet been implicated in leukocyte-vessel wall interactions in tumors, like CEACAM-1, NCAM-1 and CLEVER-1, contributes to the aggressiveness of the tumor by inducing tumor angiogenesis and tumor cell metastasis. 
Scientists have exploited the specific composition of adhesion molecules on tumor vessels for the development of different strategies to visualize tumor vasculature and assess treatment responses. Furthermore, by inhibiting the function of several tumor endothelial specific adhesion molecules, promising therapies have been generated. However, the effects of these treatment procedures are not exclusively positive since leukocyte recruitment is shown to be abolished. Therefore, angiostatic strategies using angiogenesis inhibitors that are able to inhibit angiogenesis as well as expand endothelial adhesion molecule expression and consequently leukocyte recruitment in the tumor tissue, seem a better way to go. The future of cancer treatment might lie in the concept of combining modern immunotherapeutic approaches with these angiostatic therapies.

Unfortunately, there are some pitfalls with this approach that have to be taken into account. Endothelial cell adhesion molecules that have been implicated in leukocyte recruitment, also play an important role in tumor cell metastasis. High levels of E-selectin expression can be found on endothelial cells adjacent to primary colorectal cancer nests and is even higher on endothelial cells of small vessels adjacent to the metastatic lesions. This expression appears to be induced through stimuli by cancer cells and is inversely correlated to the distance of the blood vessels from the cancer nests ${ }^{234}$. The common lymphatic endothelial and vascular endothelial receptor CLEVER-1 has been suggested to play a role in directing the traffic of cancer cells within the lymphatic system ${ }^{124}$. Finally, members of the immunoglobulin family have also been implicated in cancer metastasis. A recent paper by Klemke and coworkers showed for human melanoma cells that the interaction of the tumor cells with VCAM-1 expressed by endothelial cells leads to cancer cell migration ${ }^{235}$.

Furthermore, CD146 inhibitory antibody decreases metastasis of human melanoma ${ }^{185}$. ICAM-1 also takes part in cancer cell metastasis, although till now, this has only been attributed when ICAM-1 is expressed on tumor cells. Reliant on the tumor type, ICAM-1 expression can inhibit or induce tumor cell invasion. In a model of colorectal carcinoma, ICAM-1 expression was inversely correlated with liver metastasis ${ }^{236}$ whereas studies with lung cancer cells ${ }^{237}$, breast cancer cells ${ }^{238}$ and malignant melanoma cells ${ }^{239}$ showed an induction of metastasis when ICAM1 expression was high. One report in a model of lung cancer demonstrated that treatment with the angiogenesis inhibitor thalidomide decreased the ICAM-1 mediated metastatic potential of these cells ${ }^{240}$. This suggest that ICAM-1 expression on tumor cells is differently regulated as compared to ICAM-1 expression on endothelial cells which is, in contrast to ICAM-1 expressed by tumor cells, increased by angiostatic treatment ${ }^{65}$. 


\section{Acknowledgement}

We are indebted to Dr. A. Duijvestijn for critical reading of the manuscript.

\section{References}

1. Jaffee EM. Immunotherapy of cancer. Ann N Y Acad Sci. 1999;886:67-72.

2. Rosenberg SA. Shedding light on immunotherapy for cancer. N Engl J Med. 2004;350:1461-1463.

3. Mitchell MS. Immunotherapy as part of combinations for the treatment of cancer. Int Immunopharmacol. 2003;3:1051-1059.

4. Pardoll DM. Spinning molecular immunology into successful immunotherapy. Nat Rev Immunol. 2002;2:227-238.

5. Springer TA. Traffic signals for lymphocyte recirculation and leukocyte emigration: the multistep paradigm. Cell. 1994;76:301-314.

6. Shimizu Y, Newman W, Tanaka Y, Shaw S. Lymphocyte interactions with endothelial cells. Immunol Today. 1992;13:106-112.

7. Kunkel EJ, Jung U, Bullard DC, et al. Absence of trauma-induced leukocyte rolling in mice deficient in both P-selectin and intercellular adhesion molecule 1. J Exp Med. 1996;183:57-65.

8. Bevilacqua MP. Endothelial-leukocyte adhesion molecules. Annu Rev Immunol. 1993;11:767-804.

9. Tanaka T, Ebisuno Y, Kanemitsu N, et al. Molecular determinants controlling homeostatic recirculation and tissue-specific trafficking of lymphocytes. Int Arch Allergy Immunol. 2004;134:120-134.

10. Bonder CS, Norman MU, Swain MG, et al. Rules of recruitment for Th1 and Th2 lymphocytes in inflamed liver: a role for alpha-4 integrin and vascular adhesion protein-1. Immunity. 2005;23:153163.

11. Kurkijarvi R, Jalkanen S, Isoniemi H, Salmi M. Vascular adhesion protein-1 (VAP-1) mediates lymphocyte-endothelial interactions in chronic kidney rejection. Eur J Immunol. 2001;31:28762884.

12. Salmi M, Hellman J, Jalkanen S. The role of two distinct endothelial molecules, vascular adhesion protein-1 and peripheral lymph node addressin, in the binding of lymphocyte subsets to human lymph nodes. J Immunol. 1998;160:5629-5636.

13. Salmi M, Smith DJ, Bono P, et al. A mouse molecular mimic of human vascular adhesion protein1. Mol Immunol. 1997;34:1227-1236.

14. Tohka S, Laukkanen M, Jalkanen S, Salmi M. Vascular adhesion protein 1 (VAP-1) functions as a molecular brake during granulocyte rolling and mediates recruitment in vivo. Faseb J. 2001;15:373382.

15. Alon R, Kassner PD, Carr MW, Finger EB, Hemler ME, Springer TA. The integrin VLA-4 supports tethering and rolling in flow on VCAM-1. J Cell Biol. 1995;128:1243-1253.

16. Berlin C, Bargatze RF, Campbell JJ, et al. alpha 4 integrins mediate lymphocyte attachment and rolling under physiologic flow. Cell. 1995;80:413-422.

17. Mohamadzadeh M, DeGrendele H, Arizpe H, Estess P, Siegelman M. Proinflammatory stimuli regulate endothelial hyaluronan expression and CD44/HA-dependent primary adhesion. J Clin Invest. 1998;101:97-108.

18. Johnston B, Butcher EC. Chemokines in rapid leukocyte adhesion triggering and migration. Semin Immunol. 2002;14:83-92.

19. McIntyre TM, Prescott SM, Weyrich AS, Zimmerman GA. Cell-cell interactions: leukocyteendothelial interactions. Curr Opin Hematol. 2003;10:150-158. 
20. Schleiffenbaum B, Fehr J. Regulation and selectivity of leukocyte emigration. J Lab Clin Med. 1996;127:151-168.

21. Greenwood J, Wang Y, Calder VL. Lymphocyte adhesion and transendothelial migration in the central nervous system: the role of LFA-1, ICAM-1, VLA-4 and VCAM-1. off. Immunology. 1995;86:408-415.

22. Staunton DE, Marlin SD, Stratowa C, Dustin ML, Springer TA. Primary structure of ICAM-1 demonstrates interaction between members of the immunoglobulin and integrin supergene families. Cell. 1988;52:925-933.

23. Rothlein R, Dustin ML, Marlin SD, Springer TA. A human intercellular adhesion molecule (ICAM1) distinct from LFA-1. J Immunol. 1986;137:1270-1274.

24. Carlos TM, Harlan JM. Leukocyte-endothelial adhesion molecules. Blood. 1994;84:2068-2101.

25. Chiba R, Nakagawa N, Kurasawa K, Tanaka Y, Saito Y, Iwamoto I. Ligation of CD31 (PECAM-1) on endothelial cells increases adhesive function of alphavbeta3 integrin and enhances beta1 integrin-mediated adhesion of eosinophils to endothelial cells. Blood. 1999;94:1319-1329.

26. Ebeling O, Duczmal A, Aigner S, et al. L1 adhesion molecule on human lymphocytes and monocytes: expression and involvement in binding to alpha v beta 3 integrin. Eur J Immunol. 1996;26:2508-2516.

27. Hubbe M, Kowitz A, Schirrmacher V, Schachner M, Altevogt P. L1 adhesion molecule on mouse leukocytes: regulation and involvement in endothelial cell binding. Eur J Immunol. 1993;23:29272931.

28. Ruppert M, Aigner S, Hubbe M, Yagita H, Altevogt P. The L1 adhesion molecule is a cellular ligand for VLA-5. J Cell Biol. 1995;131:1881-1891.

29. Oleszewski M, Beer S, Katich S, et al. Integrin and neurocan binding to L1 involves distinct Ig domains. J Biol Chem. 1999;274:24602-24610.

30. Brummer J, Ebrahimnejad A, Flayeh R, et al. cis Interaction of the cell adhesion molecule CEACAM1 with integrin beta(3). Am J Pathol. 2001;159:537-546.

31. Ebrahimnejad A, Flayeh R, Unteregger G, Wagener C, Brummer J. Cell adhesion molecule CEACAM1 associates with paxillin in granulocytes and epithelial and endothelial cells. Exp Cell Res. 2000;260:365-373.

32. Irjala H, Elima K, Johansson EL, et al. The same endothelial receptor controls lymphocyte traffic both in vascular and lymphatic vessels. Eur J Immunol. 2003;33:815-824.

33. Piali L, Hammel P, Uherek C, et al. CD31/PECAM-1 is a ligand for alpha v beta 3 integrin involved in adhesion of leukocytes to endothelium. J Cell Biol. 1995;130:451-460.

34. Dumic J, Dabelic S, Flogel M. Galectin-3: an open-ended story. Biochim Biophys Acta. 2006;1760:616-635.

35. Sato S, Ouellet N, Pelletier I, Simard M, Rancourt A, Bergeron MG. Role of galectin-3 as an adhesion molecule for neutrophil extravasation during streptococcal pneumonia. J Immunol. 2002;168:1813-1822.

36. Imaizumi $T$, Kumagai $M$, Sasaki $N$, et al. Interferon-gamma stimulates the expression of galectin- 9 in cultured human endothelial cells. J Leukoc Biol. 2002;72:486-491.

37. Matsumoto R, Matsumoto $\mathrm{H}$, Seki M, et al. Human ecalectin, a variant of human galectin- 9 , is a novel eosinophil chemoattractant produced by T lymphocytes. J Biol Chem. 1998;273:16976-16984.

38. Feng D, Nagy JA, Pyne K, Dvorak HF, Dvorak AM. Neutrophils emigrate from venules by a transendothelial cell pathway in response to FMLP. J Exp Med. 1998;187:903-915.

39. Cook-Mills JM, Deem TL. Active participation of endothelial cells in inflammation. J Leukoc Biol. 2005;77:487-495.

40. Johnson-Leger C, Imhof BA. Forging the endothelium during inflammation: pushing at a halfopen door? Cell Tissue Res. 2003;314:93-105.

41. Liu Y, Shaw SK, Ma S, Yang L, Luscinskas FW, Parkos CA. Regulation of leukocyte transmigration: cell surface interactions and signaling events. J Immunol. 2004;172:7-13. 
42. Luscinskas FW, Ma S, Nusrat A, Parkos CA, Shaw SK. The role of endothelial cell lateral junctions during leukocyte trafficking. Immunol Rev. 2002;186:57-67.

43. Muller WA. Leukocyte-endothelial-cell interactions in leukocyte transmigration and the inflammatory response. Trends Immunol. 2003;24:327-334.

44. Rao RM, Shaw SK, Kim M, Luscinskas FW. Emerging topics in the regulation of leukocyte transendothelial migration. Microcirculation. 2005;12:83-89.

45. Huang MT, Larbi KY, Scheiermann C, et al. ICAM-2 mediates neutrophil transmigration in vivo: evidence for stimulus specificity and a role in PECAM-1-independent transmigration. Blood. 2006;107:4721-4727.

46. Salmi M, Koskinen K, Henttinen T, Elima K, Jalkanen S. CLEVER-1 mediates lymphocyte transmigration through vascular and lymphatic endothelium. Blood. 2004;104:3849-3857.

47. Koskinen K, Vainio PJ, Smith DJ, et al. Granulocyte transmigration through the endothelium is regulated by the oxidase activity of vascular adhesion protein-1 (VAP-1). Blood. 2004;103:33883395.

48. Salmi M, Yegutkin GG, Lehvonen R, Koskinen K, Salminen T, Jalkanen S. A cell surface amine oxidase directly controls lymphocyte migration. Immunity. 2001;14:265-276.

49. Lalor PF, Shields P, Grant A, Adams DH. Recruitment of lymphocytes to the human liver. Immunol Cell Biol. 2002;80:52-64.

50. Wagner JG, Roth RA. Neutrophil migration mechanisms, with an emphasis on the pulmonary vasculature. Pharmacol Rev. 2000;52:349-374.

51. Pober JS, Kluger MS, Schechner JS. Human endothelial cell presentation of antigen and the homing of memory/effector T cells to skin. Ann N Y Acad Sci. 2001;941:12-25.

52. Shrikant $\mathrm{P}, \mathrm{Mescher}$ MF. Control of syngeneic tumor growth by activation of CD8+ T cells: efficacy is limited by migration away from the site and induction of nonresponsiveness. J Immunol. 1999;162:2858-2866.

53. Hung K, Hayashi R, Lafond-Walker A, Lowenstein C, Pardoll D, Levitsky H. The central role of CD4(+) T cells in the antitumor immune response. J Exp Med. 1998;188:2357-2368.

54. Nagorsen D, Scheibenbogen C, Marincola FM, Letsch A, Keilholz U. Natural T cell immunity against cancer. Clin Cancer Res. 2003;9:4296-4303.

55. Frey AB, Monu N. Effector-phase tolerance: another mechanism of how cancer escapes antitumor immune response. J Leukoc Biol. 2006;79:652-662.

56. Poggi A, Zocchi MR. Mechanisms of tumor escape: role of tumor microenvironment in inducing apoptosis of cytolytic effector cells. Arch Immunol Ther Exp (Warsz). 2006;54:323-333.

57. Schrier PI, Bernards R, Vaessen RT, Houweling A, van der Eb AJ. Expression of class I major histocompatibility antigens switched off by highly oncogenic adenovirus 12 in transformed rat cells. Nature. 1983;305:771-775.

58. Gajewski TF, Meng Y, Blank $\mathrm{C}$, et al. Immune resistance orchestrated by the tumor microenvironment. Immunol Rev. 2006;213:131-145.

59. Gajewski TF, Meng Y, Harlin H. Immune suppression in the tumor microenvironment. J Immunother (1997). 2006;29:233-240.

60. Li B, Lalani AS, Harding TC, et al. Vascular endothelial growth factor blockade reduces intratumoral regulatory $\mathrm{T}$ cells and enhances the efficacy of a GM-CSF-secreting cancer immunotherapy. Clin Cancer Res. 2006;12:6808-6816.

61. Kim R, Emi M, Tanabe K. Cancer immunosuppression and autoimmune disease: beyond immunosuppressive networks for tumour immunity. Immunology. 2006;119:254-264.

62. Jain RK. Molecular regulation of vessel maturation. Nat Med. 2003;9:685-693.

63. Salmi M, Jalkanen S. VAP-1: an adhesin and an enzyme. Trends Immunol. 2001;22:211-216.

64. DeGrendele HC, Estess P, Picker LJ, Siegelman MH. CD44 and its ligand hyaluronate mediate rolling under physiologic flow: a novel lymphocyte-endothelial cell primary adhesion pathway. J Exp Med. 1996;183:1119-1130. 
65. Dirkx AE, oude Egbrink MG, Castermans K, et al. Anti-angiogenesis therapy can overcome endothelial cell anergy and promote leukocyte-endothelium interactions and infiltration in tumors. Faseb J. 2006;20:621-630.

66. Dirkx AE, Oude Egbrink MG, Kuijpers MJ, et al. Tumor angiogenesis modulates leukocyte-vessel wall interactions in vivo by reducing endothelial adhesion molecule expression. Cancer Res. 2003;63:2322-2329.

67. Griffioen AW, Damen CA, Blijham GH, Groenewegen G. Tumor angiogenesis is accompanied by a decreased inflammatory response of tumor-associated endothelium. Blood. 1996;88:667-673.

68. Kim I, Moon SO, Park SK, Chae SW, Koh GY. Angiopoietin-1 reduces VEGF-stimulated leukocyte adhesion to endothelial cells by reducing ICAM-1, VCAM-1, and E-selectin expression. Circ Res. 2001;89:477-479.

69. Melder RJ, Koenig GC, Witwer BP, Safabakhsh N, Munn LL, Jain RK. During angiogenesis, vascular endothelial growth factor and basic fibroblast growth factor regulate natural killer cell adhesion to tumor endothelium. Nat Med. 1996;2:992-997.

70. Berger R, Albelda SM, Berd D, Ioffreda M, Whitaker D, Murphy GF. Expression of plateletendothelial cell adhesion molecule-1 (PECAM-1) during melanoma-induced angiogenesis in vivo. J Cutan Pathol. 1993;20:399-406.

71. Borgstrom P, Hughes GK, Hansell P, Wolitsky BA, Sriramarao P. Leukocyte adhesion in angiogenic blood vessels. Role of E-selectin, P-selectin, and beta2 integrin in lymphotoxinmediated leukocyte recruitment in tumor microvessels. J Clin Invest. 1997;99:2246-2253.

72. Griffioen AW, Damen CA, Martinotti S, Blijham GH, Groenewegen G. Endothelial intercellular adhesion molecule-1 expression is suppressed in human malignancies: the role of angiogenic factors. Cancer Res. 1996;56:1111-1117.

73. Kuzu I, Bicknell R, Fletcher CD, Gatter KC. Expression of adhesion molecules on the endothelium of normal tissue vessels and vascular tumors. Lab Invest. 1993;69:322-328.

74. Nooijen PT, Westphal JR, Eggermont AM, et al. Endothelial P-selectin expression is reduced in advanced primary melanoma and melanoma metastasis. Am J Pathol. 1998;152:679-682.

75. Peeters CF, Ruers TJ, Westphal JR, de Waal RM. Progressive loss of endothelial P-selectin expression with increasing malignancy in colorectal cancer. Lab Invest. 2005;85:248-256.

76. Bessa X, Elizalde JI, Mitjans F, et al. Leukocyte recruitment in colon cancer: role of cell adhesion molecules, nitric oxide, and transforming growth factor beta1. Gastroenterology. 2002;122:11221132.

77. Fox SB, Turner GD, Gatter KC, Harris AL. The increased expression of adhesion molecules ICAM3, E- and P-selectins on breast cancer endothelium. J Pathol. 1995;177:369-376.

78. Berg EL, Goldstein LA, Jutila MA, et al. Homing receptors and vascular addressins: cell adhesion molecules that direct lymphocyte traffic. Immunol Rev. 1989;108:5-18.

79. Briskin M, Winsor-Hines D, Shyjan A, et al. Human mucosal addressin cell adhesion molecule- 1 is preferentially expressed in intestinal tract and associated lymphoid tissue. Am J Pathol. 1997;151:97-110.

80. De Keyser F, Elewaut D, De Wever N, Bensbaho K, Cuvelier C. The gut associated addressins: lymphocyte homing in the gut. Baillieres Clin Rheumatol. 1996;10:25-39.

81. Michl J, Qiu QY, Kuerer HM. Homing receptors and addressins. Curr Opin Immunol. 1991;3:373382.

82. Shaw SK, Brenner MB. The beta 7 integrins in mucosal homing and retention. Semin Immunol. 1995;7:335-342.

83. Salmi M, Grenman R, Grenman S, Nordman E, Jalkanen S. Tumor endothelium selectively supports binding of IL-2-propagated tumor-infiltrating lymphocytes. J Immunol. 1995;154:60026012.

84. Onrust SV, Hartl PM, Rosen SD, Hanahan D. Modulation of L-selectin ligand expression during an immune response accompanying tumorigenesis in transgenic mice. J Clin Invest. 1996;97:54-64. 
85. Enarsson K, Johnsson E, Lindholm C, et al. Differential mechanisms for T lymphocyte recruitment in normal and neoplastic human gastric mucosa. Clin Immunol. 2006;118:24-34.

86. Hellwig SM, Damen CA, van Adrichem NP, Blijham GH, Groenewegen G, Griffioen AW. Endothelial CD34 is suppressed in human malignancies: role of angiogenic factors. Cancer Lett. 1997;120:203-211.

87. Chen S, Kawashima H, Lowe JB, Lanier LL, Fukuda M. Suppression of tumor formation in lymph nodes by L-selectin-mediated natural killer cell recruitment. J Exp Med. 2005;202:1679-1689.

88. Wei S, Kryczek I, Zou L, et al. Plasmacytoid dendritic cells induce CD8+ regulatory T cells in human ovarian carcinoma. Cancer Res. 2005;65:5020-5026.

89. Zou W, Machelon V, Coulomb-L'Hermin A, et al. Stromal-derived factor-1 in human tumors recruits and alters the function of plasmacytoid precursor dendritic cells. Nat Med. 2001;7:13391346.

90. Bono P, Salmi M, Smith DJ, Jalkanen S. Cloning and characterization of mouse vascular adhesion protein-1 reveals a novel molecule with enzymatic activity. J Immunol. 1998;160:5563-5571.

91. Bono P, Salmi M, Smith DJ, et al. Isolation, structural characterization, and chromosomal mapping of the mouse vascular adhesion protein-1 gene and promoter. J Immunol. 1998;161:2953-2960.

92. Salmi M, Tohka S, Jalkanen S. Human vascular adhesion protein-1 (VAP-1) plays a critical role in lymphocyte-endothelial cell adhesion cascade under shear. Circ Res. 2000;86:1245-1251.

93. Smith DJ, Salmi M, Bono P, Hellman J, Leu T, Jalkanen S. Cloning of vascular adhesion protein 1 reveals a novel multifunctional adhesion molecule. J Exp Med. 1998;188:17-27.

94. Forster-Horvath C, Dome B, Paku S, et al. Loss of vascular adhesion protein-1 expression in intratumoral microvessels of human skin melanoma. Melanoma Res. 2004;14:135-140.

95. Irjala H, Salmi M, Alanen K, Grenman R, Jalkanen S. Vascular adhesion protein 1 mediates binding of immunotherapeutic effector cells to tumor endothelium. J Immunol. 2001;166:69376943.

96. Yoong KF, McNab G, Hubscher SG, Adams DH. Vascular adhesion protein-1 and ICAM-1 support the adhesion of tumor-infiltrating lymphocytes to tumor endothelium in human hepatocellular carcinoma. J Immunol. 1998;160:3978-3988.

97. Griffioen AW, Coenen MJ, Damen CA, et al. CD44 is involved in tumor angiogenesis; an activation antigen on human endothelial cells. Blood. 1997;90:1150-1159.

98. Siegelman MH, DeGrendele HC, Estess P. Activation and interaction of CD44 and hyaluronan in immunological systems. J Leukoc Biol. 1999;66:315-321.

99. Toole BP. Hyaluronan promotes the malignant phenotype. Glycobiology. 2002;12:37R-42R.

100. Toole BP, Hascall VC. Hyaluronan and tumor growth. Am J Pathol. 2002;161:745-747.

101. Rooney P, Kumar S, Ponting J, Wang M. The role of hyaluronan in tumour neovascularization (review). Int J Cancer. 1995;60:632-636.

102. Zhang H, Issekutz AC. Growth factor regulation of neutrophil-endothelial cell interactions. J Leukoc Biol. 2001;70:225-232.

103. Kitayama J, Nagawa H, Yasuhara H, et al. Suppressive effect of basic fibroblast growth factor on transendothelial emigration of CD4(+) T-lymphocyte. Cancer Res. 1994;54:4729-4733.

104. Tromp SC, oude Egbrink MG, Dings RP, et al. Tumor angiogenesis factors reduce leukocyte adhesion in vivo. Int Immunol. 2000;12:671-676.

105. Bouma-ter Steege JC, Baeten CI, Thijssen VL, et al. Angiogenic profile of breast carcinoma determines leukocyte infiltration. Clin Cancer Res. 2004;10:7171-7178.

106. Piali L, Fichtel A, Terpe HJ, Imhof BA, Gisler RH. Endothelial vascular cell adhesion molecule 1 expression is suppressed by melanoma and carcinoma. J Exp Med. 1995;181:811-816.

107. Zittermann SI, Issekutz AC. Endothelial growth factors VEGF and bFGF differentially enhance monocyte and neutrophil recruitment to inflammation. J Leukoc Biol. 2006;80:247-257.

108. Bouzin C, Brouet A, De Vriese J, Dewever J, Feron O. Effects of vascular endothelial growth factor on the lymphocyte-endothelium interactions: identification of caveolin-1 and nitric oxide as control points of endothelial cell anergy. J Immunol. 2007;178:1505-1511. 
109. Allory Y, Matsuoka Y, Bazille C, Christensen EI, Ronco P, Debiec H. The L1 cell adhesion molecule is induced in renal cancer cells and correlates with metastasis in clear cell carcinomas. Clin Cancer Res. 2005;11:1190-1197.

110. Bussolati B, Deambrosis I, Russo S, Deregibus MC, Camussi G. Altered angiogenesis and survival in human tumor-derived endothelial cells. Faseb J. 2003;17:1159-1161.

111. Bussolati B, Grange C, Bruno S, et al. Neural-cell adhesion molecule (NCAM) expression by immature and tumor-derived endothelial cells favors cell organization into capillary-like structures. Exp Cell Res. 2006;312:913-924.

112. Kaifi JT, Strelow A, Schurr PG, et al. L1 (CD171) is highly expressed in gastrointestinal stromal tumors. Mod Pathol. 2006;19:399-406.

113. Blaheta RA, Daher FH, Michaelis $\mathrm{M}$, et al. Chemoresistance induces enhanced adhesion and transendothelial penetration of neuroblastoma cells by down-regulating NCAM surface expression. BMC Cancer. 2006;6:294.

114. Fogel M, Mechtersheimer S, Huszar M, et al. L1 adhesion molecule (CD 171) in development and progression of human malignant melanoma. Cancer Lett. 2003;189:237-247.

115. Voura EB, Ramjeesingh RA, Montgomery AM, Siu CH. Involvement of integrin alpha(v)beta(3) and cell adhesion molecule L1 in transendothelial migration of melanoma cells. Mol Biol Cell. 2001;12:2699-2710.

116. Oliveira-Ferrer L, Tilki D, Ziegeler G, et al. Dual role of carcinoembryonic antigen-related cell adhesion molecule 1 in angiogenesis and invasion of human urinary bladder cancer. Cancer Res. 2004;64:8932-8938.

117. Tilki D, Irmak S, Oliveira-Ferrer L, et al. CEA-related cell adhesion molecule-1 is involved in angiogenic switch in prostate cancer. Oncogene. 2006;25:4965-4974.

118. Ergun S, Kilik N, Ziegeler G, et al. CEA-related cell adhesion molecule 1: a potent angiogenic factor and a major effector of vascular endothelial growth factor. Mol Cell. 2000;5:311-320.

119. Wagener C, Ergun S. Angiogenic properties of the carcinoembryonic antigen-related cell adhesion molecule 1. Exp Cell Res. 2000;261:19-24.

120. Kilic N, Oliveira-Ferrer L, Wurmbach JH, et al. Pro-angiogenic signaling by the endothelial presence of CEACAM1. J Biol Chem. 2005;280:2361-2369.

121. Skubitz KM, Campbell KD, Skubitz AP. Synthetic peptides of CD66a stimulate neutrophil adhesion to endothelial cells. J Immunol. 2000;164:4257-4264.

122. Nagaishi T, Iijima H, Nakajima A, Chen D, Blumberg RS. Role of CEACAM1 as a regulator of $T$ cells. Ann N Y Acad Sci. 2006;1072:155-175.

123. Goerdt S, Bhardwaj R, Sorg C. Inducible expression of MS-1 high-molecular-weight protein by endothelial cells of continuous origin and by dendritic cells/macrophages in vivo and in vitro. Am J Pathol. 1993;142:1409-1422.

124. Irjala H, Alanen K, Grenman R, Heikkila P, Joensuu H, Jalkanen S. Mannose receptor (MR) and common lymphatic endothelial and vascular endothelial receptor (CLEVER)-1 direct the binding of cancer cells to the lymph vessel endothelium. Cancer Res. 2003;63:4671-4676.

125. Kzhyshkowska J, Gratchev A, Goerdt S. Stabilin-1, a homeostatic scavenger receptor with multiple functions. J Cell Mol Med. 2006;10:635-649.

126. Prevo R, Banerji S, Ni J, Jackson DG. Rapid plasma membrane-endosomal trafficking of the lymph node sinus and high endothelial venule scavenger receptor/homing receptor stabilin-1 (FEEL1/CLEVER-1). J Biol Chem. 2004;279:52580-52592.

127. Salmi M, Koskinen K, Henttinen T, Elima K, Jalkanen S. CLEVER-1 mediates lymphocyte transmigration through vascular and lymphatic endothelium. Blood. 2004.

128. Griffioen AW, Molema G. Angiogenesis: potentials for pharmacologic intervention in the treatment of cancer, cardiovascular diseases, and chronic inflammation. Pharmacol Rev. 2000;52:237-268. 
129. Zhang H, Issekutz AC. Down-modulation of monocyte transendothelial migration and endothelial adhesion molecule expression by fibroblast growth factor: reversal by the anti-angiogenic agent SU6668. Am J Pathol. 2002;160:2219-2230.

130. Anastassiou G, Duensing S, Steinhoff G, et al. Platelet endothelial cell adhesion molecule-1 (PECAM-1): a potential prognostic marker involved in leukocyte infiltration of renal cell carcinoma. Oncology. 1996;53:127-132.

131. Dworzak MN, Fritsch G, Buchinger P, et al. Flow cytometric assessment of human MIC2 expression in bone marrow, thymus, and peripheral blood. Blood. 1994;83:415-425.

132. Gelin C, Aubrit F, Phalipon A, et al. The E2 antigen, a $32 \mathrm{kd}$ glycoprotein involved in T-cell adhesion processes, is the MIC2 gene product. Embo J. 1989;8:3253-3259.

133. Kovar H, Dworzak M, Strehl S, et al. Overexpression of the pseudoautosomal gene MIC2 in Ewing's sarcoma and peripheral primitive neuroectodermal tumor. Oncogene. 1990;5:1067-1070.

134. Schenkel AR, Mamdouh Z, Chen X, Liebman RM, Muller WA. CD99 plays a major role in the migration of monocytes through endothelial junctions. Nat Immunol. 2002;3:143-150.

135. Bixel MG, Petri B, Khandoga AG, et al. A CD99-related antigen on endothelial cells mediates neutrophil, but not lymphocyte extravasation in vivo. Blood. 2007.

136. Lou O, Alcaide P, Luscinskas FW, Muller WA. CD99 is a key mediator of the transendothelial migration of neutrophils. J Immunol. 2007;178:1136-1143.

137. Aurrand-Lions M, Johnson-Leger C, Imhof BA. The last molecular fortress in leukocyte transendothelial migration. Nat Immunol. 2002;3:116-118.

138. Ebnet K, Suzuki A, Ohno S, Vestweber D. Junctional adhesion molecules (JAMs): more molecules with dual functions? J Cell Sci. 2004;117:19-29.

139. Martin-Padura I, Lostaglio S, Schneemann M, et al. Junctional adhesion molecule, a novel member of the immunoglobulin superfamily that distributes at intercellular junctions and modulates monocyte transmigration. J Cell Biol. 1998;142:117-127.

140. Sobocka MB, Sobocki T, Babinska A, et al. Signaling pathways of the F11 receptor (F11R; a.k.a. JAM-1, JAM-A) in human platelets: F11R dimerization, phosphorylation and complex formation with the integrin GPIIIa. J Recept Signal Transduct Res. 2004;24:85-105.

141. Ludwig RJ, Zollner TM, Santoso S, et al. Junctional adhesion molecules (JAM)-B and -C contribute to leukocyte extravasation to the skin and mediate cutaneous inflammation. J Invest Dermatol. 2005;125:969-976.

142. Ostermann G, Weber KS, Zernecke A, Schroder A, Weber C. JAM-1 is a ligand of the beta(2) integrin LFA-1 involved in transendothelial migration of leukocytes. Nat Immunol. 2002;3:151-158.

143. Ebnet K, Aurrand-Lions M, Kuhn A, et al. The junctional adhesion molecule (JAM) family members JAM-2 and JAM-3 associate with the cell polarity protein PAR-3: a possible role for JAMs in endothelial cell polarity. J Cell Sci. 2003;116:3879-3891.

144. Zen K, Babbin BA, Liu Y, Whelan JB, Nusrat A, Parkos CA. JAM-C is a component of desmosomes and a ligand for CD11b/CD18-mediated neutrophil transepithelial migration. Mol Biol Cell. 2004;15:3926-3937.

145. Fraemohs L, Koenen RR, Ostermann G, Heinemann B, Weber C. The functional interaction of the beta 2 integrin lymphocyte function-associated antigen- 1 with junctional adhesion molecule- $A$ is mediated by the I domain. J Immunol. 2004;173:6259-6264.

146. Johnson-Leger CA, Aurrand-Lions M, Beltraminelli N, Fasel N, Imhof BA. Junctional adhesion molecule-2 (JAM-2) promotes lymphocyte transendothelial migration. Blood. 2002;100:2479-2486.

147. Lamagna C, Meda P, Mandicourt G, et al. Dual interaction of JAM-C with JAM-B and alpha(M)beta2 integrin: function in junctional complexes and leukocyte adhesion. Mol Biol Cell. 2005;16:4992-5003.

148. Santoso S, Sachs UJ, Kroll H, et al. The junctional adhesion molecule 3 (JAM-3) on human platelets is a counterreceptor for the leukocyte integrin Mac-1. J Exp Med. 2002;196:679-691.

149. Lamagna C, Hodivala-Dilke KM, Imhof BA, Aurrand-Lions M. Antibody against junctional adhesion molecule-C inhibits angiogenesis and tumor growth. Cancer Res. 2005;65:5703-5710. 
150. Naik MU, Vuppalanchi D, Naik UP. Essential role of junctional adhesion molecule-1 in basic fibroblast growth factor-induced endothelial cell migration. Arterioscler Thromb Vasc Biol. 2003;23:2165-2171.

151. Parise LV. JAM-1 regulation of endothelial cell migration: implications for angiogenesis. Arterioscler Thromb Vasc Biol. 2003;23:2119-2120.

152. Dejana E, Spagnuolo R, Bazzoni G. Interendothelial junctions and their role in the control of angiogenesis, vascular permeability and leukocyte transmigration. Thromb Haemost. 2001;86:308315.

153. Cooke VG, Naik MU, Naik UP. Fibroblast growth factor-2 failed to induce angiogenesis in junctional adhesion molecule-A-deficient mice. Arterioscler Thromb Vasc Biol. 2006;26:2005-2011.

154. Ozaki H, Ishii K, Horiuchi $\mathrm{H}$, et al. Cutting edge: combined treatment of TNF-alpha and IFNgamma causes redistribution of junctional adhesion molecule in human endothelial cells. J Immunol. 1999;163:553-557.

155. Naik MU, Mousa SA, Parkos CA, Naik UP. Signaling through JAM-1 and alphavbeta3 is required for the angiogenic action of bFGF: dissociation of the JAM-1 and alphavbeta3 complex. Blood. 2003;102:2108-2114.

156. He J, Baum LG. Endothelial cell expression of galectin-1 induced by prostate cancer cells inhibits T-cell transendothelial migration. Lab Invest. 2006;86:578-590.

157. Thijssen VL, Postel R, Brandwijk RJ, et al. Galectin-1 is essential in tumor angiogenesis and is a target for antiangiogenesis therapy. Proc Natl Acad Sci U S A. 2006;103:15975-15980.

158. Gotsch U, Borges E, Bosse R, et al. VE-cadherin antibody accelerates neutrophil recruitment in vivo. J Cell Sci. 1997;110 ( Pt 5):583-588.

159. Shaw SK, Bamba PS, Perkins BN, Luscinskas FW. Real-time imaging of vascular endothelialcadherin during leukocyte transmigration across endothelium. J Immunol. 2001;167:2323-2330.

160. Liao F, Li Y, O'Connor W, et al. Monoclonal antibody to vascular endothelial-cadherin is a potent inhibitor of angiogenesis, tumor growth, and metastasis. Cancer Res. 2000;60:6805-6810.

161. Ruoslahti E, Pierschbacher MD. Arg-Gly-Asp: a versatile cell recognition signal. Cell. 1986;44:517518.

162. Benedetto S, Pulito R, Crich SG, et al. Quantification of the expression level of integrin receptor alpha(v)beta3 in cell lines and MR imaging with antibody-coated iron oxide particles. Magn Reson Med. 2006;56:711-716.

163. Haubner R. Alphavbeta3-integrin imaging: a new approach to characterise angiogenesis? Eur J Nucl Med Mol Imaging. 2006;33 Suppl 1:54-63.

164. Haubner RH, Wester HJ, Weber WA, Schwaiger M. Radiotracer-based strategies to image angiogenesis. Q J Nucl Med. 2003;47:189-199.

165. Janssen ML, Oyen WJ, Dijkgraaf I, et al. Tumor targeting with radiolabeled alpha(v)beta(3) integrin binding peptides in a nude mouse model. Cancer Res. 2002;62:6146-6151.

166. Lim EH, Danthi N, Bednarski M, Li KC. A review: Integrin alphavbeta3-targeted molecular imaging and therapy in angiogenesis. Nanomedicine. 2005;1:110-114.

167. Liu S. Radiolabeled multimeric cyclic RGD peptides as integrin alphavbeta3 targeted radiotracers for tumor imaging. Mol Pharm. 2006;3:472-487.

168. Mulder WJ, Strijkers GJ, Habets JW, et al. MR molecular imaging and fluorescence microscopy for identification of activated tumor endothelium using a bimodal lipidic nanoparticle. Faseb J. 2005;19:2008-2010.

169. Mulder WJ, van der Schaft DW, Hautvast PA, et al. Early in vivo assessment of angiostatic therapy efficacy by molecular MRI. Faseb J. 2007;21:378-383.

170. Geninatti Crich S, Bussolati B, Tei L, et al. Magnetic resonance visualization of tumor angiogenesis by targeting neural cell adhesion molecules with the highly sensitive gadolinium-loaded apoferritin probe. Cancer Res. 2006;66:9196-9201.

171. Yan X, Lin Y, Yang D, et al. A novel anti-CD146 monoclonal antibody, AA98, inhibits angiogenesis and tumor growth. Blood. 2003;102:184-191. 
172. Boutry S, Laurent S, Elst LV, Muller RN. Specific E-selectin targeting with a superparamagnetic MRI contrast agent. Contrast Media Mol Imaging. 2006;1:15-22.

173. Mulder WJ, Strijkers GJ, Griffioen AW, et al. A liposomal system for contrast-enhanced magnetic resonance imaging of molecular targets. Bioconjug Chem. 2004;15:799-806.

174. Sibson NR, Blamire AM, Bernades-Silva M, et al. MRI detection of early endothelial activation in brain inflammation. Magn Reson Med. 2004;51:248-252.

175. Sadeghi MM, Schechner JS, Krassilnikova S, et al. Vascular cell adhesion molecule-1-targeted detection of endothelial activation in human microvasculature. Transplant Proc. 2004;36:15851591.

176. Kelly KA, Allport JR, Tsourkas A, Shinde-Patil VR, Josephson L, Weissleder R. Detection of vascular adhesion molecule-1 expression using a novel multimodal nanoparticle. Circ Res. 2005;96:327-336.

177. Nahrendorf M, Jaffer FA, Kelly KA, et al. Noninvasive vascular cell adhesion molecule-1 imaging identifies inflammatory activation of cells in atherosclerosis. Circulation. 2006;114:1504-1511.

178. Jaakkola K, Nikula T, Holopainen R, et al. In vivo detection of vascular adhesion protein-1 in experimental inflammation. Am J Pathol. 2000;157:463-471.

179. Sipkins DA, Gijbels K, Tropper FD, Bednarski M, Li KC, Steinman L. ICAM-1 expression in autoimmune encephalitis visualized using magnetic resonance imaging. J Neuroimmunol. 2000;104:1-9.

180. Temming K, Schiffelers RM, Molema G, Kok RJ. RGD-based strategies for selective delivery of therapeutics and imaging agents to the tumour vasculature. Drug Resist Updat. 2005;8:381-402.

181. Bequet-Romero M, Ayala M, Acevedo BE, et al. Prophylactic naked DNA vaccination with the human vascular endothelial growth factor induces an anti-tumor response in C57Bl/6 mice. Angiogenesis. 2007;10:23-34.

182. Slager EH, Honders MW, van der Meijden ED, et al. Identification of the angiogenic endothelialcell growth factor-1/thymidine phosphorylase as a potential target for immunotherapy of cancer. Blood. 2006;107:4954-4960.

183. Wada S, Tsunoda T, Baba $T$, et al. Rationale for antiangiogenic cancer therapy with vaccination using epitope peptides derived from human vascular endothelial growth factor receptor 2. Cancer Res. 2005;65:4939-4946.

184. Bu P, Gao L, Zhuang J, Feng J, Yang D, Yan X. Anti-CD146 monoclonal antibody AA98 inhibits angiogenesis via suppression of nuclear factor-kappaB activation. Mol Cancer Ther. 2006;5:28722878.

185. Mills L, Tellez C, Huang S, et al. Fully human antibodies to MCAM/MUC18 inhibit tumor growth and metastasis of human melanoma. Cancer Res. 2002;62:5106-5114.

186. Abella A, Garcia-Vicente S, Viguerie N, et al. Adipocytes release a soluble form of VAP-1/SSAO by a metalloprotease-dependent process and in a regulated manner. Diabetologia. 2004;47:429-438.

187. Griffioen AW, Damen CA, Mayo KH, et al. Angiogenesis inhibitors overcome tumor induced endothelial cell anergy. Int J Cancer. 1999;80:315-319.

188. Luo J, Lin J, Paranya G, Bischoff J. Angiostatin upregulates E-selectin in proliferating endothelial cells. Biochem Biophys Res Commun. 1998;245:906-911.

189. Hellebrekers DM, Castermans K, Vire E, et al. Epigenetic regulation of tumor endothelial cell anergy: silencing of intercellular adhesion molecule-1 by histone modifications. Cancer Res. 2006;66:10770-10777.

190. Hellebrekers DM, Jair KW, Vire E, et al. Angiostatic activity of DNA methyltransferase inhibitors. Mol Cancer Ther. 2006;5:467-475.

191. Cuadros C, Dominguez AL, Frost GI, Borgstrom P, Lustgarten J. Cooperative effect between immunotherapy and antiangiogenic therapy leads to effective tumor rejection in tolerant Her2/neu mice. Cancer Res. 2003;63:5895-5901. 
192. Gyorffy S, Palmer K, Podor TJ, Hitt M, Gauldie J. Combined treatment of a murine breast cancer model with type 5 adenovirus vectors expressing murine angiostatin and IL-12: a role for combined anti-angiogenesis and immunotherapy. J Immunol. 2001;166:6212-6217.

193. Huang X, Raskovalova T, Lokshin A, et al. Combined antiangiogenic and immune therapy of prostate cancer. Angiogenesis. 2005;8:13-23.

194. Nair S, Boczkowski D, Moeller B, Dewhirst M, Vieweg J, Gilboa E. Synergy between tumor immunotherapy and antiangiogenic therapy. Blood. 2003;102:964-971.

195. Yu Y, Moulton KS, Khan MK, et al. E-selectin is required for the antiangiogenic activity of endostatin. Proc Natl Acad Sci U S A. 2004;101:8005-8010.

196. Hebbar M, Revillion F, Louchez MM, Fournier C, Bonneterre J, Peyrat JP. Prognostic value of circulating soluble E-selectin concentrations in node-negative breast cancer patients. Clin Cancer Res. 1999;5:1427-1433.

197. Dosquet C, Coudert MC, Lepage E, Cabane J, Richard F. Are angiogenic factors, cytokines, and soluble adhesion molecules prognostic factors in patients with renal cell carcinoma? Clin Cancer Res. 1997;3:2451-2458.

198. Bewick M, Conlon M, Lee H, et al. Evaluation of sICAM-1, sVCAM-1, and sE-Selectin levels in patients with metastatic breast cancer receiving high-dose chemotherapy. Stem Cells Dev. 2004;13:281-294.

199. Hoffmann R, Franzke A, Buer J, et al. Prognostic impact of in vivo soluble cell adhesion molecules in metastatic renal cell carcinoma. Br J Cancer. 1999;79:1742-1745.

200. Kawano T, Yanoma S, Nakamura Y, et al. Evaluation of soluble adhesion molecules CD44 (CD44st, CD44v5, CD44v6), ICAM-1, and VCAM-1 as tumor markers in head and neck cancer. Am J Otolaryngol. 2005;26:308-313.

201. O'Hanlon DM, Fitzsimons H, Lynch J, Tormey S, Malone C, Given HF. Soluble adhesion molecules (E-selectin, ICAM-1 and VCAM-1) in breast carcinoma. Eur J Cancer. 2002;38:2252-2257.

202. Roselli M, Guadagni F, Martini F, et al. Association between serum carcinoembryonic antigen and endothelial cell adhesion molecules in colorectal cancer. Oncology. 2003;65:132-138.

203. Altomonte M, Fonsatti E, Lamaj E, Cattarossi I, Cattelan A, Maio M. Differential levels of soluble intercellular adhesion molecule-1 (sICAM-1) in early breast cancer and benign breast lesions. Breast Cancer Res Treat. 1999;58:19-23.

204. Becker JC, Dummer R, Hartmann AA, Burg G, Schmidt RE. Shedding of ICAM-1 from human melanoma cell lines induced by IFN-gamma and tumor necrosis factor-alpha. Functional consequences on cell-mediated cytotoxicity. J Immunol. 1991;147:4398-4401.

205. Gho YS, Kim PN, Li HC, Elkin M, Kleinman HK. Stimulation of tumor growth by human soluble intercellular adhesion molecule-1. Cancer Res. 2001;61:4253-4257.

206. Gho YS, Kleinman HK, Sosne G. Angiogenic activity of human soluble intercellular adhesion molecule-1. Cancer Res. 1999;59:5128-5132.

207. Koch AE, Halloran MM, Haskell CJ, Shah MR, Polverini PJ. Angiogenesis mediated by soluble forms of E-selectin and vascular cell adhesion molecule-1. Nature. 1995;376:517-519.

208. Nguyen M, Strubel NA, Bischoff J. A role for sialyl Lewis-X/A glycoconjugates in capillary morphogenesis. Nature. 1993;365:267-269.

209. Ali AA, McMillan DC, Matalka, II, McNicol AM, McArdle CS. Tumour T-lymphocyte subset infiltration and tumour recurrence following curative resection for colorectal cancer. Eur J Surg Oncol. 2004;30:292-295.

210. Bromwich EJ, McArdle PA, Canna K, et al. The relationship between T-lymphocyte infiltration, stage, tumour grade and survival in patients undergoing curative surgery for renal cell cancer. Br J Cancer. 2003;89:1906-1908.

211. Canna K, McArdle PA, McMillan DC, et al. The relationship between tumour T-lymphocyte infiltration, the systemic inflammatory response and survival in patients undergoing curative resection for colorectal cancer. Br J Cancer. 2005;92:651-654. 
212. Mantovani A, Allavena P, Sica A. Tumour-associated macrophages as a prototypic type II polarised phagocyte population: role in tumour progression. Eur J Cancer. 2004;40:1660-1667.

213. Mantovani A, Schioppa T, Porta C, Allavena P, Sica A. Role of tumor-associated macrophages in tumor progression and invasion. Cancer Metastasis Rev. 2006.

214. Treilleux I, Blay JY, Bendriss-Vermare N, et al. Dendritic cell infiltration and prognosis of early stage breast cancer. Clin Cancer Res. 2004;10:7466-7474.

215. Presta M, Dell'Era P, Mitola S, Moroni E, Ronca R, Rusnati M. Fibroblast growth factor/fibroblast growth factor receptor system in angiogenesis. Cytokine Growth Factor Rev. 2005;16:159-178.

216. Mantovani A, Bottazzi B, Colotta F, Sozzani S, Ruco L. The origin and function of tumorassociated macrophages. Immunol Today. 1992;13:265-270.

217. Mantovani A, Bussolino F, Dejana E. Cytokine regulation of endothelial cell function. Faseb J. 1992;6:2591-2599.

218. Dirkx AE, Oude Egbrink MG, Wagstaff J, Griffioen AW. Monocyte/macrophage infiltration in tumors: modulators of angiogenesis. J Leukoc Biol. 2006;80:1183-1196.

219. Cho Y, Miyamoto M, Kato K, et al. CD4+ and CD8+ T cells cooperate to improve prognosis of patients with esophageal squamous cell carcinoma. Cancer Res. 2003;63:1555-1559.

220. Eerola AK, Soini Y, Paakko P. A high number of tumor-infiltrating lymphocytes are associated with a small tumor size, low tumor stage, and a favorable prognosis in operated small cell lung carcinoma. Clin Cancer Res. 2000;6:1875-1881.

221. Hiraoka K, Miyamoto M, Cho Y, et al. Concurrent infiltration by CD8+ T cells and CD4+ T cells is a favourable prognostic factor in non-small-cell lung carcinoma. Br J Cancer. 2006;94:275-280.

222. Menard S, Tomasic G, Casalini P, et al. Lymphoid infiltration as a prognostic variable for earlyonset breast carcinomas. Clin Cancer Res. 1997;3:817-819.

223. Oshikiri T, Miyamoto M, Shichinohe T, et al. Prognostic value of intratumoral CD8+ T lymphocyte in extrahepatic bile duct carcinoma as essential immune response. J Surg Oncol. 2003;84:224-228.

224. Zhang L, Conejo-Garcia JR, Katsaros D, et al. Intratumoral T cells, recurrence, and survival in epithelial ovarian cancer. N Engl J Med. 2003;348:203-213.

225. Beyer M, Schultze JL. Regulatory T cells in cancer. Blood. 2006;108:804-811.

226. Lizee G, Radvanyi LG, Overwijk WW, Hwu P. Improving antitumor immune responses by circumventing immunoregulatory cells and mechanisms. Clin Cancer Res. 2006;12:4794-4803.

227. Ralainirina N, Poli A, Michel T, et al. Control of natural killer (NK) cell functions by CD4+CD25+ regulatory T cells. J Leukoc Biol. 2006.

228. Zou W. Regulatory T cells, tumour immunity and immunotherapy. Nat Rev Immunol. 2006;6:295307.

229. Dannull J, Su Z, Rizzieri D, et al. Enhancement of vaccine-mediated antitumor immunity in cancer patients after depletion of regulatory T cells. J Clin Invest. 2005;115:3623-3633.

230. Sutmuller RP, van Duivenvoorde LM, van Elsas A, et al. Synergism of cytotoxic T lymphocyteassociated antigen 4 blockade and depletion of $\mathrm{CD} 25(+)$ regulatory $\mathrm{T}$ cells in antitumor therapy reveals alternative pathways for suppression of autoreactive cytotoxic $\mathrm{T}$ lymphocyte responses. $\mathrm{J}$ Exp Med. 2001;194:823-832.

231. Alves A, Vibert E, Trajcevski S, et al. Adjuvant interleukin-12 gene therapy for the management of colorectal liver metastases. Cancer Gene Ther. 2004;11:782-789.

232. Klebanoff CA, Finkelstein SE, Surman DR, et al. IL-15 enhances the in vivo antitumor activity of tumor-reactive CD8+ T cells. Proc Natl Acad Sci U S A. 2004;101:1969-1974.

233. Rabinovich GA, Toscano MA, Ilarregui JM, Rubinstein N. Shedding light on the immunomodulatory properties of galectins: novel regulators of innate and adaptive immune responses. Glycoconj J. 2004;19:565-573.

234. Ye C, Kiriyama K, Mistuoka C, et al. Expression of E-selectin on endothelial cells of small veins in human colorectal cancer. Int J Cancer. 1995;61:455-460. 
235. Klemke M, Weschenfelder T, Konstandin MH, Samstag Y. High affinity interaction of integrin alpha4beta1 (VLA-4) and vascular cell adhesion molecule 1 (VCAM-1) enhances migration of human melanoma cells across activated endothelial cell layers. J Cell Physiol. 2007.

236. Tachimori A, Yamada N, Sakate Y, et al. Up regulation of ICAM-1 gene expression inhibits tumour growth and liver metastasis in colorectal carcinoma. Eur J Cancer. 2005;41:1802-1810.

237. Huang WC, Chan ST, Yang TL, Tzeng CC, Chen CC. Inhibition of ICAM-1 gene expression, monocyte adhesion and cancer cell invasion by targeting IKK complex: molecular and functional study of novel alpha-methylene-gamma-butyrolactone derivatives. Carcinogenesis. 2004;25:19251934.

238. Rosette C, Roth RB, Oeth P, et al. Role of ICAM1 in invasion of human breast cancer cells. Carcinogenesis. 2005;26:943-950.

239. Natali PG, Hamby CV, Felding-Habermann B, et al. Clinical significance of alpha(v)beta3 integrin and intercellular adhesion molecule-1 expression in cutaneous malignant melanoma lesions. Cancer Res. 1997;57:1554-1560.

240. Lin YC, Shun CT, Wu MS, Chen CC. A novel anticancer effect of thalidomide: inhibition of intercellular adhesion molecule-1-mediated cell invasion and metastasis through suppression of nuclear factor-kappaB. Clin Cancer Res. 2006;12:7165-7173. 


\section{Chapter 3}

\section{Proliferating endothelial cells and leukocyte infiltration are related prognostic markers in colorectal cancer}

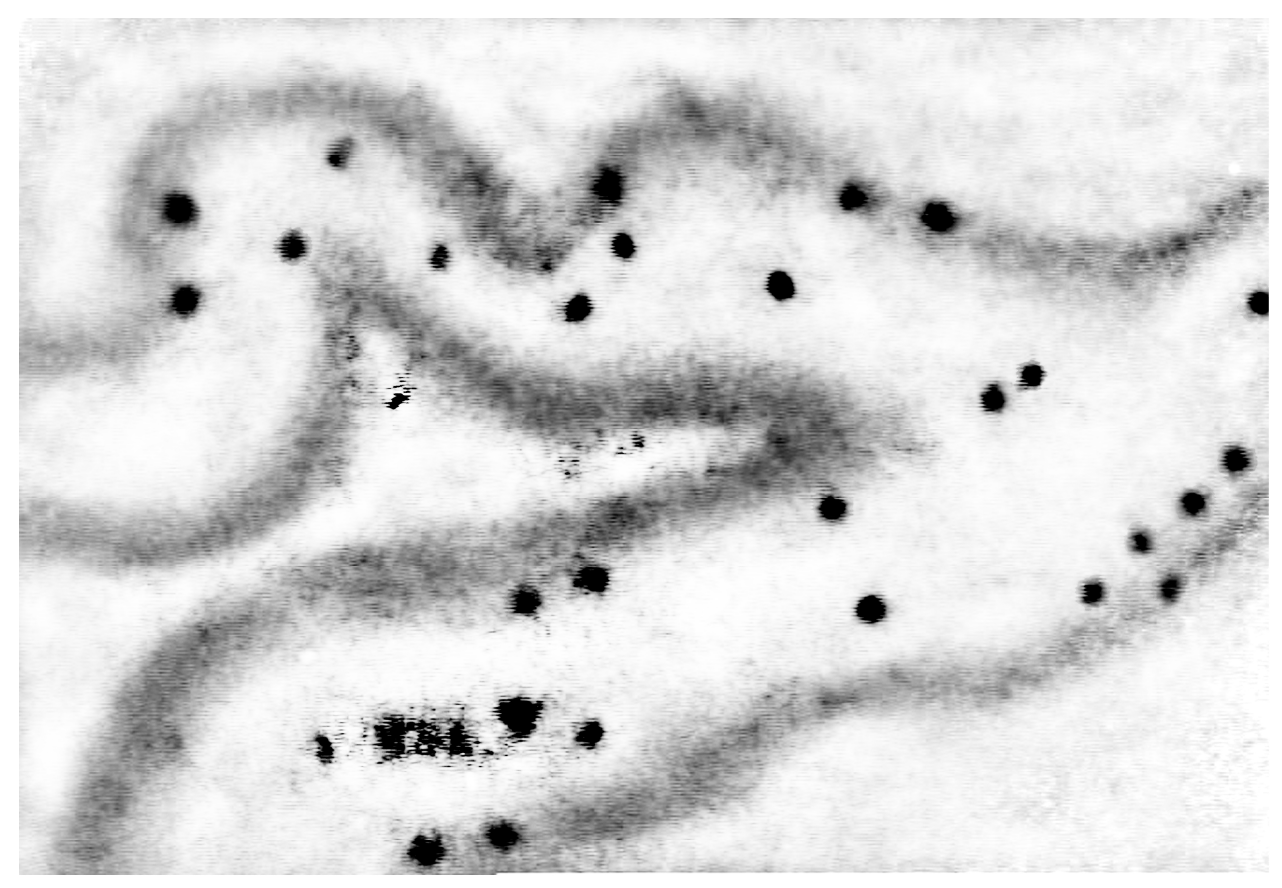

Coen I.M. Baeten, Karolien Castermans, Harry F.P. Hillen \& Arjan W. Griffioen

Clin Gastroenterol Hepatol. 2006 Nov;4(11):1351-7. 


\section{Abstract}

We aimed to retrospectively investigate the angiogenic potential in archival colorectal carcinoma (CRC) tissues and its relationship to amount and composition of the inflammatory infiltrate. In tumor tissues of 117 CRC patients with a 12 year follow-up, microvessel density (MVD) and proliferating endothelial cells (EC) were assessed by CD31/CD34 double staining with the proliferation marker Ki-67. Leukocyte infiltration was determined using CD45, CD3, CD8, CD16, CD20 and CD68 antibodies in peritumoral, tumor stroma and intratumoral areas. The number of proliferating ECs, but not MVD, is correlated to Dukes stage and survival in CRC $(\mathrm{p}<0.05)$. This parameter correlated significantly with the expression of vascular endothelial growth factor $(r=0.82 ; \mathrm{p}<0.012)$. The number of inflammatory cells in the tumor stroma, and cells infiltrated into the tumor cell nests, but not of peritumoral leukocytes, predicted patient survival. This was most obvious for $\mathrm{T}$ lymphocytes $(\mathrm{CD} 3 ; \mathrm{p}<0.05)$ and polymorphonuclear cells $(\mathrm{CD} 16 ; \mathrm{p}<0.04)$. We found a significant relationship between angiogenesis parameters and infiltrated leukocytes $(\mathrm{r}=-0.70 ; \mathrm{p}<0.02)$. Combination of high numbers of infiltrated leukocytes and low amounts of proliferating ECs demonstrated to be an improved prognostic value compared to either parameter alone $(p<0.006)$. These findings have a potential impact on therapeutic applications for both anti-angiogenesis as well as immunotherapy. 


\section{Introduction}

Colorectal cancer (CRC) is a common form of cancer in Western countries. The best available prognostic indicator of CRC is tumor stage, based on the Dukes classification, but this is not sufficient to predict the outcome of disease accurately. Several other parameters have been proposed to improve prognostic criteria, among which are angiogenic potential and infiltration by inflammatory cells ${ }^{1-3}$. Since it is now evident that these two phenomena are interrelated, the current study was performed to assess the value of both phenomena for the prognosis in CRC.

Angiogenesis is essential for tumor growth and metastasis, and is regulated by tumor cells through the production of pro-angiogenic factors such as vascular endothelial cell (EC) growth factors (VEGFs) and fibroblast growth factors (FGFs), and angiostatic factors such as platelet factor-4, thrombospondin-1, angiostatin and endostatin 4,5. Measurement of angiogenesis is commonly performed by the assessment of microvessel density (MVD) ${ }^{6}$. This parameter is controversial since it might not be a reliable indicator of ongoing angiogenesis. It has been suggested that angiogenesis is best evaluated through detection of proliferating ECs ${ }^{7}$.

The presence of immune cells in tumors is generally seen as a favorable prognostic parameter. This is evident for leukocyte subsets, including Tlymphocytes, PMNs and macrophages 8-12. However, for tumor associated macrophages adverse effects have been described 13,14. Tumor infiltration by leukocytes is regulated by a number of inflammatory cytokines, the combination of which presumably determines amount and composition of the infiltrate. In addition, infiltration is also affected by regulators of angiogenesis. Both inhibitory and stimulatory effects were found for VEGF and other angiogenic growth factors during angiogenesis ${ }^{15-17}$. In the current study, a large set of archival CRC tumor samples, for which a 12-year clinical follow-up was available, was analyzed for angiogenesis parameters and leukocyte infiltration. We show that angiogenesis and leukocyte infiltration are interrelated. Several leukocyte subsets as well as proliferating ECs are prognostic factors in colorectal cancer.

\section{Materials and Methods}

\section{Patients and tissues}

Tumor tissues from 117 patients diagnosed with colorectal cancer (CRC) between 1979 and 1982 were collected from the tissue bank of the Department of Pathology, 
Maastricht University, and used for these studies. The tissues were form patients that were enrolled in two independent studies, one of which was a study on the beneficial effect of 'no-touch' surgery, and one was a study on impact of preoperative radiotherapy ${ }^{18,19}$. For all patients clinical follow up was at least 12 years.

The mean age of the patient group $(n=117)$ at time of diagnosis was 68.1 years (range 29-87) and the mean overall survival time of the total patient population was 5.8 years (range 0.1-12.8). The mean tumor diameter was $46.3 \mathrm{~mm}$ (range 5-120). Other patient data are summarized in Table 3.1.

Table 3.1. Clinical data on the 117 CRC patients

\begin{tabular}{llccc}
\hline & & \# of patients & \% of group & tumor size $(\mathrm{mm})$ \\
\hline Gender & male & 59 & 50,4 & \\
& female & 58 & 49,6 & 47 \\
Dukes stage & & & \\
& A & 2 & 2 & 35 \\
& B & 72 & 62 & 49 \\
C & 32 & 27 & 44 \\
D & 11 & 9 & 38 \\
Primary location & & & 52 \\
& ascending colon & 18 & 15 & 45 \\
transverse colon & 16 & 14 & 42 \\
descending colon & 32 & 27 & 41 \\
rectosigmoid & 47 & 40 & 48 \\
unknown & 8 & 8 & 44 \\
\hline
\end{tabular}

a Recurrence or metastasis within follow up period of 12 years

\section{Immunohistochemistry}

Adjacent serial sections of $4 \mu \mathrm{m}$ were made from the 117 paraffin embedded colon tumor tissues. The sections were put on organosilane coated object slides (Starfrost, Germany) and air-dried for 48 hours at room temperature. After rehydration, endogenous peroxidase was blocked by incubation in $0.3 \% \mathrm{H}_{2} \mathrm{O}_{2}$ in methanol for 30 minutes. The slides were microwaved for 10 minutes in citrate buffer ( $\mathrm{pH}$ 6.0) and cooled down for 30 minutes. After rinsing with PBS, the slides were blocked for non-specific antibody binding with 5\% BSA in PBS. Primary antibodies polyclonal rabbit anti-human Ki-67 (NeoMarker, Freemont, CA.;1:200), and monoclonal antibodies to CD3 (1:50, DAKO, Glostrup, Denmark), CD8 (1:100, Novocastra, Valkenswaard, the Netherlands), CD16 (1:50, NeoMarker), CD20 (1:1000, DAKO), CD68 (1:100, DAKO) and VEGF (1:100 Santa Cruz, CA) were properly diluted and applied on the sections for a 1 hour incubation at room temperature. 
After washing with PBS, the slides were incubated in polyclonal biotin-labeled swine anti-rabbit IgG (DAKO) or rabbit anti-mouse Ig (DAKO) for 30 minutes. After a subsequent incubation with avidine-biotin complex HRP (DAKO) for 30 minutes, the slides were developed with diaminobenzidine (DAB, Sigma, Zwijndrecht, the Netherlands).

The slides were either counterstained with haematoxylin (Merck, Darmstadt, Germany) or incubated for 1 hour with a secondary cocktail of primary CD31 (1:100) and CD34 (1:50, DAKO, Monosan; QBEND-10) antibodies against ECs. After washing with PBS the slides were incubated in biotin-labelled Goat anti mouse IgG (DAKO, Glostrup, Denmark) for 1/2 hour. After incubation with avidine-biotin complex AP (DAKO) for 30 minutes, the slides were developed with alkaline phosphatase substrate KIT III (Vector Laboraties, Inc., Burlingame, CA). After treatment of the slides with insulmount to protect alkaline phsphatase from bleaching, the slides were mounted in entellan (Merck).

\section{Analysis}

MVD was assessed as described previously by two independent observers in four randomly selected high power fields (200x), the results are shown as number of vessels/ $\mathrm{mm}^{2}{ }^{20}$. Next to angiogenesis measurement by MVD, ongoing angiogenesis by proliferating ECs was determined in the same four randomly chosen fields and presented as the number of proliferating $\mathrm{EC} / \mathrm{mm}^{2}$.

To differentiate between location of leukocyte infiltration, we enumerated stained leukocytes (i) in peritumoral areas outside the tumor but directly at the tumor host interface, (ii) in areas of tumor stroma, and (iii) as infiltrated into the nests of tumor cells (referred to as 'intratumoral'), directly in contact with the tumor cells. All leukocyte subsets were determined in all three areas by counting in four randomly chosen fields. Peritumoral leukocytes were scored at low magnification (40x) and ranged from 0 (absent) to 4 (heavy) infiltration ( $0=$ no infiltration, $1=<1 \%$ of the cells, 2 = between 1 and $5 \%$ of cells, $3=$ between $5 \%$ and $20 \%, 4=>20 \%$ of cells). Similar procedure (0-4 range) was used for stromal leukocyte infiltration, at 100x magnification. Intratumoral leukocyte infiltration, leukocytes in direct contact with tumor cells, was scored at 200x magnification. Data and presented as the number of leukocytes $/ \mathrm{mm}^{2}$.

\section{Statistical analysis}

All statistical analysis was done with SPSS software. We used Mann-Whitney, student's-T, Pearson, Spearman, Log Rank tests, results were considered statistically significant when $\mathrm{p}<0,05$. 


\section{Results}

The number of proliferating endothelial cells but not microvessel density (MVD) is a prognostic factor in $C R C$

Microvessel density (MVD) was measured in 117 CRC tissue samples. MVD did neither correlate with grade/differentiation, size or localization, Dukes stage of the tumor (Figure 3.1A). Measurement of the number of proliferating endothelial cells (EC), a parameter that presumably reflects ongoing angiogenesis 7 , did result in a significant correlation with Dukes stage (Spearman's rho test; $\mathrm{p}<0.05$, Figure 3.1B). For reference, two tissues with equivalent MVD levels but with largely differing numbers of proliferating ECs are shown (Figure 3.1C and D). Correlations of proliferating ECs with tumor grade/differentiation, size or localization were not found (data not shown). Next to these vascular parameters, the expression of vascular endothelial cell growth factor (VEGF) was assessed immunohistochemically. High expression of VEGF correlated with the presence of proliferating ECs ( $r=0.82$; $\mathrm{p}<0.012$, Figure 3.1E) but not with MVD, supporting the fact that the number of proliferating ECs reflects ongoing angiogenesis better than MVD. The amount of proliferating ECs also strongly correlated with the number of proliferating tumor cells $(\mathrm{r}=0.56 ; \mathrm{p}<0.001)$, suggesting that rapid tumor cell turnover is associated with a higher angiogenic potential.
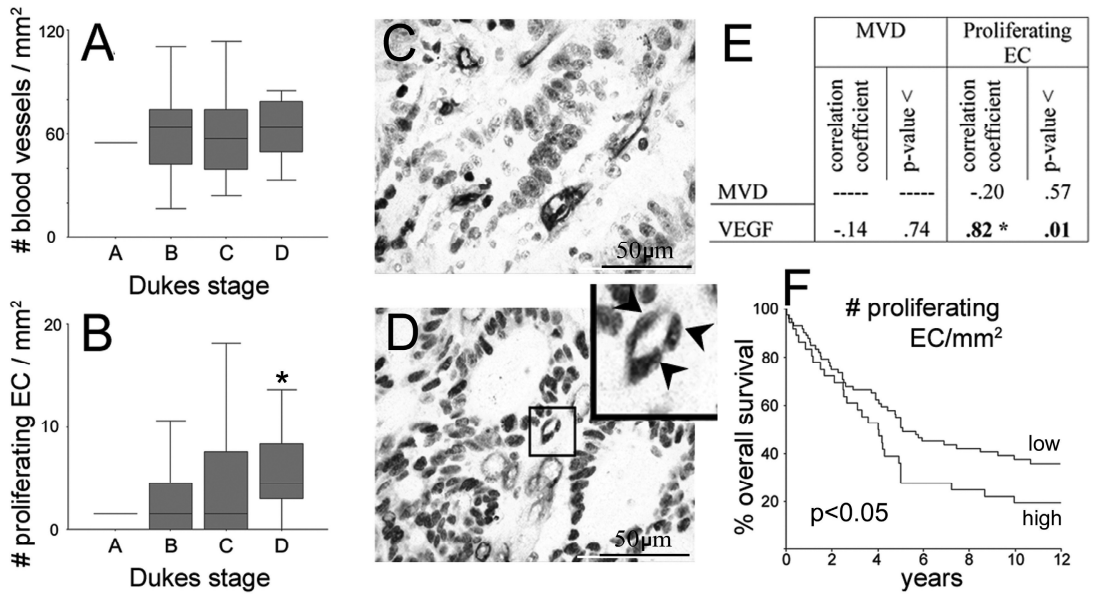

Figure 3.1. Angiogenic parameters in CRC. Relationship between MVD (A) and proliferating ECs (B) to Dukes stage $\left({ }^{*}\right.$ respresents statistical difference from Dukes B value, $\left.p<0.05\right)$. C, D) CD31/34 (blue) and ki-67 (brown) double staining of CRC tissues. Note the higher amount of proliferating ECs in figure D as compared with C, whereas equivalent amounts of bloodvessels are present (scalebars $50 \mu \mathrm{m}$ ). E) Correlation (and significance) between VEGF, MVD and proliferating ECs. F) The Kaplan Meier curve is shown for patients with proliferating ECs above or below the mean value. A significantly favorable prognosis is found in patients with lower counts of proliferating ECs (Log Rank: $p<0.05)$. 
Table 3.2. Quantification and composition of the leukocyte infiltrate for the different Dukes stages.

\begin{tabular}{lcccc}
\hline Dukes stage & Ac & B & C & D \\
\hline CD45 a & 7 & 10.7 & 6.19 & 3.64 \\
\hline CD3 ${ }^{\text {b }}$ & $0 \%$ & $31 \%$ & $22 \%$ & $31 \%$ \\
CD8 ${ }^{\text {b }}$ & $57 \%$ & $6 \%$ & $7 \%$ & $16 \%$ \\
CD16 & $11 \%$ & $20 \%$ & $19 \%$ & $16 \%$ \\
CD20 & $0 \%$ & $1 \%$ & $2 \%$ & $3 \%$ \\
CD68 & $60 \%$ & $38 \%$ & $68 \%$ & $43 \%$ \\
\hline
\end{tabular}

${ }^{a}$ number of leukocytes infiltrated between the tumor cells (intratumoral) CD45 cells $/ \mathrm{mm}^{2} .{ }^{\mathrm{b}}$ amount of leukocytes in the indicated subsets as percentage of $\mathrm{CD} 45^{+}$cells. ${ }^{\mathrm{c}}$ values for Dukes A staged tumors between brackets because this subgroup only represents 2 cases.

To determine the prognostic value of the angiogenesis parameters, patients were divided into groups with high and low numbers of proliferating cells and MVD. With a cut off point at 3.6 proliferating $\mathrm{EC} / \mathrm{mm}^{2}$ (mean value), this parameter already showed a favorable 5-year survival rate of $48 \%$ in patients with low numbers of proliferating ECs (versus $29 \%$ in patients with high numbers of proliferating ECs; $\mathrm{p}<0.05$, Figure $3.1 \mathrm{~F}$ ). This observation extended over a period up to 12 years where these values were $37 \%$ and $20 \%$, respectively. Classification in high or low MVD (cut off point, mean value; 61.1 blood vessels/ $\mathrm{mm}^{2}$ ) measurements did not show differences in survival ( $p<0.52$, not shown).
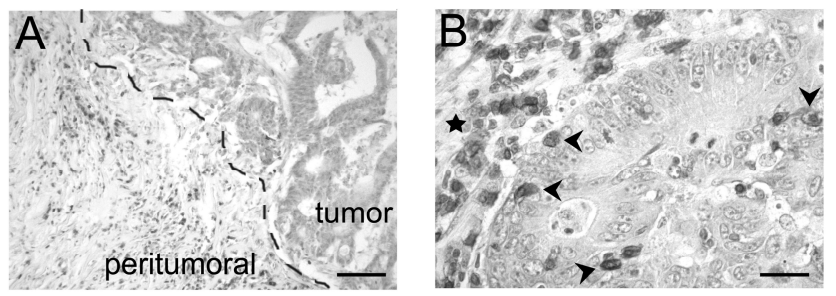

Figure 3.2. Leukocyte infiltration in CRC. A) CD45 staining of a Dukes B staged tumor at the tumor host interface, showing the intense infiltration by leukocytes in the peritumoral area. The dashed line indicates the tumor border. Scale bar represents $100 \mu \mathrm{m}$. B) A higher magnification of a Dukes B staged tumor at an intratumoral area, indicating the difference between leukocyte infiltration in the tumor stroma and in between the tumor cell nests. Stromal leukocytes area is marked by arrow heads and leukocytes infiltration between the tumor cells is marked with arrows. Scalebar represents $20 \mu \mathrm{m}$.

Intratumoral leukocyte infiltration is a prognostic factor in CRC

To investigate the patterns of leukocyte infiltration, all tissues were stained for CD45 (pan-leukocyte), CD3 (T lymphocytes), CD8 (cytotoxic T cells), CD16 (PMNs), CD20 (B lymphocytes) and CD68 (macrophages). We counted the number of these subsets in the peritumoral-, stromal- and intratumoral areas. In all three areas the composition of the inflammatory infiltrate was comparable, with a major 
representation of macrophages and PMNs (Table 3.2). There were no apparent correlations between the extent and type of leukocyte infiltration. In $35 \%$ of the samples peritumoral areas were found to be heavily infiltrated by leukocytes. This infiltration was present in a patchy pattern. No significant correlation was found between the amount of peritumoral infiltration and grade/differentiation, size, localization, Dukes stage or survival (not shown).

Leukocyte infiltration within the tumor was found in all CRC samples. Most of these leukocytes were present in the tumor stroma, while in $50 \%$ of samples also intratumoral infiltrating leukocytes were detected (Figure 3.2). The amount of stromal and intratumoral leukocytes are highly correlated (CD3, $\mathrm{r}=0.74$; $\mathrm{CD} 8, \mathrm{r}=0.70 ; \mathrm{CD} 16, \mathrm{r}=0.71 ; \mathrm{CD} 20, \mathrm{r}=0.60 ; \mathrm{CD} 68, \mathrm{r}=0.39, \mathrm{p}<0.001$ for all subsets).
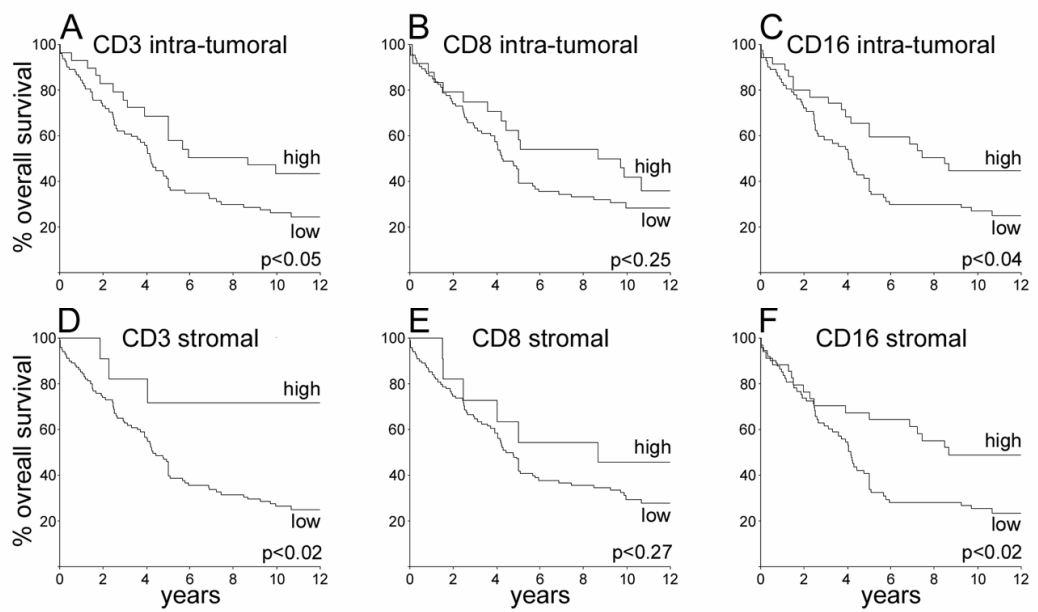

Figure 3.3. Relationship between leukocyte infiltration and patient survival. Kaplan Meier curves of patient groups separated on basis of high or low infiltration by CD3, CD8 and CD16 leukocyte subsets. Curves represent leukocyte counts areas within the tumors. Panels A-C) represent leukocyte counts within the tumor cell nests in CRC, whereas panels D-F) represent leukocyte scores in the stroma of CRC. Significance was assessed by Log Rank tests.

Intratumoral leukocyte infiltration, as assessed by CD45 staining, decreased with Dukes stage. The pattern of leukocyte subsets in the infiltrate was similar for the Dukes stages (Table 3.2). The correlation between the number of intratumoral leukocytes and Dukes stages suggested a relationship with survival. Kaplan-Meier curves indeed show that there is a significant difference in survival between subgroups with high and low leukocyte infiltration levels for both CD3 $(\mathrm{p}<0.05)$ and CD16 ( $<<0.04$ )(Figure 3.3A and C). For CD8 (Figure 3.3B) and CD20 (data not shown) only a trend to significant difference was observed. In contrast, CD68 showed no correlation with survival or clinical parameters. Due to the high correlation between stromal and intratumoral leukocyte populations (see above), 
similar relationships were found for the presence of stromal leukocytes. Also the Kaplan-Meier curves show significant results when the patient groups is separated on basis of leukocyte subsets in CRC stroma (Figure 3.3D-F).

\section{Relationship between angiogenesis and leukocyte infiltration}

We previously described that ongoing angiogenesis in tumors prevents the infiltration of leukocytes ${ }^{1,15}$. We investigated whether this process is present in the human CRC tissues. As shown in Figure 3.1E, ongoing angiogenesis as measured by proliferating EC is correlated with the expression of VEGF, suggesting a causal relationship. We found that both the number of proliferating ECs and the expression of VEGF correlated inversely with the number of infiltrated leukocytes as measured by CD45 (proliferating ECs $\mathrm{r}=-0.7$, $\mathrm{p}<0.024$; VEGF $\mathrm{r}=-0.431, \mathrm{p}<0.05$ ). Kaplan-Meier survival analysis of patient groups separated by both parameters into 4 groups (Figure 3.4), led to a markedly increased 5-year survival of $62 \%$ in the group with low number of proliferating ECs and dense leukocyte infiltration, versus $18 \%$ in the group with high numbers of proliferating ECs and low infiltration, $\mathrm{p}<0.0061)$. This result extended over the period up to 12 years $(p<0.0067)$. This result indicates that ongoing angiogenesis and leukocyte infiltration are related, and that the combination of these two parameters as a prognostic factor is a more reliable predictor of survival.
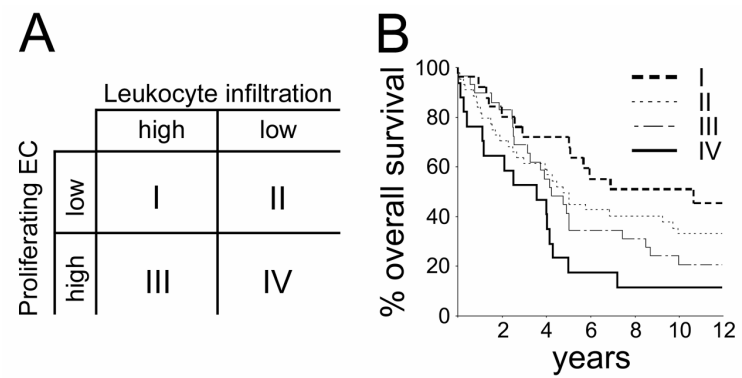

Figure 3.4. Improved survival by combining leukocyte infiltration and angiogenesis parameters. A) The patient group divided according to both leukocyte infiltration and proliferating ECs into 4 groups. B) Kaplan Meier survival curves of the patient groups as defined in panel A. Five-year survival is best in the group with high numbers of infiltrated leukocytes and low numbers of prolife-rating ECs (group I) and worst in the group with low numbers of infiltrated leukocytes and high numbers of proliferating ECs (group IV, p<0.0061).

\section{Discussion}

Several earlier studies report on the prognostic value of angiogenic parameters in colorectal cancer (CRC). Since it has been described frequently to associate with 
prognosis and clinical outcome in many tumor types, microvessel density was assessed in most of these studies. Interestingly, although several studies do report a prognostic value for vessel density ${ }^{11,21-23}$, a relatively (as compared to studies in e.g. breast- and lung carcinoma) large percentage of studies reported the absence of any prognostic value for microvessel density $24-27$, or even an inverse relationship ${ }^{28,29}$. In all these studies different immunohistochemical protocols were used to identify microvessels, including detection with CD31 11,30, CD34 ${ }^{31}$, Factor VIII related peptide von Willebrand factor ${ }^{9}$, or CD105 ${ }^{32}$. Independent on the detecting antibody, these studies report that a prognostic value of microvessel density is or is not present. It is therefore questioned whether vessel density is a measure of angiogenesis. Indeed, other studies report on alternative angiogenesis parameters that do predict patient outcome, such as expression of angiogenic growth factors ${ }^{33,34}$ or angiogenesis inhibitors ${ }^{35}$, color Doppler vascularity index ${ }^{36}$ or MR imaging 37,38. These parameters are supposedly more physiological measurements and therefore more reliable indicators of functional vascularity or ongoing angiogenesis. In the current study, we have measured ongoing angiogenesis in CRC by enumerating the number of proliferating endothelial cells (EC) in sections double stained for endothelium with both CD31 and CD34 antibodies, which we found to stain all ECs in CRC, and Ki-67, a proliferation marker. We show that the number of proliferating ECs (positively correlated to the expression of VEGF and thus to ongoing angiogenesis), but not microvessel density, is correlated with Dukes stage. Only in a few studies a patient follow-up was available to report on survival characteristics 11,30,31. For the patient group of our study a 12-year follow-up was available, which made a meaningful correlation to survival possible. We found that a high number of proliferating ECs predicts shorter survival.

Next to proliferating ECs we also found that leukocyte infiltration is a prognostic factor in CRC. We studied the presence of inflammatory cells along the invasive margin (tumor-host interface) as well as intratumorally in the cancer stroma and infiltrated into the cancer cell nests. We found that the number of infiltrated T lymphocytes as well as PMNs displayed a significant impact on prognosis and survival. In contrast, we did not determine a significant relationship between the amount of peritumoral infiltrate and clinical outcome.

Inflammatory infiltrate is generally interpreted as an indication of the host's immune reponse against the tumor. Most studies report on leukocyte infiltrate as a whole or as single subsets of T lymphocytes ${ }^{39}, \mathrm{CD} 4+\mathrm{T}$ cells ${ }^{40}, \mathrm{CD} 8+$ T cells ${ }^{41}$, PMN/natural killer cells 9,42 , eosinophils ${ }^{43,44}$ or macrophages ${ }^{10}$, to have a favorable impact on prognosis.

Our finding indicated that intratumoral leukocytes have the most significant impact on patient survival as compared to those in the tumor 
periphery. This result confirms earlier data obtained from studies in CRC 8,41. These studies described that the beneficial effect of intratumoral $\mathrm{CD}^{+} \mathrm{T}$ cells becomes apparent after longer survival times. This made the authors hypothesize that the effect is mediated by suppression of distant micrometastases rather than suppression of growth of the primary tumor. Our study, having also a fairly long patient follow-up period, indicates a clear trend of a prognostic impact of $\mathrm{CD}^{+} \mathrm{T}$ cells. The fact that we see a larger effect on the total population of $\mathrm{T}$ lymphocytes, suggests that also by $\mathrm{CD}^{+} \mathrm{T}$ cells survival curves would indicate differences. This is very likely to be the case since it has been described that a reduction in $\mathrm{CD} 4^{+} \mathrm{T}$ lymphocyte infiltration in CRC, is associated with recurrence of disease, most likely due to lack of specific cytokine release ${ }^{40}$. We also found a significant correlation between the amount of PMNs and survival. This finding is interesting since these immune cells can be considered the first line of defence against cancer.

Infiltration of tumors by leukocytes also has been correlated with poor clinical outcome. These reports indicate that cancer can be caused or promoted by infectious agents that induce chronic inflammation ${ }^{40,45,46}$. Especially the role of tumor associated macrophages is controversial. Although several studies have indicated the beneficial effect on patient survival 10,12,47,48, other studies indicate that they play an active role in enhancing tumor progression and metastatic capacity through their ability to produce VEGF and chemokines to promote angiogenesis and tissue remodeling as well as to deliver direct effects on the tumor cells leading to growth and migration ${ }^{13,49-53}$. In the current study we did not even see a trend towards any correlations with patient data or survival. This may be due to the specific attraction of macrophages by tumor-produced chemoattractants, such as colony stimulating factor- 1 and CC chemokine ligand-2, which have been described to play an important role in infiltration of breast-, ovarian- and prostate cancer $51,54,55$.

Considering the results of the current study on angiogenic potential and leukocyte infiltration, we favor the view that these observations are interrelated. We have previously demonstrated that ongoing angiogenesis impairs leukocytevessel wall interactions, due to downregulation of vascular adhesion molecules or EC anergy to inflammatory signals ${ }^{2,15}$. Very recently we have reported on the inverse relationship between angiogenic potential and leukocyte infiltration. This study was carried out in breast carcinoma. We found that medullary breast carcinoma, which is heavily infiltrated by inflammatory cells, has a lower angiogenic profile, causing a higher vascular intercellular adhesion molecule-1 expression and is therefore heavily infiltrated by inflammatory cells. This in contrast to ductal breast cancer which is a highly angiogenic tumor ${ }^{1}$. We now show this inverse relationship in CRC.

In conclusion, the current study describes the impact of both angiogenic potential and leukocyte infiltration on the prognosis of CRC, in a large group of 
patients of which a 12-year follow-up was available. It is suggested that angiogenic potential is causally related to the formation of an inflammatory infiltrate, and should therefore both be used for the improvement of CRC prognosis.

\section{Acknowledgements}

Grant support: The current research was supported by a generous grant (to HFPH and $A W G$ ) from the Coenegracht Stichting

\section{References}

1. Bouma-ter Steege JC, Baeten CI, Thijssen VL, et al. Angiogenic profile of breast carcinoma determines leukocyte infiltration. Clin Cancer Res. 2004;10:7171-7178.

2. Dirkx AE, Oude Egbrink MG, Kuijpers MJ, et al. Tumor angiogenesis modulates leukocyte-vessel wall interactions in vivo by reducing endothelial adhesion molecule expression. Cancer Res. 2003;63:2322-2329.

3. Zhang L, Conejo-Garcia JR, Katsaros D, et al. Intratumoral $\mathrm{T}$ cells, recurrence, and survival in epithelial ovarian cancer. N Engl J Med. 2003;348:203-213.

4. Czubayko F, Liaudet-Coopman ED, Aigner A, Tuveson AT, Berchem GJ, Wellstein A. A secreted FGF-binding protein can serve as the angiogenic switch in human cancer. Nat Med. 1997;3:11371140.

5. Zheng S, Han MY, Xiao ZX, Peng JP, Dong Q. Clinical significance of vascular endothelial growth factor expression and neovascularization in colorectal carcinoma. World J Gastroenterol. 2003;9: 1227-1230.

6. Vermeulen PB, Gasparini G, Fox SB, et al. Quantification of angiogenesis in solid human tumours: an international consensus on the methodology and criteria of evaluation. Eur J Cancer. 1996;32A:2474-2484.

7. Vermeulen PB, Gasparini G, Fox SB, et al. Second international consensus on the methodology and criteria of evaluation of angiogenesis quantification in solid human tumours. Eur J Cancer. 2002;38:1564-1579.

8. Chiba T, Ohtani H, Mizoi T, et al. Intraepithelial CD8+ T-cell-count becomes a prognostic factor after a longer follow-up period in human colorectal carcinoma: possible association with suppression of micrometastasis. Br J Cancer. 2004;91:1711-1717.

9. Coca S, Perez-Piqueras J, Martinez D, et al. The prognostic significance of intratumoral natural killer cells in patients with colorectal carcinoma. Cancer. 1997;79:2320-2328.

10. Funada Y, Noguchi T, Kikuchi R, Takeno S, Uchida Y, Gabbert HE. Prognostic significance of CD8+ T cell and macrophage peritumoral infiltration in colorectal cancer. Oncol Rep. 2003;10:309313.

11. Giatromanolaki A, Stathopoulos GP, Tsiobanou E, et al. Combined role of tumor angiogenesis, bcl-2, and p53 expression in the prognosis of patients with colorectal carcinoma. Cancer. 1999;86:1421-1430.

12. Khorana AA, Ryan CK, Cox C, Eberly S, Sahasrabudhe DM. Vascular endothelial growth factor, CD68, and epidermal growth factor receptor expression and survival in patients with Stage II and Stage III colon carcinoma: a role for the host response in prognosis. Cancer. 2003;97:960-968. 
13. Leek RD, Lewis CE, Whitehouse R, Greenall M, Clarke J, Harris AL. Association of macrophage infiltration with angiogenesis and prognosis in invasive breast carcinoma. Cancer Res. 1996;56:4625-4629.

14. Lewis CE, Leek R, Harris A, McGee JO. Cytokine regulation of angiogenesis in breast cancer: the role of tumor-associated macrophages. J Leukoc Biol. 1995;57:747-751.

15. Griffioen AW, Damen CA, Blijham GH, Groenewegen G. Tumor angiogenesis is accompanied by a decreased inflammatory response of tumor-associated endothelium. Blood. 1996;88:667-673.

16. Kuzu I, Bicknell R, Fletcher CD, Gatter KC. Expression of adhesion molecules on the endothelium of normal tissue vessels and vascular tumors. Lab Invest. 1993;69:322-328.

17. Melder RJ, Koenig GC, Witwer BP, Safabakhsh N, Munn LL, Jain RK. During angiogenesis, vascular endothelial growth factor and basic fibroblast growth factor regulate natural killer cell adhesion to tumor endothelium. Nat Med. 1996;2:992-997.

18. de Bruine AP, Wiggers T, Beek C, et al. Endocrine cells in colorectal adenocarcinomas: incidence, hormone profile and prognostic relevance. Int J Cancer. 1993;54:765-771.

19. Wiggers T, Jeekel J, Arends JW, et al. No-touch isolation technique in colon cancer: a controlled prospective trial. Br J Surg. 1988;75:409-415.

20. Hillen HF, Hak LE, Joosten-Achjanie SR, Arends JW. Microvessel density in unknown primary tumors. Int J Cancer. 1997;74:81-85.

21. Bhatavdekar JM, Patel DD, Chikhlikar PR, et al. Overexpression of CD44: a useful independent predictor of prognosis in patients with colorectal carcinomas. Ann Surg Oncol. 1998;5:495-501.

22. Choi HJ, Hyun MS, Jung GJ, Kim SS, Hong SH. Tumor angiogenesis as a prognostic predictor in colorectal carcinoma with special reference to mode of metastasis and recurrence. Oncology. 1998;55:575-581.

23. Vermeulen PB, Verhoeven D, Hubens G, et al. Microvessel density, endothelial cell proliferation and tumour cell proliferation in human colorectal adenocarcinomas. Ann Oncol. 1995;6:59-64.

24. Akagi K, Ikeda Y, Sumiyoshi Y, et al. Estimation of angiogenesis with anti-CD105 immunostaining in the process of colorectal cancer development. Surgery. 2002;131:S109-113.

25. Bossi P, Viale G, Lee AK, Alfano R, Coggi G, Bosari S. Angiogenesis in colorectal tumors: microvessel quantitation in adenomas and carcinomas with clinicopathological correlations. Cancer Res. 1995;55:5049-5053.

26. Fox SH, Whalen GF, Sanders MM, et al. Angiogenesis in normal tissue adjacent to colon cancer. J Surg Oncol. 1998;69:230-234.

27. Pietra N, Sarli L, Caruana P, et al. Is tumour angiogenesis a prognostic factor in patients with colorectal cancer and no involved nodes? Eur J Surg. 2000;166:552-556.

28. Abdalla SA, Behzad F, Bsharah S, et al. Prognostic relevance of microvessel density in colorectal tumours. Oncol Rep. 1999;6:839-842.

29. Mooteri S, Rubin D, Leurgans S, Jakate S, Drab E, Saclarides T. Tumor angiogenesis in primary and metastatic colorectal cancers. Dis Colon Rectum. 1996;39:1073-1080.

30. Vermeulen PB, Van den Eynden GG, Huget P, et al. Prospective study of intratumoral microvessel density, p53 expression and survival in colorectal cancer. Br J Cancer. 1999;79:316-322.

31. Yoshimura H, Chikamoto A, Honda T, et al. Relationship between microvessel quantification and inducibility of endogenous tumor necrosis factor in colorectal adenocarcinoma. Anticancer Res. 2000;20:629-633.

32. Li C, Gardy R, Seon BK, et al. Both high intratumoral microvessel density determined using CD105 antibody and elevated plasma levels of CD105 in colorectal cancer patients correlate with poor prognosis. Br J Cancer. 2003;88:1424-1431.

33. Kaio E, Tanaka S, Oka S, et al. Clinical significance of thrombospondin-1 expression in relation to vascular endothelial growth factor and interleukin-10 expression at the deepest invasive tumor site of advanced colorectal carcinoma. Int J Oncol. 2003;23:901-911.

34. Saito S, Tsuno N, Nagawa H, et al. Expression of platelet-derived endothelial cell growth factor correlates with good prognosis in patients with colorectal carcinoma. Cancer. 2000;88:42-49. 
35. Maeda K, Nishiguchi $\mathrm{Y}$, Kang SM, et al. Expression of thrombospondin-1 inversely correlated with tumor vascularity and hematogenous metastasis in colon cancer. Oncol Rep. 2001;8:763-766.

36. Chen CN, Cheng YM, Liang JT, et al. Color Doppler vascularity index can predict distant metastasis and survival in colon cancer patients. Cancer Res. 2000;60:2892-2897.

37. de Lussanet QG, Backes WH, Griffioen AW, van Engelshoven JM, Beets-Tan RG. Gadopentetate dimeglumine versus ultrasmall superparamagnetic iron oxide for dynamic contrast-enhanced MR imaging of tumor angiogenesis in human colon carcinoma in mice. Radiology. 2003;229:429-438.

38. Tuncbilek N, Karakas HM, Altaner S. Dynamic MRI in indirect estimation of microvessel density, histologic grade, and prognosis in colorectal adenocarcinomas. Abdom Imaging. 2004;29:166-172.

39. Prall F, Duhrkop T, Weirich V, et al. Prognostic role of CD8+ tumor-infiltrating lymphocytes in stage III colorectal cancer with and without microsatellite instability. Hum Pathol. 2004;35:808-816.

40. Ali AA, McMillan DC, Matalka, II, McNicol AM, McArdle CS. Tumour T-lymphocyte subset infiltration and tumour recurrence following curative resection for colorectal cancer. Eur J Surg Oncol. 2004;30:292-295.

41. Naito $\mathrm{Y}$, Saito $\mathrm{K}$, Shiiba $\mathrm{K}$, et al. CD8+ T cells infiltrated within cancer cell nests as a prognostic factor in human colorectal cancer. Cancer Res. 1998;58:3491-3494.

42. Balch CM, Riley LB, Bae YJ, et al. Patterns of human tumor-infiltrating lymphocytes in 120 human cancers. Arch Surg. 1990;125:200-205.

43. Fernandez-Acenero MJ, Galindo-Gallego M, Sanz J, Aljama A. Prognostic influence of tumorassociated eosinophilic infiltrate in colorectal carcinoma. Cancer. 2000;88:1544-1548.

44. Pretlow TP, Keith EF, Cryar AK, et al. Eosinophil infiltration of human colonic carcinomas as a prognostic indicator. Cancer Res. 1983;43:2997-3000.

45. Coussens LM, Werb Z. Inflammatory cells and cancer: think different! J Exp Med. 2001;193:F23-26.

46. Coussens LM, Werb Z. Inflammation and cancer. Nature. 2002;420:860-867.

47. Migita T, Sato E, Saito K, et al. Differing expression of MMPs-1 and -9 and urokinase receptor between diffuse- and intestinal-type gastric carcinoma. Int J Cancer. 1999;84:74-79.

48. Shimura S, Yang G, Ebara S, Wheeler TM, Frolov A, Thompson TC. Reduced infiltration of tumorassociated macrophages in human prostate cancer: association with cancer progression. Cancer Res. 2000;60:5857-5861.

49. Fujimoto J, Sakaguchi H, Aoki I, Tamaya T. Clinical implications of expression of interleukin 8 related to angiogenesis in uterine cervical cancers. Cancer Res. 2000;60:2632-2635.

50. Lee AH, Happerfield LC, Bobrow LG, Millis RR. Angiogenesis and inflammation in invasive carcinoma of the breast. J Clin Pathol. 1997;50:669-673.

51. Lin EY, Pollard JW. Role of infiltrated leucocytes in tumour growth and spread. Br J Cancer. 2004;90:2053-2058.

52. Salvesen HB, Akslen LA. Significance of tumour-associated macrophages, vascular endothelial growth factor and thrombospondin-1 expression for tumour angiogenesis and prognosis in endometrial carcinomas. Int J Cancer. 1999;84:538-543.

53. Torisu $\mathrm{H}$, Ono $\mathrm{M}$, Kiryu $\mathrm{H}$, et al. Macrophage infiltration correlates with tumor stage and angiogenesis in human malignant melanoma: possible involvement of TNFalpha and IL-1alpha. Int J Cancer. 2000;85:182-188.

54. Lin EY, Gouon-Evans V, Nguyen AV, Pollard JW. The macrophage growth factor CSF-1 in mammary gland development and tumor progression. J Mammary Gland Biol Neoplasia. 2002;7:147-162.

55. Ueno T, Toi M, Saji H, et al. Significance of macrophage chemoattractant protein-1 in macrophage recruitment, angiogenesis, and survival in human breast cancer. Clin Cancer Res. 2000;6:32823289. 


\section{Chapter 4}

\section{Anti-angiogenesis therapy can overcome endothelial cell anergy and promote leukocyte-endothelium interactions and infiltration in tumors}

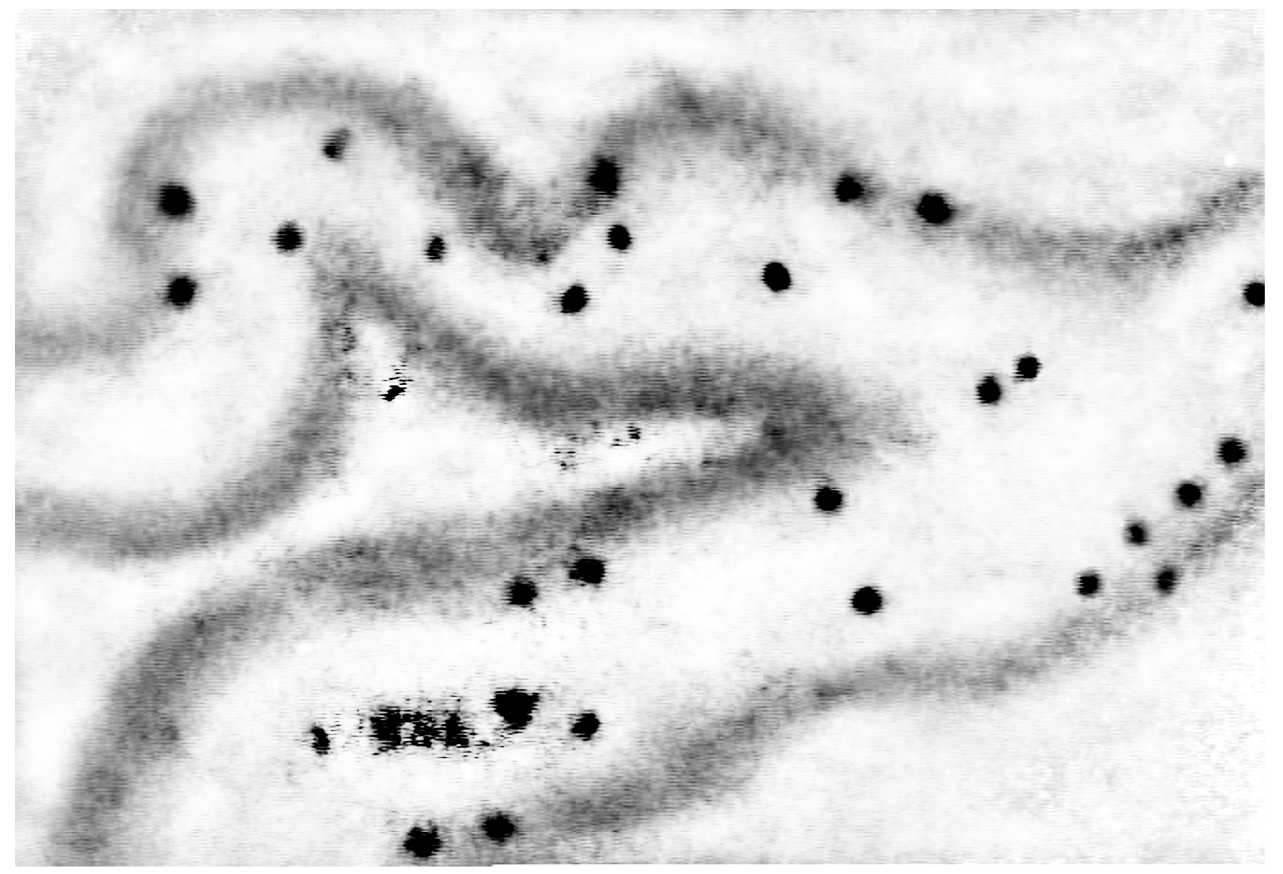

Anita E.M. Dirkx, Mirjam G.A. oude Egbrink, Karolien Castermans, Daisy W.J. van der Schaft, Victor L.J.L. Thijssen, Ruud P.M. Dings, Lucy Kwee, Kevin H. Mayo, John Wagstaff, Jessica C.A. Bouma-ter Steege, and Arjan W. Griffioen

FASEB J. 2006 Apr;20(6):621-30 


\begin{abstract}
Tumor escape from immunity, as well as the failure of several anti-cancer vaccination and cellular immunotherapy approaches, is suggested to be due to the angiogenesis mediated suppression of endothelial cell (EC) adhesion molecules involved in leukocyte-vessel wall interactions. We hypothesized that inhibition of angiogenesis would overcome this escape from immunity. We investigated this in vivo by means of intravital microscopy and ex vivo by immunohistochemistry in two mouse tumor models. The angiogenesis inhibitors anginex, endostatin and angiostatin, and also the chemotherapeutic agent paclitaxel were found to significantly stimulate leukocyte-vessel wall interactions by circumvention of EC anergy in vivo, i.e. by the upregulation of endothelial adhesion molecules in tumor vessels. This was confirmed by in vitro studies on cultured EC at the protein and mRNA levels. The new angiostatic designer peptide anginex was most potent at overcoming EC anergy; the enhanced leukocyte-vessel interactions led to an increase in the numbers of tumor infiltrating leukocytes. While anginex inhibited tumor growth and microvessel density (MVD) significantly, the amount of infiltrated leukocytes (CD45), as well as the number of $\mathrm{CD}^{+}$cytotoxic $\mathrm{T}$ lymphocytes, was enhanced markedly. The current results suggest that immunotherapy strategies can be improved by combination with antiangiogenesis.
\end{abstract}




\section{Introduction}

Over the last decades, immuno-directed anti-tumor strategies, based on adoptiveor vaccination approaches, have been developed 1,2. This approach has not been as effective as had been anticipated. Several explanations for this have been put forward. Firstly, most vaccines have been directed towards stimulating cytotoxic T-lymphocyte (CD8) responses and the continuous stimulation of these cells without T-cell help (CD4) eventually leads to anergy and tumor escape. Secondly, regulatory host T-cell responses may counteract induced immunity. Thirdly, the antigens towards which the immunity is directed are not tumor-specific enough. An alternative explanation might be that although immune effector cells are being generated in vivo, they are unable to migrate into tumor sites and therefore cannot exert an anti-tumor effect.

Angiogenesis, a pivotal process in the outgrowth and metastasis of tumors ${ }^{3-5}$, has been described to be involved in the escape of tumors from immune surveillance. We and others have previously shown that tumor EC have a suppressed expression of adhesion molecules (EC anergy ${ }^{6}$ ), such as intercellular adhesion molecule-1/-2 (ICAM-1/-2), vascular endothelial cell adhesion molecule-1 (VCAM-1) and CD34 7-9, due to exposure to angiogenic factors such as vascular EC growth factors (VEGFs) and fibroblast growth factors (FGFs) ${ }^{6,10,11}$. We have recently demonstrated in several mouse tumor models that tumors indeed inhibit leukocyte-vessel wall interactions by downregulation of vascular adhesion molecules ${ }^{12}$.

The role of angiogenesis in anti-tumor immunity is an emerging theme in both angiogenesis and immunology research fields. This is exemplified by recent studies on the major prognostic value of T-lymphocyte infiltration in tumors and the relationship with expression of angiogenic factors ${ }^{13}$, immunization against angiogenesis related proteins ${ }^{14,15}$ and ECs as vaccines ${ }^{16}$. In this study, we use several angiostatic molecules to demonstrate that angiogenesis inhibition can be a way to increase leukocyte-vessel wall interactions and subsequent infiltration. Anginex is a designed 33-mer peptide angiogenesis inhibitor that inhibits vasculature formation by induction of apoptosis in endothelial cells 17,18 . Angiostatin and endostatin are two other angiogenesis inhibitors with a direct effect on endothelial cells ${ }^{19-21}$. TNP-470 was described in the early 90 s as an angiostatic derivative of the fungus antibiotic fumagillin 22,23. Also several chemotherapeutic agents with claimed angiostatic activity ${ }^{24}$ such as paclicatxel and cyclophosphamide were included in these studies. It is suggested that the stimulating effect of angiogenesis inhibition on leukocyte-vessel wall interactions may be applicable for the improvement of various immunotherapy approaches. 


\section{Methods}

\section{Cell culture}

Human LS174T colon carcinoma cells were grown in DMEM (Life Technologies, Paisley, Scotland), supplemented with $10 \%$ fetal calf serum (FCS, Bio Whittaker, Verviers, Belgium), 1\% glutamin. Mouse B16F10 melanoma cells (kindly provided by dr. J. Fidler, Houston, Texas) were cultured using Hank's MEM (Life Technologies, Paisley, Scotland) containing 5\% FCS, 1\% non-essential amino acids (Life Technologies), 1\% sodium pyruvate (Life Technologies), 1.5 \% MEM vitamins (Life Technologies), and 2\% sodium bicarbonate (Life Technologies).

Mouse b.END5 brain endothelioma cells (obtained from ECACC, Salisbury, United Kingdom) were cultured in Dulbecco's MEM (Life Technologies) containing 10\% FCS, 1\% glutamine (Life Technologies, Paisley, Scotland), $5 \mu \mathrm{mol} / 1$ 2-mercaptoethanol (Sigma, st Louis, MO), 1\% non-essential amino acids (Life Technologies) and $1 \mathrm{mmol} / 1$ sodium pyruvate (Life Technologies). All cells were harvested using 0.25\% trypsin (Difco Laboratories, Detroit, MI)/0.02\% EDTA (Merck, Darmstadt, Germany) in $0.9 \% \mathrm{NaCl}$ solution.

Human umbilical vein endothelial cells (HUVEC) were cultured in RPMI1640 (Life Technologies, Breda, The Netherlands) supplemented with 20\% heat inactivated human pooled serum (provided by the University Hospital Maastricht), $2 \mathrm{mM}$ L-glutamin (Life Technologies), $50 \mathrm{ng} / \mathrm{ml}$ streptomycin and 50 $\mathrm{U} / \mathrm{ml}$ penicillin (ICN Biomedicals, Maidenhead, UK) in $0.2 \%$ gelatin coated tissue culture flasks at $37^{\circ} \mathrm{C}, 5 \% \mathrm{CO}_{2}$.

\section{Intravital microscopy}

In vivo experiments were approved by the local Ethical Review Committee on Animal Experiments. Small tumors were grown in the left ear of C57BL/6 mice (25$30 \mathrm{~g}$, obtained from Charles River, Maastricht, the Netherlands), as described before ${ }^{12}$. Briefly, $10 \mu \mathrm{l}$ cell suspension containing $10^{6}$ B16F10 cells was injected intradermally into the dorsal side of the ear. Within 3-5 days ear tumors grew to a diameter of about $2 \mathrm{~mm}$, at which time point the treatment started. Three antiangiogenic drugs were used, i.e., the designer peptide anginex 17,25, endostatin and angiostatin (EntreMed, Rockville, MD) ${ }^{26}$, and TNP-470 (Takeda Chemical Industries, Osaka, Japan) ${ }^{27}$, as well as two anti-neoplastic drugs with claimed antiangiogenic properties, i.e. paclitaxel (Taxol, Bristol-Myers Squibb B.V., Woerden, the Netherlands) and cyclophosphamide (Asta Medica, Diemen, the Netherlands).

For treatment of tumor bearing mice with anginex $(n=6)$, Alzet osmotic minipumps (Durect Corporation, Cupertino, USA) were implanted on the flank on 
day 5 after tumor cell administration. Pumps administered $6 \mathrm{mg} / \mathrm{kg} / \mathrm{day}$ of anginex, a dose that proved to inhibit tumor growth in this model by approximately $70-80 \%$ 17. Other groups of mice were similarly treated with endostatin (2 mg/kg/day, $\mathrm{n}=5$ ) and angiostatin ( $2 \mathrm{mg} / \mathrm{kg} / \mathrm{day}, \mathrm{n}=5){ }^{19,26}$. In two additional mice an osmotic minipump was implanted that administered equivalent amounts of control protein (bovine serum albumin). In these groups, intravital microscopic measurements were performed on day 12 after tumor cell inoculation. TNP-470 was administered according to a previously optimized protocol 27 , by i.p. injections of $20 \mathrm{mg} / \mathrm{kg}$ (in $5 \%$ glucose/ethanol solution) on days $5,8,11$ and 13 after tumor cell administration $(n=4)$. In these mice intravital microscopy was performed on day 14 . Paclitaxel $(6 \mathrm{mg} / \mathrm{kg}$ in $0.9 \% \mathrm{NaCl}$ solution, i.p.; $\mathrm{n}=7)$ and cyclophosphamide $(12.5 \mathrm{mg} / \mathrm{kg}$ in sterile water, i.p.; $\mathrm{n}=4)$ were administered on days 5 and 7 after tumor cell administration. Intravital microscopy was performed on day 8 , at which time point tumor growth was already inhibited significantly (Bouma-ter Steege, unpublished results), while no toxic side effects were observed. As a control group, 5 tumor bearing mice were used which were not treated with any of the anti-angiogenic or anti-neoplastic compounds, but treated similarly otherwise. To investigate the effect of the drugs in healthy blood vessels, we also used mice without a tumor and treated them with anginex $(n=2)$, endostatin $(n=2)$, angiostatin $(n=2)$, TNP-470 $(n=2)$, paclitaxel $(n=4)$ and cyclophosphamide $(n=2)$; as control 5 mice were left untreated.

On the day of the experiment, mice received $500 \mathrm{ng}$ recombinant murine TNF $\alpha$ (R\&D Systems, Abingdon, U.K.) i.p., 4 hours prior to intravital microscopy. Administration of $\mathrm{TNF} \alpha$ was performed to upregulate leukocyte-vessel wall interactions; without cytokine pretreatment adhering leukocytes are hardly present in mouse ear venules, which would preclude the assessment of a possible reduction in leukocyte adhesion ${ }^{28}$. Mice were anesthetized by s.c. administration of a mixture of ketamine $(0.1 \mathrm{mg} / \mathrm{g}$ b.w. Nimatek) and xylazine $(0.02 \mathrm{mg} / \mathrm{g}$ b.w. Sedamun, Ad Usem Veterinarium, Cuyk, the Netherlands). Intravital microscopy was performed as described before ${ }^{12}$. Briefly, body temperature was kept at $37^{\circ} \mathrm{C}$ by an infrared heating lamp. In all mice, venules $(10-40 \mu \mathrm{m})$ in both ears were visualized using a Leitz intravital microscope adapted for telescopic imaging ${ }^{29}$. To enable intravital microscopic observation of leukocytes, 10-20 $\mu \mathrm{l}$ of a Rhodamine 6G solution (Sigma Chemical Co., St. Louis, $\mathrm{MO} ; 1 \mathrm{mg} / \mathrm{ml}$ in sterile $0.9 \% \mathrm{NaCl}$ ) was injected into a tail vein. As many vessels as possible (typically 8-12) were recorded for 3-5 minutes each, in areas within the tumor, outside the tumor $(<2.5$ $\mathrm{mm}$ from the tumor), at the edge of the ear ( $>5 \mathrm{~mm}$ from the tumor) and in the contralateral tumor-free ear. To enable quantification of systemic leukocyte counts, $20 \mu \mathrm{l}$ blood was sampled via heart puncture at the end of every experiment. 
Leukocytes were counted and differentiated as polymorphonuclear (PMN) or monomorphonuclear (MMN).

\section{Experimental parameters}

Vessel diameters were measured using an in-house built image shearing device. Centerline blood flow velocity was determined by frame-to-frame analysis, using the fastest passing fluorescent leukocyte as a marker. The level of leukocyte rolling was determined by counting the number of rolling cells passing a vessel segment per minute. Leukocytes were considered as rolling along the vessel wall when their velocity was at least an order of magnitude lower than that of the free flowing blood cells. The level of leukocyte adhesion was assessed in a $100 \mu \mathrm{m}$ vessel segment, and expressed as number of cells per endothelial surface area (assuming the cross-section of the venules to be circular). Leukocytes were considered adherent when they remained stationary for at least 30 seconds. The total number of leukocytes interacting with the vessel wall at a particular moment was determined as well. This parameter includes not only the numbers of adhering and rolling leukocytes, but also the velocity with which the latter roll along the endothelium within a vessel segment of $100 \mu \mathrm{m}$ length. When leukocytes roll slowly, the number of interacting leukocytes observed in such a vessel segment will be higher than when they roll faster, despite similar numbers of rolling and adhering leukocytes. This information is important, because it tells something about the adhesion molecules involved; leukocytes are known to roll very slowly on E-selectin, whereas rolling on P-selectin is much faster. In addition, slowly rolling leukocytes are the first to become adherent. To determine this parameter, we counted in a frozen video frame the total number of rolling and adhering leukocytes in a $100 \mu \mathrm{m}$ vessel segment. At each time point, this count was performed in 4 randomly chosen video frames and the data were averaged.

\section{Tumor growth experiments}

At day $0,10^{6} \mathrm{LS174T}$ human colon carcinoma cells or 2x105 B16F10 melanoma cells were inoculated subcutaneously on the right flank of 6 week old Swiss nu/nu or C57BL/6 mice, respectively. At day 5, when established tumors were present (approx. $50 \mathrm{~mm}^{3}$ ), an Alzet osmotic minipump (Durect, Cupertino, CA) was placed on the left flank. For LS174T tumors, treatment was performed for 2 weeks with $6 \mathrm{mg} / \mathrm{kg} /$ day anginex in $0.9 \% \mathrm{NaCl}$ solution (saline). In the B16F10 tumors, treatment was performed for 11 days with a dose range of $0,2,6$, or $12 \mathrm{mg} / \mathrm{kg} / \mathrm{day}$ of anginex in saline). Tumor volumes were measured daily and calculated as follows: width ${ }^{2} \times$ length $\times 0.52$. At the end of experiments tumors were excised and 
snap frozen for histochemical analysis. Statistical differences in tumor growth curves were analyzed using the two way ANOVA test.

\section{Immunohistochemistry}

Five $\mu \mathrm{m}$ sections were made, dried overnight, and fixed in acetone for 15 minutes at $-20^{\circ} \mathrm{C}$. After blocking of endogenous peroxidase, sections were blocked with BSA for aspecific staining (in $1 \% \mathrm{BSA} / 20 \% \mathrm{FCS} / 0.1 \%$ Tween-20 in PBS for 30 minutes) and stained using rat anti-mouse CD31 (Pharmingen, San Diego, CA), CD8 or CD45 (both kind gifts from Dr. A Duijvestijn, Maastricht). CD31 was detected by HRP-labelled goat anti-rat Ig antibody (Chemicon), whereas CD8 and CD45 were detected by biotinylated donkey anti-rat Ig antibody (Jackson Immuno Research Laboratories, Inc) and avidin-biotin-HRP complex (Dako). Microvessel density (MVD), CD45+ and CD8 ${ }^{+}$cells were counted in 4 independent areas in each section (using a $0.25 \mathrm{~mm}^{2}$ grid at a 200 times magnification) by two independent observers. Statistical analysis was done using the Mann-Whitney U test.

\section{FACS analysis}

b.END5 cells were cultured with or without $50 \mathrm{ng} / \mathrm{ml} \mathrm{bFGF,} \mathrm{with} \mathrm{or} \mathrm{without} \mathrm{either}$ 30 or $10 \mu \mathrm{g} / \mathrm{ml}$ anginex, $500 \mu \mathrm{g} / \mathrm{ml}$ endostatin, $1 \mathrm{mg} / \mathrm{ml}$ angiostatin, $100 \mathrm{ng} / \mathrm{ml}$ TNP-470, or $10 \mathrm{ng} / \mathrm{ml}$ paclitaxel. $40 \mathrm{ng} / \mathrm{ml} \mathrm{TNF} \alpha$ was added 6 hours prior to harvesting. ICAM-1 and VCAM-1 expression was determined by rat anti-mouse ICAM-1 (CD54; R\&D systems) or rat anti-mouse VCAM-1 (CD106; Pharmingen) monoclonal antibodies, as described previously ${ }^{12}$. Similar experiments were done with HUVECs, using $10 \mathrm{ng} / \mathrm{ml}$ bFGF. ICAM-1 was detected by MEM111 mouse anti-human ICAM-1 antibody (Monosan, Uden, The Netherlands). Mouse blood leukocytes were isolated by Ficoll density gradient centrifugation (Amersham, Sweden), and incubated with R1-2 rat anti-mouse VLA-4, Mel-14 rat anti-mouse Lselectin, M17.4 rat anti-mouse LFA1 $\alpha$, or M18.2 rat anti-mouse LFA1 $\beta$ (Pharmingen), as described before ${ }^{12}$.

\section{Quantitative real time RT-PCR ( $q R T-P C R)$}

qRT-PCR was performed with murine specific primers 30 detecting beta-actin, cyclophilin, ICAM-1, VCAM-1, and E-selectin (Sigma-Genosys, UK) and analyzed with Sequence Detection System software (Applied Biosystems). The expression of each target gene was normalized to the control genes. 


\section{Statistics}

Data obtained from intravital microscopic experiments are presented as medians with interquartile ranges (i.e. the spread from the 25th to 75th percentile). Other data are presented as means with standard errors (SEM). Differences between two independent data groups were tested with the Mann-Whitney $U$ test. Differences between paired data groups were tested with the Friedman test (more than two groups), followed by a multiple-comparison procedure. Correlation between variables was determined using Spearman's correlation test. In all tests the level of significance was set at 0.05 .

\section{Results}

Leukocyte-vessel wall interactions are reduced in tumor vessels in vivo; restoration by anti-angiogenesis treatment.

It was previously shown in different mouse models that pro-angiogenic factors reduce cytokine (TNF $\alpha$ ) induced leukocyte-vessel wall interactions in tumors and also in control tissues ${ }^{10,12}$. To investigate whether angiogenesis inhibitors can revert this process in tumors, tumor bearing mice were treated with the angiostatic peptide anginex, using a protocol $(6 \mathrm{mg} / \mathrm{kg} /$ day for 7 days $)$ which inhibits tumor growth by $70-80 \%{ }^{17}$. Interestingly, this treatment completely restored the total level of cytokine induced leukocyte-vessel wall interactions inside the tumor $(\mathrm{p}<0.001)$, as well as in vessels adjacent to the tumor $(\mathrm{p}<0.05)$, to the level observed in healthy control mice (Figure 4.1). Discrimination between leukocyte rolling and adhesion revealed that treatment with anginex significantly increased both leukocyte adhesion $(p<0.05)$ and rolling $(p<0.01$, Figure 4.1) in tumor vessels. Interactions in the contralateral ears of tumor bearing mice were highly similar to results observed in healthy control mice (data not shown). In ear skin venules of mice without a tumor anginex did not significantly influence the total level of leukocyte-vessel wall interactions. Administration of bovine serum albumin as a protein control had no significant effect on leukocyte-vessel wall interactions (Figure 4.1). Intravital microscopic images of normal tissue, B16F10 tumor tissue and anginex treated tumor tissue are shown in Figure 4.2. Video images of these experiments can be viewed at http://www.fdg.unimaas.nl/AngiogenesisLab. These experiments were performed in a suboptimal TNF $\alpha$-induced situation in which both rolling and adhering leukocytes are present, at least in the control situation. In pilot experiments, in which no TNF $\alpha$ was used, leukocyte-vessel wall interactions appeared to be reduced inside a tumor as well, although the 
difference was smaller, and anginex also upregulated these interactions (unpublished data).
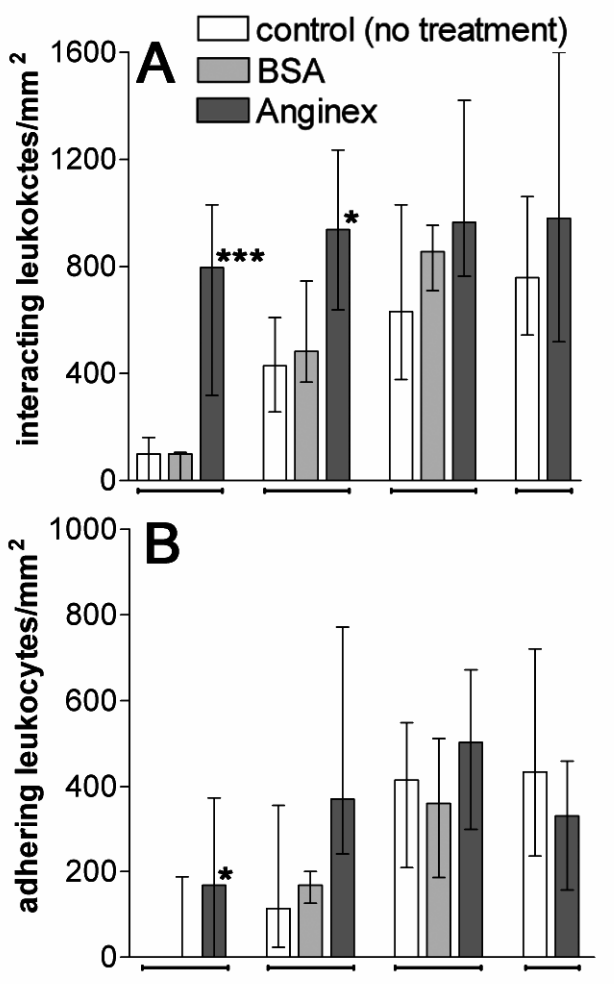

Figure 4.1. Leukocyte-vessel wall interactions are suppressed in tumor microvessels; normalization by treatment with anginex. C57B16 mice with established B16F10 tumors were treated for 7 days with anginex, bovine serum albumin (BSA) as protein control or

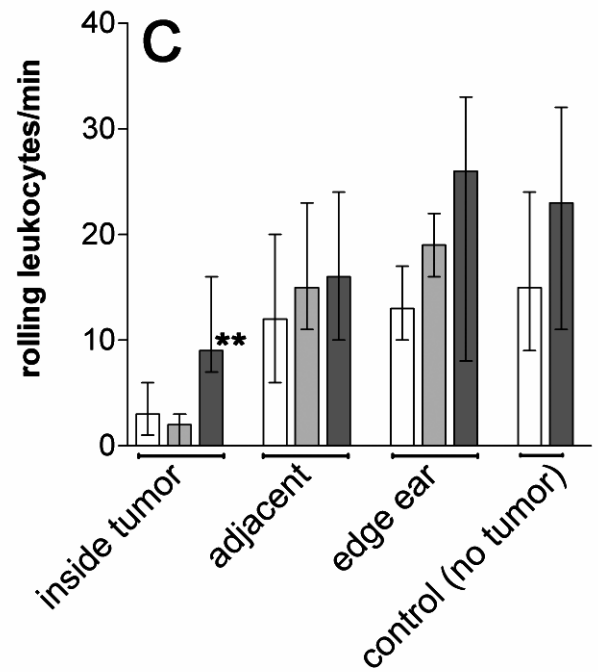
received no treatment at all. Leukocyte vessel wall interactions were analyzed using intravital microscopy, 4 hours after i.v. injection with $500 \mathrm{ng}$ TNF $\alpha$. Effects of treatment on the total level of interacting leukocytes (A), on leukocyte adhesion (B) and on leukocyte rolling (C). Data are presented as medians and interquartile ranges. Statistical significance was assessed in comparison to values in untreated control mice $\left({ }^{*} \mathrm{p}<0.05\right.$, $\left.{ }^{* *} \mathrm{p}<0.01,{ }^{* * *} \mathrm{p}<0.001\right)$. 
To investigate whether the effect of anginex is common among angiogenesis inhibitors, three other angiostatic drugs were tested (Figure 4.2A). Treatment of mice with endostatin $\left(2 \mathrm{mg} / \mathrm{kg} /\right.$ day $\left.{ }^{19}\right)$ induced an increase in leukocyte-vessel wall interactions in tumor vessels as well $(\mathrm{p}<0.01)$. Similarly, treatment of mice with angiostatin $\left(2 \mathrm{mg} / \mathrm{kg} /\right.$ day $\left.{ }^{19}\right)$ also increased leukocyte-vessel wall interactions in tumor vessels $(\mathrm{p}<0.05)$, although to a lesser extent than anginex and endostatin. The effects of both inhibitors were due to an increase in leukocyte adhesion in tumor vessels, whereas leukocyte rolling remained unchanged (Table 4.1). As with anginex, endostatin and angiostatin did not influence leukocyte-vessel wall interactions in the absence of a tumor (Table 4.1). TNP-470 did not induce an increase in the total level of leukocyte-vessel wall interactions in tumor vessels (Figure 4.2A). Instead, this compound tended to decrease both leukocyte adhesion

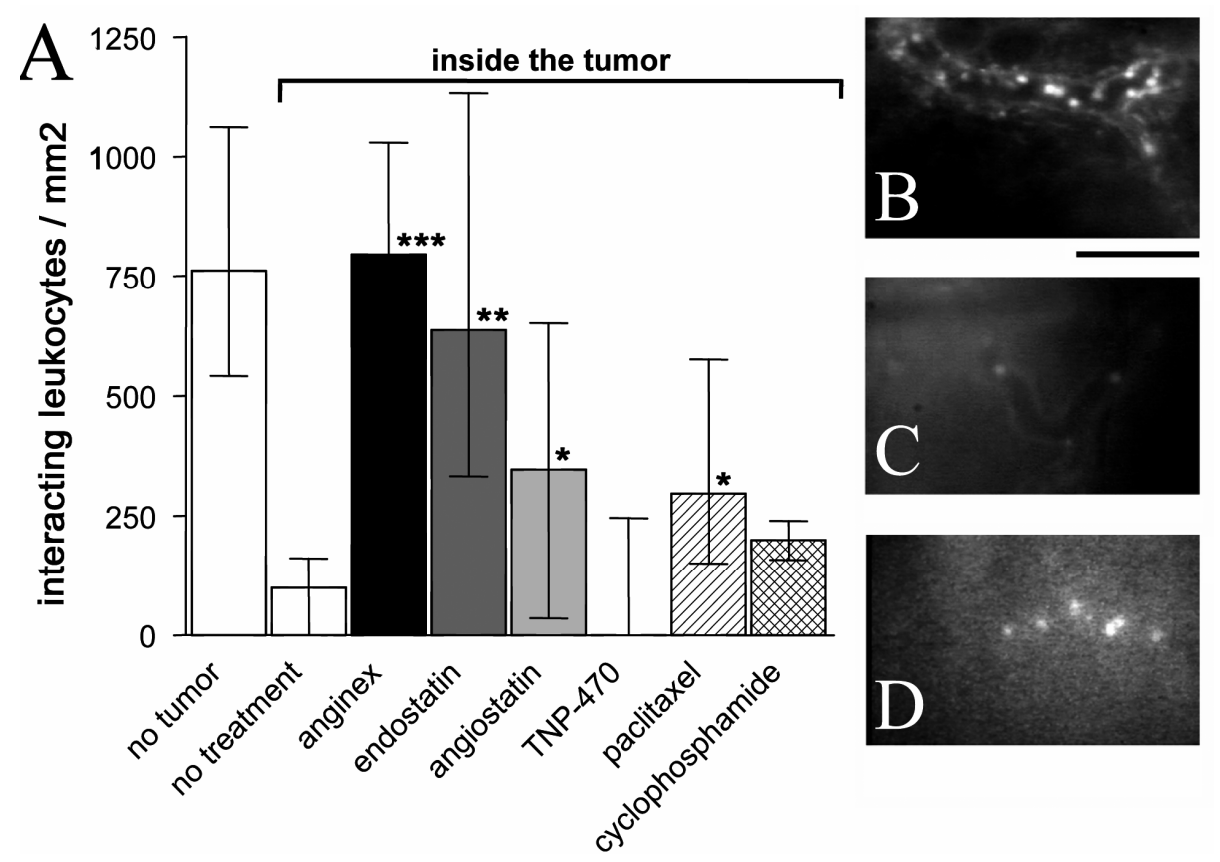

Figure 4.2. Suppressed leukocyte-vessel wall interactions in tumor vessels can be normalized by angiostatic and chemotherapeutic compounds. A) Normalization of the total number of interacting leukocytes in mouse tumor vessels to numbers observed in vessels of mice without a tumor. Data are presented as medians and interquartile ranges. Statistical significance was assessed in comparison to values in tumor vessels of untreated mice $\left({ }^{*} \mathrm{p}<0.05,{ }^{* *} \mathrm{p}<0.01,{ }^{* * *} \mathrm{p}<0.001\right)$. B-D) Typical intravital fluorescence microscopy images of a normal ear skin vessel (B), an untreated tumor vessel (C), and an anginex treated tumor vessel (D); leukocytes are fluorescently labeled with Rhodamin 6G. The bar between B and C represents $45 \mu \mathrm{m}$. Video images can be viewed at 'http//www.fdg.unimaas.nl /AngiogenesisLab'. 
and rolling and, hence, the total level of interactions (Table 4.1). This effect was seen especially in tumor-free mice, where TNP-470 significantly decreased the total level of leukocyte-vessel wall interactions $(p<0.001)$ as well as both leukocyte rolling and adhesion $(\mathrm{p}<0.01$; Table 4.1$)$.

Table 4.1. Effects of anti-angiogenesis or anti-neoplastic drugs on leukocyte-vessel wall interactions in ear skin venules of TNF $\alpha$-treated C57BL/6 mice.

\begin{tabular}{|c|c|c|c|c|}
\hline & \multicolumn{3}{|c|}{ Ear tumor } & \multirow[t]{2}{*}{ No tumor } \\
\hline & Inside tumor & $\begin{array}{l}\text { Adjacent to } \\
\text { tumor }\end{array}$ & Edge ear & \\
\hline \multicolumn{5}{|l|}{ Control (no treatment) } \\
\hline Interacting $/ \mathrm{mm}^{2}$ & $99(0-161)$ & $429(257-610)$ & $632(378-1030)$ & $758(544-1061)$ \\
\hline Adhering $/ \mathrm{mm}^{2}$ & $0(0-0)$ & $114(24-356)$ & $415(209-549)$ & $434(236-720)$ \\
\hline Rolling/min & $3(1-6)$ & $12(6-20)$ & $13(10-17)$ & $15(9-24)$ \\
\hline \multicolumn{5}{|l|}{ Anginex } \\
\hline Interacting $/ \mathrm{mm}^{2}$ & $796^{* * *}(318-1030)$ & $937^{*}(638-1235)$ & 965 (764-1421) & $979(518-1655)$ \\
\hline Adhering $/ \mathrm{mm}^{2}$ & $168^{*}(0-374)$ & $371(241-772)$ & $503(298-672)$ & $332(157-459)$ \\
\hline Rolling/min & $9^{* *}(7-16)$ & $16(10-24)$ & $26(8-33)$ & $23(11-32)$ \\
\hline \multicolumn{5}{|l|}{ Endostatin } \\
\hline Interacting $/ \mathrm{mm}^{2}$ & $637^{* *}(332-1133)$ & $693(354-1038)$ & $796(474-1384)$ & $819(503-1222)$ \\
\hline Adhering $/ \mathrm{mm}^{2}$ & $282^{* *}(0-700)$ & $157(0-321)$ & $490(163-621)$ & $233^{*}(92-479)$ \\
\hline Rolling/min & $6(2-12)$ & $25(10-47)$ & $20(8-37)$ & $18(11-23)$ \\
\hline \multicolumn{5}{|l|}{ Angiostatin } \\
\hline Interacting $/ \mathrm{mm}^{2}$ & $346^{*}(35-651)$ & 758 (355-908) & $1038^{*}(902-1664)$ & 803 (549-973) \\
\hline Adhering $/ \mathrm{mm}^{2}$ & $142^{*}(0-374)$ & $227(138-365)$ & $472(101-638)$ & $274(99-557)$ \\
\hline Rolling/min & $3(1-8)$ & $12(5-27)$ & $19(13-31)$ & $18(15-32)$ \\
\hline \multicolumn{5}{|l|}{ TNP-470 } \\
\hline Interacting $/ \mathrm{mm}^{2}$ & $0(0-245)$ & 249 (109-484) & $442(265-872)$ & $152^{* * *}(84-345)$ \\
\hline Adhering $/ \mathrm{mm}^{2}$ & $0(0-0)$ & $0^{*}(0-0)$ & $277(141-408)$ & $205^{* * *}(55-236)$ \\
\hline Rolling/min & $1(1-1)$ & $7(3-13)$ & $9^{*}(7-11)$ & $5^{* *}(3-8)$ \\
\hline \multicolumn{5}{|l|}{ Paclitaxel } \\
\hline Interacting $/ \mathrm{mm}^{2}$ & $296^{*}(150-576)$ & $332(263-454)$ & $438^{*}(290-648)$ & $571(434-860)$ \\
\hline Adhering $/ \mathrm{mm}^{2}$ & $155^{*}(0-297)$ & 138 (109-297) & $367(216-463)$ & $199 * * *(94-354)$ \\
\hline Rolling/min & $8^{* *}(5-13)$ & $30^{* *}(24-40)$ & $25^{* * *}(21-39)$ & $22^{* *}(12-42)$ \\
\hline \multicolumn{5}{|l|}{ Cyclophosphamide } \\
\hline Interacting $/ \mathrm{mm}^{2}$ & $199(158-239)$ & $265(166-435)$ & $364^{*}(315-583)$ & $303^{* * *}(133-411)$ \\
\hline Adhering $/ \mathrm{mm}^{2}$ & $187^{*}(0-239)$ & $138(0-466)$ & $364(233-599)$ & $277^{*}(133-407)$ \\
\hline Rolling/min & $0^{*}(0-1)$ & $1^{* * *}(1-3)$ & $1^{* * *}(1-4)$ & $1^{* * *}(0-1)$ \\
\hline
\end{tabular}

Data are presented as median values and interquartile ranges in parentheses; ${ }^{*} \mathrm{p}<0.05,{ }^{* *} \mathrm{p}<0.01$ and ${ }^{* * *} \mathrm{p}<0.001$ as compared to the controlgroup; number of vessels per category: control 10-47, anginex 12-24, endostatin 12-24, angiostatin 14-24, TNP470 4-10, paclitaxel 11-49, cyclophosphamide 11-23 
To test whether chemotherapeutic agents with claimed angiostatic properties ${ }^{24}$ share the capacity to overcome tumor EC anergy with specific angiogenesis inhibitors, tumor bearing mice were also treated with either paclitaxel or cyclophosphamide. Paclitaxel increased the total level of leukocyte-vessel wall interactions in tumor vessels significantly $(p<0.05)$, although interactions were still clearly lower than in healthy control vessels (Figure 4.2A). The effect of paclitaxel appeared to be due to an increase in both leukocyte adherence and leukocyte rolling (Table 4.1). In tumor-free mice, paclitaxel exhibited a dual effect by inducing an increase in leukocyte rolling $(\mathrm{p}<0.01)$ and, at the same time, decreasing leukocyte adherence $(\mathrm{p}<0.001)$. This resulted in a nearly significant decrease $(p<0.07)$ in the total level of leukocyte-vessel wall interactions (Table 4.1). The increase in interactions that is observed inside a tumor is, therefore, particularly striking.

Treatment of mice with cyclophosphamide also induced an increase in leukocyte-vessel wall interactions in tumor vessels (Figure 4.2A), but this effect did not reach the level of significance $(p<0.095)$. This effect of cyclophosphamide resulted from an increase in leukocyte adherence $(p<0.05)$, whereas leukocyte rolling appeared to be decreased ( $\mathrm{p}<0.05$; Table 4.1). In tumor-free mice, treatment with this compound clearly reduced both leukocyte rolling $(\mathrm{p}<0.001)$ and adhesion $(p<0.05)$ and, hence, also the total level of interactions $(p<0.001$; Table 4.1). Therefore, as with paclitaxel, the non-significant increase in leukocyte-vessel wall interactions in tumor vessels after treatment with cyclophosphamide is remarkable.

Table 4.2. Effect of treatment with anti-angiogenesis or anti-neoplastic drugs on systemic leukocyte concentration and percentage of polymorphonuclear (PMN) and monomorphonuclear cells (MMN) in blood of TNF $\alpha$-treated C57BL/6 mice.

\begin{tabular}{lccc}
\hline & $\begin{array}{c}\text { Systemic leukocyte count } \\
(\times 10 \% / \mathrm{ml})\end{array}$ & $\begin{array}{c}\text { PMNs } \\
(\%)\end{array}$ & $\begin{array}{c}\text { MMNs } \\
(\%)\end{array}$ \\
\hline Control (no treatment) & $6.6 \pm 0.9$ & $16 \pm 2$ & $84 \pm 2$ \\
Anginex & $9.0 \pm 0.8$ & $17 \pm 1$ & $83 \pm 1$ \\
Endostatin & $6.0 \pm 0.2$ & $12 \pm 2$ & $88 \pm 2$ \\
Angiostatin & $7.7 \pm 1.4$ & $16 \pm 3$ & $84 \pm 3$ \\
TNP-470 & $6.5 \pm 1.0$ & $33 \pm 4^{*}$ & $67 \pm 4^{*}$ \\
Paclitaxel & $5.5 \pm 0.9$ & $22 \pm 3$ & $78 \pm 3$ \\
Cyclophosphamide & $2.1 \pm 0.3^{*}$ & $5 \pm 2^{*}$ & $95 \pm 2^{*}$ \\
\hline
\end{tabular}

Data are presented as means \pm SEM; ${ }^{*} \mathrm{p}<0.01$ as compared to control. 
Leukocyte adhesion molecule expression, systemic leukocyte counts and fluid dynamic parameters

The decrease in leukocyte-vessel wall interactions in tumor vessels cannot be explained by altered adhesion molecule expression on leukocytes ${ }^{12}$. We also found that the effects of the angiogenesis inhibitors were not due to changes in leukocyte adhesion molecule expression. Differences in expression of VLA-4, L-selectin, LFA- $1 \alpha$, and LFA-1 $\beta$ on the circulating leukocytes were not observed between the different treatment groups (data not shown).

The number of leukocyte-vessel wall interactions can also be influenced by the level of leukocyte delivery to the observed blood vessels. This parameter depends on leukocyte concentration in the passing blood and on local blood flow. Treatment with anginex, endostatin, angiostatin and paclitaxel did not influence the number of circulating leukocytes or the percentage of polymorphonuclear (PMNs) and monomorphonuclear cells (MMNs; Table 4.2). TNP-470 had no effect on the systemic leukocyte count as well, although the percentage of PMNs was increased. Treatment with cyclophosphamide, however, induced a significant decrease in systemic leukocyte count $(p<0.01)$ with a concomitant decrease in the amount of PMNs $(\mathrm{p}<0.01)$.

In all treatment groups, local vessel diameters and blood flow were not influenced (data not shown). Therefore, it is suggested that the observed effects of all angiogenesis inhibitors except cyclophosphamide on leukocyte-vessel wall interactions in and around the tumor cannot be explained by changes in leukocyte delivery to the vessels. In the present mouse model, cyclophosphamide treatment appears to be associated with a decrease in leukocyte delivery to vessels due to a significant reduction in systemic leukocyte concentration.

Anti-angiogenesis treatment prevents downregulation of endothelial ICAM-1 and VCAM1 expression

To investigate whether the effects of the angiogenesis inhibitors are due to a normalization of the suppressed adhesion molecule expression on tumor ECs, in vitro experiments were performed using cultured b.END5 mouse EC. When cultured in the presence of $50 \mathrm{ng} / \mathrm{ml} \mathrm{bFGF}$, the proliferation rate of b.END5 cells is enhanced and ICAM-1 and VCAM-1 expression is downregulated by $60 \%$ and $81 \%$, respectively (Figure $4.3 \mathrm{~A}$ and $4.3 \mathrm{~B}$ ). Comparable but less pronounced results were observed by culturing in the presence of VEGF (data not shown). The bFGFmediated downregulation of ICAM-1 was also observed in HUVEC (Fig. 4.3C), which is in agreement with previous observations 6,7 . 

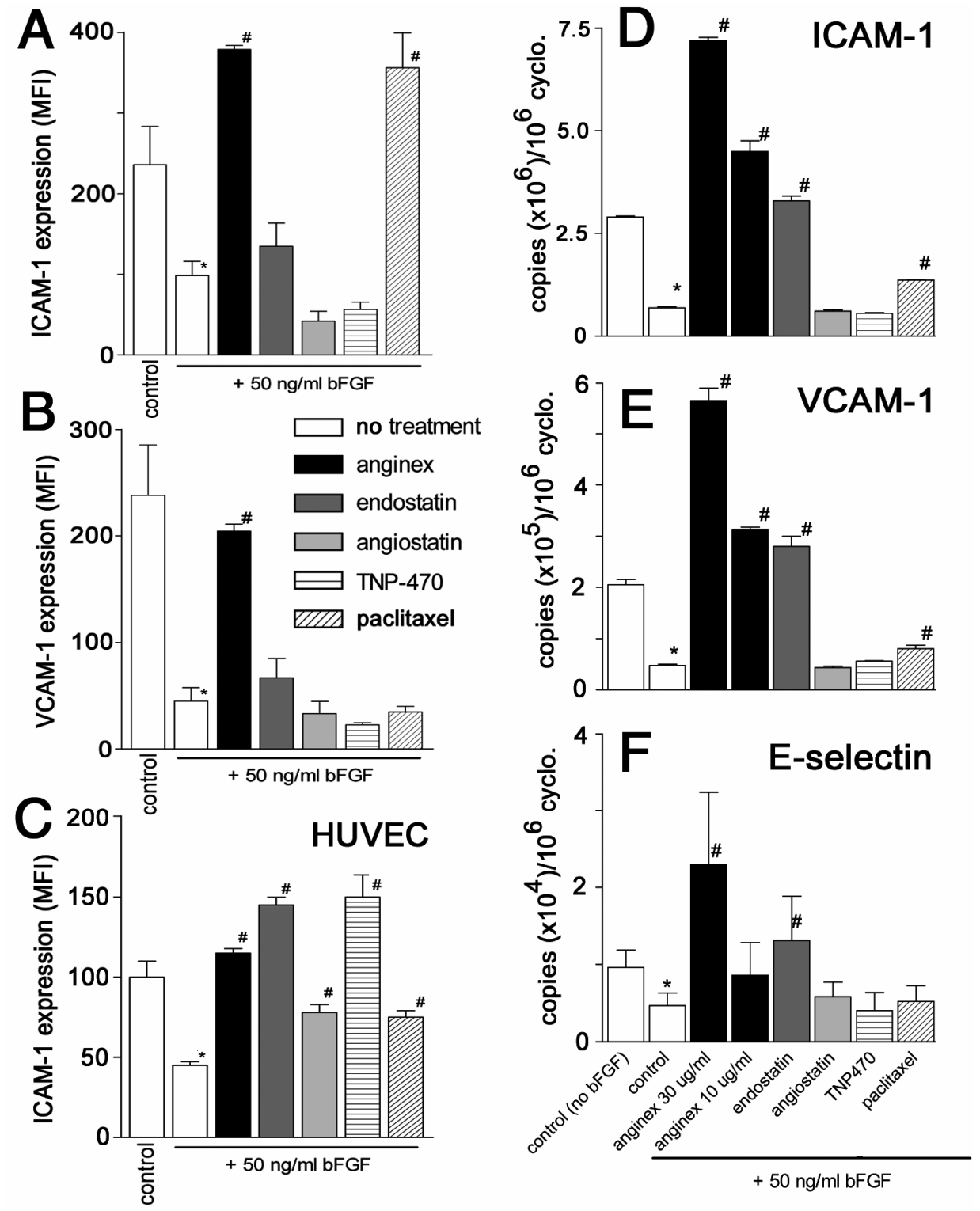

Figure 4.3. Growth factor (bFGF) induced downregulation of adhesion molecule expression on mouse EC; normalization by angiostatic and chemotherapeutic agents. A,B) FACS analysis of ICAM-1 and VCAM-1 expression in b.END5 mouse EC, with or without bFGF, and after treatment with angiostatic and chemotherapeutic agents. Data are expressed as mean fluorescence intensity (MFI). C) FACS analysis of ICAM-1 expression in HUVEC. D,E,F Quantitative real-time RT-PCR analysis of the effect of treatment on expression of ICAM-1 (D), VCAM-1 (E), and E-selectin (F). Data are presented as mean number of RNA copies per $10^{6}$ copies of cyclophilin RNA. For all panels, data are means $( \pm$ SEM) of four independent experiments. ${ }^{*} \mathrm{p}<0.05$ versus cells without $b F G F, \# p<0.05$ versus untreated cells. 
Culture in the presence of anginex completely prevented the bFGF-mediated downregulation of both ICAM-1 and VCAM-1 at the protein level (Figure 4.3A-C) and also at the RNA level (Figure 4.3C-E, for ICAM-1, VCAM-1 and E-selectin). Endostatin treatment increased adhesion molecule expression at the RNA level (Figure 4.3D-F). Angiostatin and TNP-470, the compounds with less and no activity in vivo (see Figure 4.2), did not significantly influence adhesion molecule expression in b.END5 mouse EC this in vitro bFGF-driven model. The latter compounds did have an effect on ICAM-1 expression in HUVEC, suggesting a difference in reactivity between mouse and human endothelial cells. Paclitaxel did prevent the downregulation of ICAM-1, but not VCAM-1.

To investigate adhesion molecule levels in vivo, B16F10 tumor tissues were analyzed. In untreated B16F10 tumors, low mRNA expression levels of both ICAM-1 and VCAM-1 were detectable whereas the expression of E-selectin was virtually absent (Figure 4.4A). In lung, the expression of all three adhesion molecules was over 100-fold higher as compared to expression in tumors (data not shown). Interestingly, in tumors of mice treated with anginex the expression of the EC specific molecules VCAM-1 and E-selectin was significantly upregulated by the treatment [2.38-fold $(\mathrm{p}<0.05)$ and 2.43 fold $(\mathrm{p}<0.05)$, respectively; Figure 4.4B].

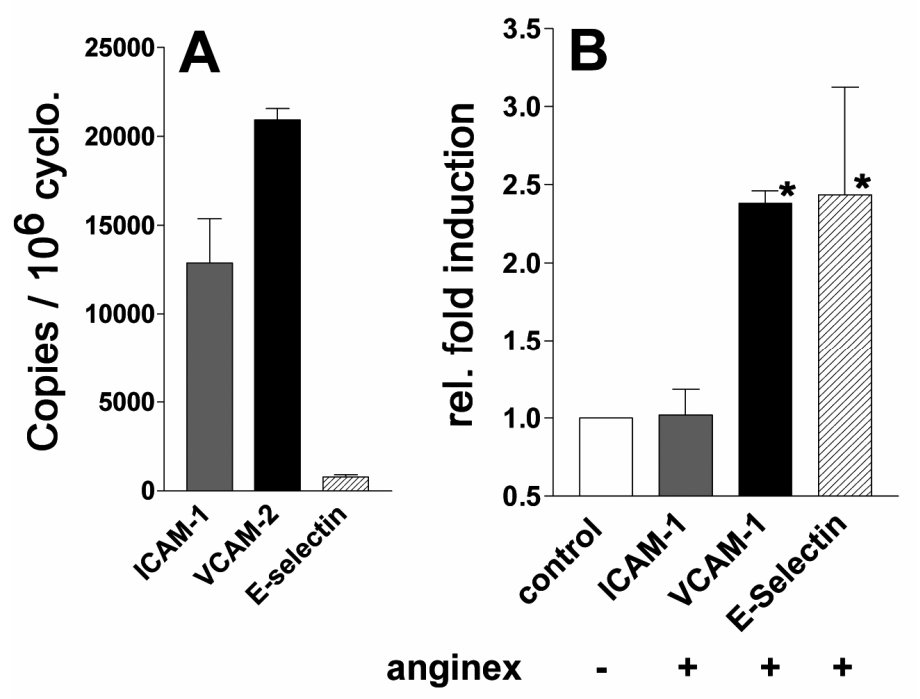

Figure 4.4. Effect of treatment with anginex on adhesion molecule expression in tumor tissue in vivo. A) Expression levels of ICAM-1, VCAM-1, and E-selectin in non-treated tumor tissues by quantitative real-time RT-PCR analysis, normalized to cyclophilin expression. B) Effect of anginex on ICAM-1, VCAM-1, and E-selectin expression in tumor tissue. Data are presented as average relative fold induction. Expression in untreated tumors was set to $1 .{ }^{*} \mathrm{p}<0.05$ as compared to untreated control tumors. 
When the change in microvessel density is also taken into account (a 3.3-fold decrease as compared to control, see Figure 4.5F) the relative increase in expression of both VCAM-1 and E-selectin is over 8-fold. The enhancement of ICAM-1 expression was not detectable using this method, most likely because this adhesion molecule is also expressed by tumor and/or stromal cells which are not affected by specific anti-angiogenesis treatment.
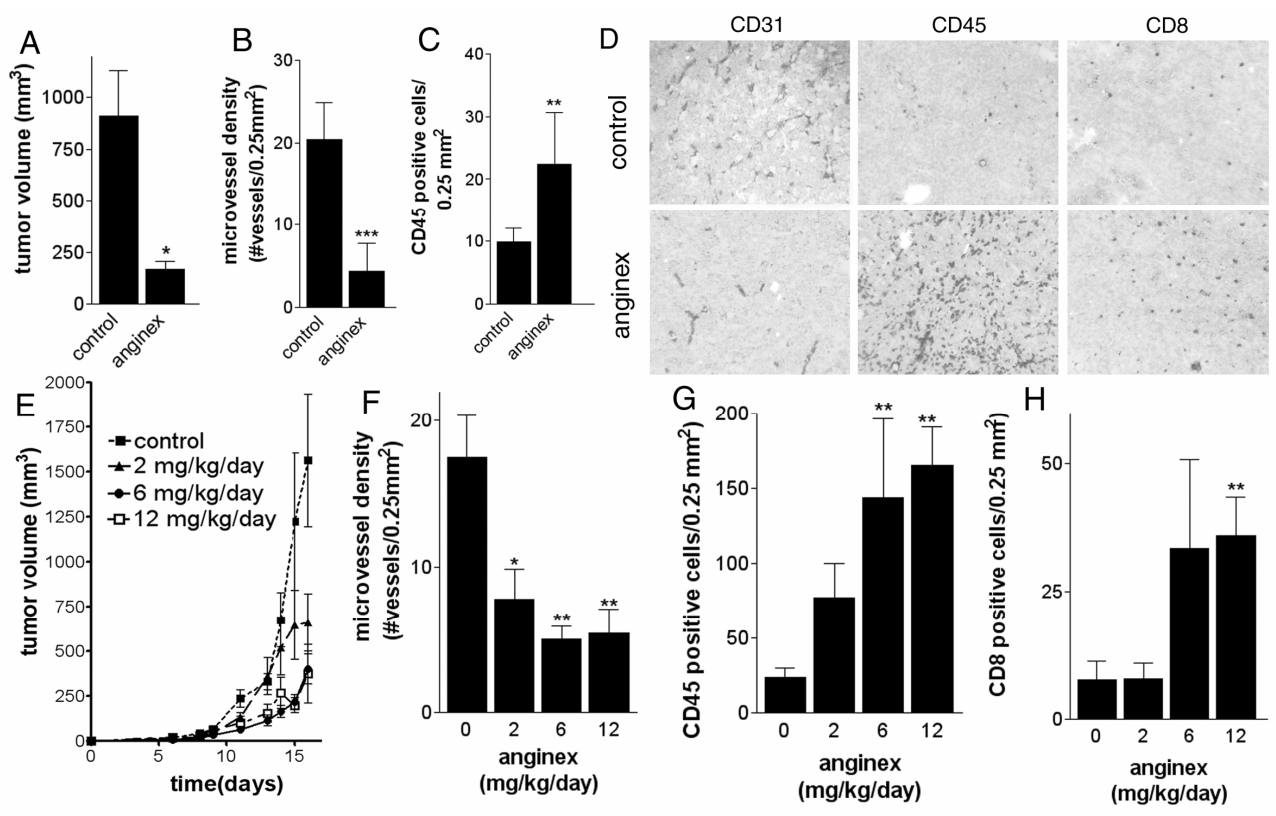

Figure 4.5. Relationship between angiogenesis inhibition and leukocyte infiltration. Tumor size (A), microvessel density assessment by CD31 staining (B) and infiltration by CD45 $5^{+}$leukocytes (C) of LS174T human colon carcinoma with and without anginex treatment. D) Immunohistochemical images of microvessel density (CD31), and infiltration by CD45+ leukocytes and CD8 $8^{+} \mathrm{T}$ lymphocytes in B16F10 melanoma of control and anginex treated mice. Bar in upper left panel represents $50 \mu \mathrm{m}$. E-H) Effect of increasing doses of anginex $(2,6,12 \mathrm{mg} / \mathrm{kg} /$ day $)$ on tumor size, microvessel density, total leukocyte (CD45)-, and cytotoxic T lymphocyte (CD8) infiltration in B16F10 melanoma. ${ }^{*} \mathrm{p}<0.01,{ }^{* *} \mathrm{p}<0.001$ and *** $\mathrm{p}<0.0001$ as compared to control.

\section{Leukocyte infiltration is enhanced by angiogenesis inhibition}

We also investigated in two different mouse tumor models whether the enhancement of endothelial adhesion molecules and leukocyte-vessel wall interactions contributes to an increased leukocyte infiltration in a tumor. After a two-week period of treatment of human LS174T bearing Swiss nu/nu mice with anginex, tumor growth $(\mathrm{p}<0.05$, Figure $4.5 \mathrm{~A})$ and microvessel density $(\mathrm{p}<0.0005$, Figure $4.5 \mathrm{~B}$ ) were significantly reduced. At the same time, anginex treatment enhanced the number of infiltrating leukocytes in the tumor over 2-fold $(\mathrm{p}<0.01)$, 
as determined using the pan-leukocyte marker CD45 (Figure 4.5C). Similar but more pronounced results were observed in the B16F10 melanoma model in immunocompetent C57BL6 mice (Figure 4.5D-G). Treatment of mice with anginex at $6 \mathrm{mg} / \mathrm{kg} /$ day resulted in a dose dependent inhibitory effect on tumor growth. The inhibition of angiogenesis, resulting in a 3.3-fold decrease in microvessel density, caused a 6.7-fold increase in infiltrated leukocytes (Figure 4.5D and G). It was interesting to see that in this immunocompetent model also cognate immunity (cytotoxic T lymphocytes, CD8) was directed to the tumor as well (4.4-fold increase, Figure 4.5D and $\mathrm{H}$ ).

\section{Discussion}

The present study demonstrates in an orthotopic syngeneic mouse model and in a human xenograft model that anti-angiogenesis treatment can overcome the suppression of endothelial adhesion molecules in tumors, leading to the amelioration of leukocyte-vessel wall interactions and to an increased inflammatory infiltrate in tumors.

It is known that tumors have the capacity to prevent the formation of a proper anti-tumor immune response by downregulation of endothelial adhesion molecules that are necessary for leukocyte-vessel wall interactions 11,12,31. This regulation is mediated by angiogenic growth factors 6,7 . It was recently demonstrated in ovarian carcinoma patients that the expression of VEGF in tumor tissue is negatively correlated with the presence of infiltrating $\mathrm{T}$ lymphocytes, which was found to be the strongest prognostic factor in ovarian carcinoma ${ }^{13}$. Similarly, we showed that the characteristic intense leukocyte infiltration in medullary breast carcinoma, as compared to ductal breast carcinoma, can be explained by their difference in angiogenic potential ${ }^{32}$. We hypothesized that when angiogenesis eradicates the infiltration of leukocytes, inhibition of angiogenesis would circumvent tumor escape from immunity and would lead to increased leukocyte infiltration. Previously, we showed in vitro that the angiogenesis inhibitors platelet factor-4 (PF4) and thrombospondin-1 not only prevent the downregulation of adhesion molecules by bFGF or VEGF, but also induce re-expression of these molecules in cultured human umbilical vein derived endothelial cells ${ }^{33}$. Similarly, angiostatin was found to enhance the expression of E-selectin ${ }^{34}$, while the synthetic angiogenesis inhibitor SU6668 reversed the bFGFmediated downregulation of ICAM-1, VCAM-1 and E-selectin ${ }^{31}$. Here, we have demonstrated that this phenomenon is shared by more angiogenesis inhibitors and that it has impact on in vivo leukocyte-vessel wall interactions and the formation of an immune infiltrate. 
In the present study, we show in vivo as well as in vitro, both at the mRNA and protein level, that angiostasis leads to re-expression of adhesion molecules on endothelial cells. The major role of ICAM-1 in leukocyte extravasation ${ }^{35}$ and the marked upregulation of ICAM-1, VCAM-1 and E-selectin in response to angiogenesis inhibition does not rule out a role for other adhesion structures. CD31, CD34 and ICAM-2, molecules with important functions in leukocyte-vessel wall interactions, are also described to be suppressed in tumor vessels 7,36. The same holds true for P-selectin, a molecule involved in leukocyte and platelet binding ${ }^{37}$. It is expected, but remains to be proven, that these molecules are also part of angiogenesis-associated regulation.

The present results indicate that not all angiogenesis inhibitors tested showed the same inflammatory response. For treatment of cancer, the agent of choice would presumably combine the strongest vessel growth inhibitory activity with the most potent inflammatory properties. Apparently, these properties are not interdependent; e.g. TNP-470 and anginex differ largely in immune modulatory activity (see Figures 4.2 and 4.3), while they are equipotent angiogenesis and tumor growth inhibitors in the B16F10 melanoma model 17, which suggests that the mechanisms of these effects are different. Anginex increased the expression of endothelial adhesion molecules on tumor endothelial cells both at mRNA and protein level. As a consequence, anginex significantly increased leukocyte-vessel wall interactions in tumor vessels to levels found in healthy control animals. This, in turn, led to increased infiltration of leukocytes into the tumor. Interestingly, angiogenesis inhibition is also suggested to be a promising approach for the treatment of diseases with a chronic inflammatory component, such as rheumatoid arthritis and psoriasis 38 , in which a concomitant pro-inflammatory activity is undesirable. It is tempting to speculate that the good results with TNP-470 in arthritis models are due to the lack of pro-inflammatory activity. It might be important, therefore, to screen a larger array of compounds for this activity in order to better judge applicability in various diseases.

Interestingly, the inflammatory activity of angiostatic compounds is also shared with certain chemotherapeutic agents. It has been observed previously that chemotherapeutic compounds such as cyclophosphamide and paclitaxel can induce leukocyte infiltration in tumors ${ }^{39}$. Currently, there is an ongoing discussion concerning the intrinsic angiostatic activity of several chemotherapeutic drugs (24). We and others have demonstrated for the tubulin binding compounds (taxanes and the vascular targeting agent combrestastatin) that an intrinsic antiangiogenesis activity exists at the level of endothelial migration and tube formation, at concentrations that do not affect cell growth ${ }^{40}$. The presently shown shared activity of paclitaxel and angiogenesis inhibitors at the level of adhesion molecule regulation and leukocyte-vessel wall interactions may support the theory 
that certain chemotherapeutics are angiostatic and may be used at ultra low dosages for prolonged periods of time as treatment of cancer.

The effects of the angiogenesis inhibitor TNP-470 on leukocyte-vessel wall interactions and adhesion molecule expression contrasted with the results obtained with the specific angiogenesis inhibitors anginex, endostatin and angiostatin. This may be explained by the fact that TNP-470 has other indirect effects, which is also suggested by the systemic decrease in leukocyte-vessel wall interactions in tumor-free mice (Table 4.1) and the change of leukocyte composition in peripheral blood (Table 4.2). Like TNP-470, cyclophosphamide also decreased leukocyte-vessel wall interactions in healthy microvessels in vivo, while paclitaxel only reduced the level of leukocyte adhesion in these vessels. This decrease in leukocyte-vessel wall interactions in a tumor-free environment may masks the upregulating effect of these agents on leukocyte-vessel wall interactions in tumor vessels.

Here, we used recently developed tumor models ${ }^{12}$ in which leukocytevessel wall interactions can be measured non-invasively, allowing longitudinal analysis during tumor development and over the course of anti-cancer treatment. The combined assessment of leukocyte-vessel wall interactions inside the vascular system and leukocyte infiltration into the tissue provides a functional meaning to changes in leukocyte adhesion. Our findings indicate that the increase in leukocyte-vessel wall interactions in tumor vessels is followed by increased infiltration of leukocytes into the tumor tissue, where they can help to suppress tumor growth. It is an interesting observation that both angiogenesis inhibitors and chemotherapeutic compounds can elucidate this effect. It is tempting to speculate that the reported, sometimes very good, results from combining both treatment strategies 18,41 is explained by this enhancement of inflammatory infiltrate. In a preliminary pilot study we found that combination of paclitaxel and anginex leads to an enhanced leukocyte infiltrate as compared with either paclitaxel or anginex alone (unpublished results). It remains to be elucidated, however, which leukocyte subtypes are involved in increased homing to the tumor.

The present study was focused on investigating the escape of tumors from immunity and how the leukocyte infiltrate can be augmented in tumors. Although the beneficial effect of cognate anti-tumor immunity is not debated at all, it should be kept in mind that several studies have shown that leukocytes, by their inflammatory cytokine/chemokine production, and by their release of matrix metalloproteinases, can contribute to angiogenesis programs and thereby to tumor progression as well ${ }^{42,43}$. Tumor associated macrophages have been mostly recognized for this phenomenon ${ }^{44}$. We, however, favor the view that leukocyte infiltration should be promoted in order to drive anti-tumor immunity. 
In conclusion, the present study demonstrates that angiogenesis inhibitors increase leukocyte-vessel wall interactions in tumor vessels, which leads to increased leukocyte infiltration into tumor tissue. This anti-tumor inflammatory effect of angiogenesis inhibitors is mediated by increased expression of adhesion molecules on tumor endothelial cells, and not by altered expression of leukocyte adhesion molecules, effects on the amount of circulating leukocytes, or other direct or indirect vascular effects modulating fluid dynamic parameters. These data strongly support the concept of combining modern immunotherapeutic approaches with angiostatic therapies. At least additive and hopefully synergistic anti-tumor responses would be expected from this combination.

\section{Acknowledgements}

The current research was supported by the Dutch Cancer Society (UM 2001-2529), the Dutch Science Foundation (NWO) - Stichting Technische Wetenschappen (MPG-5456), the US National Cancer Institute [R01 CA-96090] and by a grant from Reell BV, Elsoo, The Netherlands.

\section{References}

1. Ribas, A., Butterfield, L. H., Glaspy, J. A., Economou, J. S. (2003) Current developments in cancer vaccines and cellular immunotherapy. J.Clin.Oncol. 21, 2415-2432

2. Rosenberg, S. A. (2004) Shedding light on immunotherapy for cancer. N.Engl.J.Med. 350, 1461-1463

3. Dvorak, H. F. (2005) Angiogenesis: update 2005. J.Thromb.Haemost. 3, 1835-1842

4. Griffioen, A. W., Molema, G. (2000) Angiogenesis: potentials for pharmacologic intervention in the treatment of cancer, cardiovascular diseases and chronic inflammation. Pharmacol.Rev. 52, 237-268

5. Kerbel, R., Folkman, J. (2002) Clinical translation of angiogenesis inhibitors. Nat.Rev.Cancer 2, 727739

6. Griffioen, A. W., Damen, C. A., Blijham, G. H., Groenewegen, G. (1996) Tumor angiogenesis is accompanied by a decreased inflammatory response of tumor associated endothelium. Blood. 88, 667-673

7. Griffioen, A. W., Damen, C. A., Martinotti, S., Blijham, G. H., Groenewegen, G. (1996) Endothelial ICAM-1 expression is suppressed in human malignancies; role of angiogenic factors. Cancer Res. 56, 1111-1117

8. Piali, L., Fichtel, A., Terpe, H. J., Imhof, B. A., Gisler, R. H. (1995) Endothelial vascular cell adhesion molecule 1 expression is suppressed by melanoma and carcinoma. J.Exp.Med. 181, 811816

9. Hellwig, S. M. M., Damen, C. A., Van Adrichem, N. P. H., Groenewegen, G., Blijham, G. H., Griffioen, A. W. (1997) Endothelial CD34 is suppressed in human malignancies; role of angiogenic factors. Cancer Letters 120, 203-211 
10. Tromp, S. C., oude Egbrink, M. G. A., Dings, R. P. M., Van Velzen, S., Slaaf, D. W., Hillen, H. F. P., Tangelder, G. J., Reneman, R. S., Griffioen, A. W. (2000) Tumor angiogenesis factors reduce leukocyte adhesion in vivo. Int.Immunol. 12, 671-676

11. Melder, R. J., Koenig, G. C., Witwer, B. P., Safabakhsh, N., Munn, L. L., Jain, R. K. (1996) During angiogenesis, vascular endothelial growth factor and basic fibroblast growth factor regulate natural killer cell adhesion to tumor endothelium. Nature Med. 2, 992-997

12. Dirkx, A., oude Egbrink, M. G. A., Kuipers, M., Van de Niet, S. T., Heijnen, V. V. T., Bouma-ter Steege, J. C. M., Wagstaff, J., Griffioen, A. W. (2003) Tumor angiogenesis modulates leukocytevessel wall interactions in vivo by reducing endothelial adhesion molecule expression. Cancer Res. 63, 2322-2329

13. Zhang, L., Conejo-Garcia, J. R., Katsaros, D., Gimotty, P. A., Massobrio, M., Regnani, G., Makrigiannakis, A., Gray, H., Schlienger, K., Liebman, M. N., Rubin, S. C., Coukos, G. (2003) Intratumoral T cells, recurrence, and survival in epithelial ovarian cancer. N.Engl.J.Med 348, 203213

14. Nair, S., Boczkowski, D., Moeller, B., Dewhirst, M., Vieweg, J., Gilboa, E. (2003) Synergy between tumor immunotherapy and antiangiogenic therapy. Blood 102, 964-971

15. Niethammer, A. G., Xiang, R., Becker, J. C., Wodrich, H., Pertl, U., Karsten, G., Eliceiri, B. P., Reisfeld, R. A. (2002) A DNA vaccine against VEGF receptor 2 prevents effective angiogenesis and inhibits tumor growth. Nat.Med 8, 1369-1375

16. Wei, Y. Q., Wang, Q. R., Zhao, X., Yang, L., Tian, L., Lu, Y., Kang, B., Lu, C. J., Huang, M. J., Lou, Y. Y., Xiao, F., He, Q. M., Shu, J. M., Xie, X. J., Mao, Y. Q., Lei, S., Luo, F., Zhou, L. Q., Liu, C. E., Zhou, H., Jiang, Y., Peng, F., Yuan, L. P., Li, Q., Wu, Y., Liu, J. Y. (2000) Immunotherapy of tumors with xenogeneic endothelial cells as a vaccine. Nat.Med 6, 1160-1166

17. Van der Schaft, D. W. J., Dings, R. P. M., De Lussanet, Q. R., Van Eijk, L. I., Nap, A. W., Beets-Tan, R. G. H., Bouma-Ter Steege, J. C. A., Wagstaff, J., Mayo, K. H., Griffioen, A. W. (2002) The designer anti-angiogenic peptide anginex targets tumor endothelial cells and inhibits tumor growth in animal models. FASEB J. 63, 1991-1995

18. Dings, R. P. M., Yokoyama, Y., Ramakrishnan, S., Griffioen, A. W., Mayo, K. H. (2003) The designed angiostatic peptide anginex synergistically improves chemotherapy and antiangiogenesis therapy with angiostatin. Cancer Res. 63, 382-385

19. Kisker, O., Becker, C. M., Prox, D., Fannon, M., D'Amato, R., Flynn, E., Fogler, W. E., Sim, B. K., Allred, E. N., Pirie-Shepherd, S. R., Folkman, J. (2001) Continuous administration of endostatin by intraperitoneally implanted osmotic pump improves the efficacy and potency of therapy in a mouse xenograft tumor model. Cancer Res. 61, 7669-7674

20. Wahl, M. L., Kenan, D. J., Gonzalez-Gronow, M., Pizzo, S. V. (2005) Angiostatin's molecular mechanism: Aspects of specificity and regulation elucidated. J.Cell Biochem.

21. Folkman, J. (2002) Role of angiogenesis in tumor growth and metastasis. Semin.Oncol. 29, 15-18

22. Kusaka, M., Sudo, K., Fujita, T., Marui, S., Itoh, F., Ingber, D., Folkman, J. (1991) Potent antiangiogenic action of AGM-1470: comparison to the fumagillin parent. Biochem.Biophys.Res.Commun. 174, 1070-1076

23. Satchi-Fainaro, R., Mamluk, R., Wang, L., Short, S. M., Nagy, J. A., Feng, D., Dvorak, A. M., Dvorak, H. F., Puder, M., Mukhopadhyay, D., Folkman, J. (2005) Inhibition of vessel permeability by TNP-470 and its polymer conjugate, caplostatin. Cancer Cell 7, 251-261

24. Bocci, G., Nicolaou, K. C., Kerbel, R. S. (2002) Protracted low-dose effects on human endothelial cell proliferation and survival in vitro reveal a selective antiangiogenic window for various chemotherapeutic drugs. Cancer Res. 62, 6938-6943

25. Griffioen, A. W., Van der Schaft, D. W. J., Barendsz-Janson, A. F., Cox, A., Struijker Boudier, H. A. J., Hillen, H. F. P., Mayo, K. H. (2001) Anginex, a designed peptide that inhibits angiogenesis. Biochem.J. 2001, 233-242 
26. O'Reilly, M. S., Holmgren, L., Shing, Y., Chen, C., Rosenthal, R. A., Moses, M., Lane, W. S., Cao, Y., Sage, E. H., Folkman, J. (1994) Angiostatin: a novel angiogenesis inhibitor that mediates the suppression of metastases by a Lewis Lung Carcinoma. Cell 79, 315-328

27. Yamaoka, M., Yamamoto, T., Ikeyama, S., Sudo, K., Fujita, T. (1993) Angiogenesis inhibitor TNP470 (AGM-1470) potently inhibits the tumor growth of hormone-independent human breast and prostate carcinoma cell lines. Cancer Res. 53, 5233-5236

28. Janssen, G. H., Tangelder, G. J., oude Egbrink, M. G., Reneman, R. S. (1994) Spontaneous leukocyte rolling in venules in untraumatized skin of conscious and anesthetized animals. Am.J.Physiol 267, H1199-H1204

29. Slaaf, D. W., Alewijnse, R., Wayland, H. (1982) Use of telescopic imaging in intravital microscopy: a simple solution for conventional microscopes. Int.J.Microcirc.Clin.Exp. 1, 121-134

30. Thijssen, V. L. J. L., Brandwijk, R., Dings, R. P. M., Griffioen, A. W. (2004) Angiogenesis gene expression profiling in xenograft models to study cellular interactions. Exp.Cell Res. 299, 293

31. Zhang, H., Issekutz, A. C. (2002) Down-modulation of monocyte transendothelial migration and endothelial adhesion molecule expression by fibroblast growth factor: reversal by the antiangiogenic agent SU6668. Am.J.Pathol. 160, 2219-2230

32. Bouma-Ter Steege, J. C. A., Baeten, C. I. M., Tijssen, V. L. J. L., Satijn, S. A., Verhoeven, I. C. L., Hillen, H. F. P., Wagstaff, J., Griffioen, A. W. (2004) Angiogenic profile of breast cancinoma determines leukocyte infiltrate. Clin.Cancer Res. 10, 7171-7178

33. Griffioen, A. W., Damen, C. A., Mayo, K., Barendsz-Janson, A. F., Martinotti, S., Blijham, G. H., Groenewegen, G. (1999) Angiogenesis inhibitors overcome tumor induced endothelial cell anergy. Int.J.Cancer 80, 315-319

34. Luo, J., Lin, J., Paranya, G., Bischoff, J. (1998) Angiostatin upregulates E-selectin in proliferating endothelial cells. Biochem.Biophys.Res.Commun. 245, 906-911

35. Reiss, Y., Hoch, G., Deutsch, U., Engelhardt, B. (1998) T cell interaction with ICAM-1-deficient endothelium in vitro: essential role for ICAM-1 and ICAM-2 in transendothelial migration of T cells. Eur.J.Immunol. 28, 3086-3099

36. Griffioen, A. W. (1997) Phenotype of the tumor vasculature; cell adhesion as a target for tumor therapy. Cancer J. 10, 249-255

37. Nooijen, P. T., Westphal, J. R., Eggermont, A. M., Schalkwijk, C., Max, R., de Waal, R. M., Ruiter, D. J. (1998) Endothelial P-selectin expression is reduced in advanced primary melanoma and melanoma metastasis. Am.J.Pathol. 152, 679-682

38. Creamer, D., Sullivan, D., Bicknell, R., Barker, J. (2003) Angiogensis in psoriasis. Angiogenesis 5, 231-236

39. Demaria, S., Volm, M. D., Shapiro, R. L., Yee, H. T., Oratz, R., Formenti, S. C., Muggia, F., Symmans, W. F. (2001) Development of tumor-infiltrating lymphocytes in breast cancer after neoadjuvant paclitaxel chemotherapy. Clin.Cancer Res. 7, 3025-3030

40. Ahmed, B., Van Eijk, L., Bouma-Ter Steege, J. C. A., Van der Schaft, D. W. J., Van Esch, A. M., Lambin, P., Landuijt, W., Griffioen, A. W. (2003) A defined role of angiogenesis inhibition in the overall vascular targeting activity of combretastatin A-4 phosphate. Int.J.Cancer 104, 87-94

41. Teicher, B. A., Sotomayor, E. A., Huang, Z. D. (1992) Antiangiogenic agents potentiate cytotoxic cancer therapies against primary and metastatic disease. Cancer Res. 52, 6702-6704

42. Coussens, L. M., Raymond, W. W., Bergers, G., Laig-Webster, M., Behrendtsen, O., Werb, Z., Caughey, G. H., Hanahan, D. (1999) Inflammatory mast cells up-regulate angiogenesis during squamous epithelial carcinogenesis. Genes Dev. 13, 1382-1397

43. Coussens, L. M., Tinkle, C. L., Hanahan, D., Werb, Z. (2000) MMP-9 supplied by bone marrowderived cells contributes to skin carcinogenesis. Cell 103, 481-490

44. Leek, R. D., Lewis, C. E., Whitehouse, R., Greenall, M., Clarke, J., Harris, A. L. (1996) Association of macrophage infiltration with angiogenesis and prognosis in invasive breast carcinoma. Cancer Res. 56, 4625-4629 


\section{Chapter 5}

\section{Anti-angiogenesis therapy enhances tumor-specific immunity}

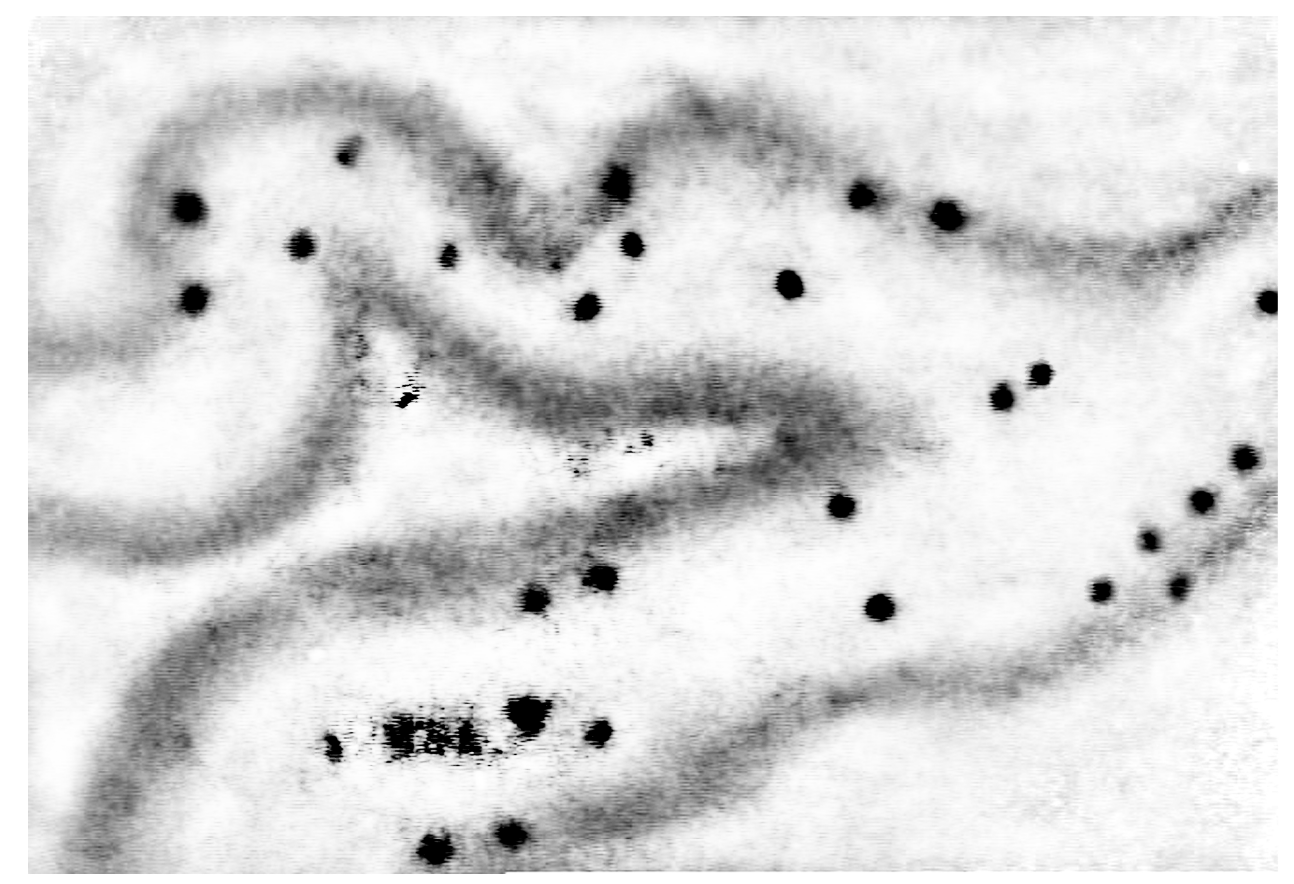

Karolien Castermans, Ruud P.M. Dings, Flavia E. Popescu, Elfriede Noessner, Mirjam G. A. oude Egbrink, Matthew F. Mescher, Kevin H. Mayo and Arjan W. Griffioen

Submitted 


\begin{abstract}
Angiogenesis suppresses endothelial cell (EC) adhesion molecule expression, thereby enabling a tumor to avoid an immune response. We hypothesized that angiostatic treatment may restore susceptibility to anti-tumor immunity. We tested this hypothesis both in vitro and in vivo with angiogenesis inhibitors, including the designer peptide anginex, and the anginex topomimetic 0118. Using activated EC in culture, we found that angiostasis restored expression levels of EC adhesion molecules ICAM-1; VCAM-1 and E-selectin at the protein and mRNA levels. This observation was substantiated in in vivo mouse tumor models. Restoration of EC adhesion molecule expression in tumor vessels led to enhanced adhesion of leukocytes in vitro and to a 3-fold increase in leukocyte-vessel wall interactions in vivo, resulting in enhanced leukocyte infiltration. While infiltration of all leukocyte subsets increased after angiostatic treatment, infiltrated cytotoxic T-cells were found to express activation markers CD25, CD69 and granzyme B. Regulatory T cells were not preferentially attracted. Next to this, the rich cytokine milieu and the Th1 type cytokine profile suggest an active ongoing anti-tumor immune response. These findings suggest that anti-angiogenesis is a way to improve immunotherapy strategies.
\end{abstract}




\section{Introduction}

A growing tumor has the ability to expand its vascular network via a process called angiogenesis 1,2 . For this to occur, tumor cells produce angiogenic factors, such as vascular endothelial growth factors (VEGFs) and fibroblast growth factors (FGFs) that activate endothelial cells (ECs) to proliferate, migrate, and differentiate, leading to the formation of new blood vessels ${ }^{2-6}$. Angiogenic factors not only induce the formation of new blood vessels, they also affect the immune system at several levels. One of these is the downregulation of endothelial cell adhesion molecules, such as intercellular adhesion molecule 1 (ICAM-1), vascular cell adhesion molecule (VCAM-1) and E-selectin, necessary for leukocyte recruitment ${ }^{7-9}$. This is one of the mechanisms of tumor escape from immunity ${ }^{10}$.

Inhibition of angiogenesis is currently considered a promising way of cancer treatment, because tumor growth and metastasis are dependent on angiogenesis. Many endogenous angiogenesis inhibitors have been identified ${ }^{11-19}$. Based on the structural similarity among these and other anti-angiogenic proteins, we designed the cytokine-like peptide anginex and showed it to be potently antiangiogenic ${ }^{20-23}$. Extensive structure-activity studies on anginex ${ }^{24-26}$ led us to design the partial-peptide mimetic 6DBF7 25 and the non-peptidic calixarene-based topomimetic $0118{ }^{27}$.

It has recently been demonstrated that inhibition of angiogenesis leads to normalization of the expression of EC adhesion molecules and enhanced leukocyte-vessel wall interactions ${ }^{28}$. Since anginex was among the most efficient inducers of these effects, we investigated in the present study the immune potentiating features of anginex and several related compounds. We show that angiogenesis inhibition, aside from inhibiting tumor angiogenesis and growth, can reverse the effects from angiogenic factors on EC adhesion molecule expression and leukocyte adhesion/infiltration. Moreover, several lines of evidence demonstrate that infiltrated lymphocytes are actively contributing to anti-tumor immunity, as they express activation markers and Th1 cytokine profiles, while regulatory $\mathrm{T}$ lymphocytes $\left(\mathrm{CD} 4{ }^{+} \mathrm{CD} 25^{+} \mathrm{Foxp} 3^{+}\right)$do not demonstrate a preferential infiltration. The current results suggest that the angiogenesis inhibitors anginex and 0118, which are about to enter clinical testing, can improve clinical immunotherapy strategies. 


\section{Materials and methods}

\section{Cell culture}

Human umbilical vein-derived endothelial cells (HUVEC), mouse B16F10 melanoma cells (kindly provided by Dr. Isaiah J. Fidler, Houston, TX) and the human epithelial ovarian carcinoma cell line, MA148 (kindly provided by Prof. Dr Ramakrishnan) were cultured as previously described ${ }^{10,21}$.

\section{Cell adhesion}

HUVEC were grown to a confluent monolayer for 3 days with or without bFGF (10ng/ml, PeproTech Inc., Rocky Hill, NJ), VEGF (40ng/ml, PeproTech Inc., Rocky Hill, NJ) and different concentrations of angiogenesis inhibitors as indicated. Human peripheral blood leukocytes were isolated by Ficoll density gradient centrifugation (Amersham, Uppsala, Sweden) and labeled with 5-(and 6)carboxyfluorescein diacetate, succinimidyl ester (CFSE; Molecular Probes, Leiden, The Netherlands). Cells were washed twice and subsequently adhered for 1 hour at room temperature to HUVEC cultures. Nonadhering cells were removed by washing with prewarmed culture medium. Cells were harvested and fixed in $1 \%$ paraformaldehyde (Merck, Amsterdam, The Netherlands) for 30 minutes at room temperature.

To determine the subpopulations of adhering leukocytes, the cell suspensions were stained first with mouse anti human: CD3, CD4, CD8, CD68 or CD16 (all DAKO, Glostrup, Denmark). After one hour incubation, cells were incubated with biotin conjugated rabbit anti mouse IgG (DAKO, Glostrup, Denmark) followed by phycoerithrine labelled strepdavidine Strep-PE(DAKO, Glostrup, Denmark). The cell suspensions were analysed on a FACScan flow cytometer.

\section{FACS analysis}

HUVEC were cultured for 3 days with or without growth factors bFGF $(10 \mathrm{ng} / \mathrm{ml})$, VEGF $(40 \mathrm{ng} / \mathrm{ml})$ and different concentrations of angiogenesis inhibitors anginex, 6DBF7, KM0118, endostatin, angiostatin (both kindly provided by EntreMed, MD) or TNP-470 (Takeda Chemical Industries, Japan). For the detection of VCAM-1 and E-selectin, 4ng/ml TNFa (PeproTech Inc., Rocky Hill, NJ) was added 6 hours prior to harvesting. Cells were trypsinized and fixed with $1 \%$ PFA for $30 \mathrm{~min}$ at room temperature. ICAM-1, VCAM-1 and E-selectin expression was detected by anti-human ICAM-1 (MEM111, Monosan, Uden, The Netherlands), VCAM-1 (1G11, Hbt, Uden, The Netherlands) or E-selectin (ENA-1, a kind gift from Dr. 
W.A. Buurman, Maastricht University, The Netherlands) followed by incubation with biotin conjugated rabbit anti mouse IgG and Strep-PE (both DAKO, Glostrup, Denmark). Detection of leukocyte adhesion molecules is performed as described previously ${ }^{10}$.

For detection of activation markers on tumor infiltrated leukocytes, tumors and lymph nodes (axillary, brachial, inguinal, and mesenteric nodes) were harvested and disrupted to yield single cell suspensions. Cells were stained with anti-CD8 $\alpha$-PerCP mAb, and anti-CD69-FITC mAb to determine CD69 surface expression, and then fixed in $0.5 \%$ formaldehyde. For granzyme B intracellular staining, cells were fixed in Cytofix buffer (BD Pharmingen) for 15 min at $4^{\circ} \mathrm{C}$, permeabilized in saponin-containing Perm/Wash buffer (BD Pharmingen) for 15 min at $4{ }^{\circ} \mathrm{C}$, and stained with anti-CD8 $\alpha$-APC mAb and anti-granzyme B-PE mAb. Cells were then washed with Perm/Wash buffer and staining buffer (PBS containing $2 \%$ FCS and $0.02 \%$ azide), and resuspended in staining buffer. For Foxp3 intracellular staining, cells were initially stained for surface molecules with anti-CD4-FITC mAb and anti-CD25-PE $\mathrm{mAb}$, then washed and incubated in Fix/Perm solution (eBioscience) at $4^{\circ} \mathrm{C}$ between 0.5 and 18 hours. Cells were then washed in Permeabilization buffer (eBioscience), and incubated with anti-Foxp3$\mathrm{APC} \mathrm{mAb}$ (eBioscience) $30 \mathrm{~min}$ at $4^{\circ} \mathrm{C}$. Finally, cells were washed in Permeabilization buffer, and resuspended in staining buffer. All fluorescent antibodies were purchased from BD Pharmingen (San Diego, CA) or eBioscience (San Diego, CA).All stained cells were analyzed on a FACSCalibur flow cytometer using CellQuest software (BD Biosciences).

\section{Animals}

The animal studies with athymic nude mice (nu/nu, 5-6 weeks old) were performed in the University of Minnesota. The mice were purchased from the National Cancer Institute.

The experiments with C57Bl/6 mice (25-30gr; Charles River, Maastricht, The Netherlands), were performed in Maastricht and Minnesota. The local Ethical Review Committees on Animal Experiments approved the experiments.

\section{Intravital microscopy}

B16F10 tumors were grown in the flank of C57Bl/6 mice by s.c. injection of $10^{5}$ cells in $100 \mu \mathrm{l}$ in $0.9 \% \mathrm{NaCl}$ solution. Anti-angiogenesis drugs were used, i.e. the new designer peptides anginex $(n=7)$ and topomimetic of anginex, KM0118 (n=8). Mice were treated daily for 3 days $(10 \mathrm{mg} / \mathrm{kg} /$ day, i.p.) when tumors had a volume of about $80 \mathrm{~mm}^{3}$ (day 11). As controls tumor-bearing mice were left untreated $(\mathrm{n}=6)$. Intravital microscopic measurements were performed as described before ${ }^{10}$ on 
day 14. To enable intravital microscopic observations of leukocytes, 10-20 $\mu$ l of a Rhodamine $6 \mathrm{G}$ solution $(1 \mathrm{mg} / \mathrm{ml}$ in $0.9 \% \mathrm{NaCl}$ solution) was injected in the tail vein when needed. Tumor vessels where visualised using a Leitz intravital microscope adapted for telescopic imaging equipped with an SW25 objective lens (numerical aperture 0.60). Microscopic images were recorded using a CCD camera (C3077, Hamamatsu, Japan), coupled to an intensifier unit (C2400-80, Hamamatsu, Japan), and stored on DVD (DVR-7000, Panasonic) for offline analysis.

\section{Tumor growth experiments}

The xenograph mouse model (human epithelial ovarian carcinoma cell line, MA148 in athymic nude mice) and the syngeneic mouse tumor model (B16F10 melanoma cells inC56Bl6 mice) were initiated as described previously ${ }^{20,21}$. In either case, animals were randomized prior to the initiation of treatment. Tumor volume was determined by measuring the diameters of tumors with callipers and calculated by the equation for volume of a spheroid: $\left(a^{2} \times b \times \pi\right) / 6$, were $a$ is the with and $b$ the length of the tumor.

\section{Tissue extracts and Th1/Th2 Multiplex Cytokine detection}

Tissue extracts were prepared from snap frozen tumor samples. Briefly, frozen tissues were cut in $10 \mu \mathrm{m}$ sections, collected into ice-cold tubes and extracted in ice-cold extraction buffer (PBS containing protease inhibitor cocktail, Sigma P8340) using brief sonication. Extracts were harvested by centrifugation and the protein content was determined using the Quanti-iT Protein Assay kit and the Qubit fluorometer (Molecular Probes, Invitrogen). For cytokine analysis, extracts were adjusted to $1 \mathrm{mg} / \mathrm{ml}$ using mouse serum sample diluent (Bio-Rad, Laboratories Inc., Hercules CA) and analyzed using the Bio-Plex Murine Cytokine Th1/Th2 Panel (Bio-Rad Laboratories) according to the Bio-Plex Precision Pro Cytokine Assay instruction manual. The pre-mixed kit allowed the simultaneous detection of cytokines IL-2, IFN- $\gamma$, TNF- $\alpha$, IL-4, IL-5, IL-10, IL-12p70, and GM-CSF. Detection limits of cytokines are shown in Figure 5.5. Data acquisition and analysis was done using the Bio-Plex Manager 4.1 Operation System (Bio-Rad) applying five parameter logistics.

\section{Immunohistochemistry}

All immunohistochemical stainings were performed on acetone fixed frozen sections $(5 \mu \mathrm{m})$. Endogenous peroxidase was blocked by immersion in $0.3 \%$ hydrogen peroxidase in PBS for 30min and aspecific binding was blocked by PBS 
containing 20\% FCS and $0.1 \%$ Tween 20 for 15 min., followed by incubation with primary antibody.

Microvessel density determination - The sections were incubated with primary antibody rat anti mouse CD31 (Pharmingen BD Company, Woerden, The Netherlands) followed by peroxidase labelled goat anti rat IgG antibody (Immunotech, Marseille, France). The peroxidase activity was detected using diaminobenzidine (DAB; Sigma, Zwijndrecht, The Netherlands).

Leukocyte tumor infiltration and in vivo determination of ICAM-1 expression The sections were incubated with primary antibody rat anti mouse CD45 (MP33, culture supernatant), CD8 (53.6.27 culture supernatant), macrophage (LFA-1, culture supernatant, a kind gift from M. de Winter), CD25 (clone PC61, kind gift from A. Duivenstijn), PMN (NIMP3, culture supernatant) or ICAM-1 (R\&D Systems, Abingdon, United Kingdom). As secondary antibody, biotin labelled donkey anti rat IgG (Jackson ImmunoResearch Lab Inc., Soham, Cambridgeshire, UK) was used. Peroxidase activity was detected with DAB, after incubation of the sections with freshly prepared Avidin-biotin complex (Vectastain Lab Inc., Burlingame, CA).

All sections were counterstained with haematoxylin (Merck, Amsterdam, The Netherlands), dehydrated and mounted with entellan (Merck, Amsterdam, The Netherlands).

Table 5.1. Sequences of primers used in quantitative real-time RT-PCR

\begin{tabular}{llll}
\hline Gene & Species & Reverse primer $5^{\prime}$ - $^{\prime}$ & Forward primer $5^{\prime}$ - $^{\prime}$ \\
\hline$\beta$-Actin & $\mathrm{h}$ & CCTGTGTGGACTTGGGAGAG & CATTCCAAATATGAGATGCATT \\
$\beta$-Actin & $\mathrm{m}$ & GGAGGAAGAGGATGCGGCA & AGCTGTGCATGTTGCTCTA \\
ICAM-1 & $\mathrm{h}$ & TAGACACTTGAGCTCGGGCA & GGCCGGCCAGCTTATACAC \\
ICAM-1 & $\mathrm{m}$ & CGTCTTGCAGGTCATCTTAGGAG & GGCGGGAAAGTTCCTG \\
VCAM-1 & $\mathrm{h}$ & ACTCCTCACCTTCCCGCTC & TCAGATTGGAGACTCAGTCATGT \\
VCAM-1 & $\mathrm{m}$ & CATTCCTTACCACCCCATTG & AGTTGGGGATTCGGTTGTTC \\
E-selectin & $\mathrm{h}$ & TAAAGCCCTCATTGCATTGA & CCCGAAGGGTTTGGTGAG \\
\hline
\end{tabular}

Primer sequences are shown as large caps $\left(5^{\prime}-3^{\prime}\right) ; \mathrm{h}=$ human; $\mathrm{m}=$ mouse

Quantitative real time RT-PCR ( $q R T-P C R)$

Total RNA isolation from cultured cells or from tumor tissue, cDNA synthesis and quantitative real-time RT-PCR were performed essentially as described previously ${ }^{29}$ using SYBR Green PCR master mix (Eurogentech, Liege, Belgium) spiked with 
20nM fluorescein (Bio-Rad, Veenendael, The Netherlands). The expression of each target gene was normalized to the expression of the control gene beta-actin. Species specific primers can be found in Table 5.1.

All data were statistically analyzed using Mann-Whitney U tests (using SPSS-10 software). Correlation between variables was determined using Spearman's correlation test. Probabilities below 0.05 were considered statistically significant.

A

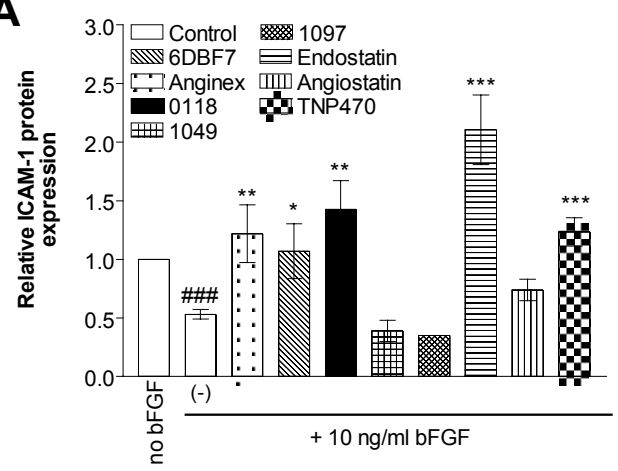

B

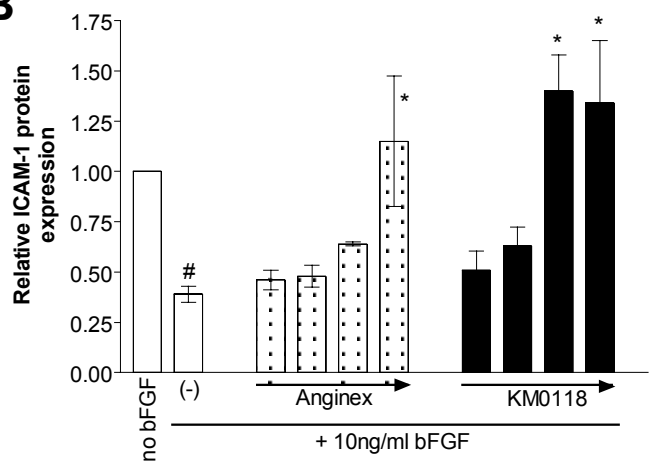

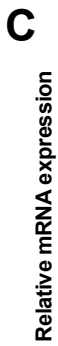

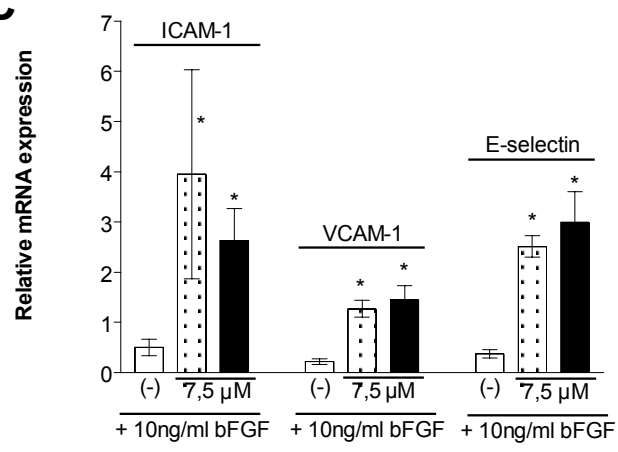

Figure 5.1. Angiostatic compounds normalize EC adhesion molecule expression in vitro. AB) FACS analysis of ICAM-1 protein expression on HUVEC, with or without bFGF treatment, after 3 days treatment with optimal concentrations of angiogenesis inhibitors. A) Anginex $(10 \mu \mathrm{M}), 6 \mathrm{DBF} 7(25 \mu \mathrm{M}), \mathrm{KM} 0118$ $(10 \mu \mathrm{M}), \quad \mathrm{XM1049}(10 \mu \mathrm{M}), \mathrm{XM1097}(10 \mu \mathrm{M})$, endostatin $(25 \mu \mathrm{M})$, angiostatin $(25 \mu \mathrm{M})$ and TNP470 (100ng/ml); B) 3 days treatment with different concentrations $(0.25,1,3$, and $7.5 \mu \mathrm{M})$ of anginex and 0118. C) Quantitative real-time RT-PCR analysis of the effect of treatment on mRNA expression of ICAM-1, VCAM-1 and E-selectin on HUVEC. Results are pre-sented as mean values $( \pm$ SEM) of 4 in-dependent experiments $[\# \mathrm{p}<0.05, \# \# \mathrm{p}<0.005$ versus no bFGF ; ${ }^{*} \mathrm{p}<0.05,{ }^{* *} \mathrm{p}<0.005,{ }^{* * *} \mathrm{p}<0.005$ versus control (-)]. 


\section{Results}

Angiostasis induced EC adhesion molecule expression and leukocyte adhesion.

We have previously shown that angiogenesis inhibitors can normalize EC adhesion molecule expression. Anginex was found to be the most effective angiostatic agent. Therefore anginex and a series of related compounds were investigated to further unravel the mechanistical insight into and application of this phenomenon. These compounds were shown to normalize bFGF-induced suppression of EC adhesion molecule levels, as demonstrated for ICAM-1. Anginex, its partial mimetic 6DBF7, and the topomimetic 0118, as well as other angiogenesis inhibitors, fully normalized bFGF- (Figure 5.1A and B) and VEGFinduced (not shown) suppression of ICAM-1 expression in dose dependent way. The 0118-related control compounds 1049 and 1097, lacking anti-angiogenesis activity, did not (Figure 5.1A). Similar results were found for VCAM-1 and Eselectin after induction by $\mathrm{TNF} \alpha$ (data not shown). These observations were confirmed at the mRNA level by real-time quantitative RT-PCR (qRT-PCR, Figure 5.1C).

Evidence that this also occurs in blood vessels in vivo is provided immunohistochemically in B16F10 melanoma tissues (Figure 5.2A). The enhanced
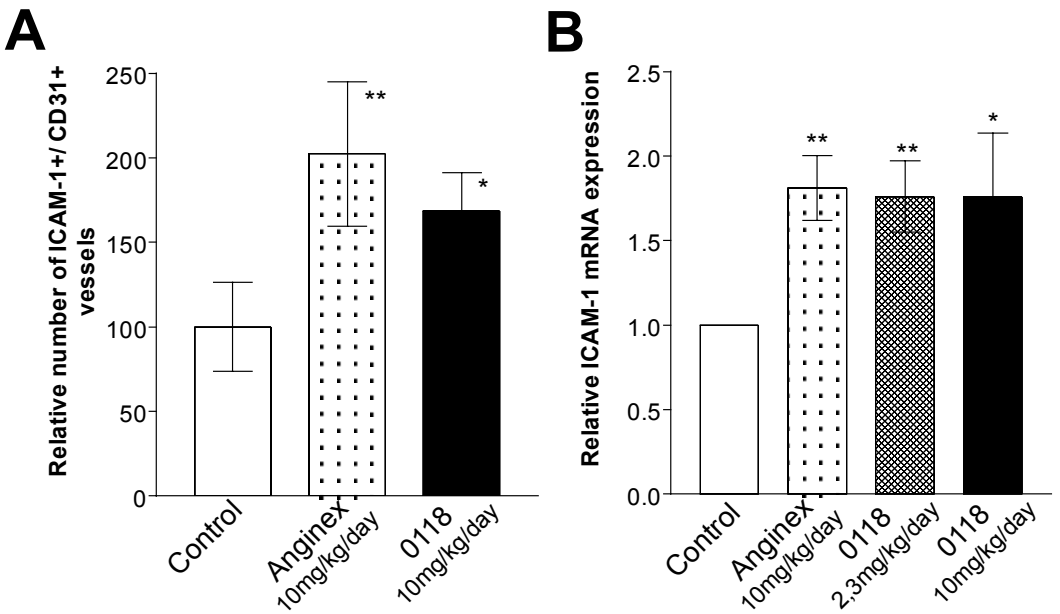

Figure 5.2. Anginex and 0118 upregulate EC adhesion molecule expression in vivo. A) Quantification of ICAM-1 positive vessels in B16F10 tumors of mice with or without anginex or 0118 treatment (all $n=6)$, shown as the relative number of ICAM-1 positive vessels per CD31 positive vessels compared to control (mean SEM, ${ }^{*} \mathrm{p}<0.05,{ }^{* *} \mathrm{p}<0.005$ ). B) Quantitative real-time RT-PCR analysis of the effect of treatment of mice on expression of ICAM-1 (using human specific primers) in vessels of MA148 tumor. Data are presented as relative expression $\left( \pm S E M,{ }^{*} \mathrm{p}<0.05,{ }^{* *} \mathrm{p}<0.005\right)$. 


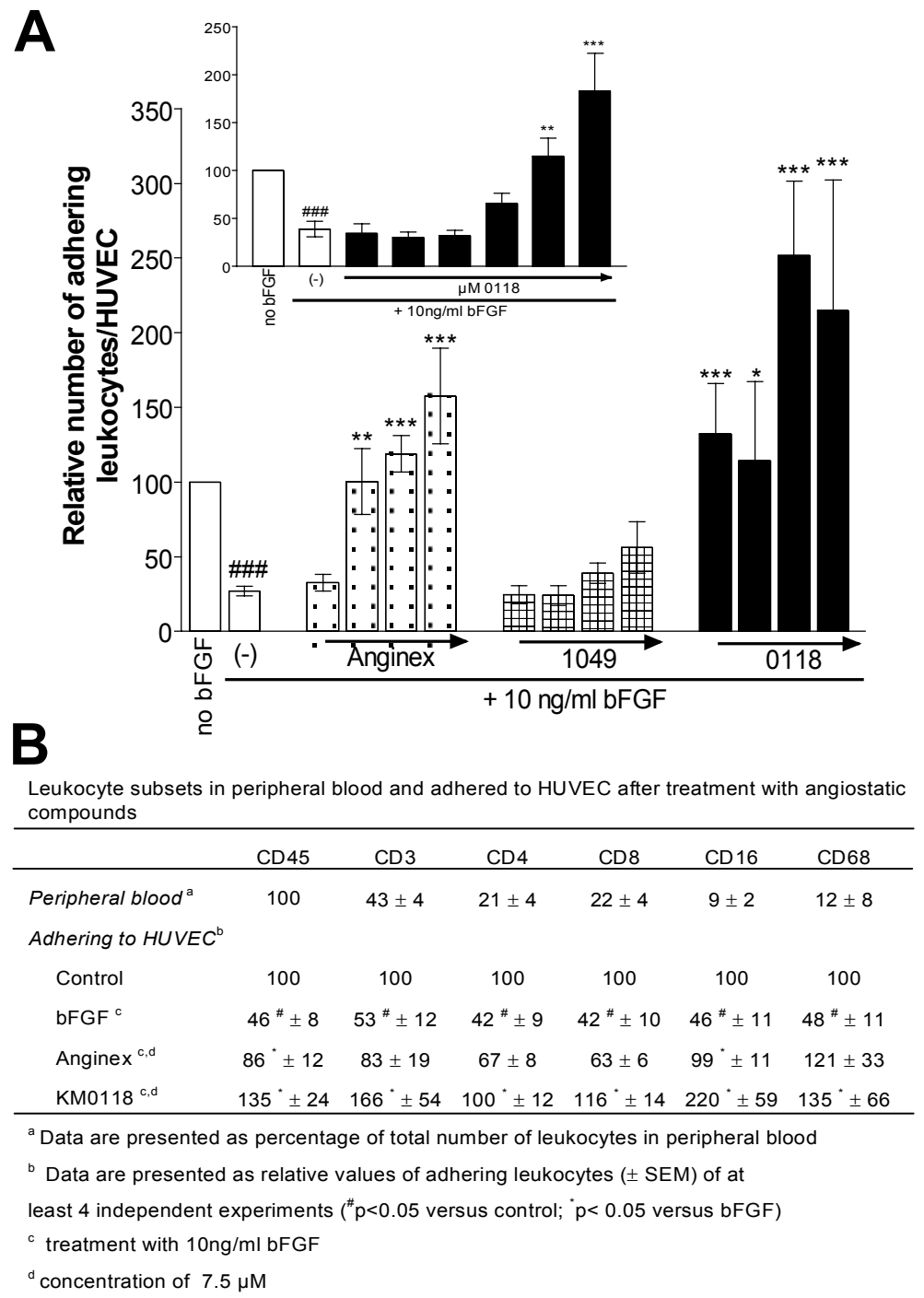

Figure 5.3. Anginex and related compounds upregulate leukocyte adhesion in vitro. A) Leukocyte adhesion experiments with CFSE-labelled blood leukocytes. HUVEC were treated with and without bFGF, and where indicated with increasing concentrations of anginex, 1049 or $0118(0.25,1,3$, and 7.5 $\mu \mathrm{M}$, as above) for 3 days prior adherence of leukocytes. The inset shows the titration of 0118 to $0.01 \mu \mathrm{M}$. Results are presented as the relative values of adhering leukocytes per HUVEC ('no bFGF' set to 100). B) Determination of different leukocyte subsets within the adherent population of leukocytes. $T$ lymphocytes (CD3), helper $\mathrm{T}$ cells (CD4), cytotoxic $\mathrm{T}$ cells (CD8), PMN/NK cells (CD16), and macrophages (CD68). Results are presented as the relative number of adhering leukocytes per HUVEC (mean values \pm SEM of at least 4 independent experiments $\left({ }^{*} p<0.05,{ }^{* *} p<0.005,{ }^{* * *} p<0.0005\right.$ versus bFGF alone, \#p<0.05, \#\# $<0.0005$ versus 'no $b F G F$ '). 
EC expression of ICAM-1 was confirmed by qRT-PCR. In a second model of MA148 human ovarian carcinoma, xenografted in nude mice, we also observed this regulation. Here we used mouse-specific primers ${ }^{29}$ to exclude a bias by expression of ICAM-1 by the tumor cells (Figure 5.2B).

We next investigated whether EC adhesion molecule normalization has impact on the capacity of leukocytes to adhere to EC. Stimulation of EC by bFGF reduced leukocyte adhesion by $>70 \%$. Treatment with anginex or 0118 normalized this suppression dose dependently (Figure 5.3A), whereas the negative control compound 1049 was ineffective. We determined that the major population of adhering leukocytes were $\mathrm{T}$ lymphocytes (data not shown). Normalization of leukocyte adhesion promoted by anginex and 0118 was notable for all leukocyte subsets tested (Figure 5.3B).

Table 5.2. Fluid dynamic parameters in tumor vessels of treated and non-treated mice. ${ }^{a}$

\begin{tabular}{lccc}
\hline & Control & Anginex & 0118 \\
\hline$n_{m} \mathrm{~b}$ & 6 & 7 & 8 \\
$n_{v} \mathrm{~b}$ & 37 & 31 & 37 \\
Diameter $(\mu M)$ & $35(25-40)$ & $30(25-40)$ & $30(25-40)$ \\
Centerline velocity $(\mathrm{mm} / \mathrm{s})$ & $0.8(0.2-0.9)$ & $0.9(0.7-1.4)$ & $1.1(0.8-1.4)^{* *}$ \\
$U\left(\mathrm{~s}^{-1}\right)^{\mathrm{b}}$ & $13(10-19)$ & $14(12-23)$ & $20.1(14-30)^{* *}$ \\
$Q\left(\mathrm{~mm}^{3} / \mathrm{s}\right) \mathrm{b}$ & $4.1 \times 10^{-4}\left(2-8 \times 10^{-4}\right)$ & $6 \times 10^{-4}\left(3-23 \times 10^{-4}\right)$ & $5 \times 10^{-4}\left(3-8 \times 10^{-4}\right)$ \\
\hline
\end{tabular}

a Data are presented as median values with interquartile ranges. Statistical significance was assessed in comparison to values in untreated mice $\left({ }^{* *} \mathrm{p}<0.005\right)^{\mathrm{b}} n_{m}$, number of mice; $n_{v}$, number of vessels; $U$ reduced velocity; $Q$ flow

Anginex and 0118 induce leukocyte-endothelium interactions in tumors.

In untreated mice, leukocyte-vessel wall interactions in B16F10 tumors are significantly reduced compared to those in normal tissue (Figure 5.4A). Interestingly, treatment with anginex or 0118 resulted in an approximate 3-fold increase in leukocyte-vessel wall interactions in these tumors (Figure 5.4B), and no change in leukocyte-vessel wall interactions in normal tissue (Figure 5.4C). Movies of these intravital microscopy experiments can be viewed at http://www.fdg.uni maas.nl/angiogenesislab/Mirrorsite/castermans\%20movies.htm, and still shots from these videos are exemplified in Fig. 3D-F for untreated, anginex treated, and 0118 treated mice, respectively. The total level of leukocyte-vessel wall interactions includes both rolling and adhering leukocytes. Discrimination between these two 
A

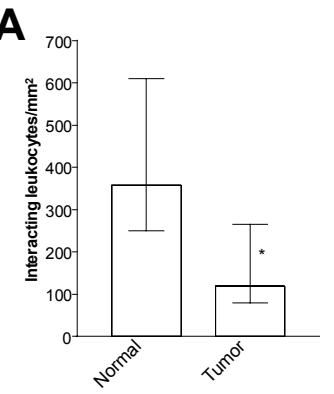

D

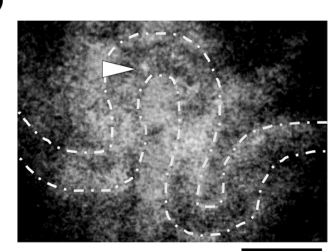

G

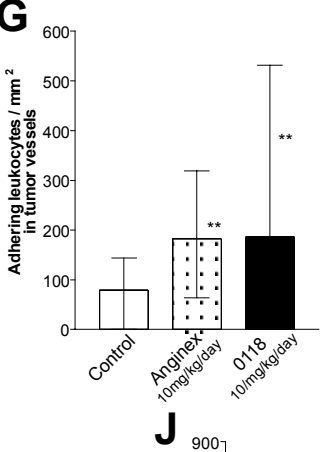

B

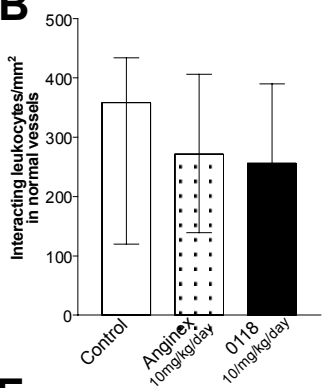

E

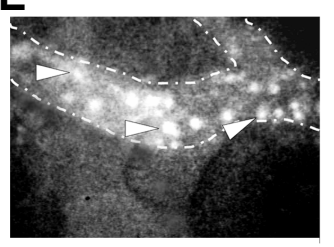

H

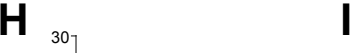

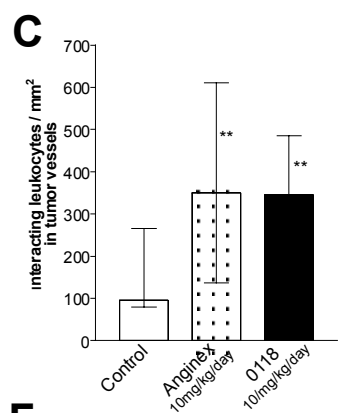

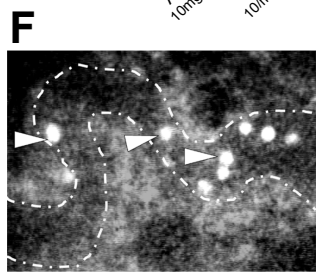

1
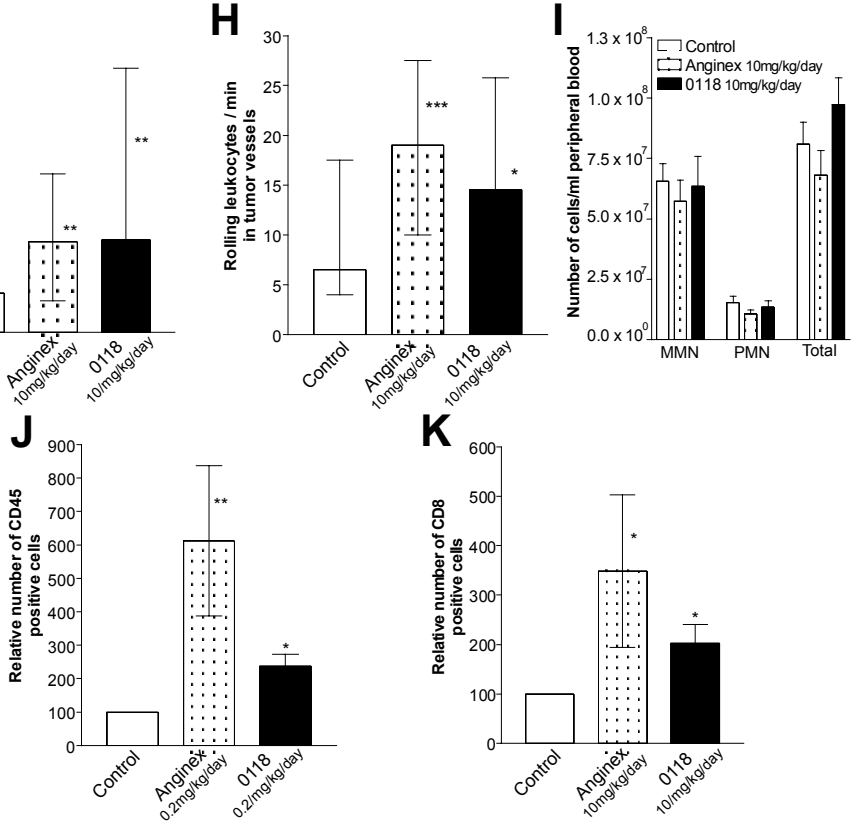

Figure 5.4. Angiogenesis inhibitors enhance leukocyte-vessel wall interactions and infiltration in tumors. Interacting leukocytes per $\mathrm{mm}^{2}$ vessel surface in (A) healthy tissue vessels compared to B16F10 tumor vessels in non-treated mice, (B) in tumor vessels and (C) in healthy tissue vessels after 3 days treatment with anginex or 0118. D-E) Intravital fluorescence microscopy images of vessels of untreated $(\mathrm{D}$, bar $=50 \mu \mathrm{m})$, anginex (E) and 0118 (F) treated mice. Number of adhering leukocytes per $\mathrm{mm}^{2}(\mathrm{G})$ and rolling leukocytes per minute $(\mathrm{H})$ in tumor vessels I) Number of circulating leukocytes (PMN and MMN) per ml peripheral blood (mean values \pm SEM, all $n=2$ ). For panels $A-C, G, H$ data are medians with interquartile ranges. Infiltrated $\mathrm{CD}_{4} 5^{+}(\mathbf{J})$ and $\mathrm{CD} 8^{+}(\mathbf{K})$ leukocytes in B16F10 melanoma after 3 days treatment. ${ }^{*} \mathrm{p}<0.05,{ }^{* *} \mathrm{p}<0.005,{ }^{* * *} \mathrm{p}<0.0005$ versus untreated mice. 
processes revealed that anginex and 0118 significantly increased leukocyte rolling as well as adhesion in tumor vessels (Figure 5.4G-H).

To exclude the possibility that the results are explained by activation of leukocytes themselves, we checked the number of circulating leukocytes (PMN and $\mathrm{MMN}$ ) in peripheral blood of treated mice and compared that to untreated animals. We found no difference among the three different groups (Figure 5.4I). We also found that the observed effects did not result from altered expression of the leukocyte adhesion molecules LFA-1 $\alpha$, LFA-1 $\beta$, VLA-4, and L-selectin on the peripheral blood leukocytes (data not shown).

Analysis of local fluid dynamic parameters showed a significant increase in blood flow velocity following treatment with 0118 (Table 5.2). This might reduce the number of leukocytes that interact with the vessel wall, which may mask an even higher induction of leukocyte-vessel wall interactions by 0118 . The results presented in Figure 5.4 can, therefore, not be explained by differences in fluid dynamic parameters.

A

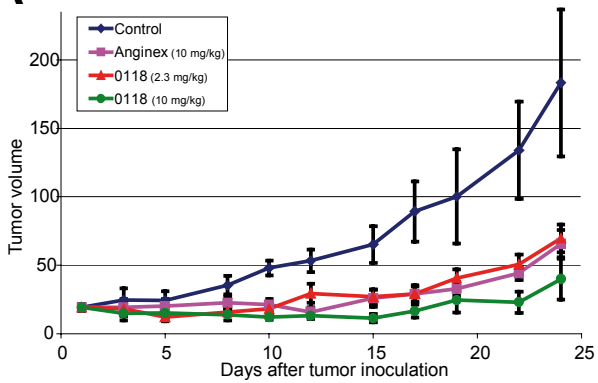

B

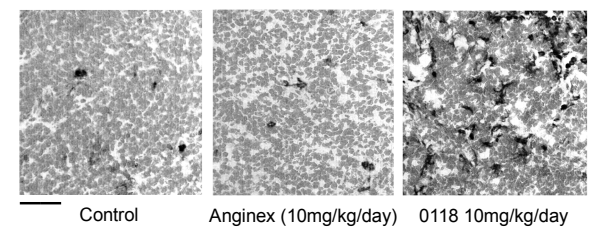

C

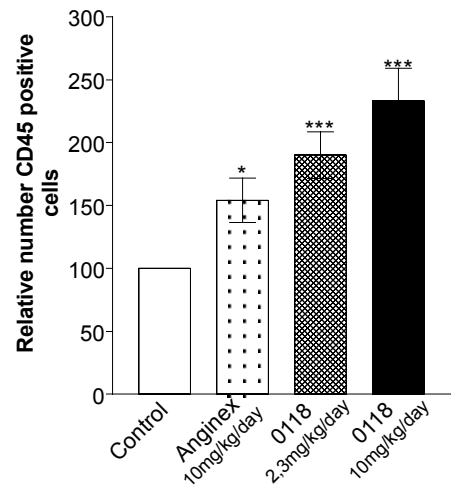

Figure 5.5. Anginex and 0118 enhance tumor leukocyte infiltration in the MA148 ovarian carcinoma. A) Tumor growth curves of MA148 ovarian carcinoma in mice treated with anginex or 0118 compared to untreated mice (all $n=7$ ). B) Immunohistochemical analysis of infiltration by $\mathrm{CD}_{4} 5^{+}$leukocytes in MA148 ovarian carcinoma of control and anginex or 0118 treated mice. The bar under control represents $40 \mu \mathrm{m}$. C) Quantification of infiltration by CD45+leukocytes in MA148 ovarian carcinoma. Data are presented as relative values (means $\pm \mathrm{SEM}$, ${ }^{*} \mathrm{p}<0.05,{ }^{* *} \mathrm{p}<0.005,{ }^{* * *} \mathrm{p}<0.0005$ versus control). 

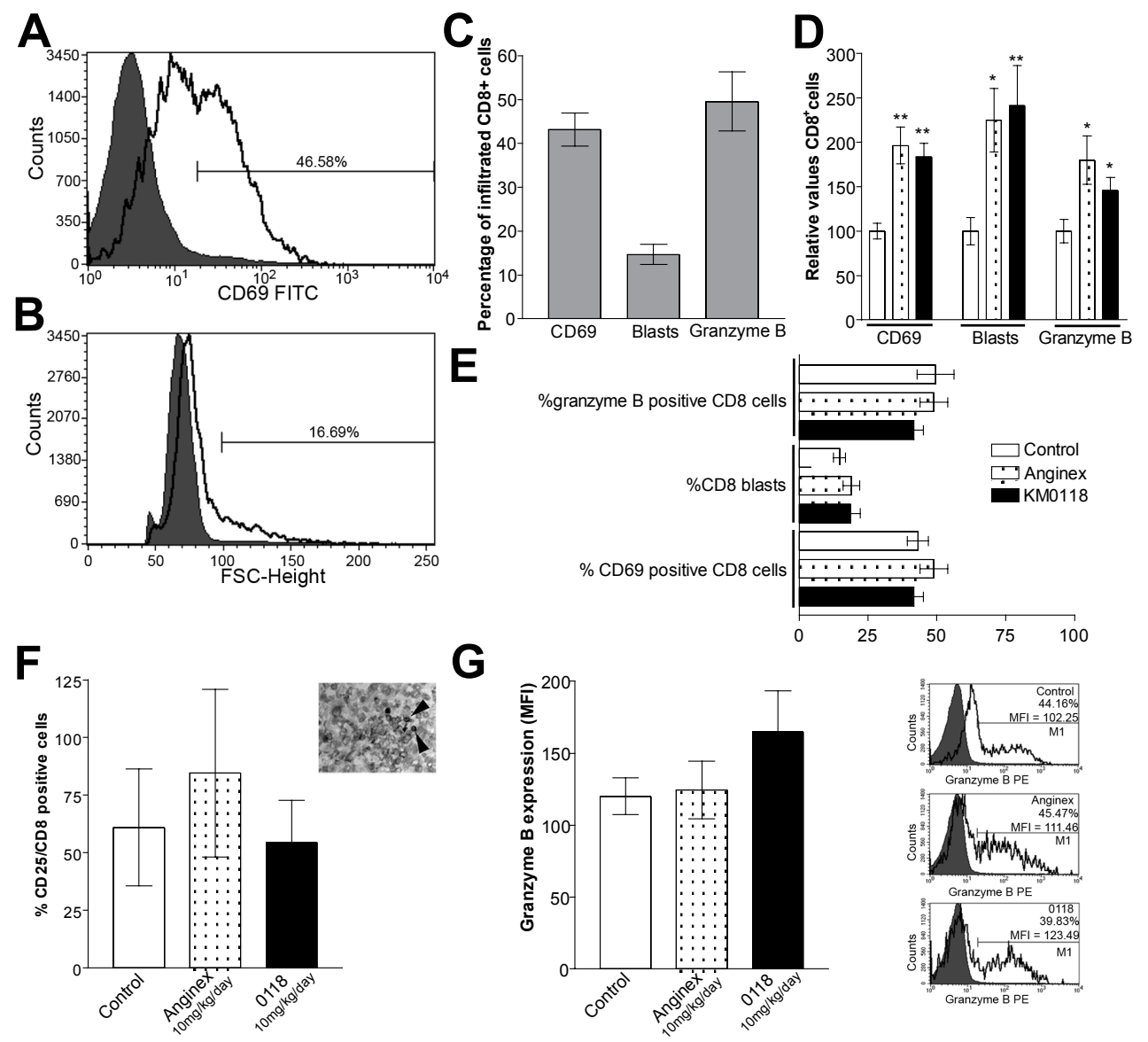

G
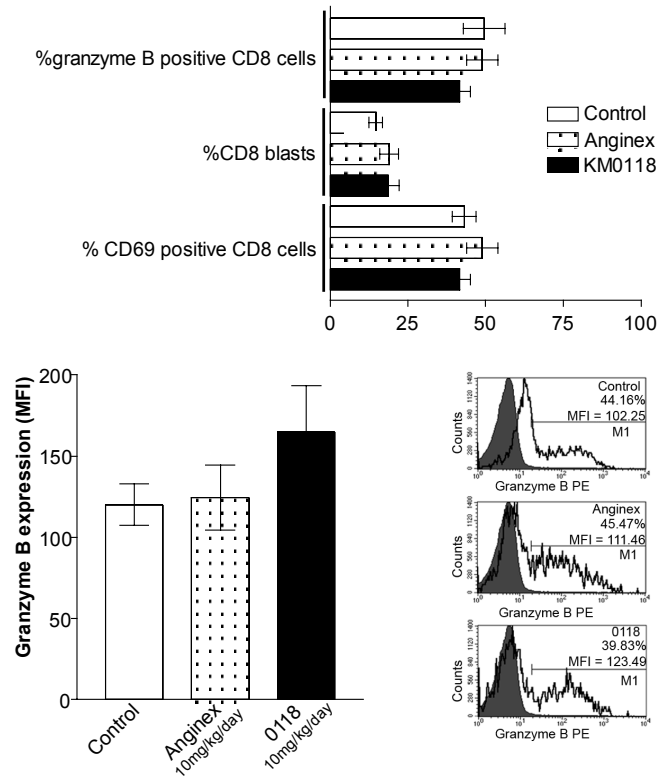

Figure 5.6. Infiltration of tumor-specific cytotoxic T lymphocytes. A) FACS analysis of B16F10 mouse melanoma infiltrated CD8 $\mathrm{T}$ cells and lymph node (LN) CD8 T cells (grey) stained for CD69. B) Forward scatter (FSC) of tumor infiltrated versus LN infiltrated (grey) CD8 ${ }^{+}$blasts. C) Percentage of activated infiltrated cytotoxic $\mathrm{T}$ cells $(\mathrm{n}=9)$ in untreated tumors, based on expression levels of activation markers D) Relative numbers of activated tumor-infiltrating CD8 T cells expressing activation markers (all $n=9$ ). E) Percentage of activated tumor infiltrated CD8 cells per total number of tumor infiltrated CD8 cells in treated versus non-treated mice, based on high expression of the indicated activation markers. F) percentage of $\mathrm{CD} 25^{+} / \mathrm{CD} 8^{+} \mathrm{T}$ cells in treated versus non-treated mice assessed by immunohistochemistry (inset). G) Granzyme B expression (MFI) for tumor infiltrated $\mathrm{CD}^{+}$cells expressing high Granzyme B (anginex, n=7; 0118, n=9; control, n=9). Right panel shows representative histograms of tumor infiltrated CD8+ cells stained for Granzyme B (LN=grey, tumor=clear), with the gates used for determining Granzyme B MFI shown. Results are presented as relative mean values of 2 independent experiments $\left( \pm \mathrm{SEM},{ }^{*} \mathrm{p}<0.05,{ }^{* *} \mathrm{p}<0.005,{ }^{* * *} \mathrm{p}<0.0005\right)$. 
Anginex and 0118 enhance leukocyte infiltration into the tumor.

To establish that an increase in leukocyte adhesion to tumor endothelium eventually leads to increased leukocyte infiltration into the tumor, we used immunohistochemistry to quantify subsets of leukocytes within the tumor. In the immunocompetent B16F10 mouse model, we observed an increase in CD45 cells (Figure 5.4J) following treatment, as well as elevated numbers of $\mathrm{CD}^{+} \mathrm{T}$ cells (Figure 5.4K), macrophages and PMNs (not shown). Also in a second mouse model of MA148 ovarian carcinoma (Figure 5.5A) ${ }^{20-22,27}$, the relative number of $\mathrm{CD}_{4} 5^{+}$cells is significantly higher in anginex and 0118 treated mice, compared to non-treated mice (Figure 5.5B-C).

\section{Infiltration of tumor-specific cytotoxic T lymphocytes.}

The results presented above indicate that the number of infiltrated $\mathrm{CD}^{+} \mathrm{T}$ lymphocytes increased after angiostatic treatment. To investigate whether they are active, we first of all performed flow cytometry of single cell suspensions derived from excised tumors, since this technique allows quantification and phenotyping of leukocytes present in the tumor tissue. Several lines of evidence indicate that effector (cytotoxic) T lymphocytes infiltrated in tumors are activated. (i) A large percentage of $\mathrm{CD}^{+} \mathrm{T}$ lymphocytes (approximately 40-50\%) expresses high levels of the leukocyte activation marker CD69 (Figure 5.6A,C) and the rest have somewhat elevated levels in comparison to lymph node CD8 T cells. (ii) A subset

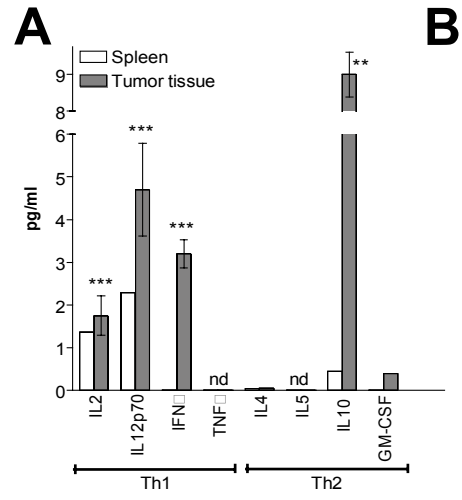

B

Cytokine content in tumor tissues of mice with or without angiostatic therapy

\begin{tabular}{lccccc}
\hline & & \multicolumn{3}{c}{ Tumor tissue } \\
\cline { 3 - 5 } & Sensitivity & Control & Anginex & $\mathbf{0 1 1 8}$ & \multirow{2}{*}{ Spleen } \\
\hline IL2 & 0.20 & $1.90 \pm 0.52$ & $1.60 \pm 0.45$ & $1.40 \pm 0.31$ & 1.57 \\
IL12p70 & 0.20 & $4.90 \pm 1.14$ & $2.80 \pm 0.79$ & $3.40 \pm 0.53$ & 2.49 \\
IFNy & 0.50 & $3.70 \pm 0.50$ & $1.80 \pm 0.56$ & $3.00 \pm 0.67$ & nd \\
IL4 & 0.18 & $0.20 \pm 0.02$ & $0.20 \pm 0.01$ & $0.20 \pm 0.02$ & 0.22 \\
IL10 & 1.00 & $10.0 \pm 3.03$ & $6.30 \pm 0.85$ & $5.10 \pm 1.11$ & 1.44 \\
\hline
\end{tabular}

All data are normalized to $1 \mathrm{mg} / \mathrm{ml}$ total protein, unit is $\mathrm{pg} / \mathrm{ml}$, presented as means \pm SEM. nd: value below sensitivity range.

Figure 5.7. Th1 and Th2 cytokine profile in mouse tumors. A) Quantification of cytokine protein expression in tumor tissue of untreated mice compared to levels in healthy spleen. Values, normalized to $1 \mathrm{mg} / \mathrm{ml}$ total protein, are presented as means $( \pm$ SEM) after adjustment to the sensitivity of the test (significant expression over sensitivity values ${ }^{* *} \mathrm{p}<0.005,{ }^{* * *} \mathrm{p}<0.0005$ ). B) Cytokine protein expression in tumor tissues of mice treated with anginex $(n=4)$ or $0118(n=6)$ compared to untreated mice $(n=11)$. Values, normalized to $1 \mathrm{mg} / \mathrm{ml}$ total protein, are presented as means ( \pm SEM). 
of about $20 \%$ of $\mathrm{CD} 8^{+} \mathrm{T}$ lymphocytes displays a blast phenotype as determined by light scatter characteristics (Figure 5.6B-C). (iii) About 50\% of the infiltrated CD8 ${ }^{+}$ $\mathrm{T}$ cells expresses high granzyme $\mathrm{B}$ levels (Figure 5.6E), suggesting cytotoxic potential and the ability to induce apoptosis in tumor cells. (iv) Results from immunohistochemistry indicate that $50-70 \%$ of infiltrated $\mathrm{CD} 8^{+} \mathrm{T}$ cells express the early activation marker IL-2R $\alpha$ (CD25, Figure 5.6F). In addition to these arguments, multiplex cytokine (protein) determination of Th1 and Th2 profiles, showed a rich cytokine milieu in tumor tissue of these mice, indicating immunogenicity of the tumor tissue. Interestingly, Th1 cytokines are more prominently expressed (IL-2, IL-12p70 and IFN- $\gamma$ ) as compared to Th2 cytokines, of which only IL10 is present (Figure 5.7A). All these data combined, suggest that immune cells infiltrated in the tumor tissue, have seen tumor antigen and support tumor-specific immunity.

Analysis of tumor tissue from mice treated with angiostatic compounds indicates that while the number of activated cytotoxic $\mathrm{T}$ cells is increased (Figure 5.6D), the level of leukocyte activation remains essentially the same as in tumors from untreated animals. This conclusion is based on analysis of (i) the ratio of activated CD8 cells to total number of CD8 cells (Figure 5.6E), and (ii) expression level of the activation marker granzyme $\mathrm{B}$ by individual cells expressing high levels (determined by mean fluorescence intensity, Figure 5.6G). In addition, expression of Th1 cytokines IL-2 and IFN- $\gamma$ is maintained after treatment with either anginex or 0118 (Figure 5.7B), while a slight but non-significant decrease of IL10 expression can be observed after angiostatic therapy.
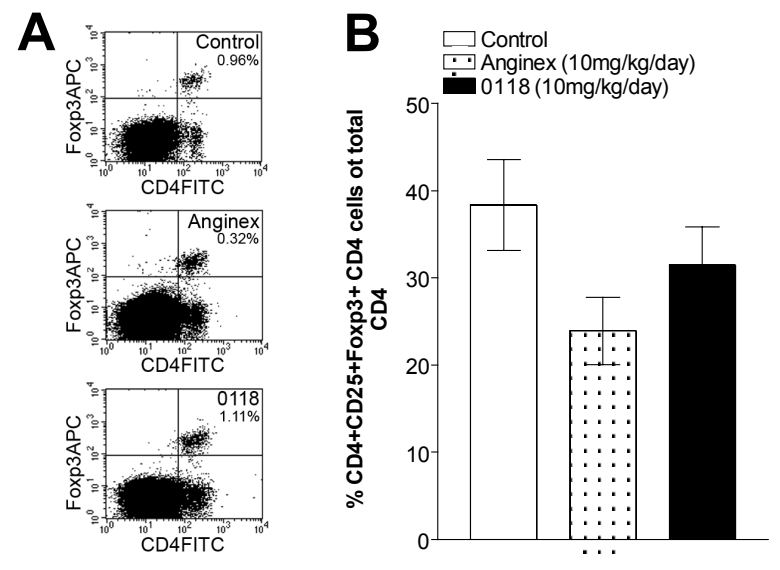

Figure 5.8. Innate immunity of infiltrated leukocytes. A) Flow cytometric analysis of regulatory $\mathrm{T}$ cells $\left(\mathrm{CD} 4{ }^{+} \mathrm{CD} 25^{+} \mathrm{Foxp}^{+}\right)$. B) Percentage of $\mathrm{CD} 4{ }^{+} \mathrm{CD} 25^{+} \mathrm{Foxp} 3+$ in treated versus non-treated mice with B16F10 mouse melanoma. Results are represented as mean values of 2 independent experiments \pm SEM 
Regulatory $T$ cells are not preferentially attracted.

Flow cytometric analysis was also used to quantify the number of regulatory $\mathrm{T}$ cells $\left(\mathrm{CD} 4{ }^{+} \mathrm{CD} 25^{+} \mathrm{Foxp} 3{ }^{+} \mathrm{T}\right.$ cells, Figure $\left.5.8 \mathrm{~A}\right)$, which are known to control and dampen the induction and effector phase of the immunological defense system ${ }^{30}$. Even though regulatory $\mathrm{T}$ cells were present in tumors from both untreated and treated (anginex and 0118) mice, the percentage of these cells in tumors from all three groups was about the same (Figure 5.8B).

\section{Discussion}

We previously demonstrated that ongoing angiogenesis, aside from allowing tumors to grow and metastasize, contributes to the escape of tumors from host immunity 7,10 . This led us to hypothesize that inhibition of angiogenesis might be able to overcome the immunocompromized state, break the tolerance and make tumors more vulnerable to host immunity. The present study supports this hypothesis by demonstrating that the angiogenesis inhibitors in general, and especially anginex and 0118 , potentiate host immunity in tumors by normalization of suppressed EC adhesion molecules and promoting leukocyte adhesion and infiltration into the tumor tissue. All leukocyte subsets show this enhanced infiltration. Furthermore, we show that the number of activated effector $\mathrm{T}$ cells with specific anti-tumor activity, is significantly increased after angiostatic treatment. Regulatory $\mathrm{T}$ cells, that can modulate specific immunity, are not preferentially attracted.

This paper suggests that the mechanism by which angiogenesis inhibitors, especially anginex and 0118, enhance anti-tumor immunity, is upregulation of EC adhesion molecules that are necessary for leukocyte-vessel wall interactions. It is an attractive idea that tumors mimicked this phenomenon from the concept of developmental biology that growing organs in a developing embryo should be protected by an immunocompromized setting ${ }^{31}$. How this suppressed expression, which should in principle be a reversible situation, is managed remains largely unknown. However, in a recent report we described, at least for ICAM-1 in tumor $\mathrm{EC}$, that upregulation occurs through epigenetic mechanisms, mainly at the level of histone deacetylation regulation of the tumor endothelial chromatin ${ }^{32}$. We also previously demonstrated that angiogenesis mediated suppression of ICAM-1 is caused by inhibition of phosphorylation of IkB, the natural inhibitor of NFkB ${ }^{33}$. Both these processes are reversible and, therefore, interesting targets for therapy. 
FACS analysis as well as immunohistochemistry showed that the total amount of leukocytes within the tumor tissue is increased after angiostatic therapy with anginex or 0118. This was clearly caused by the effect on EC since the activation status of leukocytes remained the same as determined by expression of leukocyte adhesion molecules, leukocyte activation markers and cytokine profiles. While the effect on EC might be shared among angiogenesis inhibitors in general 28 , the lack of activity on leukocytes is not. Other known angiogenesis inhibitors have been described to affect tumor immunity by a direct effect on leukocytes. For example, the endogenous angiogenesis inhibitor angiostatin displays an anti-inflammatory role, since kringles 1-3 and kringle 4 directly interact with leukocyte $\beta 1$ - and $\beta 2$ integrins, respectively. Angiostatin functions in this capacity by inhibiting $\beta 1$ - and $\beta 2$-integrin-mediated adhesion of leukocytes to proteins of the extracellular matrix and the endothelium, as well as by inhibiting their transmigration through the endothelium ${ }^{34}$. TNP-470 can, under certain conditions, inhibit T cell proliferation and NK-mediated tumor cell killing ${ }^{35}$. Interestingly, this compound has also been described to positively contribute to immunity by stimulation of B lymphocytes ${ }^{36}$. The angiogenesis inhibitor interleukin $12{ }^{37}$ was also found to stimulate immunity by the activation of cytotoxic $\mathrm{T}$ cells ${ }^{38}$. Because direct manipulation of immune functions, even stimulatory ones, may be unwanted, the use of anginex and 0118 may have an advantage in the development for clinical use.

Infiltration of leukocytes into tumors is not always beneficial to the process of tumor growth inhibition. For example, infiltration of macrophages is generally unwanted, because type M2 macrophages can produce angiogenic factors that stimulate blood vessel formation and stimulate tumor cell motility ${ }^{39-41}$. An increase in macrophage infiltration can also promote tumor growth ${ }^{42-44}$. Indeed, some studies report that tumor-associated macrophages (TAMs) are negatively correlated to survival ${ }^{45,46}$. However, others report that their presence can improve survival ${ }^{47-49}$. It has been suggested that anti-tumor activities of TAMs can be improved by replacing type M2 macrophages with type M1 which can act to inhibit tumor growth ${ }^{39-41}$. In our mouse tumor models, we observed neither an increase in tumor metastasis following angiostatic treatment, nor an increase in angiogenesis despite the increase of macrophages within the tumor tissue. This may suggest that type M2 macrophages are less abundant, or that a possible negative function was masked by the beneficial effects of other leukocyte subsets.

Most studies conclude that an increase in T-lymphocytes in tumor tissue improves patient survival 50-55. Alternatively, some studies report that substantial lymphocytic infiltration promotes tumor progression 56,57 . In the latter studies it is suggested that this immune response can not act to attenuate tumor growth. This apparent paradox may be resolved by assessing the activation status (CD69 or granzyme B) and cytolytic capacity of tumor-infiltrated lymphocytes ${ }^{58-62}$. In this 
regard, regulatory $\mathrm{T}$ cells $\left(\mathrm{T}_{\text {regs, }} \mathrm{CD} 4^{+} \mathrm{CD} 25^{+} \mathrm{Foxp}^{+}{ }^{+}\right.$cells) are undesirable. $\mathrm{T}_{\text {regs }}$ can protect the host from autoimmunity by suppressing self-reactive cells, but they also prevent the induction of tumor-associated antigen specific immunity ${ }^{63,64}$ and inhibit the effector function of cytotoxic T cells and NK cells 65,66. Different studies show that anti-tumor therapy can be improved by removal of this immunoregulatory host mechanism, which permits a robust and persistent immune response in the tumor ${ }^{67-69}$. Although in our studies the presence of $\mathrm{T}_{\text {regs }}$ was not high, it would be interesting to study the effect of blocking of $\mathrm{CD}^{+} \mathrm{CD} 25^{+} \mathrm{Foxp}^{+}$cell function, which would likely improve the effects of our angiostatic compounds on tumor growth inhibition.

The balance between Th1 and Th2 cytokine patterns determines the antitumor immune response. Th1 is essential for cellular immunity, whereas Th2 plays a key role in humoral immunity ${ }^{70,71}$. Therefore, one can imagine that Th1 cytokine profile is indicative of specific anti-tumor immunity ${ }^{71}$. Interestingly, patient studies have shown that an imbalance between Th1 and Th2 cytokine patterns in favor of Th1, improves patient survival 72-74. We found in B16F10 melanoma a rich cytokine milieu containing mainly Th1 cytokines, indicative of the immunogenic feature of melanoma. Since the expression of Th1 cytokines in our study is maintained after angiostatic treatment and the Th2 cytokine expression may be even slightly reduced, we suggest that specific anti-tumor immunity remains present within tumors of treated mice and angiostatic therapy reduces tumor growth partly by recruiting activated leukocytes into the milieu. The presence of a Th1 cytokine pattern in tumors of animals treated with anginex or 0118, may be a great promise for future immunological combination strategies.

In conclusion, the present study has demonstrated that treatment of tumors with the angiostatic agents, anginex and 0118, reduces tumor growth not only by destruction and growth inhibition of tumor vessels, but also by stimulation of tumor specific immunity. Our results strongly support the concept of combining immunotherapeutic approaches with angiostatic treatment to improve cancer therapy in the clinic.

\section{Acknowledgements}

We acknowledge the excellent technical assistance of A. Brandl and L. van Eijk. This work was supported by grants from the Dutch Cancer Society (UM-20012529) and the Deutsche Forschungsgemeinschaft DFG (E.N.: SFBTR36 and SFB455). 


\section{References}

1. Folkman J. Tumor angiogenesis. Adv Cancer Res. 1985;43:175-203.

2. Folkman J, Shing Y. Angiogenesis. J Biol Chem. 1992;267:10931-10934.

3. Ferrara N. Role of vascular endothelial growth factor in the regulation of angiogenesis. Kidney Int. 1999;56:794-814.

4. Ferrara N, Gerber HP, LeCouter J. The biology of VEGF and its receptors. Nat Med. 2003;9:669676.

5. Kerbel RS. Tumor angiogenesis: past, present and the near future. Carcinogenesis. 2000;21:505-515.

6. Basilico C, Moscatelli D. The FGF family of growth factors and oncogenes. Adv Cancer Res. 1992;59:115-165.

7. Griffioen AW, Damen CA, Blijham GH, Groenewegen G. Tumor angiogenesis is accompanied by a decreased inflammatory response of tumor-associated endothelium. Blood. 1996;88:667-673.

8. Griffioen AW, Damen CA, Martinotti S, Blijham GH, Groenewegen G. Endothelial intercellular adhesion molecule-1 expression is suppressed in human malignancies: the role of angiogenic factors. Cancer Res. 1996;56:1111-1117.

9. Melder RJ, Koenig GC, Witwer BP, Safabakhsh N, Munn LL, Jain RK. During angiogenesis, vascular endothelial growth factor and basic fibroblast growth factor regulate natural killer cell adhesion to tumor endothelium. Nat Med. 1996;2:992-997.

10. Dirkx AE, Oude Egbrink MG, Kuijpers MJ, et al. Tumor angiogenesis modulates leukocyte-vessel wall interactions in vivo by reducing endothelial adhesion molecule expression. Cancer Res. 2003;63:2322-2329.

11. O'Reilly MS, Holmgren L, Shing Y, et al. Angiostatin: a novel angiogenesis inhibitor that mediates the suppression of metastases by a Lewis lung carcinoma. Cell. 1994;79:315-328.

12. Hajitou A, Grignet C, Devy L, et al. The antitumoral effect of endostatin and angiostatin is associated with a down-regulation of vascular endothelial growth factor expression in tumor cells. Faseb J. 2002;16:1802-1804.

13. Sim BK, MacDonald NJ, Gubish ER. Angiostatin and endostatin: endogenous inhibitors of tumor growth. Cancer Metastasis Rev. 2000;19:181-190.

14. O'Reilly MS, Boehm T, Shing Y, et al. Endostatin: an endogenous inhibitor of angiogenesis and tumor growth. Cell. 1997;88:277-285.

15. Rastinejad F, Polverini PJ, Bouck NP. Regulation of the activity of a new inhibitor of angiogenesis by a cancer suppressor gene. Cell. 1989;56:345-355.

16. Gupta SK, Singh JP. Inhibition of endothelial cell proliferation by platelet factor-4 involves a unique action on S phase progression. J Cell Biol. 1994;127:1121-1127.

17. D'Amato RJ, Loughnan MS, Flynn E, Folkman J. Thalidomide is an inhibitor of angiogenesis. Proc Natl Acad Sci U S A. 1994;91:4082-4085.

18. van der Schaft DW, Toebes EA, Haseman JR, Mayo KH, Griffioen AW. Bactericidal/permeabilityincreasing protein (BPI) inhibits angiogenesis via induction of apoptosis in vascular endothelial cells. Blood. 2000;96:176-181.

19. Ingber $D$, Fujita $T$, Kishimoto $S$, et al. Synthetic analogues of fumagillin that inhibit angiogenesis and suppress tumour growth. Nature. 1990;348:555-557.

20. van der Schaft DW, Dings RP, de Lussanet QG, et al. The designer anti-angiogenic peptide anginex targets tumor endothelial cells and inhibits tumor growth in animal models. Faseb J. 2002;16:1991-1993.

21. Dings RP, van der Schaft DW, Hargittai B, Haseman J, Griffioen AW, Mayo KH. Anti-tumor activity of the novel angiogenesis inhibitor anginex. Cancer Lett. 2003;194:55-66.

22. Griffioen AW, van der Schaft DW, Barendsz-Janson AF, et al. Anginex, a designed peptide that inhibits angiogenesis. Biochem J. 2001;354:233-242. 
23. Dings RP, Yokoyama Y, Ramakrishnan S, Griffioen AW, Mayo KH. The designed angiostatic peptide anginex synergistically improves chemotherapy and antiangiogenesis therapy with angiostatin. Cancer Res. 2003;63:382-385.

24. Dings RP, Arroyo MM, Lockwood NA, et al. Beta-sheet is the bioactive conformation of the antiangiogenic anginex peptide. Biochem J. 2003;373:281-288.

25. Mayo KH, Dings RP, Flader C, et al. Design of a partial peptide mimetic of anginex with antiangiogenic and anticancer activity. J Biol Chem. 2003;278:45746-45752.

26. Dings RP, Nesmelova I, Griffioen AW, Mayo KH. Discovery and development of anti-angiogenic peptides: A structural link. Angiogenesis. 2003;6:83-91.

27. Dings RP, Chen X, Hellebrekers DM, et al. Design of nonpeptidic topomimetics of antiangiogenic proteins with antitumor activities. J Natl Cancer Inst. 2006;98:932-936.

28. Dirkx AE, oude Egbrink MG, Castermans $\mathrm{K}$, et al. Anti-angiogenesis therapy can overcome endothelial cell anergy and promote leukocyte-endothelium interactions and infiltration in tumors. Faseb J. 2006;20:621-630.

29. Thijssen VL, Brandwijk RJ, Dings RP, Griffioen AW. Angiogenesis gene expression profiling in xenograft models to study cellular interactions. Exp Cell Res. 2004;299:286-293.

30. Becker C, Stoll S, Bopp T, Schmitt E, Jonuleit H. Regulatory T cells: present facts and future hopes. Med Microbiol Immunol (Berl). 2006;195:113-124.

31. Rouwet EV, Beuk RJ, Heineman E, Slaaf DW, oude Egbrink MG. Effect of repetitive asphyxia on leukocyte-vessel wall interactions in the developing chick intestine. J Pediatr Surg. 2000;35:49-55.

32. Hellebrekers DM, Castermans K, Vire E, et al. Epigenetic regulation of tumor endothelial cell anergy: silencing of intercellular adhesion molecule-1 by histone modifications. Cancer Res. 2006;66:10770-10777.

33. Flati V, Pastore LI, Griffioen AW, et al. Endothelial cell anergy is mediated by bFGF through the sustained activation of p38-MAPK and NF-kappaB inhibition. Int J Immunopathol Pharmacol. 2006;19:761-773.

34. Chavakis T, Athanasopoulos A, Rhee JS, et al. Angiostatin is a novel anti-inflammatory factor by inhibiting leukocyte recruitment. Blood. 2005;105:1036-1043.

35. Schoof DD, Obando JA, Cusack JC, Jr., Goedegebuure PS, Brem H, Eberlein TJ. The influence of angiogenesis inhibitor AGM-1470 on immune system status and tumor growth in vitro. Int J Cancer. 1993;55:630-635.

36. Antoine N, Daukandt M, Heinen E, Simar LJ, Castronovo V. In vitro and in vivo stimulation of the murine immune system by AGM-1470, a potent angiogenesis inhibitor. Am J Pathol. 1996;148:393398.

37. Majewski S, Marczak M, Szmurlo A, Jablonska S, Bollag W. Interleukin-12 inhibits angiogenesis induced by human tumor cell lines in vivo. J Invest Dermatol. 1996;106:1114-1118.

38. Voest EE, Kenyon BM, O'Reilly MS, Truitt G, D'Amato RJ, Folkman J. Inhibition of angiogenesis in vivo by interleukin 12. J Natl Cancer Inst. 1995;87:581-586.

39. Mantovani A, Allavena P, Sica A. Tumour-associated macrophages as a prototypic type II polarised phagocyte population: role in tumour progression. Eur J Cancer. 2004;40:1660-1667.

40. Mantovani A, Schioppa T, Porta C, Allavena P, Sica A. Role of tumor-associated macrophages in tumor progression and invasion. Cancer Metastasis Rev. 2006.

41. Sica A, Schioppa T, Mantovani A, Allavena P. Tumour-associated macrophages are a distinct M2 polarised population promoting tumour progression: potential targets of anti-cancer therapy. Eur J Cancer. 2006;42:717-727.

42. Condeelis J, Pollard JW. Macrophages: obligate partners for tumor cell migration, invasion, and metastasis. Cell. 2006;124:263-266.

43. Coussens LM, Werb Z. Inflammation and cancer. Nature. 2002;420:860-867.

44. Dirkx AE, Egbrink MG, Wagstaff J, Griffioen AW. Monocyte/macrophage infiltration in tumors: modulators of angiogenesis. J Leukoc Biol. 2006.

45. Coussens LM, Werb Z. Inflammatory cells and cancer: think different! J Exp Med. 2001;193:F23-26. 
46. Mulder WJ, Strijkers GJ, Habets JW, et al. MR molecular imaging and fluorescence microscopy for identification of activated tumor endothelium using a bimodal lipidic nanoparticle. Faseb J. 2005;19:2008-2010.

47. Funada Y, Noguchi T, Kikuchi R, Takeno S, Uchida Y, Gabbert HE. Prognostic significance of CD8+ T cell and macrophage peritumoral infiltration in colorectal cancer. Oncol Rep. 2003;10:309313.

48. Ohno S, Inagawa H, Dhar DK, et al. The degree of macrophage infiltration into the cancer cell nest is a significant predictor of survival in gastric cancer patients. Anticancer Res. 2003;23:5015-5022.

49. Toomey D, Harmey J, Condron C, Kay E, Bouchier-Hayes D. Phenotyping of immune cell infiltrates in breast and colorectal tumours. Immunol Invest. 1999;28:29-41.

50. Cho Y, Miyamoto M, Kato K, et al. CD4+ and CD8+ T cells cooperate to improve prognosis of patients with esophageal squamous cell carcinoma. Cancer Res. 2003;63:1555-1559.

51. Eerola AK, Soini Y, Paakko P. A high number of tumor-infiltrating lymphocytes are associated with a small tumor size, low tumor stage, and a favorable prognosis in operated small cell lung carcinoma. Clin Cancer Res. 2000;6:1875-1881.

52. Hiraoka K, Miyamoto M, Cho Y, et al. Concurrent infiltration by CD8+ T cells and CD4+ T cells is a favourable prognostic factor in non-small-cell lung carcinoma. Br J Cancer. 2006;94:275-280.

53. Menard S, Tomasic G, Casalini $P$, et al. Lymphoid infiltration as a prognostic variable for earlyonset breast carcinomas. Clin Cancer Res. 1997;3:817-819.

54. Zhang L, Conejo-Garcia JR, Katsaros D, et al. Intratumoral $\mathrm{T}$ cells, recurrence, and survival in epithelial ovarian cancer. N Engl J Med. 2003;348:203-213.

55. Oshikiri T, Miyamoto M, Shichinohe T, et al. Prognostic value of intratumoral CD8+ T lymphocyte in extrahepatic bile duct carcinoma as essential immune response. J Surg Oncol. 2003;84:224-228.

56. Ali AA, McMillan DC, Matalka, II, McNicol AM, McArdle CS. Tumour T-lymphocyte subset infiltration and tumour recurrence following curative resection for colorectal cancer. Eur J Surg Oncol. 2004;30:292-295.

57. Bromwich EJ, McArdle PA, Canna K, et al. The relationship between T-lymphocyte infiltration, stage, tumour grade and survival in patients undergoing curative surgery for renal cell cancer. $\mathrm{Br} \mathrm{J}$ Cancer. 2003;89:1906-1908.

58. Georgiannos SN, Renaut A, Goode AW, Sheaff M. The immunophenotype and activation status of the lymphocytic infiltrate in human breast cancers, the role of the major histocompatibility complex in cell-mediated immune mechanisms, and their association with prognostic indicators. Surgery. 2003;134:827-834.

59. Ladanyi A, Somlai B, Gilde K, Fejos Z, Gaudi I, Timar J. T-cell activation marker expression on tumor-infiltrating lymphocytes as prognostic factor in cutaneous malignant melanoma. Clin Cancer Res. 2004;10:521-530.

60. Schumacher K, Haensch W, Roefzaad C, Schlag PM. Prognostic significance of activated CD8(+) T cell infiltrations within esophageal carcinomas. Cancer Res. 2001;61:3932-3936.

61. Shabtai M, Ye H, Frischer Z, Martin J, Waltzer WC, Malinowski K. Increased expression of activation markers in renal cell carcinoma infiltrating lymphocytes. J Urol. 2002;168:2216-2219.

62. Nakano O, Sato M, Naito Y, et al. Proliferative activity of intratumoral CD8(+) T-lymphocytes as a prognostic factor in human renal cell carcinoma: clinicopathologic demonstration of antitumor immunity. Cancer Res. 2001;61:5132-5136.

63. Beyer M, Schultze JL. Regulatory T cells in cancer. Blood. 2006;108:804-811.

64. Zou W. Regulatory T cells, tumour immunity and immunotherapy. Nat Rev Immunol. 2006;6:295307.

65. Lizee G, Radvanyi LG, Overwijk WW, Hwu P. Improving antitumor immune responses by circumventing immunoregulatory cells and mechanisms. Clin Cancer Res. 2006;12:4794-4803.

66. Ralainirina N, Poli A, Michel T, et al. Control of natural killer (NK) cell functions by CD4+CD25+ regulatory T cells. J Leukoc Biol. 2006. 
67. Dannull J, Su Z, Rizzieri D, et al. Enhancement of vaccine-mediated antitumor immunity in cancer patients after depletion of regulatory T cells. J Clin Invest. 2005;115:3623-3633.

68. Sutmuller RP, van Duivenvoorde LM, van Elsas A, et al. Synergism of cytotoxic T lymphocyteassociated antigen 4 blockade and depletion of $\mathrm{CD} 25(+)$ regulatory $\mathrm{T}$ cells in antitumor therapy reveals alternative pathways for suppression of autoreactive cytotoxic $\mathrm{T}$ lymphocyte responses. $\mathrm{J}$ Exp Med. 2001;194:823-832.

69. Waldmann TA. Effective cancer therapy through immunomodulation. Annu Rev Med. 2006;57:6581.

70. Mosmann TR, Sad S. The expanding universe of T-cell subsets: Th1, Th2 and more. Immunol Today. 1996;17:138-146.

71. Nishimura T, Iwakabe K, Sekimoto M, et al. Distinct role of antigen-specific T helper type 1 (Th1) and Th2 cells in tumor eradication in vivo. J Exp Med. 1999;190:617-627.

72. Sato M, Goto S, Kaneko R, Ito M, Sato S, Takeuchi S. Impaired production of Th1 cytokines and increased frequency of Th2 subsets in PBMC from advanced cancer patients. Anticancer Res. 1998;18:3951-3955.

73. Goto S, Sato M, Kaneko R, Itoh M, Sato S, Takeuchi S. Analysis of Th1 and Th2 cytokine production by peripheral blood mononuclear cells as a parameter of immunological dysfunction in advanced cancer patients. Cancer Immunol Immunother. 1999;48:435-442.

74. Kusuda T, Shigemasa K, Arihiro K, Fujii T, Nagai N, Ohama K. Relative expression levels of Th1 and Th2 cytokine mRNA are independent prognostic factors in patients with ovarian cancer. Oncol Rep. 2005;13:1153-1158. 
Chapter 5 


\section{Chapter 6}

\section{Epigenetic regulation of tumor endothelial cell anergy; silencing of ICAM-1 by histone modifications}

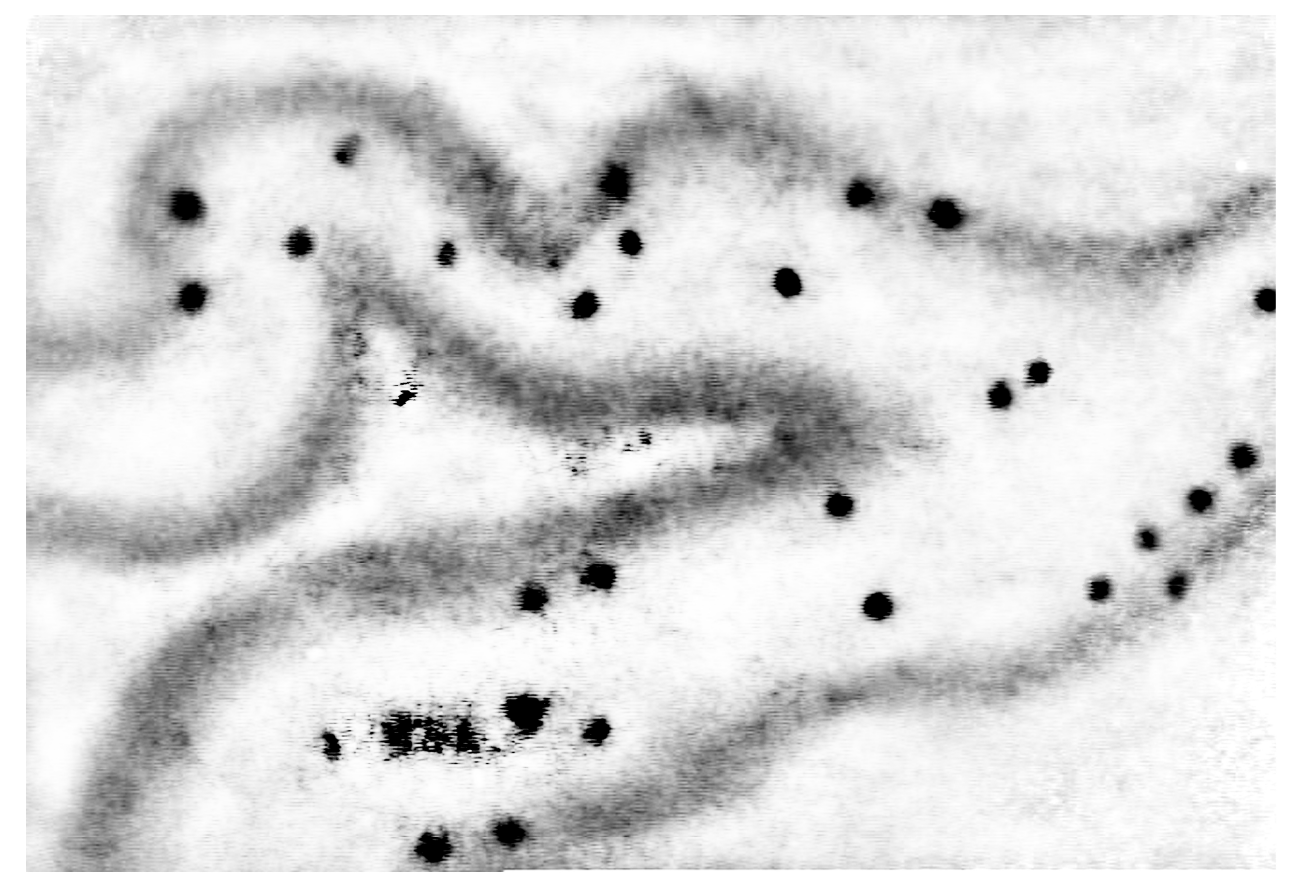

Debby M.E.I. Hellebrekers, Karolien Castermans, Emmanuelle Viré, Ruud P.M. Dings, Nicole T.H. Hoebers, Kevin H. Mayo, Mirjam G.A. oude Egbrink, Grietje Molema, François Fuks, Manon van Engeland \& Arjan W. Griffioen

Cancer Res. 2006 Nov 15;66(22):10770-7. 


\section{Abstract}

Tumors can escape from immunity by repressing leukocyte adhesion molecule expression on tumor endothelial cells (EC), and by rendering EC unresponsive to inflammatory activation. This EC anergy is induced by angiogenic growth factors and results in reduced leukocyte-vessel wall interactions, thereby attenuating infiltration of leukocytes into the tumor. This report describes a novel mechanism of EC anergy regulation. We recently reported that DNA methyltransferase (DNMT)- and histone deacetylase (HDAC) inhibitors have angiostatic activity. Here, we studied whether epigenetic mechanisms regulate this angiogenesismediated escape from immunity. We found that DNMT inhibitors 5-aza-2'deoxycytidine and zebularine, as well as HDAC inhibitor trichostatin A, reexpressed ICAM-1 on tumor-conditioned EC in vitro, resulting in restored leukocyte-EC adhesion. In addition, treatment with DNMT- or HDAC inhibitors in vivo also restored ICAM-1 expression on tumor EC from two different mouse tumor models. Furthermore, leukocyte-vessel wall interactions in mouse tumors were increased by these compounds, as measured by intravital microscopy, resulting in enhanced leukocyte infiltration. We demonstrate that ICAM-1 downregulation in tumor EC is associated with ICAM-1 promoter histone H3 deacetylation and loss of histone $\mathrm{H} 3$ lysine 4 methylation, but not with DNA hypermethylation. In conclusion, our data show that ICAM-1 is epigenetically silenced in tumor EC by promoter histone modifications, which can be overcome by DNMT- and HDAC inhibitors, suggesting a new molecular mechanism based on which novel therapeutic approaches for cancer can be pursued. 


\section{Introduction}

Leukocyte rolling on, adhesion to, and diapedesis through the tumor vessel wall are processes of key importance to immune surveillance, as well as to immunotherapy, a well-established anti-cancer approach ${ }^{1}$. Leukocyte-vessel wall interactions are mediated by endothelial cell (EC) adhesion molecules, such as intercellular adhesion molecule-1 and -2 (ICAM-1 and -2), vascular cell adhesion molecule-1 (VCAM-1), E-selectin, and CD34 ${ }^{2}$. Interference in the expression of EC adhesion molecules is one of the mechanisms tumors have developed to escape the immune response. We and others have shown previously that by producing angiogenic factors, such as vascular EC growth factors (VEGFs) and basic fibroblast growth factors (FGFs), tumors down-regulate vascular adhesion molecule expression ${ }^{3-6}$. This angiogenesis-mediated EC anergy to inflammatory signals results in diminished leukocyte-vessel wall interactions and, therefore, decreased inflammatory infiltration 7,8 .

Epigenetic mechanisms play a crucial role in regulation of gene expression by affecting chromatin accessibility. Different epigenetic processes are interconnected in gene silencing 9. DNA methylation and histone modifications are two important epigenetic mediators of transcriptional repression 10,11. Aberrant epigenetic regulation is a frequent event in cancer cells, where DNA hypermethylation and histone deacetylation within the promoters of tumor suppressor genes result in undesirable gene silencing ${ }^{12-14}$. Due to the reversibility of epigenetic events, drugs that inhibit DNA methyltransferases (DNMTs) or histone deacetylases (HDACs) can synergistically reactivate epigenetically silenced tumor suppressor genes, thereby suppressing tumor cells in vitro and in vivo ${ }^{14,15}$. Considerable promise lies in the further development of epigenetic therapies that already have demonstrated anti-tumorigenic effects for several malignancies ${ }^{16-18}$.

In contrast to the increasing knowledge on epigenetic aberrations in tumor cells, there is almost nothing known about the role of DNA methylation and histone modifications in regulation of gene expression in tumor EC. Recently, we and others have shown that DNMT- and HDAC inhibitors are potent angiostatic agents that inhibit EC growth in vitro and in vivo ${ }^{19,20}$. Since regulation of adhesion molecule expression in tumor EC is pivotal to anti-tumor immunity and ICAM-1 is the key EC adhesion molecule ${ }^{21}$, we investigated whether epigenetic mechanisms are involved in the regulation of ICAM-1 expression in tumor EC. Here, it is reported for the first time that epigenetic events regulate adhesion molecule expression and leukocyte infiltration in tumors. We found that ICAM-1 expression in tumor EC and leukocyte-EC adhesion are restored by DNMT- and HDAC inhibitors, resulting in enhanced inflammatory infiltration. Our results 
demonstrate that ICAM-1 is epigenetically silenced in angiogenically-stimulated EC through promoter histone modifications.

\section{Methods}

\section{Cells, cultures and reagents}

Human umbilical vein endothelial cells (HUVEC), mouse b.END5 brain endothelioma cells (ECACC, Salisbury, United Kingdom), mouse B16F10 melanoma cells (kindly provided by dr. J. Fidler, Houston, Texas) and human LS174T colon tumor cells were cultured as previously described 7,19. Quiescent EC were prepared by culturing for 3 days in the presence of $2 \%$ serum. Tumor conditions were mimicked by a 6-day exposure to $10 \mathrm{ng} / \mathrm{ml}$ basic Fibroblast Growth Factor (bFGF; Peprotech, London, UK) and $10 \mathrm{ng} / \mathrm{ml}$ Vascular Endothelial Growth Factor (VEGF; Peprotech). During the last 3 days, tumor-conditioned EC were treated with the DNA methyltransferase (DNMT) inhibitors 5-aza-2'deoxycytidine (DAC; $200 \mathrm{nM}{ }^{14}$ ) (Sigma, Zwijndrecht, the Netherlands) or zebularine $\left(100 \mu \mathrm{M}^{22}\right)$ (obtained from NCI, Bethesda, US), or with the histone deacetylase (HDAC) inhibitor trichostatin A (TSA; $300 \mathrm{nM}{ }^{14}$ ) (Wako, Neuss, Germany), replacing drugs and culture medium every 24 hours, as described previously 14,19. Tumor-conditioned EC treated during the last 3 days with a combination of DAC and TSA were first treated with DAC (200 nM) for $48 \mathrm{~h}$, with drug and medium replaced $24 \mathrm{~h}$ after the beginning of the treatment, followed by medium replacement and addition of TSA (300 nM) for a further $24 \mathrm{~h}{ }^{14,15}$. When applied, TNF $\alpha$ (HUVEC: $4 \mathrm{ng} / \mathrm{ml}$; Peprotech, b.END5: $40 \mathrm{ng} / \mathrm{ml}$; Peprotech) was added $6 \mathrm{~h}$ prior to harvesting 7 .

\section{FACS analysis}

The expression of ICAM-1 on HUVEC was determined by mouse anti-human ICAM-1 monoclonal antibody (MEM111, Monosan, Uden, The Netherlands), as described previously ${ }^{8}$. ICAM-1 expression on b.END5 cells was determined using rat anti-mouse ICAM-1 monoclonal antibody (CD54; R\&D systems, Abingdon, UK), as described previously ${ }^{7}$.

\section{Quantitative real-time RT-PCR ( $q R T-P C R$ )}

Total RNA was isolated from cultured cells or frozen tissue sections using the RNeasy RNA isolation kit (Qiagen, Hilden, Germany) according to the supplier's protocol. cDNA synthesis and quantitative real-time RT-PCR were performed as 
described previously ${ }^{23}$ using SYBR Green PCR master mix (Applied Biosystems, Nieuwekerk a/d IJssel, The Netherlands). Primer sequences are listed in Table 6.1.

Table 6.1. Quantitative real-time RT-PCR primers

\begin{tabular}{llll}
\hline Gene & species & Forward $\left(5^{\prime} \rightarrow 3^{\prime}\right)$ & Reverse $\left(5^{\prime} \rightarrow 3^{\prime}\right)$ \\
\hline cyclo A & human & CTCGAATAAGTTTGACTTGTGTTT & CTAGGCATGGGAGGGAACA \\
& mouse & ATTTCTTTTGACTTGCGGGC & AGACTTGAAGGGGAATG \\
ICAM-1 & human & GGCCGGCCAGCTTATACAC & TAGACACTTGAGCTCGGGCA \\
& mouse & GTGGCGGGAAAGTTCCTG & CGTCTTGCAGGTCATCTTAGGAG \\
VCAM-1 & human & TCAGATTGGAGACTCAGTCATGT & ACTCCTCACCTTCCCGCTC \\
& mouse & AGTTGGGGATTCGGTTGTTC & CATTCCTTACCACCCCATTG \\
E-selectin & human & CCCGAAGGGTTTGGTGAG & TAAAGCCCTCATTGCATTGA \\
& mouse & CCAGAATGGCGTCATGGA & TAAAGCCCTCATTGCATTGA \\
\hline
\end{tabular}

\section{Adhesion assay}

Human peripheral blood leukocytes were isolated by Ficoll density gradient centrifugation (Amersham, Uppsala, Sweden) and labelled with 5-(and -6)carboxyfluorescein diacetate, succinimidyl ester (CFSE; Molecular probes, Leiden, The Netherlands). Cells were washed twice and subsequently adhered for $1 \mathrm{hr}$ at room temperature to confluent HUVEC cultures. Non-adhering cells were removed by washing with pre-warmed culture medium. Cells were harvested and fixed in $1 \%$ paraformaldehyde (PFA, Merck, Amsterdam, The Netherlands) for 30 minutes at room temperature. Leukocyte-HUVEC adhesion was measured both by fluorescence activated cell sorter (FACS) analysis by detecting the number of CFSE-labelled leukocytes, and by counting under an inverted microscope.

\section{Mouse tumor models and intravital microscopy}

All animal experiments were approved by the local ethical review committee. At day $0,10^{5}$ B16F10 cells or $10^{6}$ LS174T cells were inoculated subcutaneously on the right flank of 6 week old C57BL/6 and Swiss nu/nu mice (obtained from Charles River, Maastricht, The Netherlands), respectively. Between day 6 and 9 (B16F10) or between day 10 and 14 (LS174T) the tumors became visible and treatments were initiated. Zebularine $(\mathrm{n}=5)$, at doses of $1000 \mathrm{mg} / \mathrm{kg}{ }^{24}$, and TSA $(\mathrm{n}=5)$, at doses of 1 $\mathrm{mg} / \mathrm{kg}{ }^{20}$, were administered daily by intraperitoneal injection in a solution of $0.9 \%$ saline for 7 (B16F10) or 10 (LS174T) days. Tumor volumes were measured as described previously ${ }^{19}$. Intravital microscopic measurements of B16F10 flank tumors were performed after 7 days of treatment. Mice were anesthetized by s.c. 
administration of a mixture of ketamine $(0.1 \mathrm{mg} / \mathrm{g}$ b.w. Nimatek; Ad Usem Veterinarium, Cuijk, The Netherlands) and xylazine $(0.02 \mathrm{mg} / \mathrm{g}$ b.w. Sedamun; Ad Usem Veterinarium). Intravital microscopy was performed as described before ${ }^{7}$. Body temperature was kept at $37^{\circ} \mathrm{C}$ by an infrared heating lamp. To enable intravital microscopic observation of leukocytes, 10-20 $\mu \mathrm{l}$ of a Rhodamine 6G solution (Sigma Chemical Co., St. Louis, MO; $1 \mathrm{mg} / \mathrm{ml}$ ) was injected into a tail vein. Images were recorded on DVD for off-line analysis.

Vessel diameter, centerline blood flow velocity, reduced velocity, local blood flow, leukocyte rolling and leukocyte adhesion were determined as before 7,25 . Vessel diameters were determined using a home-built image-shearing device. Centerline blood flow velocity was measured by frame-to-frame analysis, using the fastest passing fluorescent leukocyte as a marker. Average velocity was calculated as centerline velocity/1.6, and reduced velocity as average velocity/diameter. Local blood flow was calculated as follows: $\pi *$ (diameter/2) ${ }^{2}$ * (average velocity).

The level of leukocyte rolling was determined by counting the number of rolling cells passing a vessel segment per minute. Leukocytes were considered as rolling when their velocity along the vessel wall was at least an order of magnitude lower than that of the free-flowing blood cells. The level of leukocyte adhesion was assessed in a 100- $\mu$ m vessel segment, and expressed as number of cells per endothelial surface area (assuming the cross-section of the vessels to be circular). Leukocytes were considered adherent when they remained stationary for at least $30 \mathrm{~s}$.

\section{Immunohistochemistry}

Frozen sections of tumor tissues were stained using rat anti-mouse CD45 (gift from Dr. A Duijvesteijn, Maastricht), which was detected by biotinylated donkey anti-rat Ig antibody (Jackson Immuno Research Laboratories, Inc.) and avidinbiotin-HRP complex (Dako). The staining was visualised with DAB and the slides were counterstained with haematoxylin. $\mathrm{CD}^{4} 5^{+}$cells were counted in 3 independent areas in each section (using a $0.25 \mathrm{~mm}^{2}$ grid at a 200 times magnification) by two independent observers.

\section{Bisulfite Sequencing}

Genomic DNA was isolated using the Puregene DNA Isolation Kit (Gentra Systems, Biozym, Landgraaf, The Netherlands). Bisulfite modification of genomic DNA was carried out as described previously ${ }^{19}$. Bisulfite-treated DNA samples were then purified with a Wizard Genomic DNA Purification Kit (Promega, Leiden, The Netherlands), and desulfonated before ethanol precipitation. 
PCR products were cloned using the TA cloning kit (Invitrogen, Breda, The Nether-lands) and single colonies were picked and sequenced. Primer sequences are listed in Table 6.2.

Table 6.2. ICAM-1 Bisulfite sequencing primers

\begin{tabular}{lll}
\hline Position & Forward $\left(5^{\prime} \rightarrow 3^{\prime}\right)$ & Reverse $\left(5^{\prime} \rightarrow 3^{\prime}\right)$ \\
\hline$(-1247 ;-873)$ & GTTTTTGGATGGTTAGTGATT & AAAACTAAAACAACAACCCCC \\
$(-893 ;-489)$ & GGGGGTTGTTGTTTTAGTTT & CCTCCACTAAAAAATACCCCT \\
$(-583 ;-300)$ & GAGGTGTTTGGTTTTGTTTTGG & TTTTAAATACTACCAACTTCCCC \\
$(-322 ;-17)$ & GGGGAAGTTGGTAGTATTTAAA & CTAACCACCTAAAAACCAAAA \\
\hline
\end{tabular}

ChIP assay

Chromatin immunoprecipitation (ChIP) assays of an ICAM-1 proximal promoter region (-230 to -56) were performed essentially as described ${ }^{26}$ using anti-acetylHistone H3 (Lys 9 and Lys 14), or anti-dimethyl-Histone H3 (Lys 4) antibody (both from Upstate Biotechnology, Lake Placid, New York). One primer set for GAPDH was used to amplify a 128-bp fragment of the genomic sequence to serve as an internal control ${ }^{27}$. All PCR reactions were optimized with input DNA to ensure that PCR products were in the linear range of amplification. Primer sequences are listed in Table 6.3. PCR products were size-separated by agarose gel electrophoresis and bands were quantified using Molecular Analyst 2.1 software. Enrichment was calculated by taking the ratio between the net intensity of the ICAM1 PCR product and the net intensity of the GAPDH PCR product for the bound sample and dividing this by the same ratio calculated for the input samples ${ }^{27}$.

Table 6.3. ICAM-1 ChIP primers

\begin{tabular}{lll}
\hline Position & Forward $\left(5^{\prime} \rightarrow 3^{\prime}\right)$ & Reverse $\left(5^{\prime} \rightarrow 3^{\prime}\right)$ \\
\hline$(-230 ;-56)$ & TGGAGGCCGGGAGCAG & AAACCTCGCGCCTTCCC
\end{tabular}

\section{Statistical Analysis}

Data obtained from intravital microscopic experiments are presented as medians with interquartile ranges because of their nonsymmetrical distribution. Other data are presented as mean values \pm SEM. Differences between two independent data groups were tested with the Mann-Whitney U test using SPSS 10.0.5 software. Correlation between variables was determined using Spearman's correlation test. Statistical analysis for the tumor volumes was done by means of the two-way ANOVA test. 


\section{Results}

\section{DNMT- and HDAC inhibitors restore ICAM-1 expression in tumor-conditioned EC}

By releasing angiogenic factors, tumors suppress adhesion molecule expression on tumor endothelial cells (EC), thereby reducing leukocyte-vessel wall interactions and inflammatory infiltration $3,4,7$. To examine whether epigenetic mechanisms are involved in regulation of adhesion molecule expression on tumor EC, the effects of DNA methyltransferase (DNMT)- and histone deacetylase (HDAC)- inhibitors on EC adhesion molecule expression were studied in vitro. In tumor-conditioned HUVEC, ICAM-1 protein expression was downregulated by $81 \%$ compared to that in quiescent HUVEC $(\mathrm{p}<0.01$, Figure 6.1A). This is in agreement with previous results ${ }^{3,4}$. Treatment of tumor-conditioned HUVEC with the DNMT inhibitor 5aza-2'-deoxycytidine (DAC) significantly restored ICAM-1 protein expression $(\mathrm{p}<0.01)$. A similar effect was observed after treatment with zebularine, a recently discovered DNMT inhibitor which requires higher effective concentrations 22,24 , or with the HDAC inhibitor trichostatin A (TSA) $(\mathrm{p}<0.01)$. Since DNMTs and HDACs cooperate in gene silencing ${ }^{15}$, we further treated tumor-conditioned HUVEC with a combination of DAC and TSA ${ }^{14}$. Combined treatment also induced ICAM-1 protein expression $(\mathrm{p}<0.01)$, although no synergism was observed (Figure 6.1A). Decreased protein expression of vascular cell adhesion molecule 1 (VCAM-1) and E-selectin in tumor-conditioned HUVEC was also restored by treatment with DNMT- and/or HDAC inhibitors (data not shown). Further studies are focused on ICAM-1, because it has been shown that this is the most important EC adhesion molecule for leukocyte extravasation ${ }^{21}$.

Quantitative real-time RT-PCR analysis of ICAM-1 showed similar results, indicating that ICAM-1 protein induction by DAC, zebularine and TSA results from increased ICAM-1 mRNA levels (Figure 6.1B). DAC, zebularine, and TSA also significantly restored ICAM-1 protein and mRNA expression in tumorconditioned HUVEC treated with TNFa (data not shown), i.e. normalizing the upregulation to this inflammatory cytokine. We observed similar effects using b.END5 mouse EC (Figure 6.1C,D). ICAM-1 upregulation by DNMT- and HDAC inhibitors was not observed in B16F10 mouse melanoma cells and normal cultured human fibroblasts (data not shown), indicating that it is not a general effect of these compounds.

\section{DNMT- and HDAC inhibitors restore leukocyte-EC adhesion in vitro}

To demonstrate the functional impact of restored adhesion molecule expression on tumor-conditioned EC by using DNMT- and HDAC inhibitors, we investigated the adhesion of fluorescein-labelled human peripheral blood leukocytes to EC 
A

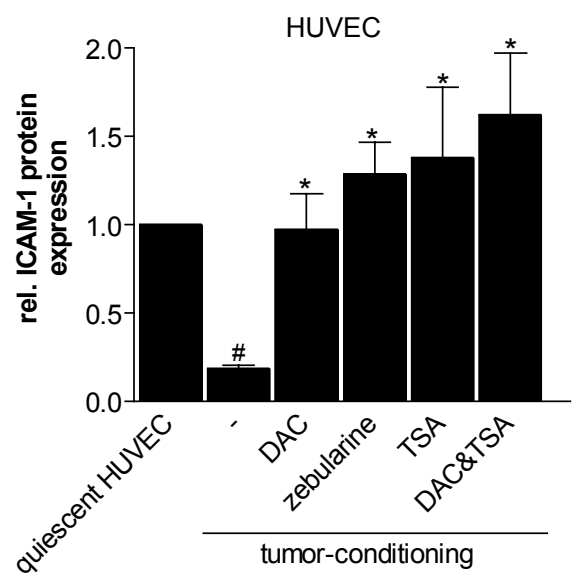

C

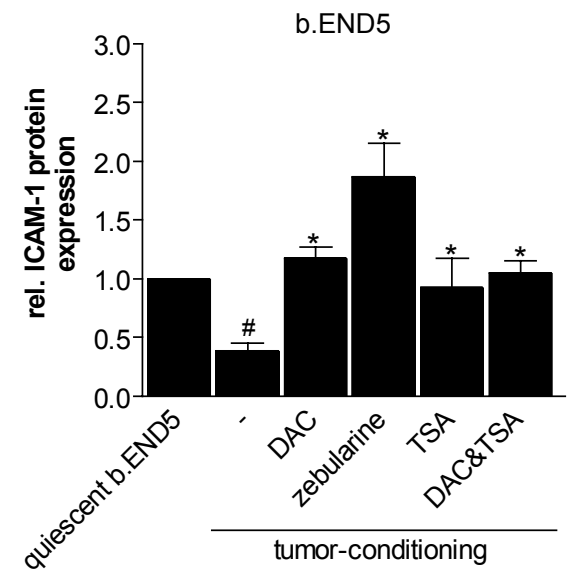

B

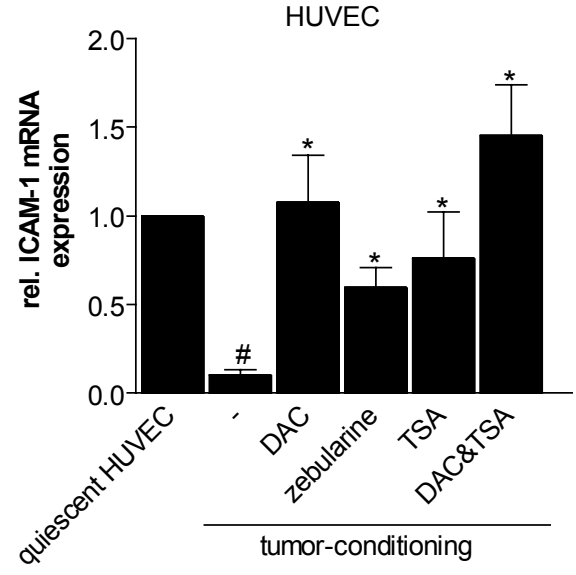

D

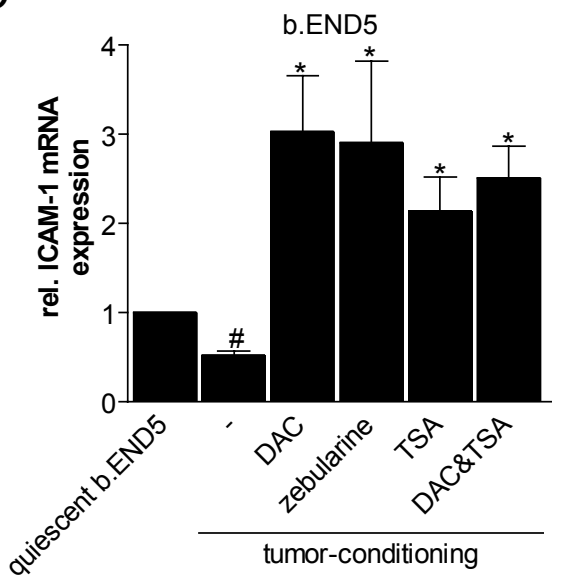

Figure 6.1. DNMT- and HDAC inhibitors restore ICAM-1 expression in tumor-conditioned EC. A) ICAM-1 protein expression measured by FACS analysis in quiescent HUVEC, tumor-conditioned HUVEC, and tumor-conditioned HUVEC treated with DAC (200 nM), zebularine $(100 \mu \mathrm{M})$, TSA (300 $\mathrm{nM}$ ), or a combination of DAC and TSA. Results are presented as mean values ( \pm SEM) of relative protein expression (quiescent HUVEC set to 1 ) of at least 3 independent experiments (\#p<0.01 vs quiescent HUVEC, ${ }^{*} \mathrm{p}<0.01$ vs. tumor-conditioned HUVEC). B) ICAM-1 mRNA expression measured by quantitative real-time RT-PCR in HUVEC. Results are plotted as mean values $( \pm$ SEM) of relative mRNA expression of 6 independent experiments ( $\# \mathrm{p}<0.001$ vs. quiescent HUVEC, ${ }^{*} \mathrm{p}<0.05$ vs. tumorconditioned HUVEC). C) ICAM-1 protein expression in b.END5 mouse EC ( $\# \mathrm{p}<0.05$ vs. quiescent b.END5, ${ }^{*} \mathrm{p}<0.05$ vs. tumor-conditioned b.END5). D) ICAM-1 mRNA expression in b.END5 EC ( $\# \mathrm{p}<0.001$ vs. quiescent $b . E N D 5,{ }^{*} \mathrm{p}<0.05$ vs. tumor-conditioned b.END5). 
monolayers. After adding these leukocytes to EC monolayers and removing nonadherent cells, the adherent leukocytes were counted both by using an inverted microscope (Figure 6.2A) and by flow cytometry (Figure 6.2B). In tumorconditioned HUVEC, leukocyte adhesion was decreased by $75 \%$ compared to that using quiescent HUVEC ( $\mathrm{p}<0.001$, Figure 6.2A,B). Treatment of tumor-conditioned HUVEC with the DNMT inhibitor DAC or zebularine significantly restored leukocyte adhesion $(p<0.01)$. The same observation was made when EC were treated with TSA, or with a combination of DAC and TSA $(\mathrm{p}<0.01)$. The restored leukocyte-EC adhesion by these compounds was mainly due to upregulation of ICAM-1 since a blocking antibody significantly decreased the effects of DNMTand HDAC inhibitors on adhesion (Figure 6.2B).

A
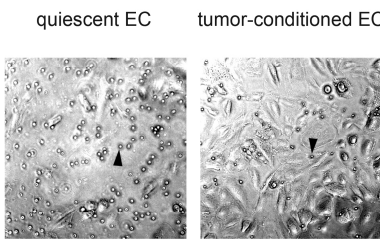

tumor-conditioned
+ zebularine
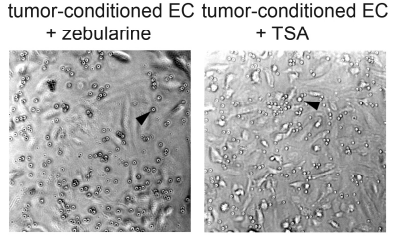

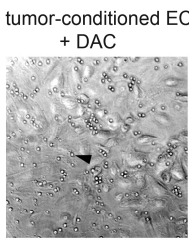

umor-conditioned EC + DAC\&TSA

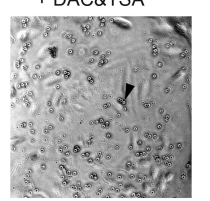

B

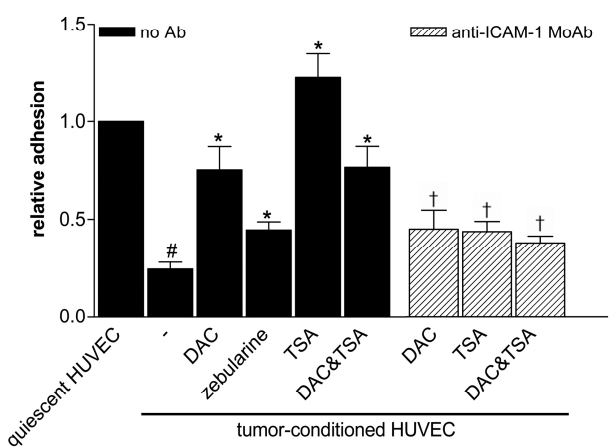

Figure 6.2. DNMT- and HDAC inhibitors restore leukocyte-EC adhesion in vitro. A) Adhesion of human peripheral blood mononuclear cells to monolayers of quiescent HUVEC, tumor-conditioned HUVEC, and tumor-conditioned HUVEC treated with DAC (200 nM), zebularine (100 $\mu \mathrm{M})$, TSA (300 $\mathrm{nM}$ ), or a combination of DAC and TSA. Leukocytes are indicated by the arrow heads. B) Quantification of adhered CSFE-labelled leukocytes to EC by flow cytometry. Results are presented as mean values ( \pm SEM) of relative adhesion (quiescent HUVEC set to 1 ) of 3 independent experiments (\# $\mathrm{p}<0.001$ vs quiescent HUVEC, ${ }^{*} \mathrm{p}<0.01$ vs. tumor-conditioned HUVEC, ${ }^{* *} \mathrm{p}<0.0001$ vs. tumorconditioned HUVEC, ${ }^{+} \mathrm{p}<0.05$ vs. tumor-conditioned HUVEC).

\section{Zebularine and TSA induce leukocyte-vessel wall interactions in tumor vessels in vivo}

In order to infiltrate a tumor, leukocytes must interact first with the tumor vessel wall. We recently demonstrated that leukocyte-vessel wall interactions are reduced in tumors, as compared to those in healthy control vessels ${ }^{7}$. Here, we examined whether restored leukocyte-EC adhesion by DNMT- and HDAC inhibitors in vitro is also observed in tumor vessels in vivo. To quantify leukocytevessel wall interactions in tumor blood vessels, intravital microscopy was used on immunocompetent B16F10 melanoma-bearing C57BL/6 mice (Figure 6.3A-C). 
A

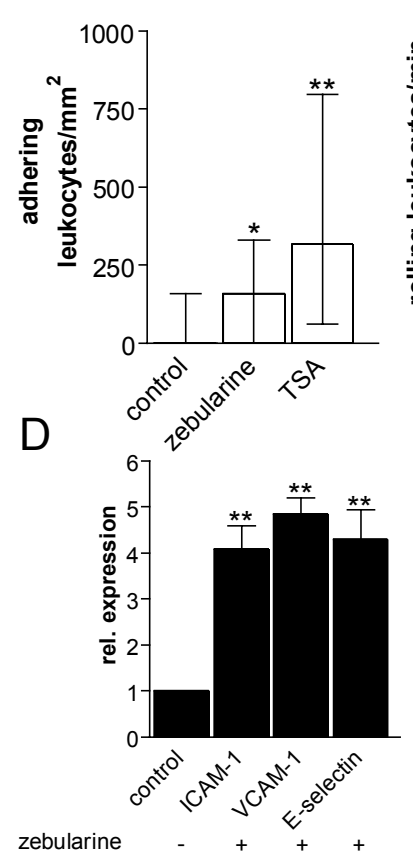

$\mathrm{B}$
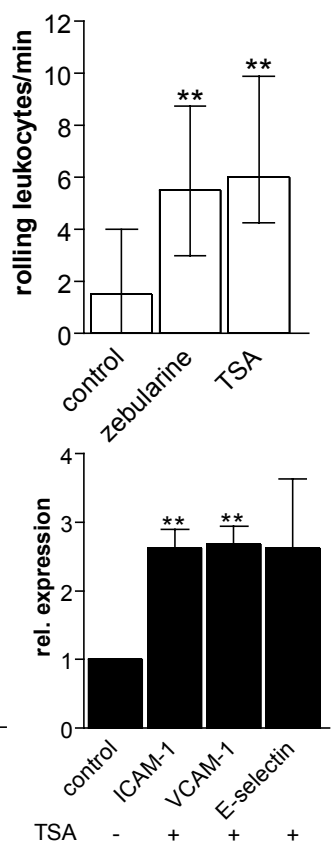

E

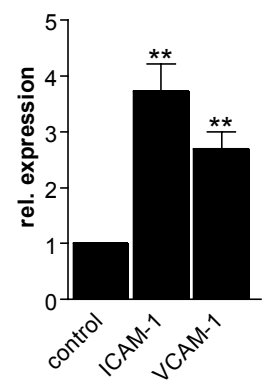

zebularine

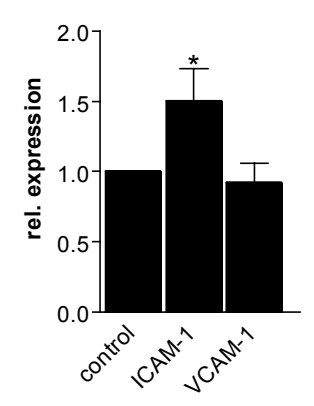

TSA
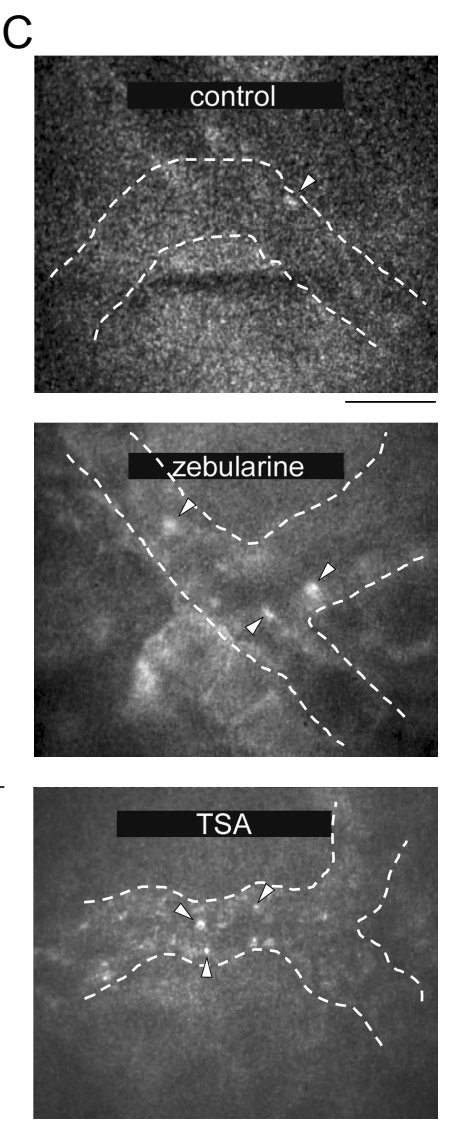

Figure 6.3. Increased leukocyte-vessel wall interactions and ICAM-1 expression in tumor vessels in vivo by zebularine and TSA. Adhering (A) and rolling (B) leukocytes in flank tumor vessels of C57Bl6 mice bearing B16F10 mouse melanoma tumors. Mice were treated with zebularine $(n=5)$ or TSA $(n=5)$. Data are presented as medians with interquartile ranges. Statistical significance was assessed in comparison to values in tumor vessels of untreated mice $(n=5$; control $)\left({ }^{*} p<0.01,{ }^{* *} p<0.001\right)$. C) Typical intravital fluorescence microscopy images of an untreated, zebularine treated and TSA treated tumor vessel. Leukocytes are fluorescently labelled with Rhodamine 6G. Vessels are indicated by the dashed lines, examples of leukocytes by the arrow heads. The bar represents $25 \mu \mathrm{m}$. Because the stills have rather low resolution, the video recordings can be observed at 'http://www.fdg.unimaas.nl/AngiogenesisLab/mirrorsite/movies.htm'. For numbers of mice and vessels see Table 6.1. Expression levels of ICAM-1, VCAM-1 and E-selectin in B16F10 (D) and LS174T (E) tumor tissues of mice treated with zebularine or TSA measured by quantitative real-time RT-PCR. Results are plotted as mean values $( \pm$ $\mathrm{SEM})$ of relative mRNA expression compared to untreated control mice $\left({ }^{*} \mathrm{p}<0.05,{ }^{* *} \mathrm{p}<0.001\right.$ vs. control mice). 
In B16F10 flank tumors in mice treated with zebularine (the DNMT inhibitor of choice because of its lower toxicity profile and higher stability) ${ }^{24}$, both leukocyte adhesion (Figure 6.3A) and leukocyte rolling (Figure 6.3B) were significantly increased compared to those in untreated tumors $(p<0.01$ and $p<0.001$, respectively). The HDAC inhibitor TSA also significantly restored leukocyte adhesion and rolling in tumor vessels (Figure 6.3A,B).

Vessel diameter and local blood flow did not differ between these groups (Table 6.4), indicating that observed effects from zebularine and TSA cannot be explained simply by changes in local fluid dynamic conditions. Centerline velocity and reduced velocity were significantly increased in TSA treated mice compared with those from the control group $(p<0.05)$. However, no correlation between these parameters and leukocyte adhesion or rolling could be found in these mice. Therefore, observed differences in leukocyte-vessel wall interactions cannot be explained by differences in fluid dynamic parameters.

Table 6.4. Fluid dynamic parameters in tumor vessels of treated and untreated mice ${ }^{a}$

\begin{tabular}{llll}
\hline & control & zebularine & TSA \\
\hline $\mathbf{n}_{\mathbf{m}^{\mathrm{b}}}$ & 9 & 5 & 5 \\
$\mathbf{n}_{\mathbf{v}}$ & 30 & 29 & 22 \\
Diameter $(\mu \mathrm{m})$ & $20(20-30)$ & $25(20-35)$ & $25(19-25)$ \\
Centerline velocity $(\mathbf{m m} / \mathbf{s})$ & $0.7(0.5-0.9)$ & $0.6(0.4-0.8)$ & $1.1^{*}(0.9-1.5)$ \\
$\mathbf{U}\left(\mathbf{s}^{-1}\right)$ & $15.6(11.7-35.2)$ & $13(9.4-25)$ & $29^{*}(23.8-42)$ \\
$\mathbf{Q}(\mathbf{n} \mathbf{l} / \mathbf{s})$ & $0.17(0.08-0.30)$ & $0.15(0.07-0.34)$ & $0.27(0.17-0.44)$ \\
\hline
\end{tabular}

aData are presented as median values and interquartile ranges. Statistical significance was assessed in comparison to values in untreated mice $\left({ }^{*} \mathrm{p}<0.05\right)$ ${ }^{\mathrm{b}} \mathrm{n}_{\mathrm{m}}$, number of mice; $\mathrm{n}_{\mathrm{v}}$, number of vessels; $\mathrm{U}$, reduced velocity; $\mathrm{Q}$, flow

To examine whether DNMT- and HDAC inhibitor-induced increased leukocytevessel wall interactions in vivo were associated with enhanced expression of EC adhesion molecules, quantitative real-time RT-PCR was performed on B16F10 tumor tissues. ICAM-1 expression was significantly induced in B16F10 tumors of mice treated with zebularine or TSA compared with that in untreated mice $(\mathrm{p}<0.001$, Figure 6.3D). VCAM-1 was also upregulated in both zebularine- and TSA treated B16F10 tumors. For E-selectin, there was a significant induction upon zebularine treatment $(\mathrm{p}<0.001)$, but not with TSA treatment which only suggested a trend in the same direction (Figure 6.3D). Since expression of VCAM-1 and Eselectin is restricted to the EC of the tumors, increased mRNA levels reflect effects of zebularine and TSA on the expression of these molecules on tumor EC. ICAM-1, 
however, is expressed by tumor EC, as well as by tumor and/or stromal cells. For this reason, enhancement of ICAM-1 expression observed in zebularine and TSA treated B16F10 tumor-bearing mice might have been due in part to expression in tumor cells. However, no effects of these compounds were observed on ICAM-1 expression in B16F10 cells in vitro (data not shown). We also investigated these effects in the human xenograft model of LS174T colon carcinoma in athymic mice. In this model, human tumors have recruited a vasculature of mouse origin. Using species-specific primers, we developed a technique to discriminate between human (tumor) and mouse mRNAs within the xenograft tumor ${ }^{23}$. Using this technique, we found that with zebularine, expression of both ICAM- 1 and VCAM-

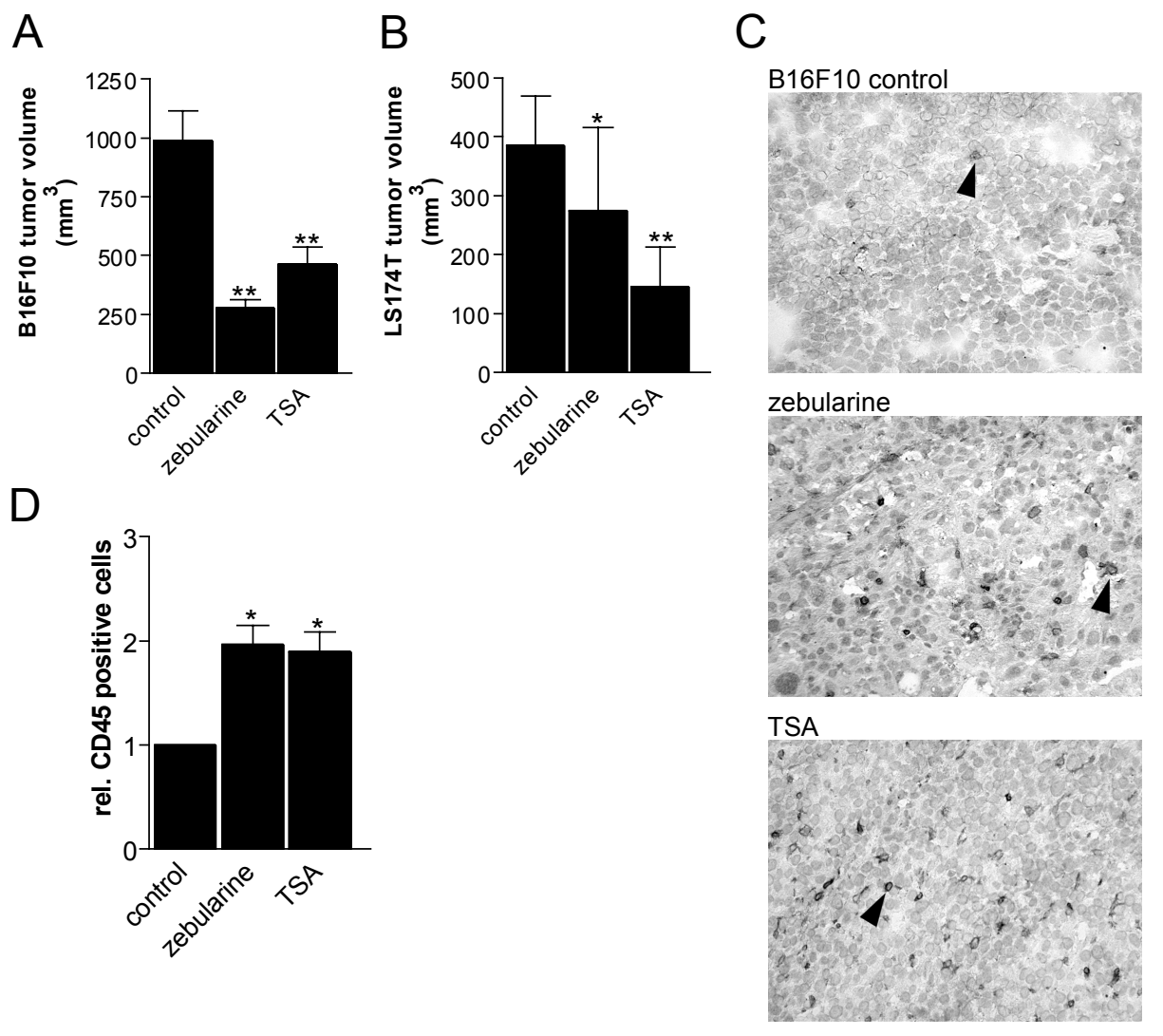

Figure 6.4. Leukocyte infiltration is enhanced by zebularine and TSA. Tumor size of B16F10 mouse melanoma tumors (A) and human LS174T colon carcinoma (B) after treatment with or without zebularine or TSA for 7 (B16F10) or 10 (LS174T) days. Data are expressed as mean tumor volume \pm SEM $\left({ }^{*} \mathrm{p}<0.01,{ }^{* *} \mathrm{p}<0.001\right)$. C) Cryosections of B16F10 tumors from control mice and treated mice stained with CD45 antibody for leukocyte infiltration. D) Quantification of CD45 positive leukocytes in B16F10 tumors treated with zebularine or TSA. Results are plotted as relative mean values ( \pm SEM) of CD45 positive leukocytes compared to control mice $\left({ }^{*} \mathrm{p}<0.001\right)$. 
1 was significantly induced in the vasculature of LS174T tumors (Figure 6.3E, $\mathrm{p}<0.001)$. Treatment of LS174T tumor bearing mice with TSA significantly increased expression of ICAM-1 ( $<<0.05)$, but not VCAM-1. In this mouse model, E-selectin mRNA levels in EC were undetectable.

\section{Leukocyte infiltration is enhanced by zebularine and TSA}

Leukocyte-EC adhesion and leukocyte-vessel wall interactions preceed extravasation and infiltration into the tumor. To study the latter effect, we examined whether increased EC adhesion molecule expression and leukocytevessel wall interactions induced by using zebularine and TSA treatment, contribute to an enhanced tumor leukocyte infiltration. Treatment of B16F10 or LS174T tumor-bearing mice with zebularine or TSA significantly decreased tumor growth (Figure 6.4A,B) and microvessel density (data not shown), as we reported previously ${ }^{19}$. The number of infiltrating leukocytes in both B16F10 and LS174T tumors was determined by staining for the pan-leukocyte marker CD45. In B16F10 tumors, both zebularine and TSA significantly enhanced the number of infiltrating leukocytes by approximately 2 -fold (Figure 6.4C,D, $\mathrm{p}<0.001$ ). Comparable results were observed in LS174T tumors ( $\mathrm{p}<0.001$ for zebularine and $\mathrm{p}<0.01$ for TSA, data not shown).

ICAM-1 downregulation in tumor-conditioned EC is associated with promoter histone $\mathrm{H} 3$ deacetylation and loss of $\mathrm{H} 3$ lysine 4 methylation

Since ICAM- 1 is the primary EC adhesion molecule ${ }^{21}$, regulation of its expression is pivotal to EC anergy. Re-expression of ICAM-1 by inhibitors of DNA methylation and histone deacetylation suggests that epigenetic mechanisms may be responsible for silencing of this gene in tumor EC. Therefore, epigenetic modifications in the ICAM-1 promoter of quiescent and tumor-conditioned HUVEC were examined. Three $5^{\prime} \mathrm{CpG}$ islands (GC content $>60 \%$, ratio of $\mathrm{CpG}$ to $\mathrm{GpC}>0.6$ and minimum length $200 \mathrm{bp})^{28}$ were identified in the ICAM-1 promoter region (Figure 6.5A). DNA methylation of ICAM-1 promoter CPG islands was evaluated by genomic bisulfite sequencing. Interestingly, only a few methylated CpG sites were present in the ICAM-1 promoter of quiescent- and tumorconditioned HUVEC (Figure 6.5A). Furthermore, the ICAM-1 promoter showed no major differences in methylation patterns between quiescent- and activated EC in the region examined. We also examined DNA methylation of part of the ICAM1 promoter (-322 to -17$)$ in tumor EC obtained from colorectal tumors by laser microdissection. Similar to tumor-conditioned EC, hardly any methylation was found in the region examined (Figure 6.5A). These results demonstrate that 

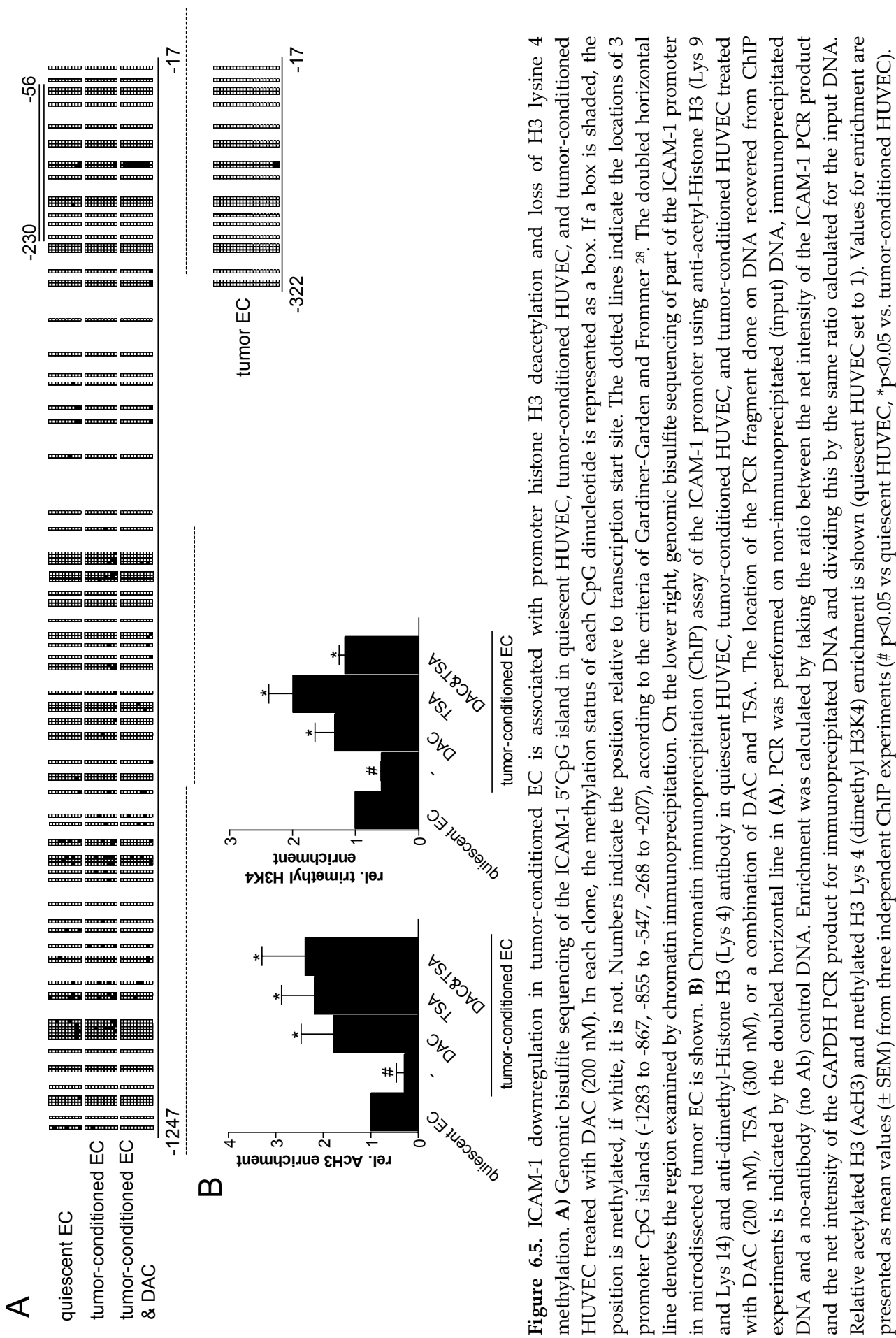
silencing of ICAM-1 in tumor EC occurs independently of direct dense promoter methylation.

To study whether ICAM-1 downregulation in tumor-conditioned EC is associated with promoter histone deacetylation, we examined acetylation of histone H3 (Lys 9 and 14) in the proximal ICAM-1 promoter region (-230 to -56) by using chromatin immunoprecipitation (ChIP). Interestingly, ICAM-1 promoter histone acetylation was significantly decreased in activated HUVEC compared to quiescent HUVEC, correlating with the decreased gene expression (Figure 6.5B, $\mathrm{p}<0.05)$. Treatment of tumor-conditioned HUVEC with DAC, TSA or a combination of both drugs, greatly increased ICAM-1 promoter histone acetylation, which is associated with gene reactivation induced by these compounds. We also examined another key gene activating histone modification, namely lysine 4 methylation of histone $\mathrm{H} 3$. This histone modification also was significantly decreased in tumor-conditioned EC, and was increased by DAC and TSA (Figure 6.5B, $\mathrm{p}<0.05$ ). This led us to conclude that ICAM-1 downregulation in tumor-conditioned EC, and resulting EC anergy, is associated with loss of promoter histone $\mathrm{H} 3$ acetylation and of histone $\mathrm{H} 3$ lysine 4 methylation, but not with DNA hypermethylation.

\section{Discussion}

Suppression of endothelial cell (EC) adhesion molecule expression that leads to reduced leukocyte-vessel wall interactions and leukocyte infiltration, is one of the mechanisms tumors have developed to escape from immunity ${ }^{5,7,8}$. This EC anergy is mediated by angiogenic factors like vascular EC growth factor (VEGF) and basic fibroblast growth factor (bFGF) ${ }^{3,4}$. The mechanism behind angiogenic factormediated silencing of tumor EC adhesion molecules was hitherto unknown. Here, we demonstrate that epigenetic mechanisms are involved in the regulation of EC anergy through repression of ICAM-1 by promoter histone modifications.

In the present study, we found that DNA methyltransferase (DNMT)- and histone deacetylase (HDAC) inhibitors re-express ICAM-1 in tumor EC, both at protein and mRNA level, and restore leukocyte-EC adhesion in vitro and in vivo. While tumor growth and angiogenesis were inhibited by zebularine and TSA, as we published recently ${ }^{19}$, the amount of infiltrated leukocytes was enhanced markedly in both the syngeneic B16F10 mouse melanoma model and the human LS174T xenograft model. Overall, this provides functional meaning to the observed changes in leukocyte adhesion. This is consistent with what we observed on the molecular level, namely ICAM-1 expression is significantly increased upon DNMT- and HDAC inhibitor treatment of tumors in both these mouse models. 
Although upregulation of other adhesion molecules, such as CD34, P-selectin and CD44 (that are also involved in leukocyte-vessel wall interactions) can not be excluded, it is unlikely that enhanced leukocyte-vessel wall interactions result from increased expression of adhesion molecules on leukocytes ${ }^{18}$ or changing fluid dynamic parameters (Table 6.1). DNMT- and HDAC inhibitors decrease tumor cell growth by reactivation of epigenetically silenced tumor suppressor genes ${ }^{15}$. Therefore, increased leukocyte infiltration and leukocyte-vessel wall interactions by zebularine and TSA in vivo could result from their inhibitory effects on tumor cells (e.g. interfering in the production of angiogenic factors like bFGF and VEGF). The increased leukocyte-EC adhesion in vitro, however, where no other cells (tumor cells) are present, show that these compounds directly restore EC ICAM-1 expression and enhance leukocyte-EC adhesion.

Post-translational modifications of histone amino-terminal tails are important epigenetic modifications, which together form the "histone code" 11,29-31. This "histone code" is "read" by proteins that modulate chromatin structure, thereby regulating gene transcription ${ }^{32}$. Hyperacetylation of histone $\mathrm{H} 3$ and $\mathrm{H} 4$ lysine residues is generally associated with active chromatin, whereas deacetylation has been correlated with inactive genes 33. Another histone modification that has been associated with transcriptionally active chromatin is methylation at lysine 4 of histone $\mathrm{H} 3{ }^{34,35}$. In cancer cells, histone modifications work in concert with DNA methylation to silence tumor suppressor genes ${ }^{13,27,36}$. In fact, DNA methylation seems to be dominant over histone deacetylation in maintaining transcriptional repression of tumor suppressor genes, because these genes can be activated by DAC but not by TSA alone ${ }^{15}$. Our data indicate that in tumor EC, histone modifications alone are responsible for ICAM-1 downregulation. ICAM-1 can be reactivated by both DAC and TSA alone, through increasing ICAM-1 promoter histone $\mathrm{H} 3$ acetylation and $\mathrm{H} 3$ lysine 4 methylation. Increased histone acetylation, H3 lysine 4 methylation and/or gene expression by DNMT inhibitors independently of effects on DNA methylation have been described before ${ }^{36-38}$. The potency of the DNMT inhibitors DAC and zebularine to reactivate ICAM-1 independently of promoter DNA methylation indicates that methylation-independent silencing activity of DNMTs might be essential for ICAM-1 downregulation in tumor EC. Methylation-independent transcriptional repressor effects of DNMTs have been linked to the interaction of these enzymes with histone methyltransferases and HDACs 37,39-41.

In tumor cells, induction of ICAM-1 by DNMT- 42 and HDAC inhibitors 43 , as well as ICAM-1 promoter DNA hypermethylation (in a region within the area we examined by bisulfite sequencing $)^{44}$, have been described. The suggested difference between tumor cells and tumor EC in the involvement of promoter DNA hypermethylation in ICAM-1 silencing is very interesting. Some studies have 
demonstrated that DNA methylation, which is a more stable epigenetic modification compared to the more dynamic nature of histone modifications, serves to maintain instead of initiate gene silencing ${ }^{45,46}$. It is attractive to speculate that transcription of ICAM-1 is irreversibly "locked" into a permanently silent state in tumor cells by promoter DNA hypermethylation, and that ICAM-1 downregulation in tumor-conditioned EC is a more reversible phenomenon that only involves histone modifications. It could be argued that culturing HUVEC for 6 days with angiogenic growth factors is not sufficient to induce irreversible gene silencing by promoter DNA methylation. Therefore, we also examined ICAM-1 promoter DNA methylation in tumor EC obtained from colorectal tumors by using laser capture microdissection. However, no meaningful promoter methylation was observed in these cells.

Several studies have reported on transcriptional regulators of basal- and cytokine-induced expression of ICAM-1 ${ }^{47}$. Inflammatory cytokines such as TNF $\alpha$ induce ICAM-1 transcription predominantly through activation of the transcription factor NF-kB ${ }^{48}$. However, preliminary results of electrophoretic mobility shift assay (EMSA) showed that NF-kB activity was not decreased in tumor-conditioned versus quiescent $\mathrm{EC}$, and was not increased by treatment with DAC and/or TSA (data not shown). These data suggest that regulation of ICAM-1 expression in tumor-conditioned EC by DNMT and HDAC inhibitors does not involve NF-kB activation. Nevertheless, involvement of other transcriptional mechanisms in regulating ICAM-1 expression during EC anergy, besides the epigenetic regulation of tumor EC ICAM-1 expression described in this study, cannot be ruled out. In addition, different (epi)genetic mechanisms can cooperate in ICAM-1 transcriptional activation- and repression during tumor angiogenesis.

The potential therapeutic implications of this work are substantial. Untill now, augmentation of anti-tumor immunity by DNMT- and HDAC inhibitors was recognized but attributed mainly to induction of molecules on tumor cells, like cancer testis antigens, HLA class I antigens, and costimulatory/accessory molecules ${ }^{49,50}$. Here, we show a new mechanism by which DNMT- and HDAC inhibitors might be used in anti-cancer therapy, for reversal of EC anergy. Together with our recent findings ${ }^{19}$ and findings of others ${ }^{20,51}$, demonstrating that these compounds are powerful inhibitors of EC growth and tumor angiogenesis in vitro and in vivo, our current data demonstrate that DNMT- and HDAC inhibitors have direct effects on tumor EC. Therefore, the therapeutic targets of these compounds can be extended beyond merely tumor cells. Aside from the inhibitory effects of epigenetic therapy on tumor cell growth through re-expression of previously silenced tumor suppressor genes, the potential use of DNMT- and HDAC inhibitors as angiostatic and immunotherapeutic agents makes them promising anticancer drugs. 
In conclusion, we have demonstrated a role of epigenetics in regulation of EC anergy. We show that ICAM-1 is epigenetically repressed in tumor EC by promoter histone modifications, and that DNMT- and HDAC inhibitors reinduce expression of this gene by reversal of histone modifications in the ICAM-1 promoter, thereby restoring leukocyte-vessel wall interactions and leukocyte infiltration. This work has laid the foundation for a novel anti-cancer approach, whereby DNMT- and HDAC inhibitors may be used to modulate leukocyte infiltration into tumors.

\section{Acknowledgments}

We are grateful to dr. A. Bloem for providing the F10.2 monoclonal ICAM-1 blocking antibody.

\section{References}

1. Ribas A, Butterfield LH, Glaspy JA, Economou JS. Current developments in cancer vaccines and cellular immunotherapy. J Clin Oncol. 2003;21:2415-2432.

2. Springer TA. Traffic signals for lymphocyte recirculation and leukocyte emigration: the multistep paradigm. Cell. 1994;76:301-314.

3. Griffioen AW, Damen CA, Martinotti S, Blijham GH, Groenewegen G. Endothelial intercellular adhesion molecule-1 expression is suppressed in human malignancies: the role of angiogenic factors. Cancer Res. 1996;56:1111-1117.

4. Griffioen AW, Damen CA, Blijham GH, Groenewegen G. Tumor angiogenesis is accompanied by a decreased inflammatory response of tumor-associated endothelium. Blood. 1996;88:667-673.

5. Melder RJ, Koenig GC, Witwer BP, Safabakhsh N, Munn LL, Jain RK. During angiogenesis, vascular endothelial growth factor and basic fibroblast growth factor regulate natural killer cell adhesion to tumor endothelium. Nat Med. 1996;2:992-997.

6. Hellwig SM, Damen CA, van Adrichem NP, Blijham GH, Groenewegen G, Griffioen AW. Endothelial CD34 is suppressed in human malignancies: role of angiogenic factors. Cancer Lett. 1997;120:203-211.

7. Dirkx AE, Oude Egbrink MG, Kuijpers MJ, et al. Tumor angiogenesis modulates leukocyte-vessel wall interactions in vivo by reducing endothelial adhesion molecule expression. Cancer Res. 2003;63:2322-2329.

8. Dirkx AE, oude Egbrink MG, Castermans K, et al. Anti-angiogenesis therapy can overcome endothelial cell anergy and promote leukocyte-endothelium interactions and infiltration in tumors. FASEB J. 2006;20:621-630.

9. Vire E, Brenner C, Deplus R, et al. The Polycomb group protein EZH2 directly controls DNA methylation. Nature. 2006;439:871-874.

10. Jaenisch R, Bird A. Epigenetic regulation of gene expression: how the genome integrates intrinsic and environmental signals. Nat Genet. 2003;33 Suppl:245-254.

11. Jenuwein T, Allis CD. Translating the histone code. Science. 2001;293:1074-1080.

12. Herman JG, Baylin SB. Gene silencing in cancer in association with promoter hypermethylation. N Engl J Med. 2003;349:2042-2054. 
13. Jones PA, Laird PW. Cancer epigenetics comes of age. Nat Genet. 1999;21:163-167.

14. Suzuki H, Gabrielson E, Chen W, et al. A genomic screen for genes upregulated by demethylation and histone deacetylase inhibition in human colorectal cancer. Nat Genet. 2002;31:141-149.

15. Cameron EE, Bachman KE, Myohanen S, Herman JG, Baylin SB. Synergy of demethylation and histone deacetylase inhibition in the re-expression of genes silenced in cancer. Nat Genet. 1999;21:103-107.

16. Silverman LR, Mufti GJ. Methylation inhibitor therapy in the treatment of myelodysplastic syndrome. Nat Clin Pract Oncol. 2005;2 Suppl 1:S12-23.

17. Minucci S, Pelicci PG. Histone deacetylase inhibitors and the promise of epigenetic (and more) treatments for cancer. Nat Rev Cancer. 2006;6:38-51.

18. Huang $X$, Raskovalova $\mathrm{T}$, Lokshin A, et al. Combined antiangiogenic and immune therapy of prostate cancer. Angiogenesis. 2005;8:13-23.

19. Hellebrekers DM, Jair KW, Vire E, et al. Angiostatic activity of DNA methyltransferase inhibitors. Mol Cancer Ther. 2006;5:467-475.

20. Kim MS, Kwon HJ, Lee YM, et al. Histone deacetylases induce angiogenesis by negative regulation of tumor suppressor genes. Nat Med. 2001;7:437-443.

21. Reiss $Y$, Hoch G, Deutsch U, Engelhardt B. T cell interaction with ICAM-1-deficient endothelium in vitro: essential role for ICAM-1 and ICAM-2 in transendothelial migration of T cells. Eur J Immunol. 1998;28:3086-3099.

22. Cheng JC, Yoo CB, Weisenberger DJ, et al. Preferential response of cancer cells to zebularine. Cancer Cell. 2004;6:151-158.

23. Thijssen VL, Brandwijk RJ, Dings RP, Griffioen AW. Angiogenesis gene expression profiling in xenograft models to study cellular interactions. Exp Cell Res. 2004;299:286-293.

24. Cheng JC, Matsen CB, Gonzales FA, et al. Inhibition of DNA methylation and reactivation of silenced genes by zebularine. J Natl Cancer Inst. 2003;95:399-409.

25. Mills L, Tellez C, Huang S, et al. Fully human antibodies to MCAM/MUC18 inhibit tumor growth and metastasis of human melanoma. Cancer Res. 2002;62:5106-5114.

26. Metivier R, Penot G, Hubner MR, et al. Estrogen receptor-alpha directs ordered, cyclical, and combinatorial recruitment of cofactors on a natural target promoter. Cell. 2003;115:751-763.

27. Fahrner JA, Eguchi S, Herman JG, Baylin SB. Dependence of histone modifications and gene expression on DNA hypermethylation in cancer. Cancer Res. 2002;62:7213-7218.

28. Gardiner-Garden M, Frommer M. CpG islands in vertebrate genomes. J Mol Biol. 1987;196:261282.

29. Strahl BD, Allis CD. The language of covalent histone modifications. Nature. 2000;403:41-45.

30. Kouzarides T. Histone methylation in transcriptional control. Curr Opin Genet Dev. 2002;12:198209.

31. Fox SB, Turner GD, Gatter KC, Harris AL. The increased expression of adhesion molecules ICAM3, E- and P-selectins on breast cancer endothelium. J Pathol. 1995;177:369-376.

32. Margueron R, Trojer P, Reinberg D. The key to development: interpreting the histone code? Curr Opin Genet Dev. 2005;15:163-176.

33. Struhl K. Histone acetylation and transcriptional regulatory mechanisms. Genes Dev. 1998;12:599606.

34. Litt MD, Simpson M, Gaszner M, Allis CD, Felsenfeld G. Correlation between histone lysine methylation and developmental changes at the chicken beta-globin locus. Science. 2001;293:24532455.

35. Kawano T, Yanoma S, Nakamura Y, et al. Evaluation of soluble adhesion molecules CD44 (CD44st, CD44v5, CD44v6), ICAM-1, and VCAM-1 as tumor markers in head and neck cancer. Am J Otolaryngol. 2005;26:308-313.

36. Nguyen $M$, Strubel NA, Bischoff J. A role for sialyl Lewis-X/A glycoconjugates in capillary morphogenesis. Nature. 1993;365:267-269. 
37. Fuks F, Burgers WA, Brehm A, Hughes-Davies L, Kouzarides T. DNA methyltransferase Dnmt1 associates with histone deacetylase activity. Nat Genet. 2000;24:88-91.

38. Schmelz K, Sattler N, Wagner M, Lubbert M, Dorken B, Tamm I. Induction of gene expression by 5-Aza-2'-deoxycytidine in acute myeloid leukemia (AML) and myelodysplastic syndrome (MDS) but not epithelial cells by DNA-methylation-dependent and -independent mechanisms. Leukemia. 2005;19:103-111.

39. Robertson KD, Ait-Si-Ali S, Yokochi T, Wade PA, Jones PL, Wolffe AP. DNMT1 forms a complex with $\mathrm{Rb}, \mathrm{E} 2 \mathrm{~F} 1$ and $\mathrm{HDAC} 1$ and represses transcription from E2F-responsive promoters. Nat Genet. 2000;25:338-342.

40. Rountree MR, Bachman KE, Baylin SB. DNMT1 binds HDAC2 and a new co-repressor, DMAP1, to form a complex at replication foci. Nat Genet. 2000;25:269-277.

41. Fuks F, Hurd PJ, Deplus R, Kouzarides T. The DNA methyltransferases associate with HP1 and the SUV39H1 histone methyltransferase. Nucleic Acids Res. 2003;31:2305-2312.

42. Arnold JM, Cummings M, Purdie D, Chenevix-Trench G. Reduced expression of intercellular adhesion molecule-1 in ovarian adenocarcinomas. Br J Cancer. 2001;85:1351-1358.

43. Maeda T, Towatari M, Kosugi H, Saito H. Up-regulation of costimulatory/adhesion molecules by histone deacetylase inhibitors in acute myeloid leukemia cells. Blood. 2000;96:3847-3856.

44. Friedrich MG, Chandrasoma S, Siegmund KD, et al. Prognostic relevance of methylation markers in patients with non-muscle invasive bladder carcinoma. Eur J Cancer. 2005;41:2769-2778.

45. Tamaru H, Selker EU. A histone H3 methyltransferase controls DNA methylation in Neurospora crassa. Nature. 2001;414:277-283.

46. Piali L, Hammel P, Uherek C, et al. CD31/PECAM-1 is a ligand for alpha v beta 3 integrin involved in adhesion of leukocytes to endothelium. J Cell Biol. 1995;130:451-460.

47. Hou J, Baichwal V, Cao Z. Regulatory elements and transcription factors controlling basal and cytokine-induced expression of the gene encoding intercellular adhesion molecule 1. Proc Natl Acad Sci U S A. 1994;91:11641-11645.

48. Ledebur HC, Parks TP. Transcriptional regulation of the intercellular adhesion molecule-1 gene by inflammatory cytokines in human endothelial cells. Essential roles of a variant NF-kappa B site and p65 homodimers. J Biol Chem. 1995;270:933-943.

49. Altomonte M, Fonsatti E, Lamaj E, Cattarossi I, Cattelan A, Maio M. Differential levels of soluble intercellular adhesion molecule-1 (sICAM-1) in early breast cancer and benign breast lesions. Breast Cancer Res Treat. 1999;58:19-23.

50. De Smet C, Lurquin C, Lethe B, Martelange V, Boon T. DNA methylation is the primary silencing mechanism for a set of germ line- and tumor-specific genes with a CpG-rich promoter. Mol Cell Biol. 1999;19:7327-7335.

51. Hajitou A, Grignet C, Devy L, et al. The antitumoral effect of endostatin and angiostatin is associated with a down-regulation of vascular endothelial growth factor expression in tumor cells. Faseb J. 2002;16:1802-1804. 
Chapter 6 


\section{Chapter 7}

\section{Angiostatic activity of the anti-tumor cytokine interleukin-21}

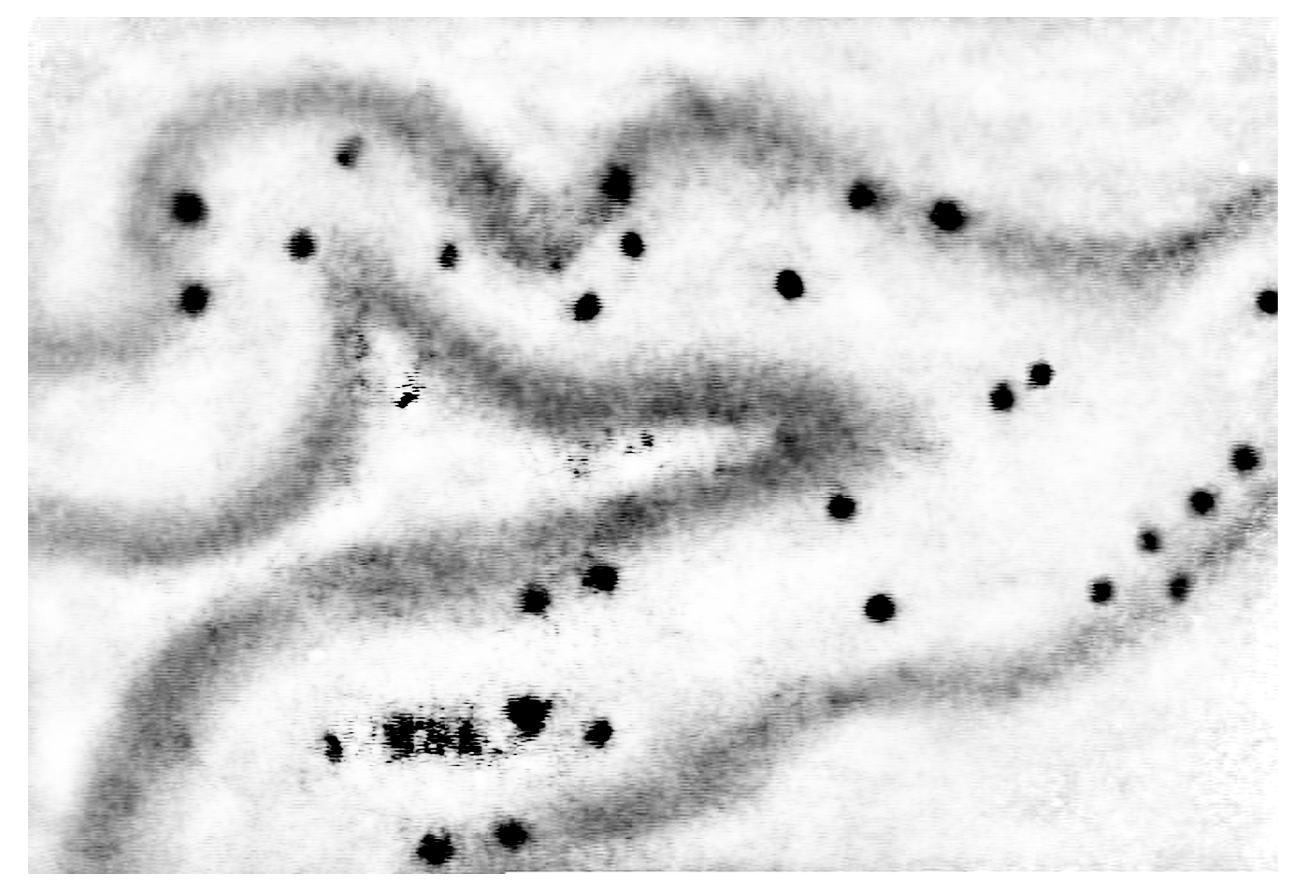

Karolien Castermans, Sebastien P. Tabruyn, Rong Zeng, Cheryl Eppolito, Warren J. Leonard, Protul A. Shrikant, Arjan W. Griffioen

Accepted for publication in Blood (pending revision) 


\section{Abstract}

Interleukin (IL)-21 is a recently described immunoregulatory cytokine. It has been identified as a very potent immunotherapeutic agent in several cancer types in animal models and clinical studies are ongoing. IL-21 belongs to the type-I cytokine family of which other members, i.e. IL-2 and IL-4, have been shown to exert activities on vascular endothelial cells (EC). We hypothesized that IL-21, in addition to inducing the anti-tumor immune response, also inhibits tumor angiogenesis. In vitro experiments showed a decrease of proliferation and sprouting of activated EC after IL-21 treatment. We found that the IL-21 receptor is expressed on vascular EC. Furthermore, in vivo studies in the chorioallantoic membrane of the chick embryo and in mouse tumors demonstrated that IL-21 treatment disturbs vessel architecture and affects vessel outgrowth. Our results also confirm the earlier suggested angiostatic potential of IL-2 in vitro and in vivo. The angiostatic effect of IL-21 is confirmed by the decrease in expression of angiogenesis related genes. Interestingly, IL-21 treatment of EC leads to a decrease of Stat3 phosphorylation. Our research shows that IL-21 is a very powerful antitumor compound which combines the induction of an effective anti-tumor immune response with inhibition of tumor angiogenesis. 


\section{Introduction}

Interleukin (IL)-21, the most recently described member of the common gammachain cytokine family, is found to be a potent immunoregulatory cytokine ${ }^{1}$. This cytokine is produced by activated $\mathrm{CD} 4^{+} \mathrm{T}$ cells and targets several immune cells ${ }^{2-5}$ including NK cells 3,4,6-8, dendritic cells, CTLs $3,4,9,10$ as well as B cells ${ }^{11-14}$. Structurally, IL-21 is considered to be a member of the type-I-cytokine family, which includes IL-2, IL-4 and IL-15 2,15-17. The receptors for all these type I cytokines utilize the common-cytokine-receptor-gamma-chain 2,15-17. In leukocytes, type-I cytokines activate the Janus family tyrosine kinases, JAK1 and JAK3 2, which in turn regulate activation of signal and activator of transcription 1 (Stat1), Stat 3 and, Stat5a and Stat5b 2,9,18,19. This activation of Stats is cell-type specific. IL-2 and IL-15 mainly activate STAT5a and STAT5b, whereas IL-4 primarily activates Stat ${ }^{2}$. Interestingly, Stat3 phosphorylation in endothelial cells has been associated with induction of angiogenesis ${ }^{20,21}$. Recent studies suggest that IL-21 can be used as an immunomodulatory compound 22,23 , and its use in the clinical setting is underway 24.

The process of new blood vessel formation or angiogenesis, is essential for tumor growth and metastasis, as it is critical for supply of oxygen and nutrients. Inhibition of angiogenesis is therefore a promising strategy for treatment of cancer 25,26. Several anti-angiogenesis compounds have been developed and tested based on their ability to inhibit pro-angiogenic growth factors such as VEGF [SU6668, SU11248 and bevacizumab ${ }^{27-29}$ ] or intervention in signal transduction in endothelial cells directly [TNP-470, endostatin and anginex ${ }^{30-33}$. Members of the type-I-cytokine family, i.e. IL-2, -4 , are suggested to affect the formation of new blood vessels ${ }^{34-36}$, but their ability to block angiogenesis has not been carefully tested. It is our hypothesis that IL-21 inhibits angiogenesis and thus mediates antitumor efficacy partly due to its effects on endothelial growth and sprouting. These properties along with its ability to regulate various immune cells endow IL-21 with the potent ability to promote tumor regression.

To test this notion, we conducted experiments to demonstrate the effects of IL-21 on endothelial cells and compared it to IL-2 and anginex, a potent antiangiogenic compound. Our results demonstrate that IL-21 mediates angiostatic properties, as determined by in vitro and in vivo assays. This contributes to IL-21's anti-tumor activity in vivo. The addition of IL-21 induces a rapid decrease in Stat3 phosphorylation. These results suggest that IL-21 is a very powerful anti-tumor compound, with the ability to induce an effective anti-tumor immune response and simultaneously inhibit tumor angiogenesis. This is the first demonstration of the anti-angiogenic property of IL-21, which may have considerable implications for the use of IL-21 in future clinical trials. 


\section{Material and Methods}

\section{Cell culture and reagents}

The murine EC cell line SVEC4-10 and TME were purchased from ATCC and cultured in DMEM (Gibco Invitrogen, Breda, The Netherlands) supplemented with 10\% FCS (Hyclone Perbio Science, Erembodegem-Aalst, Belgium), 2mM HEPES and 2mM L-glutamine (Gibco) in 0.2\% gelatine (Sigma, Zwijndrecht, the Netherlands) coated tissue culture flasks (Costar Corp., Cambridge, MA). The cells were subcultured 1:10. Human umbilical vein derived endothelial cells were cultured as described previously ${ }^{30}$. Angiogenic stimulation of the ECs was induced by $10 \mathrm{ng} / \mathrm{ml}$ bFGF and/or $40 \mathrm{ng} / \mathrm{ml}$ VEGF (Perpotech, London, United Kingdom). Primary mouse endothelial cells we isolated as described earlier ${ }^{37}$. Normal hart tissues derived from C57Bl/6 mice were mechanically and enzymatically digested. The obtained single cell suspensions were allowed to adhere to gelatin coated tissue culture flasks (Costar Corp.). The remaining adherent cell population was stained for the CD31 marker and separated from other cells by sorting (FACSAria; BD Biosciences, Alphen a/d Rijn, The Netherlands). Cells were cultured in DMEM containing 20\% FCS.

EG7 thymoma cells transfected with OVA where cultured in RPMI (Gibco) supplemented with 10\% FCS (Perbio Science), 25mM Hepes buffer, $2 \mathrm{mM}$ Lglutamine, $100 \mathrm{U} / \mathrm{ml}$ Penicillin, $100 \mu \mathrm{g} / \mathrm{ml}$ Streptomycin, $1 \mathrm{mM}$ sodium pyruvate, $1 \mathrm{x}$

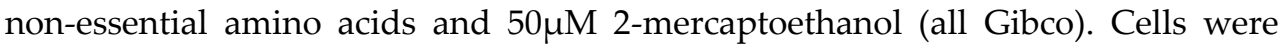

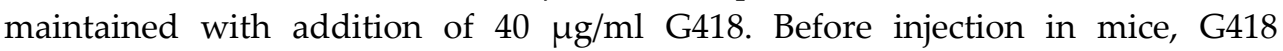
concentration was increased to $400 \mu \mathrm{g} / \mathrm{ml}$ for two rounds of expansion.

Recombinant mouse IL-21 protein was obtained as previously described ${ }^{38}$. Recombinant mouse IL-2 was obtained from R\&D systems (Minneapolis, MN). Anginex was kindly provided by Dr. K. Mayo (Department of biochemistry, Minnesota, Minneapolis, MN).

\section{In vitro and ex vivo sprouting assay}

In vitro sprouting and tube formation was studied using Cytodex-3 beads overgrown with SVEC4-10 endothelial cells in a three-dimensional collagen gel (PureCol, INAMED biomaterials, Fremont, CA) containing $10 \mathrm{ng} / \mathrm{ml} \mathrm{bFGF}$ as described previously ${ }^{39}$. Sprout formation was stimulated with medium containing $10 \mathrm{ng} / \mathrm{ml} \mathrm{bFGF}$ and $40 \mathrm{ng} / \mathrm{ml}$ VEGF. Recombinant IL-21, IL-2 or anginex were added in the medium on top of the gel. After 72 hours the length of the sprouts was analyzed.

Ex vivo sprouting was investigated by using rings of the mouse thoracic aorta as was described earlier ${ }^{31}$. 1-mm-thick cross-sectional rings were placed in 
the wells of a 96-well tissue culture plate in the previous described collagen gel. Medium (DMEM, 20\% FCS, $2 \mathrm{mM}$ L-glutamine, $2 \mathrm{mM}$ sodiumpyruvaat, $20 \mathrm{mM}$ HEPES, 1\% nonessential amino acids, 1.5\% MEM vitamins, antibiotics, 1 IU/100 ml heparin (Gibco Invitrogen, Breda, The Netherlands) containing recombinant IL-21, IL-2 or anginex was put on top of the gels. Vascular sprouting from each ring was examined using an inverted microscope. The width of the tube formation area was measured at three different predefined places of the aortic ring. Different culture conditions were tested at least in triplicate.

\section{Flow cytometry}

Endothelial cells were fixed with 1\% PFA for 30min at room temperature. IL-21 receptor $\alpha$ (IL21-R $\alpha$ ) expression was detected biotinylated $\mathrm{mAb}$ to IL-21R $\alpha{ }^{13}$. Subsequently the cell suspensions were incubated with phycoerithrine labelled strepdavidine (DAKO, Glostrup, Denmark). Stained cells were analyzed on a FACSscan flow cytometer using Cell Quest software (Becton Dickinson, Sunnyvale, CA).

\section{Proliferation and apoptosis measurement}

Endothelial cell proliferation was measured using a $\left[{ }^{3} \mathrm{H}\right]$ thymidine (Amersham Life Science, Roosendaal, the Netherlands) incorporation assay as described previously ${ }^{39}$. Angiogenically stimulated SVEC4-10 were exposed for 3 days to recombinant mouse IL-21, IL-2 or anginex before proliferation was assessed. At least three independent experiments were performed. In each experiment measurements were done in triplicate.

Apoptosis was measured by propidium iodide (PI) (Brunschwig Chemie,Amsterdam, The Netherlands) staining as described previously ${ }^{39}$. bFGF (10 ng/ml) stimulated cells were cultured for 3 days in the presence or absence of IL-21, IL-2 or anginex. After this period, the cells were harvested, fixed in $70 \%$ ethanol, centrifuged, resuspended in DNA extraction buffer and incubated for 20' at $37^{\circ} \mathrm{C}$. After incubation, PI was added at a final concentration of $20 \mu \mathrm{g} / \mathrm{ml}$, and the DNA profile was directly analyzed with the FACScalibur.

\section{Migration measurement}

Migration of murine endothelial cells was measured using the wound assay ${ }^{31}$. In brief, SVEC4-10 cells were seeded in gelatin-coated cell culture plates (Costar Corp., Cambridge, MA) and grown to confluence. Using a blunt pipette tip, a cross-shaped wound was made in the well. Cells were washed with PBS and fresh medium containing $10 \mathrm{ng} / \mathrm{ml}$ bFGF with or without IL-21, IL-2 or anginex. Wound 
width was measured at four predefined locations at start and at 2, 4, 6, 8, and 24 hours after wounding.

\section{Chorioallantoic membrane assay (CAM)}

The chorioallantoic membrane (CAM) assay was performed in fertilized White Leghorn eggs as described previously ${ }^{39}$. In brief, CAMs were treated by daily addition of sterile PBS, recombinant mouse IL-21 or IL-2 from days 10 to 13 . On day 14, the CAMs were photographed. Quantification of vascularization was done by enumeration of intersections with five concentric rings that were superimposed on the photographs.

\section{Mouse tumor model}

C57Bl/6 mice were injected subcutaneously at the base of the spine with $5 \times 10^{6}$ mouse EG7 tumor cells on day 0. On day 10, 12, 14, 16 and 18 after tumor inoculation, mice were treated with interperitoneal injections of either PBS, 2000 I.U. IL-2 or $20 \mu \mathrm{g}$ IL- 21 in a volume of $500 \mu \mathrm{L}$. At day 20, tumors were excised and snap frozen in liquid nitrogen.

\section{Immunohistochemistry}

Immunohistochemical staining was performed on frozen sections $(5 \mu \mathrm{m})$, fixed in acetone on ice and air dried. Immersing the slides in $0.3 \%$ hydrogen peroxidase in PBS for 30min blocked endogenous peroxidase. After washing three times with PBS, aspecific binding was blocked by PBS containing 20\% FCS and $0.1 \%$ Tween 20 for $15 \mathrm{~min}$. The sections were incubated with rat anti mouse CD31 (Pharmingen BD Company, Woerden, The Netherlands) primary antibody for 1hour, followed by incubation with peroxidase labelled goat anti-rat IgG antibody (Immunotech, Marseille, France). The peroxidase activity was detected using diaminobenzidine (DAB; Sigma, Zwijndrecht, The Netherlands).

\section{Quantitative real time RT-PCR ( $q R T-P C R)$}

Total RNA isolation from cultured cells, cDNA synthesis and quantitative realtime RT-PCR were performed essentially as described previously ${ }^{40}$ using iQ SYBR Green PCR Supermix (Biorad, Veenendael, The Netherlands). The expression of each target gene was normalized to the expression of the control gene cyclophilin A. 


\section{Western Blot analysis}

$10 \mathrm{ng} / \mathrm{ml}$ bFGF stimulated SVEC4-10 cells or primary mouse endothelial cells were incubated with IL-2, IL-21 or anginex for 5 or 30 minutes. Cells were harvested and permeabilized in NP40 lysis buffer (50 mM Tris- $\mathrm{HCl}$ [pH 7.5], $150 \mathrm{mM} \mathrm{NaCl}, 0.5 \%$ NP40, $1 \mathrm{mM}$ Na3VO4, $5 \mathrm{mM} \mathrm{NaF}, 1 \mathrm{mM}$ AEBSF, $0.8 \mathrm{mM}$ Aprotinin, $21 \mathrm{mM}$ Leupeptin, $36 \mathrm{mM}$ Bestatin, $15 \mathrm{mM}$ Pepstatin A, and $14 \mathrm{mM}$ E-64). Whole cell lysates (about $10 \mathrm{ug} / \mathrm{sample}$ ) were fractionated on $4-12 \%$ polyacrylamide gels (Invitrogen), western blotted. Blots were probed with antibodies to phosphorylated Stat1 (Y701), Stat3 (Y705), Stat5 (Y694 for Stat5a and Y699 for Stat5b)(Cell Signalling), and then re-probed with antibodies to Stat1, Stat3, Stat5a, Stat5b (Santa Cruz).

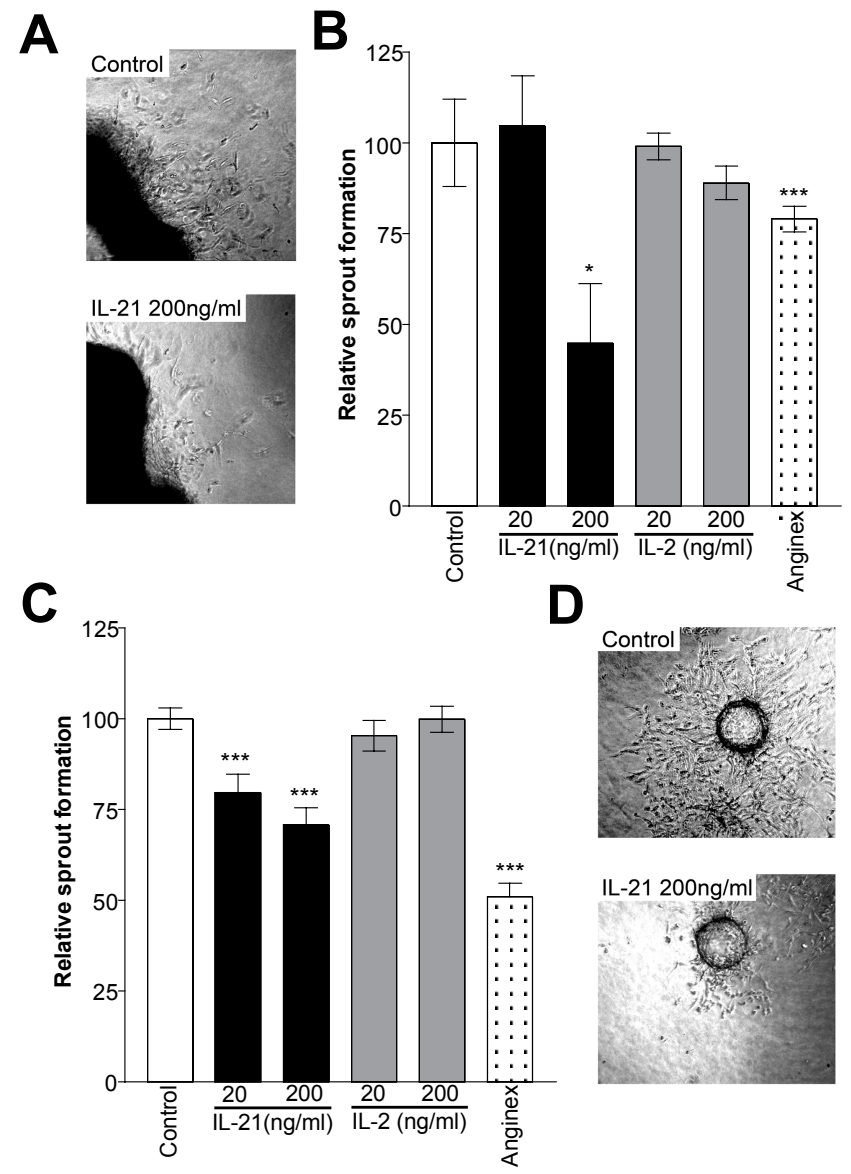

Figure 7.1. Il-21 inhibits angiogenic sprouting of endothelial cells A) A mouse aortic ring treated with bFGF (10ng/ml) and bFGF and IL-21 $200 \mathrm{ng} / \mathrm{ml}$. B) Quantification of sprouting of primary mouse endothelial cells from isolated aortic rings in a 3D collagen matrix. C) Sprouting of bFGF (10ng/ml) stimulated SVEC4-10 cells grown on beads embedded in a 3D collagen matrix. D) An example of sprouting of SVEC410 cells treated with bFGF (10ng/ml, upper panel) and bFGF and IL-21 (lower panel). Data are represented as relative mean values of at least 3 experiments. $\left({ }^{* * *} p<0.0005,{ }^{*} p<0.05\right.$ compared to control). 


\section{Results}

\section{IL-21 inhibits sprout formation by EC.}

The sprouting of primary aortic EC into a 3-dimensional semi-natural collagen matrix was inhibited by approximately $60 \%$ in the presence of IL-21 $(200 \mathrm{ng} / \mathrm{ml}$, Figure $7.1 \mathrm{~A}, \mathrm{~B})$. This is a profound inhibitory effect since it is stronger than that induced by the positive control, the in-house designed and developed angiogenesis inhibitor anginex. In the present study we compared the effects of IL21 with those of IL-2, a member of the same cytokine family and previously suggested to affect blood vessel formation. Interestingly, treatment with recombinant mouse IL-2 in this assay, did not lead to significantly inhibited sprout formation by mouse aortic EC (Figure 7.1B).

A similar in vitro assay using the SVEC4-10 cell line was used to demonstrate a direct effect on EC. This murine cell line is an excellent tool for angiogenesis research since it is inducible by angiogenic growth factors ${ }^{31}$. Addition of IL-21 inhibited bFGF-induced sprouting by 20-30\% (Figure 7.1C,D). Similar as in the aortic ring assay, IL-2 did not inhibit the sprouting of SVEC cells, whereas the positive control anginex reduced the sprout formation by approximately 50\% (Figure $7.1 \mathrm{C}$ ).

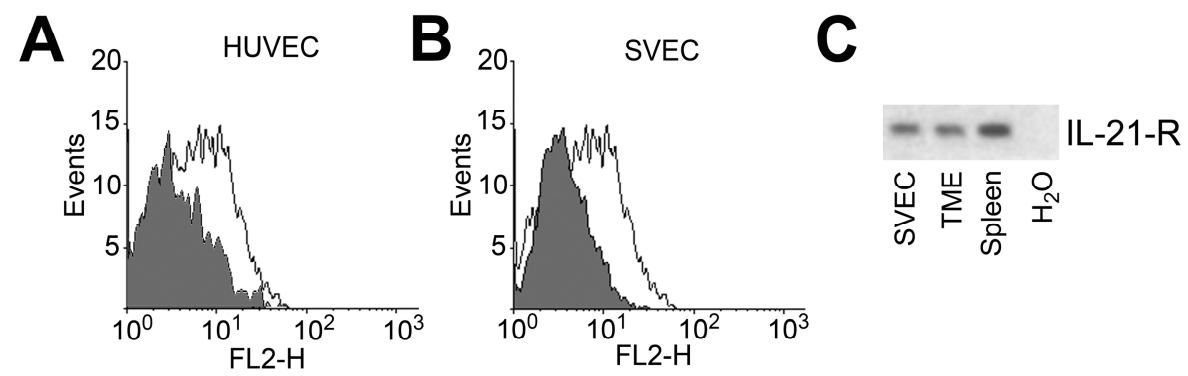

Figure 7.2. IL-21 receptor $\alpha$-chain is expressed by endothelial cells A) FACS analysis of HUVEC stained for IL-21-R $\alpha$-chain (white), conjugate control is represented by grey histogram. B) SVEC4-10 stained for IL-21-R $\alpha$. C) mRNA expression of IL-21-R $\alpha$ in mouse endothelial cell lines SVEC and TME. Positive control is spleen tissue, negative control is no template in the PCR reaction $\left(\mathrm{H}_{2} \mathrm{O}\right)$.

The IL-21 receptor is expressed by EC

Flow cytometry identified the IL-21 receptor to be expressed by SVEC. This expression was very low but showed a 2 -fold increase over the conjugate control. Similar results were found for human endothelial cells (HUVEC, Figure 7.2A and 7.2B). These data were confirmed at the transcriptional level by quantitative realtime RT-PCR (qRT-PCR). The expression level of the IL-21 receptor was very low 
in the endothelial cells compared to the positive control spleen (Ct values of respectively 33,72 and 20,24) but within the boundaries of our assay (data not shown). Analysis of this PCR on agarose gel showed unambiguously the presence of the IL-21 receptor $\alpha$-chain in endothelial cells (Figure 7.2C).

This expression of the IL-21 receptor $\alpha$-chain on endothelial cells suggests that the inhibitory effects by IL-21 as described above might be via a direct effect on the endothelial cells, through the IL-21 receptor. The IL-2 receptor $\alpha$-chain was also demonstrated to be expressed in EC by RT-PCR (data not shown).
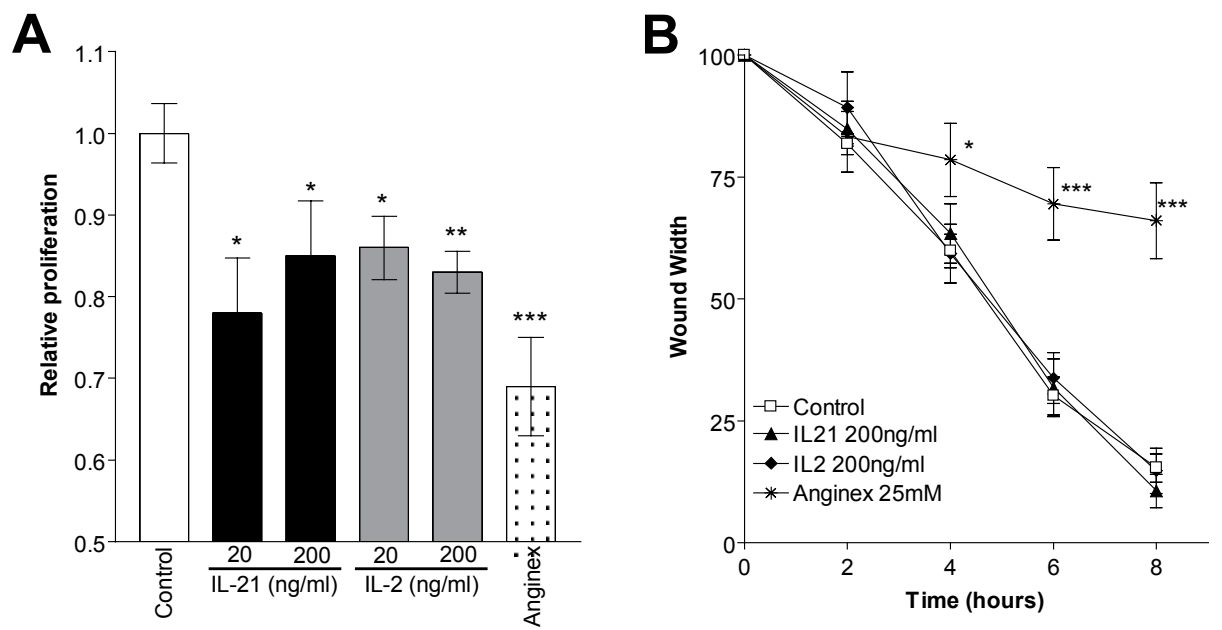

Figure 7.3. Proliferation but not migration is inhibited by IL-21 or IL-2 treatment A) Proliferation of angiogenically stimulated (bFGF $10 \mathrm{ng} / \mathrm{ml}$ ) SVEC4-10 is inhibited by 3 days of treatment with IL21, IL-2 or anginex. B) Wound assay of SVEC4-10 cells. Migration of EC is not effected by treatment with IL-21 nor IL-2. The angiogenesis inhibitor anginex inhibits migration of SVEC4-10 by approximately $70 \%$. Data are represented as relative mean values of at least 4 experiments. $\left({ }^{* * *} p<0.0005,{ }^{* *} p<0.005, p<0.05\right.$ compared to control).

IL-21 and IL-2 inhibit growth factor induced proliferation but not migration of endothelial cells.

To further investigate the mechanism by which IL-21 caused inhibition of EC sprouting and thus angiogenesis in vitro, the anti-proliferative activity of IL-21 was tested in a ${ }^{3} \mathrm{H}$-thymidine incorporation assay. SVEC4-10 cells were stimulated with bFGF and cultured for three days in the presence of IL-21, IL-2 or anginex. A slight but significant reduction of EC proliferation by approximately $20 \%$ was observed after treatment with IL-21. Comparable results were found for IL-2 (Figure 7.3A). The inhibition of proliferation by IL-21 and IL-2 was not associated with induction of cell death, as flow cytometric analysis of DNA fragmentation showed, in 
A
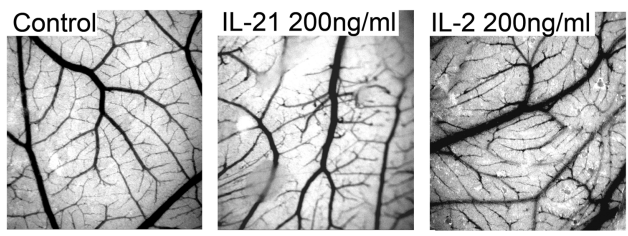

B

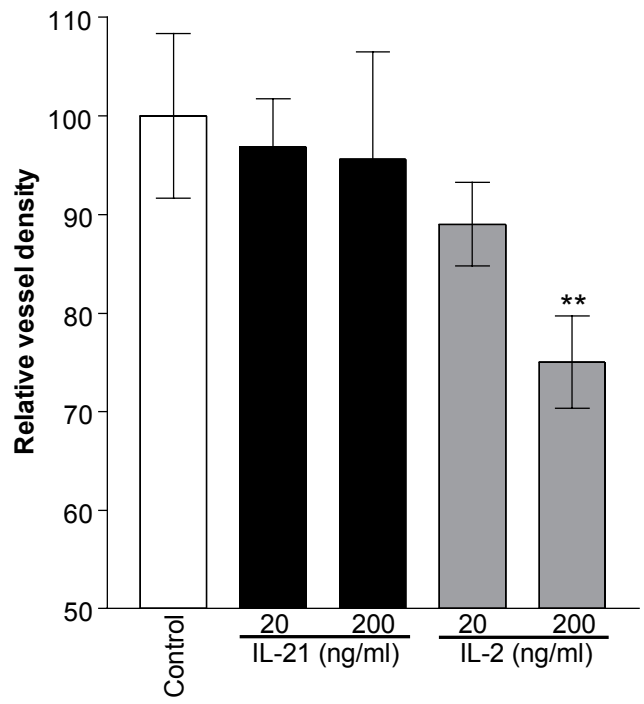

C

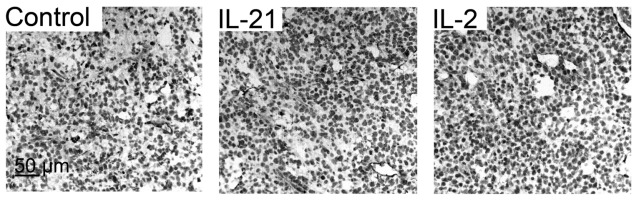

D

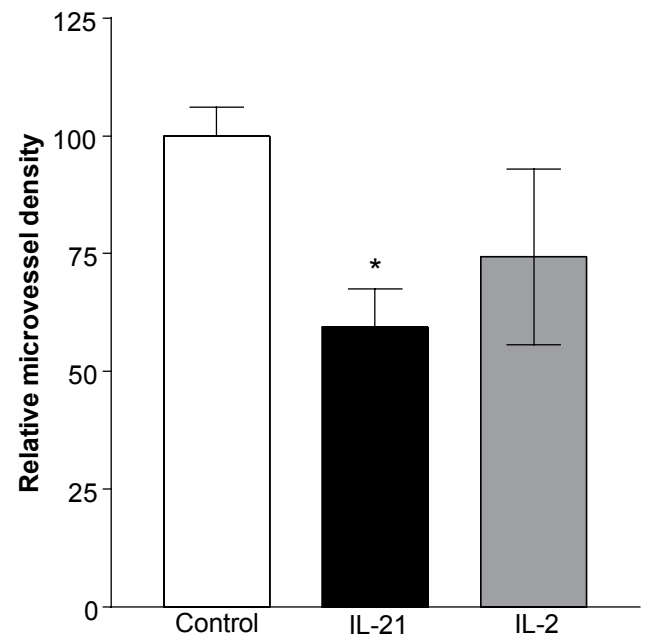

Figure 7.4. IL-21 and IL-2 inhibit angiogenesis in vivo A-B) Treatment of CAMs with $200 \mathrm{ng} / \mathrm{ml}$ IL-2 reduces vessel formation in CAMs whereas IL-21 does not effect the number of vessels in CAMs $(\mathrm{n}=7$ for each group). Morphological examination shows that vessels in CAMs treated with $20 \mathrm{ng} / \mathrm{ml}$ or $200 \mathrm{ng} / \mathrm{ml}$ IL-21 are tortuous and irregular compared to control CAMs (B). C) Images of CD31 staining of EF7 tumor sections of mice treated with PBS (control), $20 \mu \mathrm{g}$ IL-21 or 2000 I.U. IL-2. D) IL-2 $(n=4)$ and IL-21 $(n=5)$ treatment reduce microvessel density in tumor tissues compared to control (PBS, $n=5$ ). Results are presented as relative mean values $\left({ }^{* *} \mathrm{p}<0.005,{ }^{*} \mathrm{p}<0.05\right.$ compared to control). 
contrast to the positive control anginex ${ }^{31}$, no increase of apoptotic or necrotic cells after IL-21 or IL-2 treatment (data not shown).

Next to proliferation, migration of endothelial cells is a key process in the formation of new blood vessels during angiogenesis. EC migration was investigated using the wound assay. While anginex inhibited the wound closure efficiently, IL-21 as well as IL-2 did not have an effect. It is concluded that IL-21 does not affect migration of EC (Figure 7.3B).

\section{IL-21 and IL-2 affect in vivo angiogenesis in the chick embryo chorioallantoic membrane (CAM) assay.}

In vivo angiogenesis was first investigated in the chorioallantoic membrane (CAM) of the chicken embryo, an assay that represents developmental angiogenesis. Although treatment of the CAMs with IL-21 did not reduce vessel density (Figure 7.4B), a disturbed, tortuous and irregular growth of vessels was detected as compared to control CAMs (Figure 7.4A). Recombinant IL-2 showed a similarly disturbed vessel outgrowth. In addition, IL-2 did reduce vessel density in the CAMs by $25 \%$ (Figure $7.4 \mathrm{~A}, \mathrm{~B}$ ). This response to IL-2 confirms results presented in earlier reports ${ }^{35}$.

\section{IL-21 inhibits tumor angiogenesis in vivo}

Effects of IL-21 and IL-2 on tumor angiogenesis in vivo were determined by treatment of EG7 tumor bearing mice with IL-21, IL-2 or PBS (control) at concentrations that have previously been shown to be effective (Figure 7.4C) ${ }^{38}$. Immunohistochemical staining of tumor sections of mice treated with recombinant mouse IL-21 using CD31 antibody showed a significantly decreased microvessel density, as compared to PBS treated mice (Figure 7.4C,D). Treatment of mice with IL-2 showed a decreased vessel formation in tumors as well, but this inhibition was not found to be statistically significant (Figure 7.4C,D).

\section{IL-21 and IL-2 regulate expression of angiogenesis-related genes in activated EC}

In order to investigate the feature of the angiostatic response of EC after exposure to IL-21 and IL-2, we performed qRT-PCR on samples of in vitro cultured endothelial cells and the above presented mouse tumor tissues. In cultured endothelial cells, the major angiogenesis related growth factor vascular endothelial growth factor A (VEGFA) and both of its receptors VEGFR1 and -2 are significantly decreased by exposure to IL-21, as compared to bFGF treatment alone (Figure 7.5A). The IL-21 induced downregulation of VEGF-A and VEGFR2 is shared with the angiogenesis inhibitor anginex (Figure 7.5A). The expression of angiopoietins, mediators of vessel sprouting, maturation and remodeling, are also 
affected by IL-21 treatment in vitro. Angiopoietin-1 and -3 (ANG1, -3) show a lower expression after IL-21 treatment (Figure 7.5B), while neither IL-2 nor anginex treatment show this effect in ECs. The expression of the tyrosine kinase receptor-1 (TIE1), one of both receptors of the angiopoietin family, is diminished after IL-21 treatment, an effect that is shared with IL2 and anginex in endothelial cells (Figure 7.5C). These results support the observation of anti-angiogenesis activity by IL-21 and IL-2. In tumor tissues of mice treated with IL-21 we also observed a significant decrease of VEGFA and both receptors VEGFR1, and -2, as compared to PBS treatment (Figure 7.5D). The mRNA expression of angiopoietins is also reduced upon IL-21 treatment (Figure 7.5E), though only significantly for angiopoietin-2. A significant decline of approximately $75 \%$ is determined for TIE1 and TIE2 expression in tumor tissues of IL-21 treated mice (Figure 7.5F). In experiments treatment with IL-2 did never induce significant changes of expression.
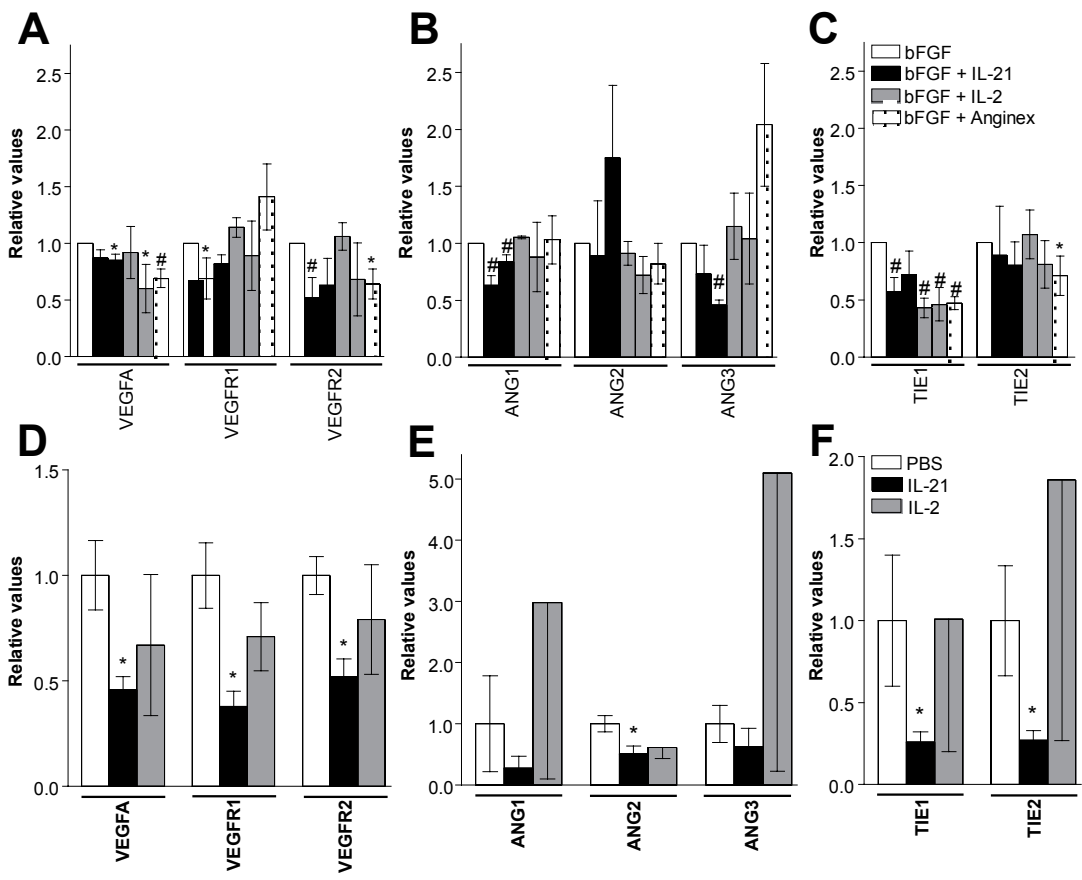

Figure 7.5. IL-21 and IL-2 regulate expression of angiogenesis-related genes in activated EC and tumor tissues A-C) Regulation of mRNA expression levels of angiogenesis factors in bFGF $(10 \mathrm{ng} / \mathrm{ml})$ stimulated SVEC4-10 after three days of IL-21, IL-2 or anginex treatment. Concentrations of the compounds are as indicated in previous figures, first bar $20 \mathrm{ng} / \mathrm{ml}$, second bar $200 \mathrm{ng} / \mathrm{ml}$ and anginex $25 \mu \mathrm{M}$. Results are represented as relative means of at least 3 experiments. $\left({ }^{*} \mathrm{p}<0.05, \# \mathrm{p}<0.005\right.$ compared to bFGF). D-E) Regulation of mRNA expression levels of angiogenesis factors in tumor tissues of EG7 tumors after PBS $(n=4)$, IL-21 $(20 \mu \mathrm{g}, \mathrm{n}=4)$ or IL-2 (I.U. 2000, $n=3)$ treatment. Results are represented as relative means $\left({ }^{*} \mathrm{p}<0.05\right)$. 
Regulation of Stat phosphorylation in EC after IL-21 treatment

In leukocytes, IL-21 signals through the IL21 receptor and the JAK/Stat pathway. JAK1 and/or JAK3 can activate Stat1, Stat3 and to a lesser extent Stat5 by phosphorylation after induction by IL-21. In order to investigate if similar signaling can occur in endothelial cells we performed western blot analysis on protein lysates of SVEC4-10 (Figure 7.6A) and primary mouse EC (Figure 7.6B).

Western blot analysis of bFGF stimulated SVEC4-10 showed presence of activated (phosphorylated) Stat3 (P-Stat3) and a slight activation of Stat1 (P-Stat1, Figure 7.6A lane 1). Interestingly, incubation of SVEC4-10 for 30 minutes with IL21 induced a dramatic and significant decrease in the expression of phosphorylated Stat3, a feature shared with the angiogenesis inhibitor anginex. Similar effects were observed for IL-2. This regulation was not visible after 5 minutes of exposure to either IL-21, IL-2 or anginex.

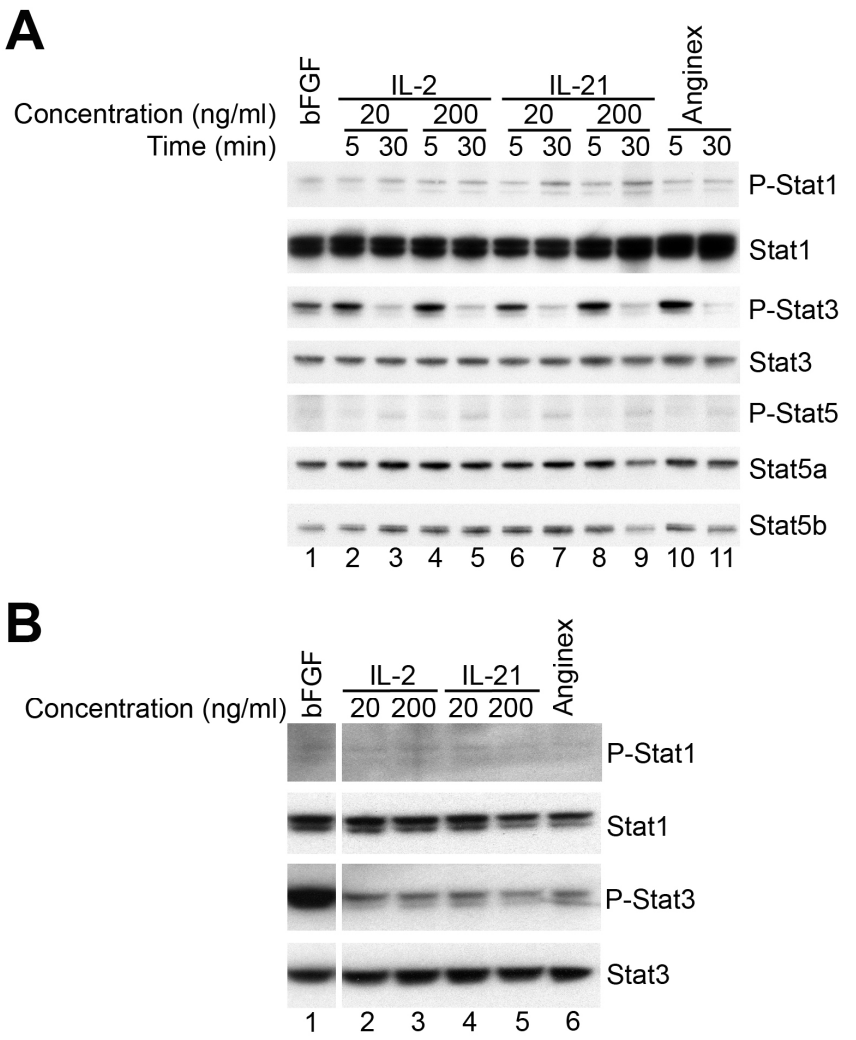

Figure 7.6. Decreased Stat3 activation is correlated with angiostatic activity. A) Western blot analysis of cell lysates of $10 \mathrm{ng} / \mathrm{ml}$ bFGF stimulated SVEC4-10 after 5 or 30 minutes incubation with IL-2, IL-21 or anginex. After 30 minutes, IL-2, IL-21 and anginex treated cells showed decreased Stat3 phosphorylation (P-Stat3). B) Western blot analysis $(n=1)$ of cell lysates of bFGF stimulated primary mouse endothelial cells after 30 minutes with IL-21, IL-2 or anginex. 
Primary mouse endothelial cells showed expression of P-Stat3 after bFGF stimulation, as well (Figure 7.6B, lane 1). Also in these primary endothelial cells, phosphorylation of Stat3 was diminished after 30 minutes of exposure to the compounds (Figure 7.6B, lane 2-6). No differences could be detected for the other Stat proteins tested. Since Stat3 activation has been implicated in angiogenesis before ${ }^{20,21}$, the diminishing effects of IL-21 and IL-2 on Stat3 phosphorylation reinforces the angiostatic activities of both IL-21 and IL-2 and implicates the role of diminished STAT3 activation in the observed anti-angiogenesis effects.

\section{Discussion}

IL-21 is a pleiotropic cytokine with immune-regulatory properties and immunetherapeutic capacity. In this study we have identified a novel function for IL-21. We demonstrate that the IL-21 receptor is present on endothelial cells and can mediate angiostatic properties by several in vitro assays. While IL-21 moderately inhibits the proliferation of ECs, it markedly inhibited sprouting of angiogenically stimulated endothelial cells. In addition, it also reduces vessel formation and disturbs vessel architecture in vivo. IL-21 was found to reduce the expression of VEGFR2 and TIE1 in endothelial cells, contributing to the lower angiogenic profile. Also, exposure of endothelial cells to IL-21 led to a decrease in expression of VEGF-A, angiopoietin-1 and -3. Similar results on gene expression were found when testing sample of intact tumor tissue, indicating that the effects are shared by other cells, including the tumor cells, as well. The results of the current report are in line with an earlier report on disruption of the vascular network as found in tumors of mice treated with IL-21 ${ }^{41}$. Furthermore, the decrease of Stat3 phosphorylation in activated endothelial cells after treatment with IL-21, an effect that is shared with the angiogenesis inhibitor anginex, suggests that angiostatic signaling by IL-21 in EC is mediated through Stat3.

The current report also confirms the earlier described angiostatic power of IL-2. This type-I cytokine reduced proliferation of angiogenically stimulated endothelial cells in vitro as well as vessel formation in vivo. In contrast to IL-21, IL2 did not reduce sprouting of aortic rings nor endothelial cells. This difference, and the fact that IL-21 seems to be a more powerful angiogenesis inhibitor than IL-2, could be explained by differential expression of ANG1, ANG3 and TIE1 in endothelial cells induced by IL-21 and IL-2 treatment. Angiopoietins and their receptors are essential for vessel sprouting, remodeling and maturation ${ }^{42}$. A decrease of their expression might interfere with these processes during angiogenesis. This is also in line with our observations in the CAM assay that showed a disturbed and tortuous character of the vessels after IL-21 treatment. 
Interestingly, IL-21 also decreases the expression of VEGFR1 in EC. This is also consistent with the observed inhibition of sprouting and disturbed vessel morphology because a defect in VEGFR1 can lead to the assembly of endothelial cells into abnormal vascular channels ${ }^{43}$. However we could detect irregular vessel morphology in the CAMs after IL-2 treatment as well, indicating that other factors, e.g. nitric oxide ${ }^{35}$, might be involved in the disturbed vessel outgrowth in CAMs as well. These data suggest that IL-2 is likely to be involved in survival rather than in differentiation mechanisms, which IL-21 seems to be. The regulation of VEGFA, VEGFR1 and -2 gene expression in tumor tissues is similar for both IL-21 and IL-2, although the effects of IL-21 are stronger. In addition to these VEGF related genes, IL-21 decreases the expression of the angiopoietin family as well. This differential regulation of gene expression can explain the predominant effects of IL-21 over IL2, on tumor angiogenesis. Since IL-2 and IL-21 both affect hematopoietic cells differently 2,38, these cells, when present e.g. in the ex vivo sprouting assay and the tumor growth experiment, could mediate the effects of the cytokines on the endothelium. The clear effects in the cultured EC experiments, favors the view of different effects directly on the endothelium.

Cytokines of the type-I family share the $\gamma$-chain, but they can have different effects on leukocytes ${ }^{2}$. Here we show that they also have different effects on endothelial cells. For IL-15 it has been shown that it can induce angiogenesis 44,45 . Our results demonstrate that both IL-2 and IL-21 can inhibit angiogenesis but in a different way.

In leukocytes, IL-21 signaling has recently been investigated and occurs via the Janus family tyrosine kinases, JAK1 and JAK3. These kinases then mediate activation of Stat1, Stat 3 and to a lesser extend Stat5a and Stat5b ${ }^{2}$. The activation of a specific Stat-molecule by IL-21 depends on the leukocyte subgroup ${ }^{2,9}$. We argued that similar signaling may occur in endothelial cells as well. Therefore we tested whether phosphorylated Stat3 is detectable in activated EC. We found that phosphorylated Stat 3 is present in activated endothelial cells, and that signaling through Stats in EC is very different from that in leukocytes. In contrast to the situation in lymphocytes, Stat3 phosphorylation is decreased in endothelial cells after 30 minutes of incubation with either IL-21 or IL-2, an effect that is shared with the angiostatic compound anginex. Interestingly, recent research linked phosphorylation of Stat3 in EC to induction of angiogenesis ${ }^{20,21}$. Together these data suggest that treatment with IL-21 and IL-2, similar as exposure to anginex, inhibits angiogenesis by reducing the phosphorylation of Stat3; a molecule which has already been proposed to be an interesting target for tumor therapy in various cancer types by inhibiting tumor derived VEGF and angiogenesis ${ }^{46-48}$. Our data suggests that inhibition of Stat3 could also inhibit tumor angiogenesis by a direct effect on endothelial cells. 
In conclusion, the ability of IL-21of to promote survival of tumor bearing mice 38 along with the novel observations reported in this study provide further impetus for the use of IL-21 in therapeutic approaches for cancer.

\section{References}

1. Brandt K, Singh PB, Bulfone-Paus S, Ruckert R. Interleukin-21: A new modulator of immunity, infection, and cancer. Cytokine Growth Factor Rev. 2007;18:223-232.

2. Leonard WJ, Spolski R. Interleukin-21: a modulator of lymphoid proliferation, apoptosis and differentiation. Nat Rev Immunol. 2005;5:688-698.

3. Parrish-Novak J, Dillon SR, Nelson A, et al. Interleukin 21 and its receptor are involved in NK cell expansion and regulation of lymphocyte function. Nature. 2000;408:57-63.

4. Parrish-Novak J, Foster DC, Holly RD, Clegg CH. Interleukin-21 and the IL-21 receptor: novel effectors of NK and T cell responses. J Leukoc Biol. 2002;72:856-863.

5. Sivakumar PV, Foster DC, Clegg CH. Interleukin-21 is a T-helper cytokine that regulates humoral immunity and cell-mediated anti-tumour responses. Immunology. 2004;112:177-182.

6. Brady J, Hayakawa Y, Smyth MJ, Nutt SL. IL-21 induces the functional maturation of murine NK cells. J Immunol. 2004;172:2048-2058.

7. Kasaian MT, Whitters MJ, Carter LL, et al. IL-21 limits NK cell responses and promotes antigenspecific $\mathrm{T}$ cell activation: a mediator of the transition from innate to adaptive immunity. Immunity. 2002;16:559-569.

8. Wang G, Tschoi M, Spolski R, et al. In vivo antitumor activity of interleukin 21 mediated by natural killer cells. Cancer Res. 2003;63:9016-9022.

9. Zeng R, Spolski R, Casas E, Zhu W, Levy DE, Leonard WJ. The molecular basis of IL-21-mediated proliferation. Blood. 2007.

10. Zeng R, Spolski R, Finkelstein SE, et al. Synergy of IL-21 and IL-15 in regulating CD8+ T cell expansion and function. J Exp Med. 2005;201:139-148.

11. Ozaki K, Spolski R, Feng CG, et al. A critical role for IL-21 in regulating immunoglobulin production. Science. 2002;298:1630-1634.

12. Ozaki K, Spolski R, Ettinger R, et al. Regulation of B cell differentiation and plasma cell generation by IL-21, a novel inducer of Blimp-1 and Bcl-6. J Immunol. 2004;173:5361-5371.

13. Jin $\mathrm{H}$, Carrio R, Yu A, Malek TR. Distinct activation signals determine whether IL-21 induces B cell costimulation, growth arrest, or Bim-dependent apoptosis. J Immunol. 2004;173:657-665.

14. Mehta DS, Wurster AL, Whitters MJ, Young DA, Collins M, Grusby MJ. IL-21 induces the apoptosis of resting and activated primary B cells. J Immunol. 2003;170:4111-4118.

15. Mehta DS, Wurster AL, Grusby MJ. Biology of IL-21 and the IL-21 receptor. Immunol Rev. 2004;202:84-95.

16. Asao H, Okuyama C, Kumaki S, et al. Cutting edge: the common gamma-chain is an indispensable subunit of the IL-21 receptor complex. J Immunol. 2001;167:1-5.

17. Vosshenrich CA, Di Santo JP. Cytokines: IL-21 joins the gamma(c)-dependent network? Curr Biol. 2001;11:R175-177.

18. Habib T, Senadheera S, Weinberg K, Kaushansky K. The common gamma chain (gamma c) is a required signaling component of the IL-21 receptor and supports IL-21-induced cell proliferation via JAK3. Biochemistry. 2002;41:8725-8731.

19. Suto A, Wurster AL, Reiner SL, Grusby MJ. IL-21 inhibits IFN-gamma production in developing Th1 cells through the repression of Eomesodermin expression. J Immunol. 2006;177:3721-3727. 
20. Hilfiker-Kleiner D, Limbourg A, Drexler H. STAT3-mediated activation of myocardial capillary growth. Trends Cardiovasc Med. 2005;15:152-157.

21. Valdembri D, Serini G, Vacca A, Ribatti D, Bussolino F. In vivo activation of JAK2/STAT-3 pathway during angiogenesis induced by GM-CSF. Faseb J. 2002;16:225-227.

22. di Carlo E, de Totero D, Piazza T, Fabbi M, Ferrini S. Role of IL-21 in immune-regulation and tumor immunotherapy. Cancer Immunol Immunother. 2007;56:1323-1334.

23. Sondergaard H, Frederiksen KS, Thygesen $P$, et al. Interleukin 21 therapy increases the density of tumor infiltrating CD8(+ )T cells and inhibits the growth of syngeneic tumors. Cancer Immunol Immunother. 2007.

24. Davis ID, Skrumsager BK, Cebon J, et al. An open-label, two-arm, phase I trial of recombinant human interleukin-21 in patients with metastatic melanoma. Clin Cancer Res. 2007;13:3630-3636.

25. Molema G, Griffioen AW. Rocking the foundations of solid tumor growth by attacking the tumor's blood supply. Immunol Today. 1998;19:392-394.

26. Folkman J. Tumor angiogenesis: therapeutic implications. N Engl J Med. 1971;285:1182-1186.

27. Ferrara N, Hillan KJ, Novotny W. Bevacizumab (Avastin), a humanized anti-VEGF monoclonal antibody for cancer therapy. Biochem Biophys Res Commun. 2005;333:328-335.

28. Laird AD, Vajkoczy P, Shawver LK, et al. SU6668 is a potent antiangiogenic and antitumor agent that induces regression of established tumors. Cancer Res. 2000;60:4152-4160.

29. Mendel DB, Laird AD, Xin X, et al. In vivo antitumor activity of SU11248, a novel tyrosine kinase inhibitor targeting vascular endothelial growth factor and platelet-derived growth factor receptors: determination of a pharmacokinetic/pharmacodynamic relationship. Clin Cancer Res. 2003;9:327-337.

30. Griffioen AW, van der Schaft DW, Barendsz-Janson AF, et al. Anginex, a designed peptide that inhibits angiogenesis. Biochem J. 2001;354:233-242.

31. van der Schaft DW, Dings RP, de Lussanet QG, et al. The designer anti-angiogenic peptide anginex targets tumor endothelial cells and inhibits tumor growth in animal models. Faseb J. 2002;16:1991-1993.

32. O'Reilly MS, Boehm T, Shing Y, et al. Endostatin: an endogenous inhibitor of angiogenesis and tumor growth. Cell. 1997;88:277-285.

33. Kusaka M, Sudo K, Fujita T, et al. Potent anti-angiogenic action of AGM-1470: comparison to the fumagillin parent. Biochem Biophys Res Commun. 1991;174:1070-1076.

34. Orucevic A, Lala PK. Role of nitric oxide in IL-2 therapy-induced capillary leak syndrome. Cancer Metastasis Rev. 1998;17:127-142.

35. Sakkoula E, Pipili-Synetos E, Maragoudakis ME. Involvement of nitric oxide in the inhibition of angiogenesis by interleukin-2. Br J Pharmacol. 1997;122:793-795.

36. Volpert OV, Fong $\mathrm{T}$, Koch AE, et al. Inhibition of angiogenesis by interleukin 4. J Exp Med. 1998;188:1039-1046.

37. Dirkx AE, Oude Egbrink MG, Kuijpers MJ, et al. Tumor angiogenesis modulates leukocyte-vessel wall interactions in vivo by reducing endothelial adhesion molecule expression. Cancer Res. 2003;63:2322-2329.

38. Moroz A, Eppolito C, Li Q, Tao J, Clegg CH, Shrikant PA. IL-21 enhances and sustains CD8+ T cell responses to achieve durable tumor immunity: comparative evaluation of IL-2, IL-15, and IL-21. J Immunol. 2004;173:900-909.

39. van der Schaft DW, Toebes EA, Haseman JR, Mayo KH, Griffioen AW. Bactericidal/permeabilityincreasing protein (BPI) inhibits angiogenesis via induction of apoptosis in vascular endothelial cells. Blood. 2000;96:176-181.

40. Thijssen VL, Brandwijk RJ, Dings RP, Griffioen AW. Angiogenesis gene expression profiling in xenograft models to study cellular interactions. Exp Cell Res. 2004;299:286-293.

41. Di Carlo E, Comes A, Orengo AM, et al. IL-21 induces tumor rejection by specific CTL and IFNgamma-dependent CXC chemokines in syngeneic mice. J Immunol. 2004;172:1540-1547. 
42. Eklund L, Olsen BR. Tie receptors and their angiopoietin ligands are context-dependent regulators of vascular remodeling. Exp Cell Res. 2006;312:630-641.

43. Fong GH, Rossant J, Gertsenstein M, Breitman ML. Role of the Flt-1 receptor tyrosine kinase in regulating the assembly of vascular endothelium. Nature. 1995;376:66-70.

44. Kuniyasu $\mathrm{H}$, Ohmori $\mathrm{H}$, Sasaki $\mathrm{T}$, et al. Production of interleukin 15 by human colon cancer cells is associated with induction of mucosal hyperplasia, angiogenesis, and metastasis. Clin Cancer Res. 2003;9:4802-4810.

45. Rodella L, Zamai L, Rezzani R, et al. Interleukin 2 and interleukin 15 differentially predispose natural killer cells to apoptosis mediated by endothelial and tumour cells. Br J Haematol. 2001;115:442-450.

46. Masuda M, Ruan HY, Ito A, et al. Signal transducers and activators of transcription 3 up-regulates vascular endothelial growth factor production and tumor angiogenesis in head and neck squamous cell carcinoma. Oral Oncol. 2006.

47. Weerasinghe $\mathrm{P}$, Garcia $\mathrm{GE}, \mathrm{Zhu} \mathrm{Q}$, et al. Inhibition of Stat3 activation and tumor growth suppression of non-small cell lung cancer by G-quartet oligonucleotides. Int J Oncol. 2007;31:129136.

48. Wu Z, Kim HP, Xue HH, Liu H, Zhao K, Leonard WJ. Interleukin-21 receptor gene induction in human T cells is mediated by T-cell receptor-induced Sp1 activity. Mol Cell Biol. 2005;25:97419752. 


\section{Chapter 8}

\section{Vascular adhesion protein-1 mediates leukocyte recruitment in tumors.}

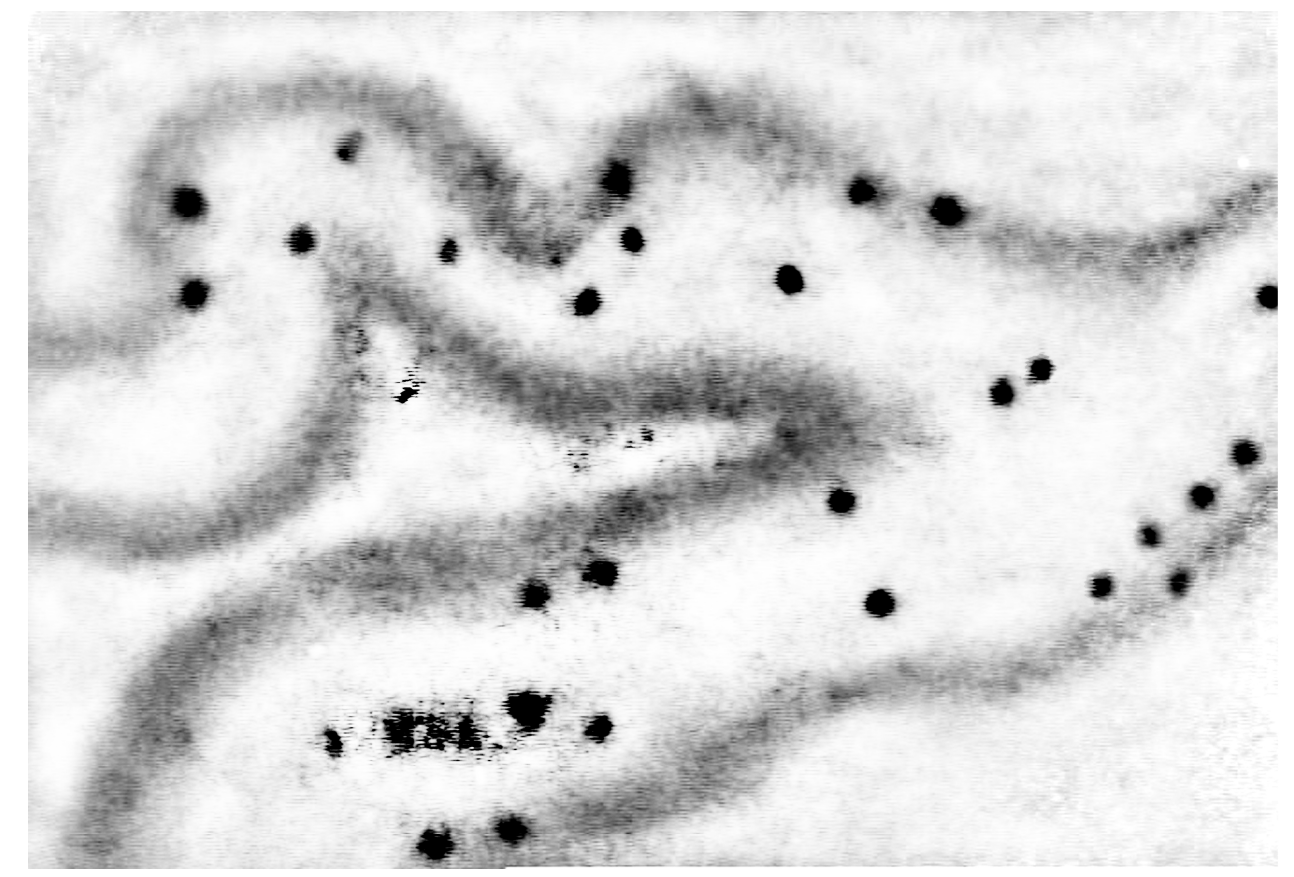

Karolien Castermans, Mirjam G. A. oude Egbrink, Sirpa Jalkanen, Arjan W. Griffioen

In preparation 


\begin{abstract}
Tumors can escape from the immune system in different ways. One remarkable method is the suppression of endothelial cell adhesion molecules like intercellular adhesion molecule (ICAM)-1, ICAM-2, vascular adhesion molecule (VCAM)-1 and endothelial (E)-selectin. This suppression is induced by angiogenic factors like basic fibroblast growth factor (bFGF) and vascular endothelial growth factor (VEGF) and leads to diminished leukocyte recruitment to the tumor site and eventually to tumor progression. We studied the role of vascular adhesion protein (VAP)-1 in leukocyte vessel wall interactions and recruitment of leukocytes into tumor tissue. We found that the number of VAP-1 positive vessels is similar in normal and tumor vessels. The expression in these normal vessels is not affected by VEGF treatment and leukocyte interactions in these vessels are VAP-1 independent. In tumor vessels, VAP-1 mediates leukocyte vessel wall interactions. VAP-1 function-blocking antibody decreased the number of interacting leukocytes from 191 leukocytes $/ \mathrm{mm}^{2}$ to 106 leukocytes $/ \mathrm{mm}^{2}$. Both leukocyte rolling (decrease of $50 \%$ ) and adhesion (decrease of $45 \%$ ) were affected. This is in contrast to normal vessels where it only mediates leukocyte rolling. The important role of VAP-1 in leukocyte recruitment makes it a promising target in the search for new cancer treatment based on immunotherapies.
\end{abstract}




\section{Introduction}

Over the last decades, several novel treatment strategies for cancer have been developed. Immunotherapy is one of the most promising strategies, especially the design of methods that generate tumor-specific immune effector cells through the use of tumor vaccines or cytokine therapies ${ }^{1-4}$. However, several mechanisms counteract the development of a proper anti-tumor immune response and the formation of an effective inflammatory infiltrate. One of these mechanisms is the suppression of adhesion molecules on cancer blood vessels, making extravasation through these vessels a difficult hurdle for anti-tumor immunity ${ }^{5-8}$. Studies from our lab have identified the angiogenic character of the tumor vessels, induced by angiogenic factors like basic fibroblast growth factor (bFGF) and vascular endothelial growth factor (VEGF), to partly mediate this decrease of expression 6,7,9. Chronic stimulation of endothelial cells by angiogenic factors, abundantly present in the tumor microenvironment, diminishes expression of intercellular adhesion molecule (ICAM)-1, ICAM-2, vascular adhesion molecule (VCAM)-1 and endothelial (E)-selectin. Consequently, reduced leukocyte-vessel wall interactions and low leukocyte infiltration can be observed in the tumor, leading to tumor progression $5,8,10$.

A novel endothelial adhesion molecule, vascular adhesion molecule (VAP)-1, has been primarily found to mediate leukocyte-vessel wall interactions in inflamed tissues ${ }^{11,12}$. VAP-1 is a bifunctional molecule that can support leukocyte adhesion under shear conditions via enzyme-activity dependent (Semicarbazidesensitive amine oxidation $=$ SSAO) and enzyme-activity independent ways ${ }^{13-15}$. This endothelial adhesion molecule has been mainly implicated in leukocyte rolling and transmigration in vivo ${ }^{15-17}$. The expression of VAP-1 has also been identified on tumor vessels and has been shown to mediate leukocyte adhesion on these vessels in an $e x$ vivo adhesion assay ${ }^{18}$. However, its functional role in tumor vessels in vivo has not been elucidated completely. Strong expression of VAP-1 on tumor vessels of hepatocellular carcinomas is associated with an intense $\mathrm{T}$ cell infiltrate 19,20 . On the other hand, in melanoma, the amount of VAP-1 expressed on intratumoral vessels is not correlated with the intensity of $\mathrm{T}$ cell infiltration in the tumor, although presence of VAP-1 on tumor vessels increases patient survival ${ }^{21}$. In this study it was also shown that VAP-1 expression in peritumoral vessels is much higher than on intratumoral vessels. These findings led us to hypothesize that VAP-1, like the other endothelial adhesion molecules ICAM-1, -2, VCAM-1 and E-selectin, is decreased in tumor vessels leading to reduced leukocyte recruitment to the tumor site. And we hypothesized that this decline is induced by angiogenic factors present in the tumor microenvironment. 
We found that VEGF stimulation of normal vessels did not reduce VAP-1 protein expression. However, VAP-1 protein present on these stimulated vessels does not seem to mediate any leukocyte-vessel wall interactions in vivo. This is in contrast to the unstimulated vessels were VAP-1 mediates leukocyte rolling as measured by intravital microscopy. In tumors vessels, VAP-1 protein expression is shown to be able to mediate leukocyte-vessel wall interactions. Interestingly, VAP-1 mediates leukocyte rolling as well as adhesion in the tumor tissue. These findings suggest that, in contrast to our hypothesis, the level of VAP-1 expression on vessels is not affected by VEGF stimulation although the functionality seems to be decreased. In addition we found that VAP-1 plays an important role in leukocyte recruitment to the tumor tissue which makes VAP-1 an interesting molecule for use in novel immunotherapeutic cancer therapies.

\section{Material and Methods}

\section{Cell culture}

Mouse B16F10 melanoma cells (kindly provided by Dr. Isaiah J. Fidler, Houston, TX) were culture as described previously ${ }^{5}$.

\section{Immunohistochemistry}

All immunohistochemical stainings were performed on acetone fixed frozen sections $(5 \mu \mathrm{m})$. Endogenous peroxidase was blocked by immersion in $0.3 \%$ hydrogen peroxidase in PBS for 30min and aspecific binding was blocked by PBS containing 20\% FCS and 0.1\% Tween 20 for 15 min., followed by incubation with primary antibody.

Microvessel density determination - The sections were incubated with biotin labelled lectin (Sigma Aldrich, Zwijndrecht, The Netherlands) followed by incubation of the sections with freshly prepared Avidin-biotin complex (DAKO, Glostrup, Denmark). The peroxidase activity was detected using diaminobenzidine (DAB; Sigma).

VAP-1 staining - VAP-1 function blocking antibody 7-88 (kind gift from Prof. S. Jalkanen) ${ }^{22}$ was administered in vivo. After blocking steps, sections were incubated with secondary antibody, biotin labelled donkey anti rat IgG (Jackson ImmunoResearch Lab Inc., Soham, Cambridgeshire, UK) followed by incubation of the sections with freshly prepared Avidin-biotin complex. The peroxidase activity was detected using DAB. All sections were counterstained with haematoxylin (Merck, Amsterdam, The Netherlands), dehydrated and mounted with entellan (Merck, Amsterdam, The Netherlands). 


\section{Preparation of growth factor pellets}

Heparin alginate pellets were prepared as previously described ${ }^{10}$. HeparinSepharose beads (Amersham, Uppsala, Sweden) mixed with sodium alginate (Sigma Aldrich) were allowed to polymerize in a matrix and hardened in $\mathrm{CaCl}_{2}$. The pellets (volume of $8 \mu \mathrm{l}$ ) were then sterilized in $70 \%$ ethanol and stored in physiological saline containing $1 \mathrm{mM} \mathrm{CaCl} 2$ at $4^{\circ} \mathrm{C}$. Pellets were loaded with $300 \mathrm{ng}$ human recombinant VEGF (this was produced by us as previously described ${ }^{23}$ ).

\section{Animals and experimental protocol}

All experiments were approved by the local ethical committee on the use of laboratory animals. They were performed on male C57B1/6 mice (25-30gr; Charles River, Maastricht, The Netherlands).

Cremaster muscle- One VEGF (5 mice) or PBS loaded pellet (6 mice) as control, was placed in the scrotum of a isoflurane (2.0-2.5\% in $80 \%$ oxygen) anesthetized mouse on day 0 . On day 1 and 2 extra bolus injections of VEGF (30 ng) or PBS in a volume of about $0.2 \mathrm{ml}$ were given intrascrotally under sedation. The cremaster muscle was prepared for intravital microscopy on day 3 as described previously ${ }^{24}$.

Tumor model - B16F10 tumors were grown in the flank of C57B1/6 mice by s.c. injection of $10^{5}$ cells in $100 \mu \mathrm{l}$ in $0.9 \% \mathrm{NaCl}$ solution. Intravital microscopic measurements were performed as described before ${ }^{5}$ on day 14 after tumor inoculation.

Throughout the experiments body temperature was kept at $37^{\circ} \mathrm{C}$. In all animals murine recombinant TNF $\alpha$ (500ng, R\&D Systems, Abington, U.K.) was injected i.p. 4 hours before measurements. This was performed because leukocyte adhesion is hardly present in the absence of cytokines, which would preclude the assessment of a reduction in leukocyte adhesion, if any. The exposed tissue was continuously superfused with Krebs solution $\left(34-35^{\circ} \mathrm{C} ; \mathrm{pH} 7.35-7.40\right)$. To enable intravital microscopic observations of leukocytes, 10-20 $\mu$ l of a Rhodamine 6G solution $(1 \mathrm{mg} / \mathrm{ml}$ in $0.9 \% \mathrm{NaCl}$ solution) was injected into the tail vein when needed. Vessels were visualized using a Leitz intravital microscope, adapted for telescopic imaging and equipped with an SW25 objective lens (numerical aperture 0.60). Microscopic images were recorded using a CCD camera (C3077, Hamamatsu, Japan), coupled to an intensifier unit (C2400-80, Hamamatsu, Japan), and stored on DVD (DVR-7000, Panasonic) for offline analysis. Experimental fluid dynamic parameters were determined as described previously and are summarized in Table $8.1{ }^{25}$. All data were statistically analyzed using MannWhitney U tests (using SPSS-10 software). Probabilities below 0.05 were considered statistically significant. 


\section{Results}

VAP-1 is expressed in normal and angiogenic blood vessels.

In order to investigate the hypothesis that endothelial VAP-1 is involved in leukocyte vessel wall interactions, we made use of the cremaster muscle preparation in mice. This system allows local exposure to angiogenic growth factors as we have described earlier ${ }^{10}$. We found that blood vessels of the cremaster muscle express VAP-1, as determined at the protein level by immunohistochemistry (Figure 8.1A). Quantification showed that about $16 \%$ of the vessels within the muscle are positive for VAP-1 (figure 8.1B).

Exposure of the tissue for 3 days to VEGF by means of loaded heparin alginate pellets, significantly increased the microvessel density within the muscle as compared to tissues exposed to unloaded pellets (Figure 8.2A). Also the absolute number of VAP-1 positive vessels was increased after stimulation with VEGF (Figure 8.2B), however, the percentage of VAP-positive vessels did not increase significantly after VEGF treatment (Figure 8.2C). These results suggests that VEGF does not affect VAP-1 expression on these vessels. This is in contrast to the expression of ICAM-1, the main mediator of leukocyte vessel wall interactions, which is decreased upon chronic stimulation with angiogenic growth factors ${ }^{5-7}$.

In the tumor model of syngeneic B16F10 melanoma, VAP-1 expression is observed in approximately $19 \%$ of the tumor vessels (Figure $8.1 \mathrm{~A}, \mathrm{~B}$ ). This is in line
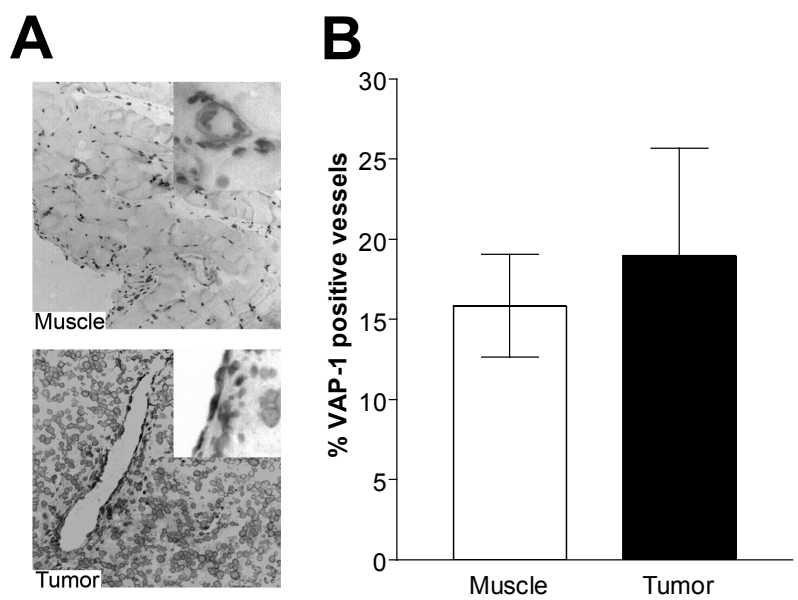

Figure 8.1. VAP-1 is expressed on normal and tumor blood vessels A) Immunohistochemical staining of cremaster muscle $(n=7)$ and tumor tissue $(n=4)$ stained for VAP-1. B) Percentage of VAP-1 positive vessels in TNF- $\alpha$ stimulated muscle and tumor tissues as determined by immunohistochemistry. 
with previous reports in human cutaneous melanoma ${ }^{21}$. Regulation of VAP-1 expression in vitro is difficult, since its expression is rapidly lost during cell culture and after immortalization of cell lines. Therefore we had to limit further investigations to these two in vivo mouse models.

\section{VAP-1 mediates leukocyte rolling in resting vessels.}

To investigate the role of VAP-1 in leukocyte-vessel wall interactions in resting and angiogenically stimulated vessels in vivo, we performed intravital microscopy. Leukocyte-vessel wall interactions in PBS (control) treated cremaster muscles were quantified before and after systemic administration of function-blocking VAP-1 antibody. Treatment with VAP-1 antibody did not significantly alter leukocytevessel wall interactions in PBS treated muscles (Figure 8.3A clear bars). The total level of leukocyte-vessel wall interactions includes both leukocyte rolling and firm adhesion. Discrimination between these two processes revealed that VAP-1 antibody significantly inhibited the number of rolling leukocytes in vessels of control muscles by approximately 65\% (from 40 to 14 rolling leukocytes/min, Figure $8.3 \mathrm{~B}$, open bars). This is in line with previous reports which demonstrated an important role for VAP-1 in leukocyte rolling ${ }^{13,22}$. In contrast, no significant effect was found at the level of leukocyte adhesion (Figure 8.3C, open bars).

In order to mimic angiogenic tumor vessels in this cremaster model we inserted VEGF loaded slow-release pellets, resulting in exposure of the vessels to this angiogenic growth factor. We were unable to detect a decrease in leukocytevessel wall interactions after VEGF treatment in the cytokine stimulated cremaster muscles. Systemic treatment of these mice with the blocking VAP-1 antibody did
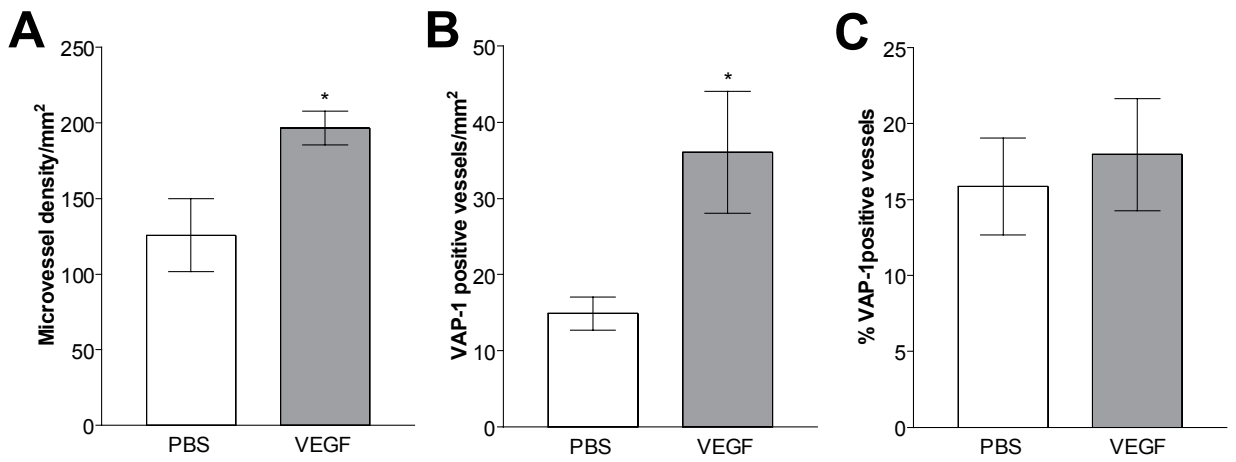

Figure 8.2. VAP-1 expression in angiogenically stimulated muscle blood vessels A) Microvessel density per $\mathrm{mm}^{2}$, B) Number of VAP-1 positive vessels and, C) Percentage of VAP-1 positive vessels in TNF- $\alpha$ stimulated control (PBS, $n=7$ ) or $\operatorname{VEGF}(n=4)$ stimulated cremaster muscles. ${ }^{*} \mathrm{p}<0.05$ compared to control). 
not inhibit leukocyte-vessel wall interactions (Figure 8.2A, grey bars). Interestingly, subdivision of the rolling and adhesion processes shows that after VEGF treatment, neither leukocyte rolling nor adhesion are blocked by the VAP-1 antibody (Figure 8.3B, C, grey bars). This suggests that, after VEGF treatment, leukocyte-vessel wall interactions in the cremaster muscle are not mediated by VAP-1.

Administration of the VAP-1 blocking antibody had no effect on local fluid dynamic parameters that were determined in the vessels of the PBS treated cremaster muscle. In VEGF stimulated vessels of the cremaster muscle we could detect a significant decrease of reduced velocity (U) after administration of the blocking VAP-1 antibody (Table 8.1). This might reduce the number of leukocytes that interact with the vessel wall and can therefore not explain the differential effect of the VAP-1 antibody on leukocyte rolling in PBS and VEGF treated muscles.

Table 8.1. Fluid dynamic parameters in tumor blood vessels of treated and non-treated mice. ${ }^{a}$

\begin{tabular}{|c|c|c|c|c|c|c|}
\hline \multirow[b]{2}{*}{$\begin{array}{l}V A P-1 \\
\text { Antibody }\end{array}$} & \multicolumn{2}{|c|}{ PBS cremaster muscle } & \multicolumn{2}{|c|}{ VEGF cremaster muscle } & \multicolumn{2}{|c|}{ B16F10 melanoma tumor } \\
\hline & - & + & - & + & - & + \\
\hline$n m^{b}$ & 7 & 6 & 6 & 5 & 7 & 7 \\
\hline$n v^{b}$ & 30 & 37 & 30 & 32 & 37 & 43 \\
\hline Diameter $(\mu m)$ & $30(30-43)$ & $35(30-45)$ & $35(30-40)$ & $38(30-50)$ & $30(25-43)$ & $30(25-45)$ \\
\hline $\begin{array}{l}\text { Centerline } \\
\text { velocity }(\mathrm{mm} / \mathrm{sec})\end{array}$ & $1,9(1,1-2,6)$ & $1,5(1,3-2,3)$ & $1,6(1,2-2,3)$ & $1,5(1,1-1,8)$ & $1,7(1,3-1,8)$ & $1,6(1,3-2,2)$ \\
\hline$U\left(s^{-1}\right)^{b}$ & $31(16-43)$ & $23(19-36)$ & $34(25-41)$ & $23(18-26)^{* *}$ & $27(19-40)$ & $35(22-44)$ \\
\hline$Q\left(\mathrm{~mm}^{3} / \mathrm{sec}\right)^{b}$ & $11(5-22) \times 10^{-4}$ & $12(8-32) \times 10^{-4}$ & $12(7-23) \times 10^{-4}$ & $127-23) \times 10^{-4}$ & $9(5-16) \times 10^{-4}$ & $7(5-11) \times 10^{-4}$ \\
\hline
\end{tabular}

a Data are presented as median values with interquartile ranges. Statistical significance was assessed in comparison to values in antibody treated and non-antibody treated mice $\left({ }^{* *} \mathrm{p}<0,005\right) .{ }^{\mathrm{b}} n_{m}$, number of mice; $n^{v}$, number of vessels; $U$ reduced velocity; $Q$ flow

\section{VAP-1 mediates leukocyte-vessel wall interactions in tumors.}

In tumors, the in vivo function of VAP-1 in leukocyte-vessel wall interactions was also examined by intravital microscopy. Leukocyte-vessel wall interactions were measured in tumor vessels before and after administration of VAP-1 antibody. Interestingly, the VAP-1 blocking antibody significantly reduced leukocyte-vessel wall interactions in tumor vessels (106 leukocytes $/ \mathrm{mm}^{2}$ ) compared to no treatment (191 leukocytes/mm², Figure 8.3A, black bars). This suggests that VAP-1 indeed mediates leukocyte recruitment in tumor vessels. Furthermore, discrimination between leukocyte rolling and adhesion showed a significant $50 \%$ decrease of leukocyte rolling in tumor vessels after administration with VAP-1 blocking antibody (from 6 to 3 leukocytes/min, $p=0.007$ ). The number of adhering leukocytes was decreased as well by approximately $45 \%$ (from 257 
leukocytes $/ \mathrm{mm}^{2}$ to 146 leukocytes $/ \mathrm{mm}^{2},(\mathrm{p}=0.117$, Figure 8.3B and C, black bars). Administration of the VAP-1 function-blocking antibody had no effect on any of the local fluid dynamic parameters that were determined. This information suggests that VAP-1 might mediate leukocyte rolling as well as adhesion in tumor vessels.
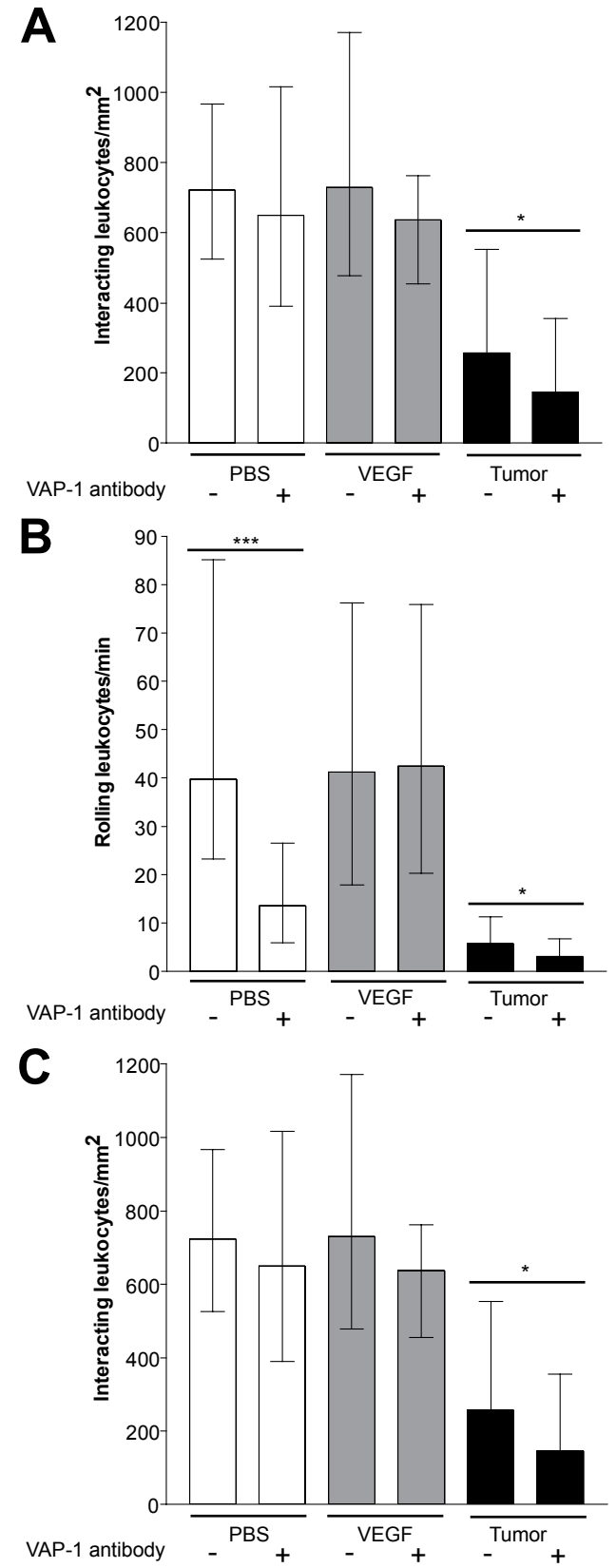

Figure 8.3. Leukocyte-vessel wall interactions in cremaster muscle and tumor tissues A) Interacting leukocytes per $\mathrm{mm}^{2}$ vessel surface, B) Number of adhering leukocytes per $\mathrm{mm}^{2}$, and C) rolling leukocytes per minute in cremaster muscles treated with PBS (open bars,n=5) or VEGF (grey bars, $n=5$ ), or in tumor vessels (black bars, $n=6$ ) after cytokine stimulation with TNF- $\alpha .{ }^{*} \mathrm{p}<0.05$, *** $\mathrm{p}<0.0005$ versus untreated mice. 


\section{Discussion}

A tumor has developed several mechanisms to escape from an effective immune response. One of them is the decrease of expression of endothelial cell adhesion molecules ICAM-1, VCAM-1 and E-selectin leading to decreased leukocyte recruitment to the tumor tissue ${ }^{5-7,9}$. We have found that the novel adhesion molecule VAP-1 is still expressed in tumors and that the amount of VAP-1 positive vessels in the tumor is similar to the amount in the healthy cremaster muscle. VAP-1 expression in tumors is also functional as a mediator of leukocyte recruitment. These data propose that VAP-1 is not down-regulated on tumor vessels as we hypothesized and as was suggested by previous publications ${ }^{19-21}$.

Interestingly, VAP-1 mediates leukocyte rolling as well as leukocyte adhesion in tumor vessels as we were able to block both processes in the tumor by means of a VAP-1 function-blocking antibody. This is in contrast with our findings in the unstimulated vessels of the muscle which show that VAP-1 mediates primarily leukocyte rolling. Since the expression of ICAM-1, -2 and VCAM-1, all implicated in firm adhesion of leukocytes to endothelial cells 26,27 , is diminished in tumor vessels, there may be a possibility that VAP-1 partly takes over this adhesive function in these vessels. Dirkx et al. showed that the expression of adhesion molecules on leukocytes is not affected by the presence of a tumor and this can therefore not explain the differences in leukocyte vessel wall interactions in resting and tumor vessels after treatment with the VAP-1 antibody ${ }^{5}$.

The tumor derived angiogenic factor VEGF, which reduces expression of ICAM-1, VCAM-1 and E-selectin, did not decrease the expression of VAP-1 on normal vessels. However, VAP-1 present on the VEGF stimulated vessels does not seem to mediate any leukocyte interactions with the vessel wall. This is not due to differences is the number of leukocytes in the peripheral blood since previous experiments in the cremaster model showed no effect after local treatment with VEGF ${ }^{10}$. Garpenstrand et al. demonstrated a correlation between VEGF and the serum level of VAP-1 in cancer patients and suggested an important role for the enzymatic function of VAP-1 (SSAO) in inducing angiogenesis ${ }^{28}$. This might explain the loss of leukocyte adhesion functions of VAP-1 after VEGF stimulation, because the main focus of VAP-1 might then be on controlling angiogenesis.

The used function-blocking VAP-1 antibody blocks only the adhesive and not the enzymatic activities of VAP-1. This obstruction, however, is sufficient to inhibit functional binding of leukocytes to VAP-1 22. Since all end-products of the VAP-1/SSAO catalyzed reaction are biologically active substances they may affect other processes. The SSAO reaction results in the generation of aldehydes, ammonium and hydrogen peroxide ${ }^{29}$. Among the end-products, hydrogen peroxide is an emerging signalling molecule ${ }^{30}$. A recent paper by us has shown 
that the enzymatic activity of VAP-1 can also prime the endothelial microenvironment of vessels for enhanced leukocyte extravasation ${ }^{31}$. The VAP-1 dependent oxidase reaction results in induction of E- and P- selectin synthesis. This might also be an explanation for the apparent lack of leukocyte adhesion function of VAP-1 after VEGF stimulation. The enzymatic function of VAP-1 might stimulate E-, and P-selectin activity extensively so that the amount of leukocyte interactions is not affected after the administration of the blocking antibody.

Our data demonstrate an important role for VAP-1 in leukocyte recruitment to tumors. This information suggests that VAP-1 might be a powerful novel target for future immunotherapies for cancer treatment.

\section{References}

1. Jaffee EM. Immunotherapy of cancer. Ann N Y Acad Sci. 1999;886:67-72.

2. Mitchell MS. Immunotherapy as part of combinations for the treatment of cancer. Int Immunopharmacol. 2003;3:1051-1059.

3. Pardoll DM. Spinning molecular immunology into successful immunotherapy. Nat Rev Immunol. 2002;2:227-238.

4. Rosenberg SA. Shedding light on immunotherapy for cancer. N Engl J Med. 2004;350:1461-1463.

5. Dirkx AE, Oude Egbrink MG, Kuijpers MJ, et al. Tumor angiogenesis modulates leukocyte-vessel wall interactions in vivo by reducing endothelial adhesion molecule expression. Cancer Res. 2003;63:2322-2329.

6. Griffioen AW, Damen CA, Blijham GH, Groenewegen G. Tumor angiogenesis is accompanied by a decreased inflammatory response of tumor-associated endothelium. Blood. 1996;88:667-673.

7. Griffioen AW, Damen CA, Martinotti S, Blijham GH, Groenewegen G. Endothelial intercellular adhesion molecule-1 expression is suppressed in human malignancies: the role of angiogenic factors. Cancer Res. 1996;56:1111-1117.

8. Griffioen AW, Tromp SC, Hillen HF. Angiogenesis modulates the tumour immune response. Int J Exp Pathol. 1998;79:363-368.

9. Griffioen AW, Relou IA, Gallardo Torres HI, et al. The angiogenic factor bFGF impairs leukocyte adhesion and rolling under flow conditions. Angiogenesis. 1998;2:235-243.

10. Tromp SC, oude Egbrink MG, Dings RP, et al. Tumor angiogenesis factors reduce leukocyte adhesion in vivo. Int Immunol. 2000;12:671-676.

11. Jalkanen S, Salmi M. Vascular adhesion protein-1 (VAP-1)--a new adhesion molecule recruiting lymphocytes to sites of inflammation. Res Immunol. 1993;144:746-749; discussion 754-762.

12. Salmi M, Jalkanen S. A 90-kilodalton endothelial cell molecule mediating lymphocyte binding in humans. Science. 1992;257:1407-1409.

13. Salmi M, Jalkanen S. VAP-1: an adhesin and an enzyme. Trends Immunol. 2001;22:211-216.

14. Bonder CS, Norman MU, Swain MG, et al. Rules of recruitment for Th1 and Th2 lymphocytes in inflamed liver: a role for alpha-4 integrin and vascular adhesion protein-1. Immunity. 2005;23:153163.

15. Salmi M, Yegutkin GG, Lehvonen R, Koskinen K, Salminen T, Jalkanen S. A cell surface amine oxidase directly controls lymphocyte migration. Immunity. 2001;14:265-276.

16. Koskinen K, Vainio PJ, Smith DJ, et al. Granulocyte transmigration through the endothelium is regulated by the oxidase activity of vascular adhesion protein-1 (VAP-1). Blood. 2004;103:33883395. 
17. Tohka S, Laukkanen M, Jalkanen S, Salmi M. Vascular adhesion protein 1 (VAP-1) functions as a molecular brake during granulocyte rolling and mediates recruitment in vivo. Faseb J. 2001;15:373382.

18. Irjala H, Salmi M, Alanen K, Grenman R, Jalkanen S. Vascular adhesion protein 1 mediates binding of immunotherapeutic effector cells to tumor endothelium. J Immunol. 2001;166:69376943.

19. Yoong KF, McNab G, Hubscher SG, Adams DH. Vascular adhesion protein-1 and ICAM-1 support the adhesion of tumor-infiltrating lymphocytes to tumor endothelium in human hepatocellular carcinoma. J Immunol. 1998;160:3978-3988.

20. Yoong KF, Williams A, Hubscher SG, Salmi M, Jalkanen S, Adams DH. Vascular adhesion protein1 and intercellular adhesion molecule-1 mediate T-cell binding to human hepatocellular carcinoma. Biochem Soc Trans. 1997;25:257S.

21. Forster-Horvath C, Dome B, Paku S, et al. Loss of vascular adhesion protein-1 expression in intratumoral microvessels of human skin melanoma. Melanoma Res. 2004;14:135-140.

22. Irjala $\mathrm{H}$, Elima $\mathrm{K}$, Johansson EL, et al. The same endothelial receptor controls lymphocyte traffic both in vascular and lymphatic vessels. Eur J Immunol. 2003;33:815-824.

23. Wood JM, Bold G, Buchdunger E, et al. PTK787/ZK 222584, a novel and potent inhibitor of vascular endothelial growth factor receptor tyrosine kinases, impairs vascular endothelial growth factor-induced responses and tumor growth after oral administration. Cancer Res. 2000;60:21782189.

24. Baez S. An open cremaster muscle preparation for the study of blood vessels by in vivo microscopy. Microvasc Res. 1973;5:384-394.

25. Dirkx AE, oude Egbrink MG, Castermans $\mathrm{K}$, et al. Anti-angiogenesis therapy can overcome endothelial cell anergy and promote leukocyte-endothelium interactions and infiltration in tumors. Faseb J. 2006;20:621-630.

26. Carlos TM, Harlan JM. Leukocyte-endothelial adhesion molecules. Blood. 1994;84:2068-2101.

27. Greenwood J, Wang Y, Calder VL. Lymphocyte adhesion and transendothelial migration in the central nervous system: the role of LFA-1, ICAM-1, VLA-4 and VCAM-1. off. Immunology. 1995;86:408-415.

28. Garpenstrand $H$, Bergqvist $M$, Brattstrom $D$, et al. Serum semicarbazide-sensitive amine oxidase (SSAO) activity correlates with VEGF in non-small-cell lung cancer patients. Med Oncol. 2004;21:241-250.

29. Klinman JP, Mu D. Quinoenzymes in biology. Annu Rev Biochem. 1994;63:299-344.

30. Reth M. Hydrogen peroxide as second messenger in lymphocyte activation. Nat Immunol. 2002;3:1129-1134.

31. Jalkanen S, Karikoski M, Mercier N, et al. The oxidase activity of vascular adhesion protein-1 (VAP-1) induces endothelial E- and P-selectins and leukocyte binding. Blood. 2007. 
Chapter 9

General discussion and concluding remarks

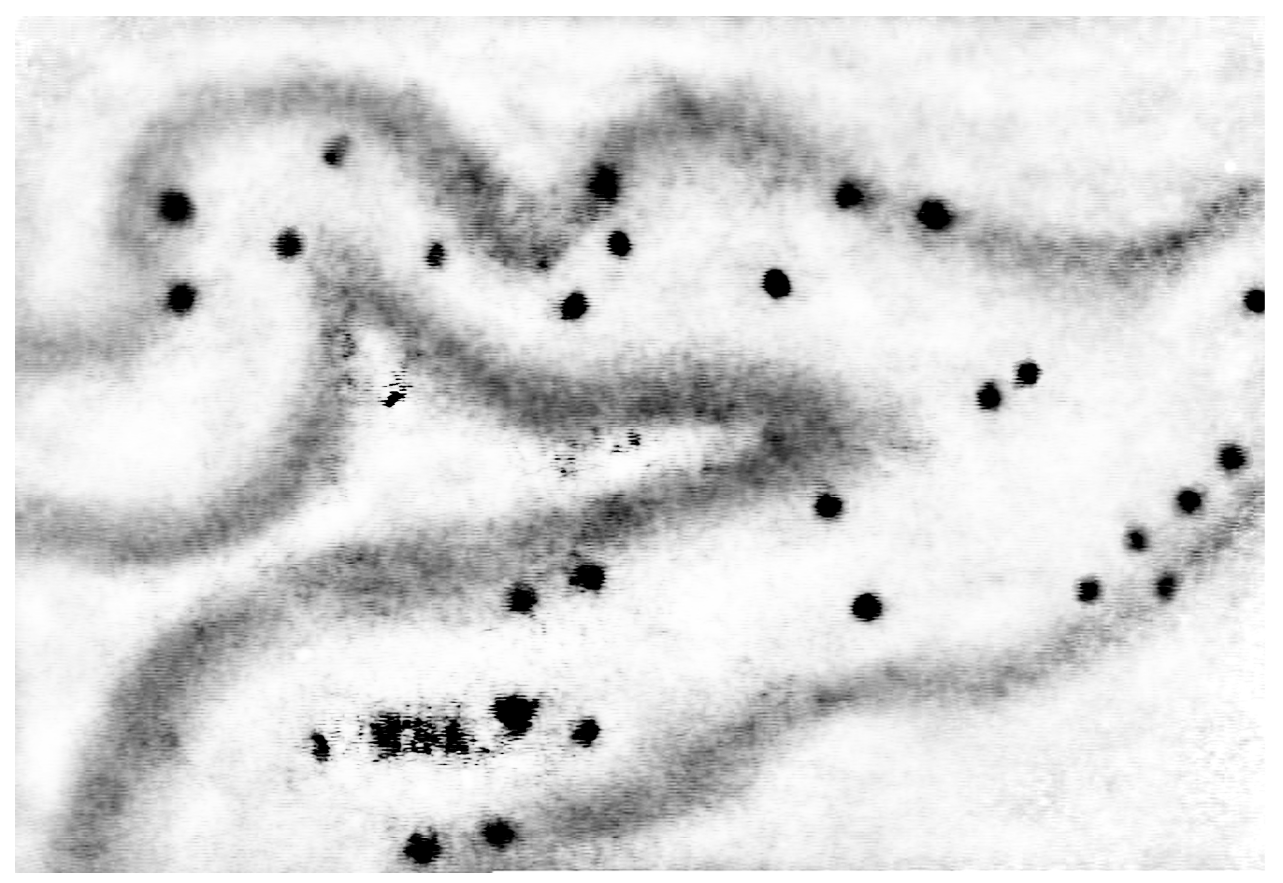




\section{General discussion}

Tumors possess numerous mechanisms by which their growth and progression are maintained. Next to enhanced execution of proliferation pathways and inhibition of mechanisms leading to apoptosis, they secure their supply of oxygen and nutrients by inducing and sustaining the formation of new blood vessels, also called angiogenesis. Furthermore, tumors affect the hosts' immune response in several ways leading to tumor ignorance, tolerance and escape from eradication by effector immune cells.

The aim of this research was to investigate and gain new insights in the relationship between angiogenesis and the immune response in tumors. This information can be of great help for the development of new cancer treatment strategies using the combination of angiogenesis inhibition and immunotherapy. Both processes, tumor angiogenesis and the anti-tumor immune response, are regulated by tumor derived factors. Angiogenic factors like bFGF and VEGF, induce endothelial cells to proliferate, migrate and form new blood vessels. Interestingly, these factors also reduce leukocyte recruitment to the tumor tissue by diminishing expression of endothelial cell adhesion molecules. We found that by inhibition of angiogenesis, the expression of endothelial cell adhesion molecules can be restored on tumor vessels and leukocyte recruitment is stimulated.

It seems contradictory to state that a decrease in vessels will lead to an increase of leukocytes in tissues since vessels are the main means of transportation for leukocytes. Vasculature in tumors displays a very irregular, tortuous and disorganized morphology. In addition, these immature vessels are leaky and can be compressed by the interstitial pressure induced by the proliferating tumor cells. The perfusion rates are low and unevenly distributed leading to a hypoxic and acidic environment in the tumor tissue ${ }^{1,2}$. This has implications for various treatment strategies. The abnormalities form a physiological barrier to the delivery of therapeutic agents like chemotherapeutic drugs to the tumor ${ }^{1}$. Since oxygen is an important factor in radiation therapy, hypoxia will reduce the efficiency of this treatment ${ }^{3}$. The acidic and hypoxic nature of the tumor environment leads to dysfunction of immune cells which has implications in immunotherapies ${ }^{1}$. Treatment of the tumors with angiostatic agents will not only reduce the formation of new vessels but will also normalize the vessels that are already present in the tumor and will improve their vascular function. Oxygen delivery is more efficiently after angiostatic treatment and the $\mathrm{pH}$ in the tissue is normalized leading to better responses to radiation and immunotherapy ${ }^{1}$. Furthermore, leakiness of vessels increases due to endothelial cell death and the amount of adhesion molecules on the vessels is increased which gives the leukocytes more 
occasions to interact with the vessel wall and infiltrate within the tumor tissue (Chapter 4 and 5 and references ${ }^{4-6}$ ). However, this stabilization of vessels is transient, which has been referred to as the normalization window. Extensive treatment with angiostatic agents eventually will lead to the destruction of all vessels and hinder delivery of oxygen and drugs ${ }^{7,8}$. It is therefore important to combine treatments with angiogenesis inhibitors within this window of opportunity.

Several reports suggest that a profound infiltration of leukocytes in the tumor tissue will lead to tumor progression rather then eradication ${ }^{9-11}$. However, in this light it is important to make a distinction between the innate and adaptive immune cells. The balance between these immune processes largely determines the outcome for the tumor ${ }^{12}$. Chronic activation of the innate immune cells (dendritric cells, macrophages, neutrophils) in the tumor microenvironment, will lead to cancer progression ${ }^{13}$. These cells are able to produce various factors like VEGF and IL-8 that stimulate tumor angiogenesis, tumor progression as well as metastasis ${ }^{14}$. Conversely, full activation of adaptive immune cells (B cells, CD4 ${ }^{+}$ cells, CD8 ${ }^{+}$cells) will induce eradication of malignant cells ${ }^{13}$. Excessive humoral over cell-mediated immunity stimulates tumor development 15,16. The balance between the different forms of immunity is thereby critical in determining carcinogenesis and is dysregulated in favor of the tumor cells. A better way to evaluate the prognosis of patients based on leukocyte infiltration is to analyze the different subsets in the tumor tissue and their activation status. In chapter 3 we identified that in patients with colorectal cancer the amount of $\mathrm{CD}^{+}$cells is an excellent positive marker for survival, even better than the general used histopathological staging. Several scientists have reported that the activation status of the tumor infiltrated leukocytes gives a good indication for patients outcome as well ${ }^{17-20}$.

Since there are immune cells that can infiltrate the tumor tissue despite the diminished expression of ICAM-1, VCAM-1 and E-selectin, additional leukocyte recruitment mechanisms that are less affected by the tumor microenvironment are likely to be present. In chapter 8 we describe a novel mechanism, namely the recently discovered adhesion molecule vascular adhesion protein (VAP)- 1 . This molecule mediates rolling and adhesion of leukocytes to the tumor vessel wall. Other less well-known endothelial cell adhesion molecules that are suggested to mediate leukocyte recruitment like peripheral lymph node addressin (PNAd), neural cell adhesion molecule (NCAM) and carcinoembryonic antigen-related cell adhesion molecule (CEACAM)-1, have been described to be unaffected or even increased on tumor vessels (chapter 2). This is inconsistent with the escape mechanism from the immune response of the tumor. Interestingly, these endothelial cell adhesion molecules can, besides mediating leukocyte adhesion, 
also contribute to tumor progression. VAP-1 has enzymatic and non-enzymatic roles in leukocyte-vessel wall interactions. Preliminary results suggest that the end products formed by the oxidase function of VAP-1, stimulate tumor angiogenesis. The increased expression of PNAd in gastric adenocarcinomas leads to recruitment of a-typical T lymphocytes to the tumor tissue ${ }^{21}$. And NCAM and CEACAM-1 expression in a tumor are correlated with angiogenic vasculature and tumor progression ${ }^{22-25}$. These reports suggest that the tumor uses these endothelial cell adhesion molecules for its further development and the tumor tolerates the possibility of leukocyte recruitment via these molecules.

As stated previously, angiogenesis inhibitors can restore the expression of adhesion molecules on endothelial cells in tumors thereby increasing the leukocyte influx into the tumor tissue (chapter 4, 5 and 6). However, several of these compounds can directly affect the function and activation of leukocytes as well, which can have implications for future combination therapies. Angiostatin and histone deacetylase (HDAC) inhibitors have a negative effect on leukocyte function and activation ${ }^{26-28}$. TNP-470 has been described to modulate human and murine lymphocyte function ${ }^{29}$. This angiogenesis inhibitor is able to induce B cell proliferation through the activation of T cells ${ }^{30-32}$. On the contrary, Schoof et al. demonstrated that under certain conditions of drug administration, the immune system function can be inhibited by TNP-470. In combination with IL-2 stimulation or antibody induction, a decrease of natural killer cell-mediated tumor cell killing and T cell proliferation can be observed ${ }^{33}$. This suggests that TNP-470 would not be a reliable compound to use in combination with an immunotherapy based on for instance cytokine administration. More interesting partners for use together with immunotherapy are endostatin and synthetic compounds anginex and 0118. Endostatin needs the expression of E-selectin for performing its function and has not been reported to affect leukocyte function ${ }^{34}$. Results obtained for anginex and 0118 indicate that these angiogenesis inhibitors only increase the leukocyte influx in a tumor by stimulation of endothelial cell adhesion molecule expression and not by a direct effect on the leukocytes (chapter 5).

There are various options of immunotherapies that can be used to combine with angiostatic therapy. All of which have their own benefits and pitfalls. There are 3 requirements for an effective immunotherapy: (i) sufficient number of effective $\mathrm{T}$ cells have to be present in the tumor bearing host, (ii) these $\mathrm{T}$ cells have to be capable in reaching and extravasating the site of the cancer and, (ii) these cells must posses the appropriate effector mechanism to destroy cancer cells. Currently, no immunization strategies that are capable of meeting them all 35 do not exist. We have shown that angiostatic treatment can improve the leukocyte influx in the tumor tissue and thereby contributes to the fulfillment of one of the requirements. Adoptive $\mathrm{T}$ cell transfer is a strategy that is designed to fulfill the 
other necessities and consists of the infusion of various mature $\mathrm{T}$ cell subsets which are well suited for genetic manipulation 36,37 . However, the first treatments in rodents were reported in 1955. Now, 50 years later, still no T cell therapy has been FDA-approved. The procedure is labor intensive and very costly. Furthermore, there are often no guarantees of specific antigens ${ }^{38}$. A technique gaining more popularity with the tumor immunologists is the dendritic cell (DC) vaccination. This therapy comprises of the immunization of patients with autologous, patient derived DCs loaded with tumor antigens ex vivo ${ }^{39}$. There are some limitations regarding this strategy as well and a recent phase III clinical trail in melanoma patients failed ${ }^{40}$. No consensus has been reached regarding the maturation status nor the delivery of the cells ${ }^{41}$. Besides transfer of immune cells, immunotherapy also includes therapies consisting of non-specific immune modulation like treatment with cytokines ${ }^{42}$. Treatment with cytokines like IL-2 and IL-12 has shown promising results in mice ${ }^{43,44}$, however clinical studies do not confirm these positive data 35,45,46. Currently, administration of cytokines is combined with adoptive $\mathrm{T}$ cell transfer, $\mathrm{DC}$ vaccination or cancer gene therapy strategies to improve their efficiency ${ }^{42,47}$. Interestingly, there are a few reports that describe the combination of angiogenesis inhibition and immunotherapy which are based on vaccines developed to eradicate tumor endothelial cells. Cytotoxic T cells are targeted to angiogenic receptors e.g. VEGFR2, present on activated tumor endothelial cells and eradicate these cells. These combination strategies are therefore merely angiostatic treatments $48-50$.

Overall, immunotherapies in mice have been very successful, in contrast to studies in patients where the results were disappointing. There are a few explanations for these contradictory responses. In mice, immune treatments are often started even before the tumor has been induced. This is a very different situation from the patient studies. In clinical trails, the majority of patients have late stage metastatic disease that either had failed standard effective therapies or have disease for which no standard effective therapy exists ${ }^{35}$. The majority of the studies have been performed on patients with melanoma or renal cell carcinoma in contrast to in mice where numerous tumor types have been tested with different efficacy. Tumors in mice are predominantly induced and have not developed spontaneously over several years like in humans. Therefore, mouse models are not completely suitable to use in de search for new cancer therapies in humans but still they are valuable in elucidating various processes during the assessment of an effective immune response and tumor development.

Up to now, there has been a big discrepancy between the induced immune responses and clinical outcome, which is probably related to the extent and quality of the induced immune response, resulting in the frequent observation of induction of an immune response in the absence of an objective clinical response ${ }^{39}$. 
Therefore there is a great need for new assays that can accurately detect and quantify $\mathrm{T}$ cell mediated, antigen specific immune responses and these assays should be standardized. One technique that shows potential is the detection of different patterns of intracellular cytokine secretion in the tumor. The amount of $\mathrm{T}$ helper 1 (IL-2, IFN $\gamma, \mathrm{TNF} \alpha$ ) or T helper 2 (IL-4, IL-5, IL-6, IL-10, IL-13) cytokines could be used to differentiate between memory/effector $\mathrm{T}$ cells with different immune functions ${ }^{51}$.

\section{Concluding remarks for future cancer therapy}

The most promising strategy for cancer treatment is most likely the combination of different therapies. By treatment with angiostatic compounds, the tumor can be deprived of its oxygen and nutrients on which the tumor depends for its growth and development. In addition, this therapy increases the influx of anti-tumor immune cells in the tumor tissue (chapter 4-5). A combination with a treatment that increases the cell mediated adaptive immunity by stimulating the activity of these tumor infiltrated leukocytes would have great potential in the destruction of a growing tumor. IL-21 is such a compound that induces anti-tumor adaptive immunity and has already proven its power as a single therapy in various mouse models ${ }^{52}$. However, as previously mentioned, the scheduling of the treatments has to be perfect. Anti-angiogenesis treatment creates only a temporal window of opportunity in which the vessels are normalized and the combined therapy can reach the tumor tissue in an optimal manner 7,8 . Additionally, several angiostatic compounds have a negative effect on leukocyte function. We consider the powerful angiostatic compounds anginex and 0118 very potent candidates for this combination treatment as they have not been shown to affect leukocyte activation. IL-21 treatment did not demonstrate any toxicity and can therefore be administered systemically in contrast to several cytokines like IL-2 that have shown toxic properties 53,54 . Treatment with toxic compounds should be restricted to targeted delivery to the tumor microenvironment. 


\section{References}

1. Fukumura D, Jain RK. Tumor microenvironment abnormalities: causes, consequences, and strategies to normalize. J Cell Biochem. 2007;101:937-949.

2. Jain RK. Molecular regulation of vessel maturation. Nat Med. 2003;9:685-693.

3. Brown JM. The hypoxic cell: a target for selective cancer therapy--eighteenth Bruce F. Cain Memorial Award lecture. Cancer Res. 1999;59:5863-5870.

4. Dirkx AE, Oude Egbrink MG, Kuijpers MJ, et al. Tumor angiogenesis modulates leukocyte-vessel wall interactions in vivo by reducing endothelial adhesion molecule expression. Cancer Res. 2003;63:2322-2329.

5. Griffioen AW, Damen CA, Mayo KH, et al. Angiogenesis inhibitors overcome tumor induced endothelial cell anergy. Int J Cancer. 1999;80:315-319.

6. Huang X, Wong MK, Yi H, et al. Combined therapy of local and metastatic $4 \mathrm{~T} 1$ breast tumor in mice using SU6668, an inhibitor of angiogenic receptor tyrosine kinases, and the immunostimulator B7.2-IgG fusion protein. Cancer Res. 2002;62:5727-5735.

7. Lin MI, Sessa WC. Antiangiogenic therapy: creating a unique "window" of opportunity. Cancer Cell. 2004;6:529-531.

8. Winkler F, Kozin SV, Tong RT, et al. Kinetics of vascular normalization by VEGFR2 blockade governs brain tumor response to radiation: role of oxygenation, angiopoietin-1, and matrix metalloproteinases. Cancer Cell. 2004;6:553-563.

9. Ali AA, McMillan DC, Matalka, II, McNicol AM, McArdle CS. Tumour T-lymphocyte subset infiltration and tumour recurrence following curative resection for colorectal cancer. Eur J Surg Oncol. 2004;30:292-295.

10. Bromwich EJ, McArdle PA, Canna K, et al. The relationship between T-lymphocyte infiltration, stage, tumour grade and survival in patients undergoing curative surgery for renal cell cancer. $\mathrm{Br} \mathrm{J}$ Cancer. 2003;89:1906-1908.

11. Mantovani A, Schioppa T, Porta C, Allavena P, Sica A. Role of tumor-associated macrophages in tumor progression and invasion. Cancer Metastasis Rev. 2006.

12. de Visser KE, Coussens LM. The interplay between innate and adaptive immunity regulates cancer development. Cancer Immunol Immunother. 2005;54:1143-1152.

13. de Visser KE, Coussens LM. The inflammatory tumor microenvironment and its impact on cancer development. Contrib Microbiol. 2006;13:118-137.

14. Coussens LM, Werb Z. Inflammatory cells and cancer: think different! J Exp Med. 2001;193:F23-26.

15. Johansson M, Tan T, de Visser KE, Coussens LM. Immune cells as anti-cancer therapeutic targets and tools. J Cell Biochem. 2007;101:918-926.

16. Tan TT, Coussens LM. Humoral immunity, inflammation and cancer. Curr Opin Immunol. 2007;19:209-216.

17. Georgiannos SN, Renaut A, Goode AW, Sheaff M. The immunophenotype and activation status of the lymphocytic infiltrate in human breast cancers, the role of the major histocompatibility complex in cell-mediated immune mechanisms, and their association with prognostic indicators. Surgery. 2003;134:827-834.

18. Ladanyi A, Somlai B, Gilde K, Fejos Z, Gaudi I, Timar J. T-cell activation marker expression on tumor-infiltrating lymphocytes as prognostic factor in cutaneous malignant melanoma. Clin Cancer Res. 2004;10:521-530.

19. Nakano O, Sato M, Naito Y, et al. Proliferative activity of intratumoral CD8(+) T-lymphocytes as a prognostic factor in human renal cell carcinoma: clinicopathologic demonstration of antitumor immunity. Cancer Res. 2001;61:5132-5136.

20. Schumacher K, Haensch W, Roefzaad C, Schlag PM. Prognostic significance of activated CD8(+) T cell infiltrations within esophageal carcinomas. Cancer Res. 2001;61:3932-3936. 
21. Enarsson K, Johnsson E, Lindholm C, et al. Differential mechanisms for T lymphocyte recruitment in normal and neoplastic human gastric mucosa. Clin Immunol. 2006;118:24-34.

22. Allory Y, Matsuoka Y, Bazille C, Christensen EI, Ronco P, Debiec H. The L1 cell adhesion molecule is induced in renal cancer cells and correlates with metastasis in clear cell carcinomas. Clin Cancer Res. 2005;11:1190-1197.

23. Bussolati B, Grange C, Bruno S, et al. Neural-cell adhesion molecule (NCAM) expression by immature and tumor-derived endothelial cells favors cell organization into capillary-like structures. Exp Cell Res. 2006;312:913-924.

24. Oliveira-Ferrer L, Tilki D, Ziegeler G, et al. Dual role of carcinoembryonic antigen-related cell adhesion molecule 1 in angiogenesis and invasion of human urinary bladder cancer. Cancer Res. 2004;64:8932-8938.

25. Tilki D, Irmak S, Oliveira-Ferrer L, et al. CEA-related cell adhesion molecule-1 is involved in angiogenic switch in prostate cancer. Oncogene. 2006;25:4965-4974.

26. Chavakis T, Athanasopoulos A, Rhee JS, et al. Angiostatin is a novel anti-inflammatory factor by inhibiting leukocyte recruitment. Blood. 2005;105:1036-1043.

27. Kozlowska A, Jagodzinski PP. Effect of Trichostatin A on CD4 surface density in peripheral blood T cells. Folia Histochem Cytobiol. 2006;44:259-262.

28. Huang $\mathrm{X}$, Raskovalova $\mathrm{T}$, Lokshin $\mathrm{A}$, et al. Combined antiangiogenic and immune therapy of prostate cancer. Angiogenesis. 2005;8:13-23.

29. Berger R, Albelda SM, Berd D, Ioffreda M, Whitaker D, Murphy GF. Expression of plateletendothelial cell adhesion molecule-1 (PECAM-1) during melanoma-induced angiogenesis in vivo. J Cutan Pathol. 1993;20:399-406.

30. Antoine N, Bours V, Heinen E, Simar LJ, Castronovo V. Simulation of human B-lymphocyte proliferation by AGM-1470, a potent inhibitor of angiogenesis. J Natl Cancer Inst. 1995;87:136-139.

31. Antoine N, Daukandt M, Heinen E, Simar LJ, Castronovo V. In vitro and in vivo stimulation of the murine immune system by AGM-1470, a potent angiogenesis inhibitor. Am J Pathol. 1996;148:393398.

32. Locigno R, Antoine N, Bours V, Daukandt M, Heinen E, Castronovo V. TNP-470, a potent angiogenesis inhibitor, amplifies human $\mathrm{T}$ lymphocyte activation through an induction of nuclear factor-kappaB, nuclear factor-AT, and activation protein-1 transcription factors. Lab Invest. 2000;80:13-21.

33. Schoof DD, Obando JA, Cusack JC, Jr., Goedegebuure PS, Brem H, Eberlein TJ. The influence of angiogenesis inhibitor AGM-1470 on immune system status and tumor growth in vitro. Int J Cancer. 1993;55:630-635.

34. Yu Y, Moulton KS, Khan MK, et al. E-selectin is required for the antiangiogenic activity of endostatin. Proc Natl Acad Sci U S A. 2004;101:8005-8010.

35. Rosenberg SA. Shedding light on immunotherapy for cancer. N Engl J Med. 2004;350:1461-1463.

36. Berger C, Berger M, Feng J, Riddell SR. Genetic modification of T cells for immunotherapy. Expert Opin Biol Ther. 2007;7:1167-1182.

37. Leen AM, Rooney CM, Foster AE. Improving $\mathrm{T}$ cell therapy for cancer. Annu Rev Immunol. 2007;25:243-265.

38. June CH. Principles of adoptive T cell cancer therapy. J Clin Invest. 2007;117:1204-1212.

39. Tuyaerts S, Aerts JL, Corthals J, et al. Current approaches in dendritic cell generation and future implications for cancer immunotherapy. Cancer Immunol Immunother. 2007;56:1513-1537.

40. Schadendorf D, Ugurel S, Schuler-Thurner B, et al. Dacarbazine (DTIC) versus vaccination with autologous peptide-pulsed dendritic cells (DC) in first-line treatment of patients with metastatic melanoma: a randomized phase III trial of the DC study group of the DeCOG. Ann Oncol. 2006;17:563-570.

41. Gilboa E. DC-based cancer vaccines. J Clin Invest. 2007;117:1195-1203.

42. Mitchell MS. Immunotherapy as part of combinations for the treatment of cancer. Int Immunopharmacol. 2003;3:1051-1059. 
43. Jackaman C, Bundell CS, Kinnear BF, et al. IL-2 intratumoral immunotherapy enhances CD8+ T cells that mediate destruction of tumor cells and tumor-associated vasculature: a novel mechanism for IL-2. J Immunol. 2003;171:5051-5063.

44. Tahara H, Lotze MT. Antitumor effects of interleukin-12 (IL-12): applications for the immunotherapy and gene therapy of cancer. Gene Ther. 1995;2:96-106.

45. Mahvi DM, Henry MB, Albertini MR, et al. Intratumoral injection of IL-12 plasmid DNA - results of a phase I/IB clinical trial. Cancer Gene Ther. 2007;14:717-723.

46. van Herpen CM, van der Laak JA, de Vries IJ, et al. Intratumoral recombinant human interleukin12 administration in head and neck squamous cell carcinoma patients modifies locoregional lymph node architecture and induces natural killer cell infiltration in the primary tumor. Clin Cancer Res. 2005;11:1899-1909.

47. Minuzzo S, Moserle L, Indraccolo S, Amadori A. Angiogenesis meets immunology: cytokine gene therapy of cancer. Mol Aspects Med. 2007;28:59-86.

48. Niederman TM, Ghogawala Z, Carter BS, Tompkins HS, Russell MM, Mulligan RC. Antitumor activity of cytotoxic $\mathrm{T}$ lymphocytes engineered to target vascular endothelial growth factor receptors. Proc Natl Acad Sci U S A. 2002;99:7009-7014.

49. Niethammer AG, Xiang R, Becker JC, et al. A DNA vaccine against VEGF receptor 2 prevents effective angiogenesis and inhibits tumor growth. Nat Med. 2002;8:1369-1375.

50. Okaji Y, Tsuno NH, Saito S, et al. Vaccines targeting tumour angiogenesis--a novel strategy for cancer immunotherapy. Eur J Surg Oncol. 2006;32:363-370.

51. Clay TM, Hobeika AC, Mosca PJ, Lyerly HK, Morse MA. Assays for monitoring cellular immune responses to active immunotherapy of cancer. Clin Cancer Res. 2001;7:1127-1135.

52. Leonard WJ, Spolski R. Interleukin-21: a modulator of lymphoid proliferation, apoptosis and differentiation. Nat Rev Immunol. 2005;5:688-698.

53. MacFarlane MP, Yang JC, Guleria AS, et al. The hematologic toxicity of interleukin-2 in patients with metastatic melanoma and renal cell carcinoma. Cancer. 1995;75:1030-1037.

54. McDermott DF. Update on the application of interleukin-2 in the treatment of renal cell carcinoma. Clin Cancer Res. 2007;13:716s-720s. 
Chapter 9 


\section{Summary}

In this thesis the study on the relationship between blood vessel formation, a process called angiogenesis, and the immune system in solid tumors is described. In this study, special emphasis was put on investigating the recruitment of leukocytes into the tumor tissue and the role of blood vessels in this process.

Cancer is in many cases still a deadly disease. The main established therapies like surgery, chemotherapy and radiotherapy are insufficient for cure. Therefore the search for new, efficient strategies which can eradicate cancer, is still ongoing. One promising approach is the inhibition of angiogenesis. By diminishing the formation of new blood vessels, the tumor is deprived from oxygen and nutrients necessary for its growth and development. In addition, these blood vessels increase tumor metastasis. Angiogenesis is strictly regulated and occurs mainly during embryonic development. In adults this process can be observed during the female reproductive cycle, wound healing and in diverse diseases like arthritis, psoriasis and cancer. In cancer the regulation of angiogenesis is completely disturbed. Chronic stimulation of the angiogenesiscascade by different tumor derived growth factors induces formation of new blood vessels which maintain tumor growth. This continuous stimulation of vessel formation and the associated growth factors have a tremendous effect on the endothelial cells that line the vessel wall.

Endothelial cells play an important role in recruiting white blood cells from the blood into the tumor tissue. These leukocytes interact with the vessel wall by binding to adhesion molecules like ICAM-1, VCAM-1 and E-selectin, present on the endothelial cells. They roll along and firmly adhere to the endothelial cells and finally transmigrate through the vessel wall into the tumor tissue where they can eradicate the tumor cells. Angiogenic factors decrease the expression of these endothelial cell adhesion molecules leading to diminished leukocyte influx into the tumor tissue. Through this phenomenon a tumor can escape from an effective anti-tumor immune response. The regulation of endothelial cell adhesion molecule expression by tumor derived factors is described in chapter 2 of this thesis. The specific composition of adhesion molecules present on tumor vessels is used for various imaging modalities to visualize the tumor and his vasculature. Furthermore, a variety of therapies is based on the destruction of tumor vessels and thereby the tumor via this specific composition of endothelial cell adhesion molecules.

The amount of vessel formation and leukocyte infiltration can determine patient survival. A study using tumor tissues of patients with colorectal cancer showed that angiogenesis, particularly the number of proliferating endothelial cells, is a negative prognostic marker for patient survival. Conversely, a high 
number of white blood cells in the tumor tissue has very often a positive effect on survival of cancer patients (chapter 3). These results indicate that inhibition of angiogenesis and accompanying stimulation of leukocyte infiltration in the tumor, is a potential strategy to treat people with cancer.

Experiments in mouse tumor models demonstrated that angiogenesis inhibition is associated with the normalization of adhesion molecule expression on tumor endothelial cells. This increase consequently leads to enhanced leukocytevessel wall interactions and an induction of leukocyte influx in the tumor tissue (chapter 4 and 5). Treatment of human endothelial cells with angiogenesis inhibitors induces a similar increase of adhesion molecule expression and leukocyte adhesion on activated endothelial cells. The increase of white blood cells in the tumor tissue after angiostatic treatment does not confine to one specific subtype of cells. The number of activated leukocytes in the tumor is significantly up-regulated upon treatment with angiogenesis inhibitors. Immunosuppressive cells like regulatory $\mathrm{T}$ cells which suppress the anti-tumor immune response, were found not to be preferentially attracted. We can conclude from these data that angiogenesis inhibitory treatment of tumors reduces tumor growth not only by diminishing vessel formation but also by stimulating the specific anti-tumor immune response (chapter 5). This concept supports the hypothesis that cancer can be more efficiently treated by combining anti-angiogenesis and immunotherapy.

The mechanism behind this restoration of endothelial cell adhesion molecule expression on tumor vessels by angiostatic therapy can partially be explained by epigenetic processes. Promotor histone modifications suppress the expression of ICAM-1 in tumor (-conditioned) endothelial cells in vitro and in vivo. DNA methyltrasferase- and histone deacetylase inhibitors, capable to eradicate angiogenesis, are able to reactivate the expression of ICAM-1 on tumor endothelial cells and stimulate leukocyte-vessel wall interactions (chapter 6).

The search for a suitable immunotherapy to use in combination with our angiogenesis inhibitors led to the cytokine interleukin-21. This cytokine has been successfully used in different mouse tumor models and is now being tested in phase I clinical trails. Interleukins are known to be able to affect angiogenesis, positively as well as negatively. The effect of IL-21 on tumor angiogenesis is important information if this cytokine is to be used in combination with angiogenesis inhibitors in cancer treatment. In vitro and in vivo experiments demonstrated that IL-21 can inhibit angiogenesis. This inhibition is associated with the reduced activation of signal transducer and activator of transcription 3 (Stat3) and declined expression of angiogenic factors/receptors. By combining angiostatic and immunostimulatory properties, IL-21 may be a future powerful soldier in the battle against cancer (chapter 7). 
The above-mentioned studies mainly discuss the regulation of the most familiar adhesion molecules expressed by tumor endothelial cells like ICAM-1, VCAM-1 and E-selectin which mediate leukocyte-vessel wall interactions. However, other, more recently described and less studied molecules exist that are implicated in leukocyte recruitment to the tumor tissue as well. Vascular adhesion protein 1 (VAP-1) is such a molecule. In vivo experiments show that VAP-1 is involved in both rolling and adhesion of leukocytes to the tumor vessel wall. In addition, the number of VAP-1 positive vessels is not affected by angiogenic factors which is in contrast to the effects on ICAM-1 expression (chapter 8).

The results described in this thesis demonstrate a strong relationship between angiogenesis and the immune response in a tumor. Inhibition of tumor angiogenesis, simultaneously leads to induction of the anti-tumor immune response. IL-21, a cytokine known for its immune regulatory and immunotherapeutic capacities, can inhibit angiogenesis as well. This thesis shows that the combination of angiogenesis inhibition and immunotherapy can be a new break-through in the search for new strategies to fight cancer. 
Summary 


\section{Samenvatting}

In dit proefschrift wordt de relatie tussen angiogenese ofwel bloedvatvorming en het immuunsysteem tegen solide tumoren beschreven. Met name de rekrutering van witte bloedcellen in het tumorweefsel en de rol daarbij van tumor bloedvaten, wordt onderzocht.

Kanker is in vele gevallen nog steeds een ongeneselijke ziekte. Vaak zijn de meest courante vormen van therapie zoals chirurgie, chemotherapie of radiotherapie onvoldoende om de ziekte te overwinnen. Er is dus nog steeds een grote nood aan nieuwe, efficiënte strategieën om kanker te bestrijden. Een veelbelovende nieuwe strategie bij de behandeling van kanker is inhibitie van angiogenese. Door de bloedvatgroei te remmen worden tumoren afgesneden van hun aanvoer van zuurstof en voedingsstoffen die tumoren nodig hebben om te kunnen groeien en ontwikkelen. Bloedvaten vergemakkelijken bovendien de metastasering van kanker. De vorming van nieuwe bloedvaten is een proces dat onder strikte regulatie staat en voornamelijk in de embryonale levensfase voorkomt. Bij volwassenen wordt dit proces tijdens de menstruatiecyclus, wondgenezing en in verschillende ziekten zoals artritis, psoriasis en kanker, waargenomen. In kanker en andere ziekten is de regulatie van angiogenese volledig zoek. De angiogenese-cascade wordt in tumoren continu gestimuleerd door groeifactoren waardoor er voortdurend nieuwe bloedvaten worden gevormd die de groei van de tumor onderhouden. Deze constante stimulatie van angiogenese en de daar bijhorende groeifactoren hebben een grote invloed op de endotheelcellen die de bloedvatwand bekleden.

Deze endotheelcellen spelen een belangrijke rol in de rekrutering van witte bloedcellen in het tumorweefsel. Witte bloedcellen gaan in interactie met de vaatwand. Door binding met adhesiemoleculen zoals ICAM-1, VCAM-1 en Eselectine, rollen en hechten witte bloedcellen, ook leukocyten genoemd, aan de endotheelcellen. Vervolgens migreren ze door de vaatwand in het weefsel waar ze tumorcellen kunnen vernietigen. Angiogene factoren verlagen de expressie van deze adhesiemoleculen waardoor minder leukocyten het tumorweefsel kunnen binnendringen. De tumor ontsnapt op deze manier aan de antitumor immuunrespons. De regulatie van de expressie van adhesiemoleculen op endotheelcellen door de tumor wordt uitvoerig beschreven in hoofdstuk 2. De specifieke samenstelling van adhesiemoleculen in tumorvaten kan gebruikt worden om de tumor en zijn vaatstructuur in beeld te brengen. Verder bestaat er een verscheidenheid aan behandelingsstrategieën die de tumorvasculatuur en bijgevolg de tumor vernietigen op basis van deze specifieke samenstelling van adhesiemoleculen. 
De mate van angiogenese en de infiltratie van witte bloedcellen in het tumorweefsel kunnen de overleving van kankerpatiënten bepalen. Een studie met materiaal van patiënten met dikke darm kanker toonde aan dat angiogenese, met name de hoeveelheid delende endotheelcellen, een negatieve prognostische factor voor overleving is. Een hoog aantal witte bloedcellen in de tumor heeft een positief effect op overleving van kankerpatiënten (hoofdstuk 3). Deze resultaten geven aan dat inhibitie van angiogenese en daarmee stimulatie van de infiltratie van witte bloedcellen in de tumor, een goed plan van aanpak is om mensen met kanker te behandelen.

Experimenten met tumormodellen in muizen hebben aangetoond dat inhibitie van angiogenese gepaard gaat met een herstel van de expressie van adhesiemoleculen op de endotheelcellen. Dit leidt tot een verhoging van interacties tussen leukocyten en de vaatwand en vervolgens tot een toename van leukocyten in het tumorweefsel (hoofdstuk 4-5). Behandeling van humane endotheelcellen met angiogenese inhibitoren induceert een vergelijkbare verhoging van de expressie van adhesiemoleculen en leukocytadhesie. De toename van witte bloedcellen in een tumor na angiostatische behandeling beperkt zich niet tot een enkele groep van leukocyten. Het aantal geactiveerde effector Tcellen neemt significant toe in tumorweefsel na behandeling met angiogenese inhibitoren. Immuunsuppressive cellen zoals regulatoire T-cellen die een antitumor immuunresponse kunnen onderdrukken, worden niet preferentieel aangetrokken. Behandeling van tumoren met angiogenese inhibitoren verhindert tumorgroei dus niet alleen door bloedvatgroei te remmen maar ook door specifiek de antitumor immuunrespons te stimuleren (hoofdstuk 5). Dit concept ondersteunt het idee om kanker te bestrijden door anti-angiogenese behandeling te combineren met immuuntherapie.

Het mechanisme achter dit herstel van de adhesiemolecuul expressie na angiostatische behandeling wordt deels verklaard door epigenetische processen. Promotor histone modificaties onderdrukken de expressie van ICAM-1 in tumor (geconditioneerde) endotheelcellen in vitro en in vivo. DNA methyltransferase- en histon deacetylase inhibitoren, in staat om tumorangiogenese te remmen, kunnen de expressie van ICAM-1 in tumorendotheelcellen reactiveren en leukocytevaatwand interacties stimuleren (hoofdstuk 6).

Een zoektocht naar een geschikte immuuntherapie die in combinatie met angiogenese inhibitie kan gebruikt worden, leidde naar het cytokine interleukine 21 (IL-21). Dit cytokine is reeds succesvol gebleken in verschillende tumormodellen in muizen en wordt momenteel in fase I klinische studies getest. Van cytokines is het geweten dat zij een positief of negatief effect op angiogenese kunnen hebben. De invloed van IL-21 op angiogenese is dus belangrijke informatie indien dit cytokine in combinatie met angiogenese inhibitoren voor 
kankertherapie gebruikt zal worden. In vitro en in vivo experimenten hebben aangetoond dat IL-21 angiogenese remt. Dit gaat gepaard met een remming van signaal transducer en activator van transcriptie 3 (Stat3) activiteit alsook met een verlaging van expressie van angiogene factoren/receptoren. Door de combinatie van antiangiogenese en immuuntherapie, is IL-21 een krachtig molecule ter bestrijding van kanker (hoofdstuk 7).

Bovenstaande studies bespreken voornamelijk de regulatie van de meest bekende adhesiemoleculen op tumorendotheelcellen zoals ICAM-1, VCAM-1 en Eselectine die leukocyte-vaatwand interacties tot stand brengen. Maar er zijn ook verscheidene minder bestudeerde moleculen die een rol spelen in leukocyt rekrutering in tumorweefsel. Vasculair adhesie proteine 1 (VAP-1) is zo een molecule. In vivo experimenten tonen aan dat VAP-1 zowel leukocytadhesie alsook het rollen van leukocyten langsheen het tumorendotheel tot stand brengt. Bovendien wordt het aantal VAP-1 positieve vaten in tumoren niet beïnvloedt door angiogene factoren in tegenstelling tot ICAM-1 positieve tumorvaten (hoofdstuk 8).

Aan de hand van de resultaten van dit proefschrift kan er besloten worden dat er wel degelijk een sterke relatie is tussen angiogenese en het immuunsysteem in een tumor. Door angiogenese in een tumor te remmen wordt tegelijkertijd de antitumor immuunrespons aangewakkerd. IL-21, een cytokine dat bekend is omwille van zijn immuunregulatoire eigenschappen en zijn effectiviteit in antitumor immuuntherapieën, is ook in het bezit van angiogenese remmende functies. Dit proefschrift toont aan dat de combinatie van angiogenese inhibitie en immuuntherapie een nieuwe doorbraak kan zijn in de zoektocht naar middelen om kanker te bestrijden. 
Samenvatting 


\section{Curriculum vitae}

Karolien Castermans was born in Hasselt (B) on the 30 th of March in 1979. After her secondary school education in Humaniora Virga Jesse in Hasselt, she started her first year at the Limburg University in Diepenbeek in 1997, studying Biology. She completed her bachelor in Biology Cum Laude in 1999. In 2001 she finished her master in Biology, major Biochemistry - Physiology, Cum Laude at the University of Antwerp. The focus of her graduation thesis was 'The role of Fytohormones in the interaction Azorhizobium caulinodans - Sesbania rostrata'. In 2002 she started as a technician in the Angiogenesis Laboratory in the Department of Pathology at the Maastricht University and worked on the relationship between angiogenesis and the immune system in solid tumors. This became the topic of her PhD. thesis one year later which she has now completed. As of September 2007 she will be working as a postdoc in the laboratory of Molecular Biology and Genetic Engineering Unit in the University of Liège on the effect of 16K hPRL on the recruitment of endothelial progenitor cells in tumors.

\section{Publications}

Castermans K, oude Egbrink MGA, Jalkanen S, Griffioen AW. VAP-1 mediates leukocyte-vessel wall interactions tumor vessels. In progress

Hillen F, Kaijzel EL, Castermans K, oude Egbrink MGA, Lowik CWGM, Griffioen AW. A transgenic Tie2-GFP athymic mouse model; a tool for vascular biology in xenograft tumors. Submitted

Castermans K, Tabruyn SP, Shrikant PA, Leonard WJ, Zeng R, Griffioen AW. Interleukin-21 has an intrinsic angiostatic function. Accepted in Blood (pending revisions)

Castermans K, Dings RPM, Popescu FE, oude Egbrink MGA, Van Eijk LI, Mescher MF, Mayo KH and Griffioen AW. Antiangiogenesis therapy enhances tumor-specific immunity. Submitted

Castermans K, Griffioen AW. Tumor blood vessels, a difficult hurdle for leukocyte recruitment. Biochimica et Biophysica Acta 1776 (2007) 160-174 doi: 10.1016/j.bbcan.2007.07.005

Koole R, van Schooneveld M, Hilhorst J, Castermans K, de Mello Donega C, Vanmaekelbergh D, Griffioen AW, Nicolay K, Fayad ZA, Meijerink A, Mulder 
WJM Lipid Coated Silica Nanoparticles; a Contrast Agent Platform for TargetSpecific Multimodality Imaging. Submitted

Mulder WJM, Castermans K, van Beijnum JR, oude Egbrink MGA, Chin PTK, Storm G, Strijkers GJ, Griffioen AW, Nicolay K Multimodality molecular imaging of tumor angiogenesis using quantum dots. Submitted

Tabruyn SP, Sabatel C, Verhaeghe C, Castermans K, Nguyen NQN, Cornet A, Griffioen AW, Martial JA and Struman I. The Angiostatic 16K Human Prolactin Overcomes Endothelial Cell Anergy and Promotes Leukocyte Infiltration via Nuclear Factor-\{kappa\}B Activation. Mol Endocrinol. 2007 Jun;21(6):1422-9.

Baeten CI, Castermans K, Lammering G, Hillen F, Wouters BG, Hillen HF, Griffioen AW, Baeten CG. Effects of radiotherapy and chemotherapy on angiogenesis and leukocyte infiltration in rectal cancer. Int J Radiat Oncol Biol Phys. 2006 Nov 15;66(4):1219-1227

Hellebrekers DM, Castermans K, Vire E, Dings RP, Hoebers NT, Mayo KH, Oude Egbrink MG, Molema G, Fuks F, van Engeland M, Griffioen AW. Epigenetic regulation of tumor endothelial cell anergy: silencing of intercellular adhesion molecule-1 by histone modifications. Cancer Res. 2006 Nov 15;66(22):10770-7

Baeten CI, Castermans K, Hillen HF, Griffioen AW. Proliferating endothelial cells and leukocyte infiltration as prognostic markers in colorectal cancer. Clin Gastroenterol Hepatol. 2006 Nov;4(11):1351-7.

Dirkx AE, oude Egbrink MG, Castermans K, van der Schaft DW, Thijssen VL, Dings RP, Kwee L, Mayo KH, Wagstaff J, Bouma-ter Steege JC, Griffioen AW. Anti-angiogenesis therapy can overcome endothelial cell anergy and promote leukocyte-endothelium interactions and infiltration in tumors. FASEB J. 2006 Apr;20(6):621-30.

Van der Schaft DW, Hillen F, Pauwels P, Kirschmann DA, Castermans K, Egbrink MG, Tran MG, Sciot R, Hauben E, Hogendoorn PC, Delattre O, Maxwell PH, Hendrix MJ, Griffioen AW. Tumor cell plasticity in Ewing sarcoma, an alternative circulatory system stimulated by hypoxia. Cancer Res. 2005 Dec 15;65(24):11520-8. 


\section{Dankwoord}

Alhoewel dit stukje tekst helemaal achteraan mijn proefschrift staat wordt het waarschijnlijk door de meeste onder jullie als eerste gelezen. Het moet bijgevolg een leuk tekstje zijn, dat vlot leest en duidelijk is voor iedereen. Ik vond het moeilijk om te schrijven, vandaar dat ik het ook lang heb uitgesteld. Er zijn zoveel mensen die ik wil bedanken, die ieder op hun eigen manier hebben bijgedragen aan de realisatie van dit boekje en die de afgelopen 5 jaar mijn leven kleur hebben gegeven.

Arjan, dankzij jou heb ik de echte inhoud van de wetenschap leren kennen. Het is een uitdagend veld met vele ups en down (meer downs dan ups). Dankjewel voor alle voor alle raad, ideeën, oppeppers en correcties (ook van mijn 'Belgische taal') die hebben geleid tot dit mooie boekje.

AIO's van het angiogeneselab, Debby, Veerle, Judy, Coen, Anita, Judy, Ricardo, Vivian, een heel aantal van jullie hebben het al tot Postdoc geschopt, of hebben elders een leuke baan gevonden. Anderen zijn bijna zover (ja Veerle en Vivian, jullie komen er ook, en dat zal sneller gaan als jullie denken en willen). Jullie weten allemaal dat het heel belangrijk is om tijdens je promotieperiode bij mensen steun te krijgen. Dat heb ik bij jullie allemaal gevonden. Ik kon bij jullie altijd terecht voor 'vraagjes' en vond bij jullie ook altijd een luisterend oor als de proeven/muizen weer eens niet deden wat ik van hen verwachtte. Ook het leuke 'tetteren' zorgde voor de nodige afleiding als de dingen niet liepen zoals gepland. Mercikes.

Nee Femke, ik ben je niet vergeten in het lijstje van de AIOs. Jij verdient enkele regeltjes voor jou alleen. We hebben ons samen door de laatste maanden geworsteld. Ik heb enorm veel steun aan je gehad. Als ik weer met een vraagje kwam, reageerde je onmiddellijk en deed je je best om me zo snel mogelijk te helpen. Ik kan me dan ook geen betere paranimf bedenken dan jou en ben heel blij dat je hebt toegezegd. Dankuwel, echt waar.

Een lab draait niet zonder analisten, ook niet het angiogeneselab. Petra, Loes, Edith, Sarah, Sietske, Nicole en Kim, een aantal van jullie hebben andere horizonten opgezocht, sommigen zijn nog niet zo lang in het lab. Ik heb genoten van jullie aanwezigheid, behulpzaamheid, efficiëntie en opmonterende eigenschappen. Het was altijd leuk om naar het lab te lopen als ik enkele uurtjes achter mijn computerke had gespendeerd. Mercikes voor al jullie hulp en voor de gezelligheid.

En natuurlijk mag ik de Postdocs niet vergeten. Jessica en Daisy, van jullie beiden heb ik veel geleerd. Jammer dat ik maar voor een korte periode van jullie ervaring heb kunnen genieten. Dankzij jullie ben ik nu zeer bedreven in het 
manipuleren van muisjes zonder al te veel bijtwonden. Victor, dankjewel voor alle antwoorden op de vragen die ik aan je stelde voornamelijk gerelateerd aan Photoshop (wanneer komt die cursus er nu eindelijk?). Sebastien, of course you also deserve a 'thank you' for all the help and ideas you gave me. I enjoyed our meetings and hope you have a nice time in San Francisco. See you soon in Liège. Ingrid, you have only been in Maastricht for a short time, however your ideas in the general meeting have been very helpful. I look forward to our work and publications together in the future. Thanx.

Het angiogeneselab is een onderdeel van een veel grotere groep. Ja, ik vind het echt een groep. Iedereen van de afdeling pathologie, dankjewel. Iedereen van het 'methyleringslab', de 'Cardios', alle AIOs, pathologen, mensen van de diagnostiek, het secretariaat, jullie maken het werken in Nederland, Maastricht heel aangenaam. Ik denk dat er maar weinig plaatsen zijn die aan deze afdeling kunnen tippen.

Ook andere afdelingen binnen de Universiteit Maastricht wil ik bedanken voor al hun hulp met name de afdeling fysiologie, lab microcirculatie. Ik heb toch verscheidene uurtjes op jullie lab doorgebracht in het donker met mijn muisjes. Ik wil graag iedereen bedanken voor al hun hulp bij de intravitaalmicroscoop, het doneren van muizen, hulp met de muizen en alle nuttige tips en raad.

Ook de medewerkers van het CPV wil ik bedanken. Jullie hebben echt een hart voor dieren en maken het leven van de dieren zo aangenaam mogelijk. En natuurlijk wil ik ook alle muisjes bedanken die dit proefschrift hebben helpen verwezenlijken.

Marjan, je verdient ook zeker enkele regeltjes in mijn proefschrift. Ik had mij geen beter en leuker kamergenootje kunnen bedenken dan jou. Ik vond onze 2 jaar samen op de kamer echt plezant. Je stond altijd klaar met goede raad en was altijd heel behulpzaam. Je kon me ook altijd goed opmonteren en kalmeren als ik weer aan het stressen was over 'dat boekje'. Dankjewel (en ook Leon) voor alles.

Ook mensen buiten Maastricht verdienen een bedankje. Willem, dankjewel voor de leuke proeven samen. Jou enthousiasme voor de wetenschap en de proeven is besmettelijk. Ik hoop dat je het naar je zin hebt in het verre New York. Kevin and Ruud, although you are far away, across the big ocean, still it was a very pleasant and fruitful collaboration. Thank you.

Naast mijn collega's, die ook vrienden zijn geworden, zijn er ook een heleboel mensen buiten de werkomgeving die een bedankje verdienen voor al hun steun. Ik 
wil graag al mijn kameraden bedanken en zeker ook Bart en Patricia vermelden. Jullie hebben altijd interesse getoond voor mijn werk. Tijdens etentjes, fietstochtjes, wandelingetjes of gezellige 'babbelavonden' werd er vaak een keer gevraagd hoe het met mijn muisjes ging.

Zonder mijn familie was het ook nooit gelukt. Mama, papa, dankuwel om mij de kans en de vrijheid geven te hebben om te studeren wat ik wilde en mijn eigen weg te laten gaan. Niks moest, alles (nou ja, veel) mocht. Ik kan jullie nu fier laten zien wat ik dankzij jullie heb kunnen realiseren. Dankuwel voor alles.

Poly en Monique, dankuwel voor alle steun en alle hulp in de afgelopen jaren.

Zusje, jij bent voor mij echt een persoon bij wie ik rust vind. Ik kan bij jou echt voor alles terecht. De keuze om jou als paranimf te kiezen was voor mij al heel lang gemaakt, nog voor er sprake was van een boekje. Ook jullie, Christophe, Lindsey en Eline (jullie kleintjes kunnen het nog niet lezen maar papa of mama leest het wel voor) spelen een grote rol in mijn leven en hebben er mee voor gezorgd dat deze thesis tot een goed einde is gebracht. Mercikes.

En dan blijft er nog een persoon over die ik moet bedanken en dat ben jij, Sven. Ik zie $u$ doodgraag en zou dit nooit zonder jou hebben kunnen klaarspelen. Ik zou niet weten wat ik zonder jou zou moeten doen. Dankuwel.

$\mathrm{Nu}$ hoop ik dat ik niemand vergeten ben, dat zou ik heel erg vinden. Dus nog een laatste maal dankjewel aan iedereen die op de een of andere manier aan dit boekje heeft bijgedragen.

Zo, dan is dit nu het laatste zinnetje van mijn boekje en dan is het af, klaar, finished, done, finit, prêt,... Oeff. 
Dankwoord 